\title{
Free Trade Zones: Characteristics and Tenant Behaviour
}

\author{
By \\ Shavin Malhotra \\ Eric Sprott School of Business
}

A thesis submitted to the Faculty of Graduate Studies and Research in conformity with the requirement for the degree of Doctor of Philosophy (Management)

Carleton University

December 2007

(C) Shavin Malhotra, 2007 


$\begin{array}{ll}\begin{array}{l}\text { Library and } \\ \text { Archives Canada }\end{array} & \begin{array}{l}\text { Bibliothèque et } \\ \text { Archives Canada }\end{array} \\ \begin{array}{l}\text { Published Heritage } \\ \text { Branch }\end{array} & \begin{array}{l}\text { Direction du } \\ \text { Patrimoine de l'édition }\end{array} \\ \begin{array}{l}\text { 395 Wellington Street } \\ \text { Ottawa ON K1A ON4 } \\ \text { Canada }\end{array} & \begin{array}{l}\text { 395, rue Wellington } \\ \text { Ottawa ON K1A ON4 } \\ \text { Canada }\end{array}\end{array}$

Yourfile Votre référence

ISBN: 978-0-494-36790-2

Ourfile Notre référence

ISBN: 978-0-494-36790-2

NOTICE:

The author has granted a nonexclusive license allowing Library and Archives Canada to reproduce, publish, archive, preserve, conserve, communicate to the public by telecommunication or on the Internet, loan, distribute and sell theses worldwide, for commercial or noncommercial purposes, in microform, paper, electronic and/or any other formats.

The author retains copyright ownership and moral rights in this thesis. Neither the thesis nor substantial extracts from it may be printed or otherwise reproduced without the author's permission.
AVIS:

L'auteur a accordé une licence non exclusive permettant à la Bibliothèque et Archives Canada de reproduire, publier, archiver, sauvegarder, conserver, transmettre au public par télécommunication ou par l'Internet, prêter, distribuer et vendre des thèses partout dans le monde, à des fins commerciales ou autres, sur support microforme, papier, électronique et/ou autres formats.

L'auteur conserve la propriété du droit d'auteur et des droits moraux qui protège cette thèse. $\mathrm{Ni}$ la thèse ni des extraits substantiels de celle-ci ne doivent être imprimés ou autrement reproduits sans son autorisation.
In compliance with the Canadian

Privacy Act some supporting forms may have been removed from this thesis.

While these forms may be included in the document page count, their removal does not represent any loss of content from the thesis.
Conformément à la loi canadienne sur la protection de la vie privée, quelques formulaires secondaires ont été enlevés de cette thèse.

Bien que ces formulaires aient inclus dans la pagination, il n'y aura aucun contenu manquant.

\section{Canadä}




\section{ABSTRACT}

Free Trade Zones (FTZs) are geographically-defined areas within countries that are intended to provide a barrier-free environment for business, often accompanied by special incentives, for firms considering in-zone operations. FTZs are an important institution given their success in improving the economic development and international competitiveness of host countries, and also by virtue of their role in the internationalization strategy of business firms. There are more than 2,500 FTZs across 130 countries; the number of FTZs has doubled in the last five years. While there is sufficient research on FTZs in the area of developmental and regional economics, business research is sparse and limited in its scope. This thesis provides a comprehensive view of FTZs including its operations, structure, role, function, and orientation, suggests a new taxonomy for FTZs, and also examines the FTZ-tenant arrangement by studying the motives, perceptions, and satisfaction of tenant firms.

The objectives of this study were achieved by following an extensive three-phase methodology, which included a content analysis of 105 FTZ websites as part of Phase I. Phase II included in-depth case studies of four different FTZs, which involved 35 interviews with zone officials and company managers. Finally, Phase III involved a broad-based survey of 115 tenant firms spread across two different FTZs.

Detailed analysis of the three phases suggests that FTZs can be categorized as three main types, based on their function and orientation - Export, Import, and Trade. The results also show that FTZs offer more than just "duty-free" benefits, importantly, they also offer strategic advantages which include among others, proximity to important markets and international trade routes, potential role in a global and/or a regional 
distribution system, and supplying of important business facilities such as storage, manufacturing, warehouse, and infrastructure. Additionally, it was found that (1) better location factors such as banking and transport facilities, and proximity to industry clusters, (2) internalization benefits, and (3) lower market risk in the zone, significantly impact tenant firm's satisfaction with the zone investment climate. The results from this study should benefit the academic and business community alike. 


\section{ACKNOWLEDGEMENTS}

The doctoral journey can at times be long and arduous. Along this path, I have had the great fortune of meeting many inspiring people who have encouraged and supported me. First of all, I would like to thank my supervisor and mentor Dr. Nicolas Papadopoulos, for all his time, support and direction throughout the doctoral process. Dr. Papadopoulos was a great supervisor who provided me with critical and constructive guidance. His intellectual input on conceptual matters, his advice about methodology, and his help in interpreting unexpected findings have been substantial. He was also a great mentor in terms of teaching me the nuances of becoming a good academic. I owe my deepest gratitude to him for being a true supervisor and a mentor.

In addition, I would like to thank Dr. George H. Haines Jr. and Dr. Roland Thomas who were members of my thesis committee, for their unwavering support and insightful guidance throughout the study, and for being very generous with their time. They have also contributed greatly to resolving methodological issues and to provide valuable checkpoints throughout the journey.

The graduate community at Sprott School of Business was a great inspiration to me. Their contributions and helpful comments were immeasurable in the development and successful completion of this study. In particular, I will like to thank Irfan Butt, PengCheng Zhu, Vedmani Sharan, Lihuan Huang, and Nubia Cabezas-Navas for their help and generous suggestions on how to improve the quality of this study.

The thesis would also not have been possible without the help of the zone officials who generously gave both their time and shared their experiences. Thanks to my friends and family, especially my parents, Satish Kumar Malhotra and Heera Rani Malhotra, who 
have always supported me. My eternal gratitude to my lovely and supporting wife Taru Malhotra, who encouraged me and actively participated in this process, collecting data, reading drafts, and discussing my ideas. To her and my son Ayush this thesis belongs. 


\section{Table of Contents}

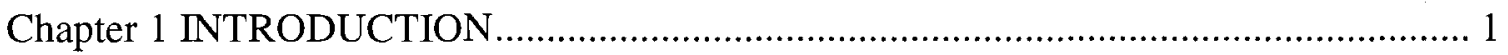

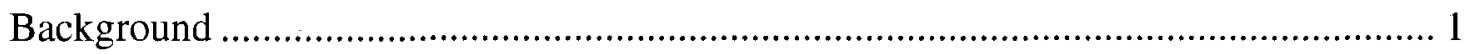

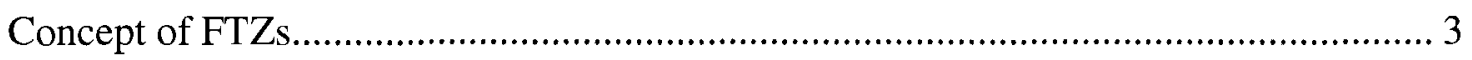

Advantages and Strategic Role of FTZs .......................................................... 7

Individual Zones as Assembly, Distribution, and/or Just-In-Time-Marketing Hubs .. 9

Zone Networks as Part of Supply Chain and Global Strategic Planning ................. 10

Conceptualization, Methodological Approach, and Importance of the Study .............. 11

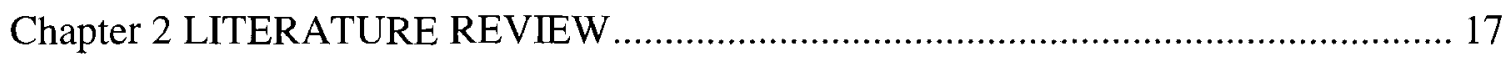

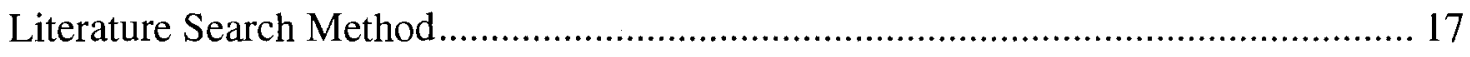

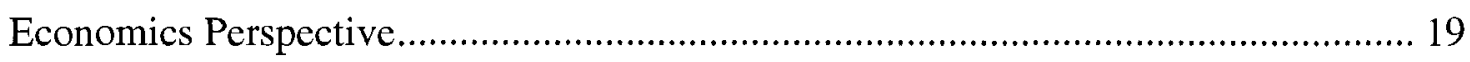

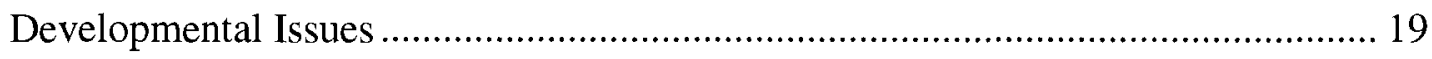

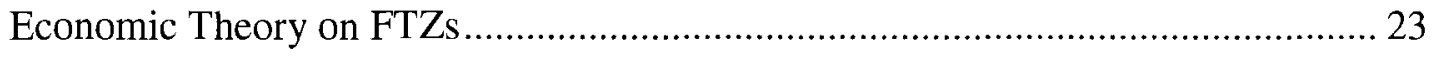

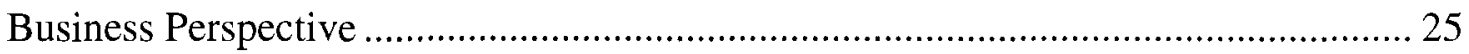

Chapter 3 TYPES OF FREE TRADE ZONES......................................................... 29

Export-Oriented Zones: Export Processing Zones..................................................... 34

EPZ Benefits for Host Countries .................................................................... 35

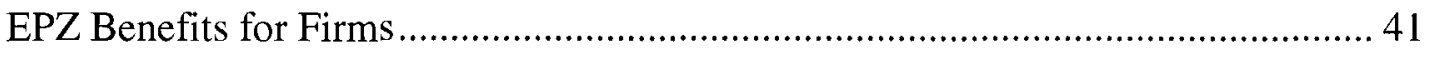

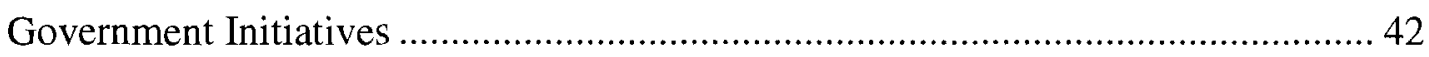

Import-Oriented Zones: U.S. Foreign Trade Zones ...................................... 44

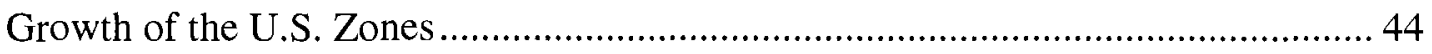

Geographic Distribution and Main Zone Users.............................................. 47

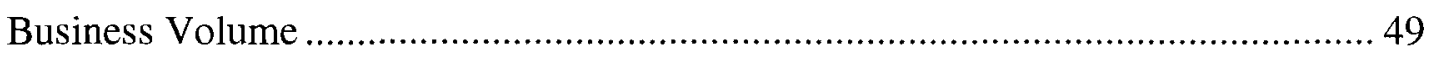

Trade-Oriented Zones: Dubai's Free Trade Zones ............................................. 50

Jebel Ali Free Trade Zone ....................................................................... 50 
Summary: Types of Zones and Research on FTZs ................................................. 51

Chapter 4 CONCEPTUAL FRAMEWORK ………………....................................... 53

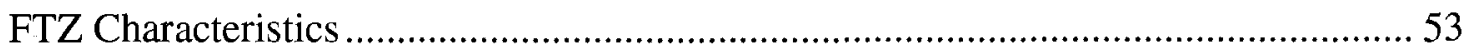

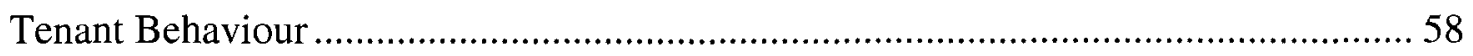

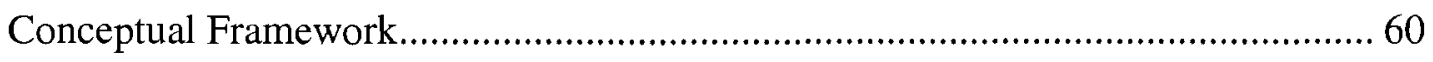

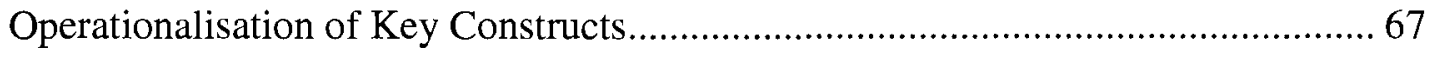

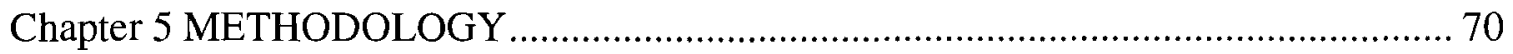

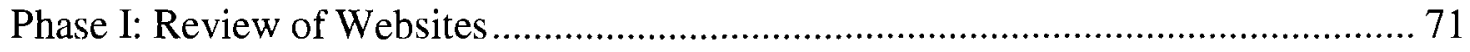

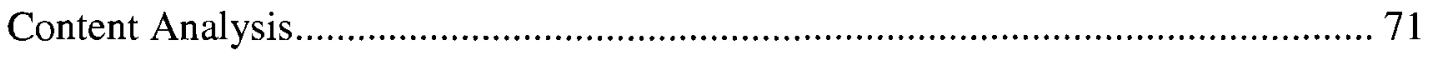

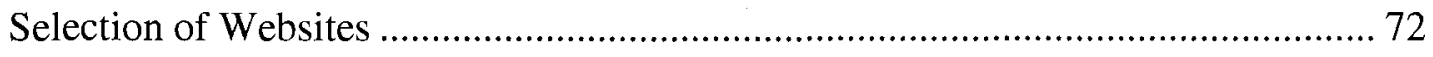

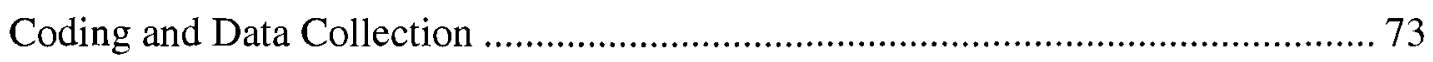

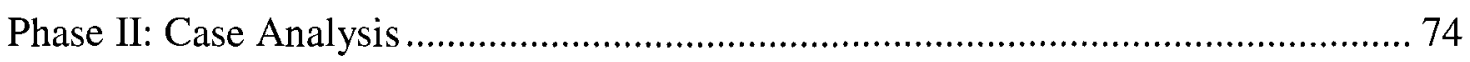

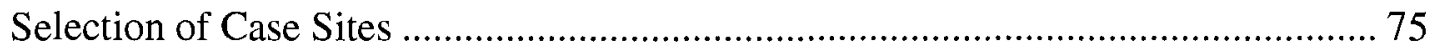

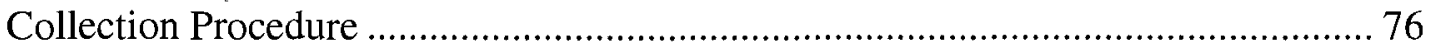

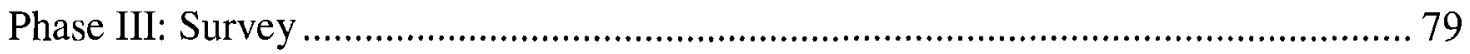

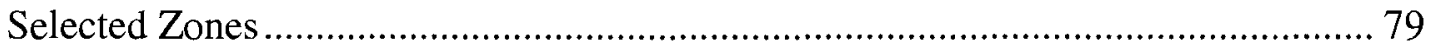

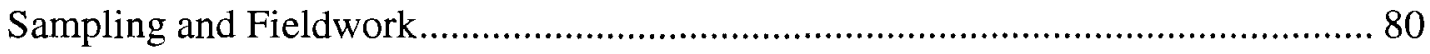

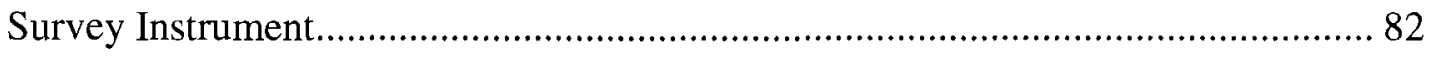

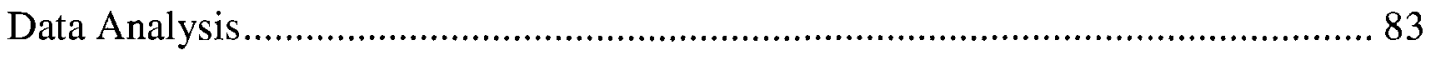

Chapter 6 PHASE I RESULTS: WEBSITE ANALYSIS …………………………..... 85

Sample

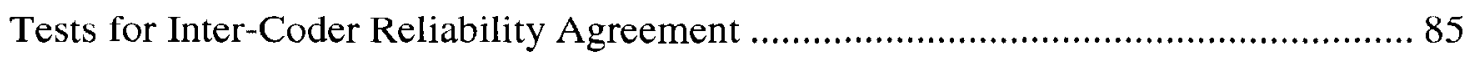

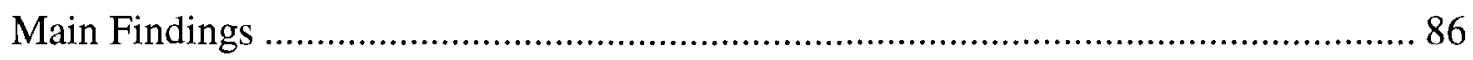

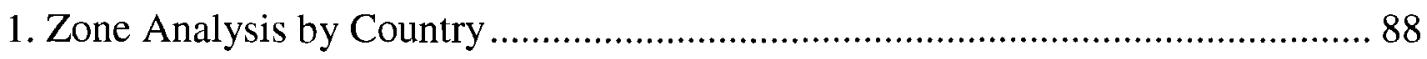

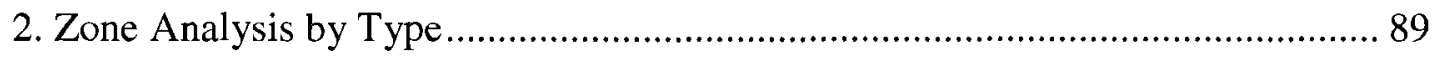




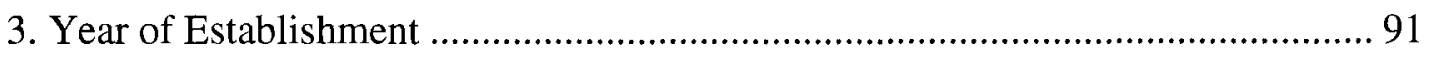

4. Zone Analysis by Developed and Developing Countries....................................... 93

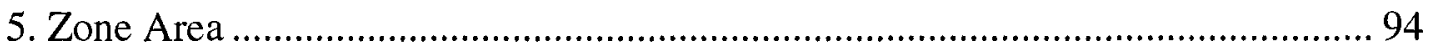

6. Zone Proximity to Major Cities, Ports, Airports, and/or Borders .......................... 96

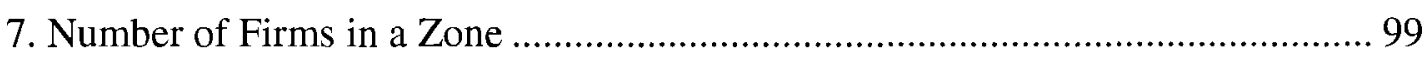

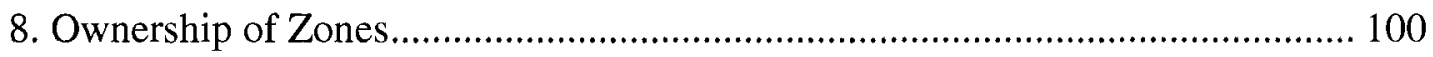

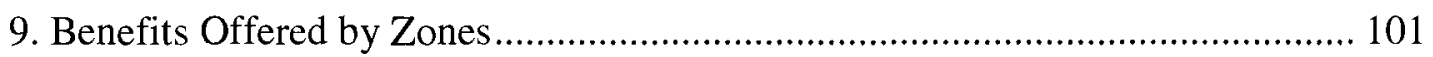

10. Marketing or Promotional Tools Used by Zones ............................................ 105

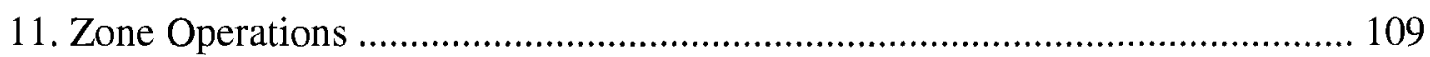

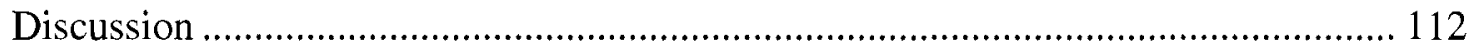

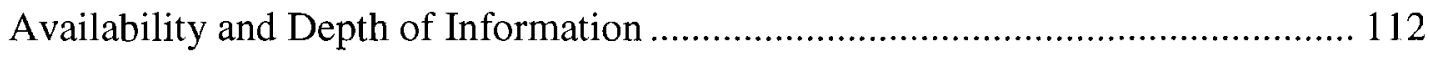

Demographic Characteristics............................................................................. 113

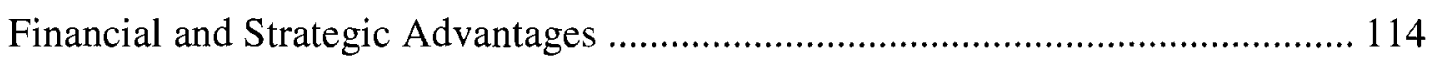

Chapter 7 PHASE II RESULTS: CASE ANALYSIS ................................................. 116

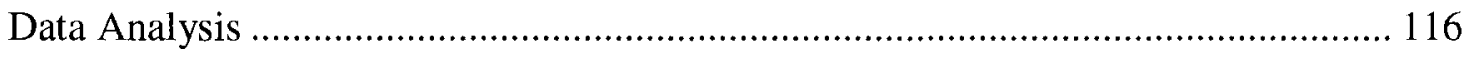

Sample Description ........................................................................................... 118

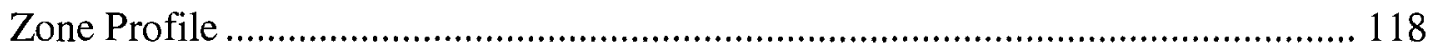

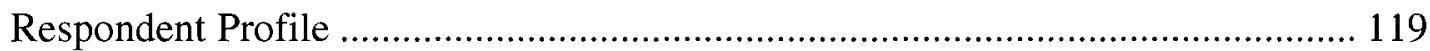

Case Profile of Noida Special Economic Zone …………......................................... 120

Background on Indian SEZ Program................................................................... 120

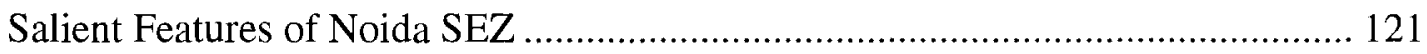

Case Profile of Shenzhen Special Economic Zone ……............................................. 129

Background on Chinese SEZ Program ................................................................... 129

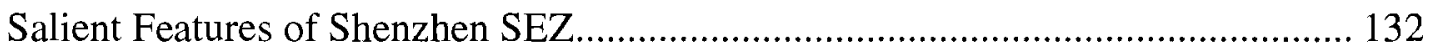

Case Profile of New Orleans Foreign Trade Zone ..................................................... 137 
Background on the U.S. Foreign Trade Zone Program........................................... 137

Salient Features of New Orleans Zone ................................................................ 142

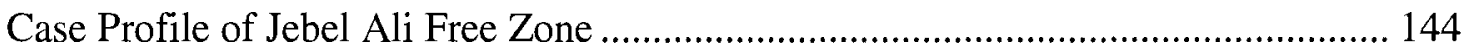

Background on Dubai's Free Trade Zone Program.................................................. 144

Salient Features of Jebel Ali Free Zone................................................................ 147

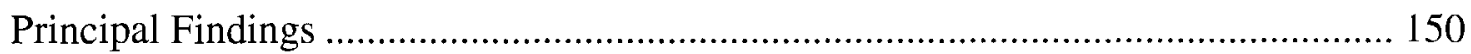

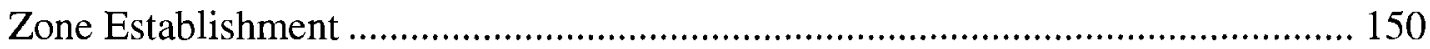

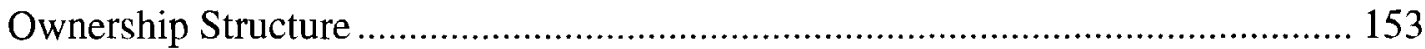

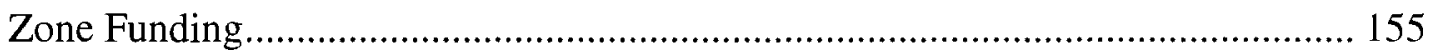

Zone Evolution and Fit with the Country's Economic Strategy .............................. 157

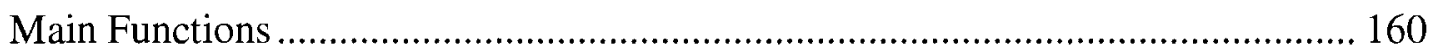

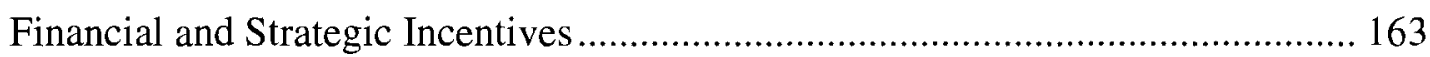

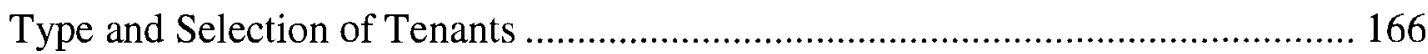

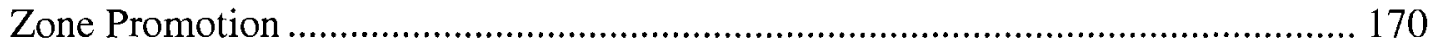

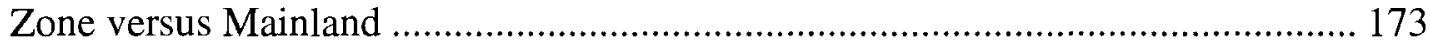

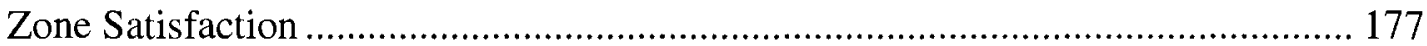

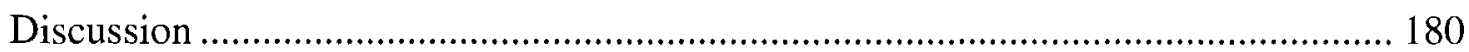

Chapter 8 PHASE III RESULTS: SURVEY ANALYSIS …………………………... 183

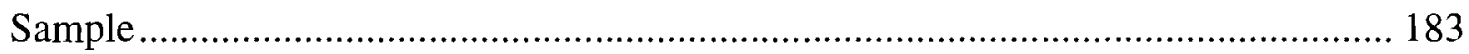

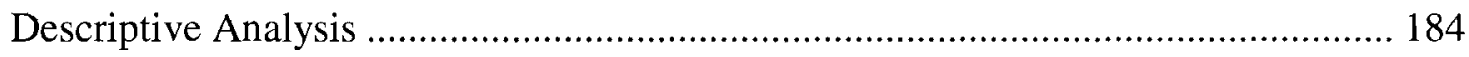

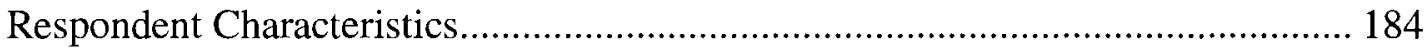

Parent Company's Home Country ……………………….................................. 185

Year of Establishment of Zone Companies............................................................. 185

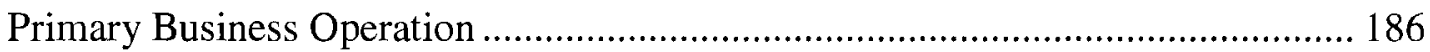

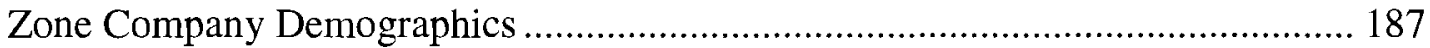


Assessment of Zone Investment Climate.................................................................. 188

Investment Assessment - Comparison of Zone Climate......................................... 189

Investment Assessment - Comparison of Zone and Host Country Climate ........... 194

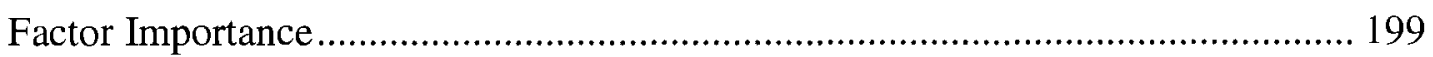

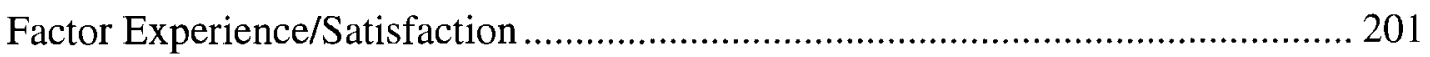

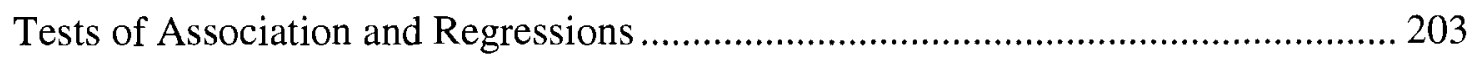

Correlation between Factor Items and Overall Satisfaction ..................................... 204

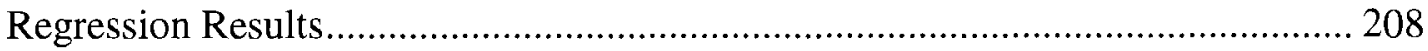

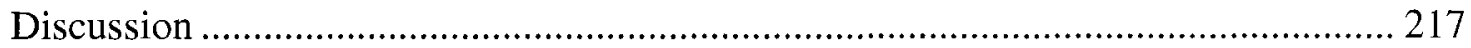

Chapter 9 CONCLUSION AND IMPLICATIONS …………….................................. 220

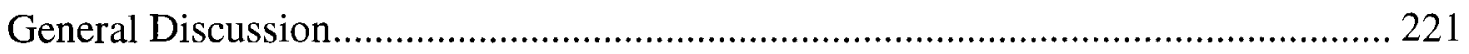

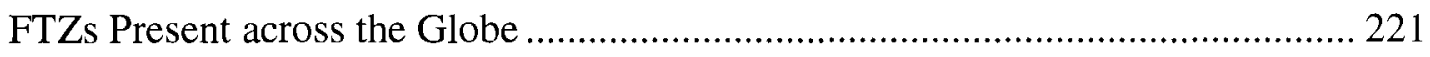

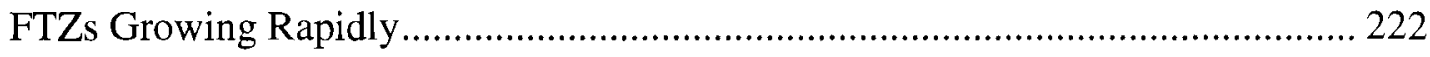

FTZs Control Important Information ................................................................... 224

FTZs Follow a Lifecycle Theory .............................................................................. 229

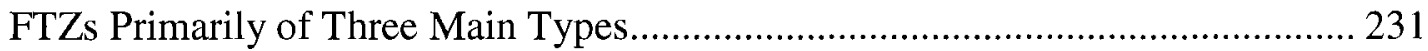

FTZs Offer More than Just Duty Free Benefits......................................................... 233

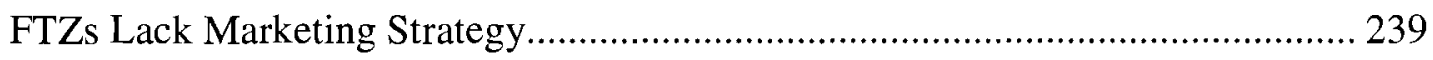

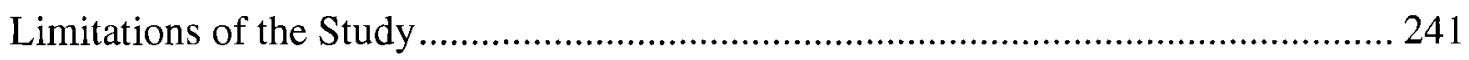

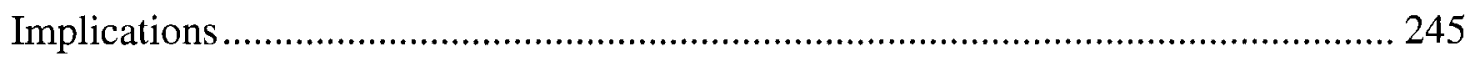

Implications for Policy Makers ......................................................................... 245

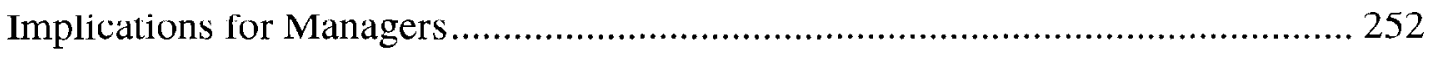

Implications for Research and Future Research Directions .................................. 259

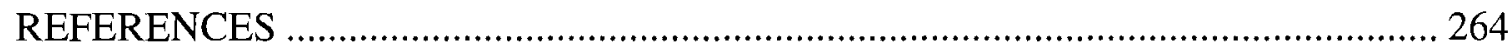

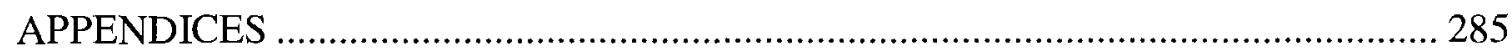




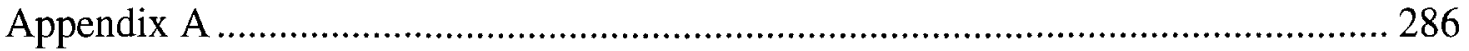

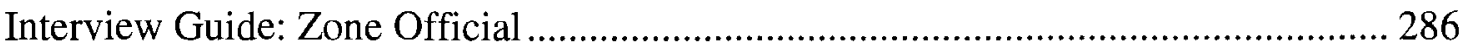

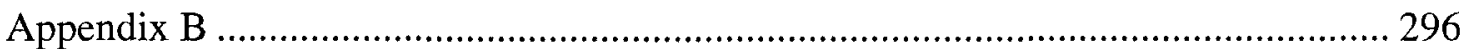

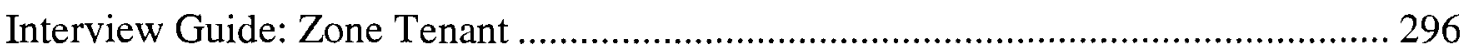

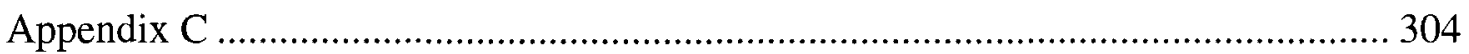

Leave-behind Questionnaire: Zone Officials ............................................................... 304

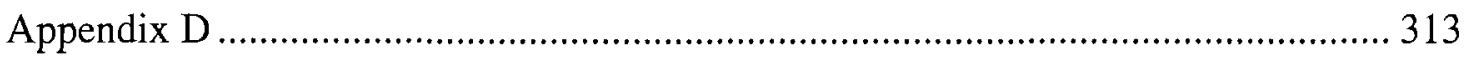

Leave-behind and Survey Questionnaire: Zone Tenant ........................................... 313 


\section{List of Tables}

Table 1.1 Firm Ownership in FTZs across 12 Countries in the early 1990s ..................... 3

Table 3.1 List of Common FTZ Terminologies....................................................... 29

Table 3.2 Contribution of EPZs to Total Exports for 22 Countries............................... 36

Table 3.3 Employment in EPZs in Regions across the World..................................... 39

Table 3.4 New GP Zones, Expansions, and New Subzones in the U.S........................ 46

Table 3.5 Distribution of Establishment of GP Zones by State .................................. 47

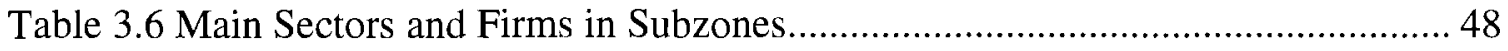

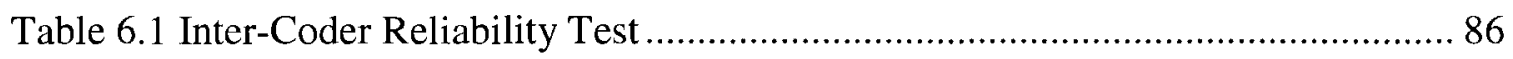

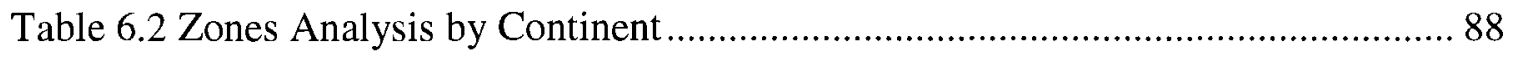

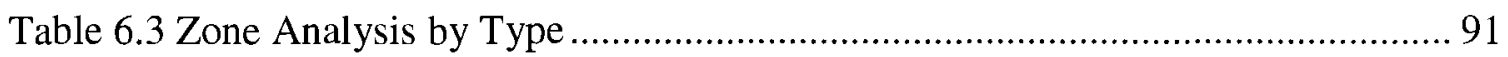

Table 6.4 Year of Establishment of the Zones....................................................... 92

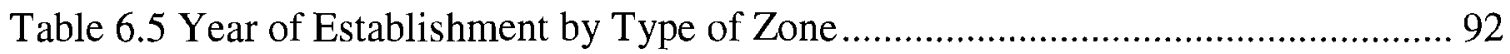

Table 6.6 Zone Analysis by Development of Country .......................................... 93

Table 6.7 Mean Area of Zones in Hectares ................................................................ 94

Table 6.8 Top Five Zones in terms of Area .................................................. 95

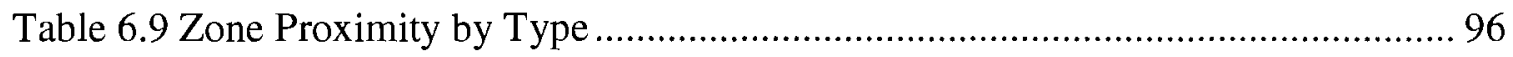

Table 6.10 Zone Proximity to Number of Landmarks............................................. 97

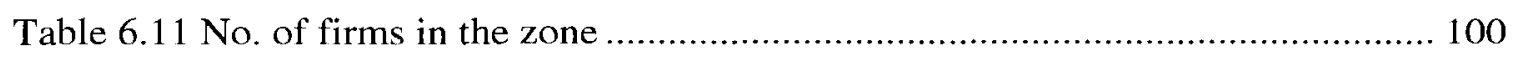

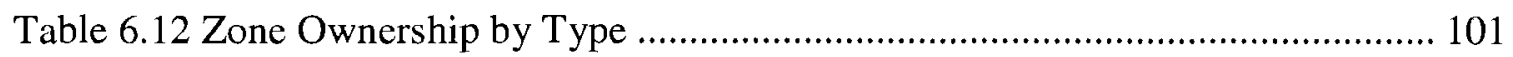

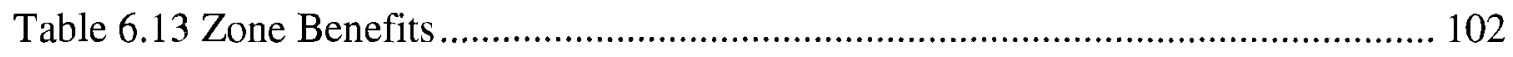

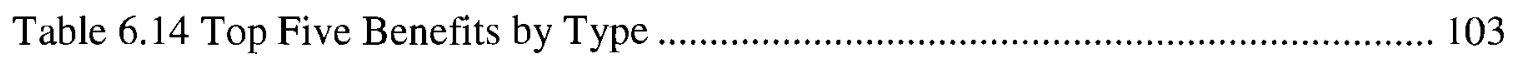


Table 6.15 Number of benefits offered by the zone

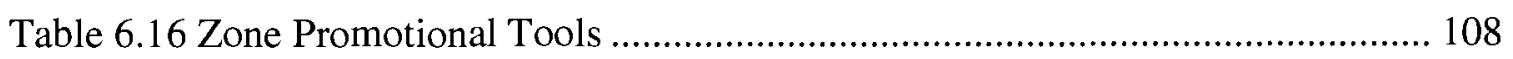

Table 6.17 Top Five Promotional Tools by Zone Type.................................................. 110

Table 6.18 Number of Marketing Tools on the Website .............................................. 110

Table 6.19 Zone Operations in Different Sectors .......................................................... 111

Table 6.20 Zone Operations by Type ………………........................................... 112

Table 7.1 Number of Interviews and Leave-Behind Questionnaires............................. 117

Table 7.2 Zones Selected for Case Studies............................................................. 119

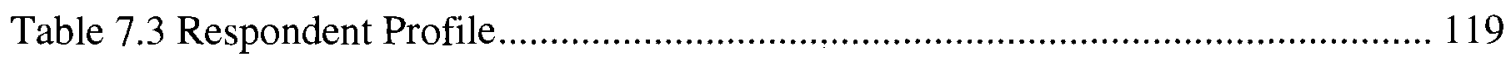

Table 7.4 Growth of Exports from Noida SEZ by Sector............................................. 125

Table 7.5 Breakdown across Sectors of Units in Production, Approved, and Implemented

Table 7.6 Exports from SEZs and their Share of the Total National Exports ............... 131

Table 7.7 Real and Per Capita GDP of Shenzhen SEZ ................................................. 134

Table 7.8 Value of Shenzhen's Exports and Imports ................................................. 136

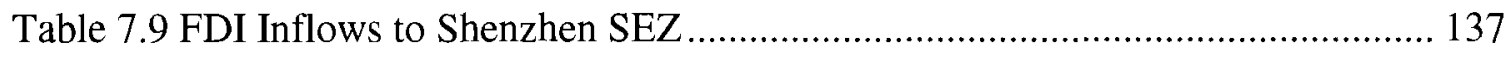

Table 7.10 Value of Shipments into Foreign Trade Zones ........................................... 139

Table 7.11 Reasons for Establishing Zone …………............................................. 151

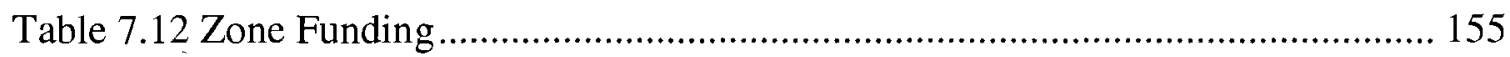

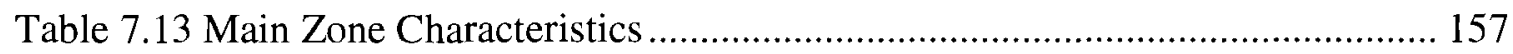

Table 7.14 Importance of Different Activities............................................................ 161

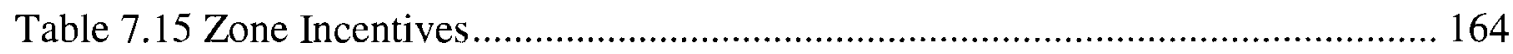

Table 7.16 Domestic and Foreign Firms at the Zones ................................................ 167 
Table 7.17 Officials' Assessment of Investment Climate in Zone and Country

Table 7.18 Assessment of Investment Factors: Zone Officials ............................... 178

Table 7.19 Assessment of Investment Factors: Zone Tenants................................. 178

Table 8.1 Year of Establishment of Zone Companies ........................................ 186

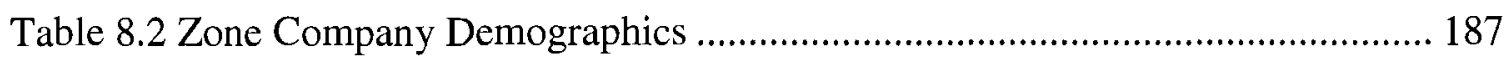

Table 8.3 Comparison of Zone Investment Climate ............................................ 190

Table 8.4 Comparison of Zone and Host Country Climate ................................... 195

Table 8.5 Comparison of Factor Importance across Zones .................................... 199

Table 8.6 Comparison of Factor Importance between Zones and Host Country........... 200

Table 8.7 Comparison of Factor Experience across Zones....................................... 202

Table 8.8 Comparison of Factor Experience between Zones and Host Country........... 203

Table 8.9 Pearson Correlation between Overall Satisfaction and Factor Items ............ 205

Table 8.10 Principal Components Analysis of Investment Items (Varimax Rotation;

Entries in Table are Rotated Factor Loadings) ...................................................... 211

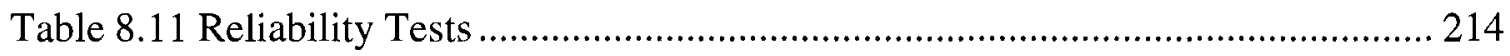

Table 8.12 Multiple Regression Results (Dependent Variable - Tenants' Satisfaction with

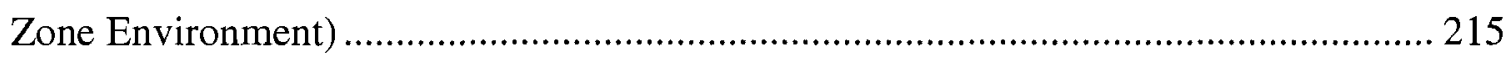

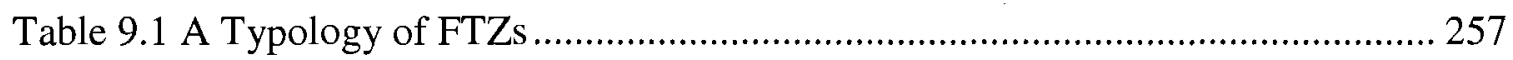




\section{List of Figures}

Figure 3.1 Cumulative Growth of All Zone Types in the U.S.................................... 46

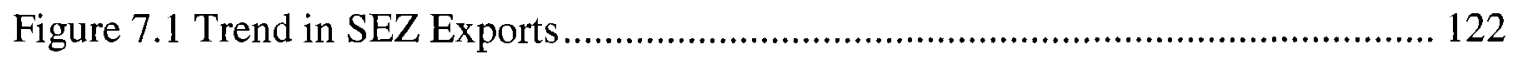

Figure 7.2 SEZ Exports as \% Share of Total Indian Exports ................................... 122

Figure 7.3 Composition of Exports from Indian SEZs $(2004-05)$............................... 124

Figure 7.4 Exports from Noida SEZ: Sector Contribution ........................................ 125

Figure 7.5 Exports to Different Countries from Noida SEZ ...................................... 126

Figure 7.6 Value of Shenzhen's Exports and Imports............................................. 135

Figure 7.7 Foreign Trade Zones: Merchandise Received (General Purpose Zones and

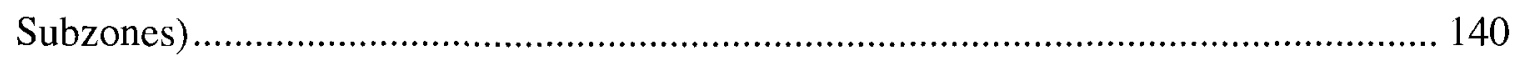

Figure 7.8 Foreign Trade Zones: Exports (General Purpose Zones and Subzones)....... 141

Figure 7.9 Company Demographics at Jebel Ali Free Zone..................................... 149

Figure 7.10 Activities at Jebel Ali Free Zone ...................................................... 150

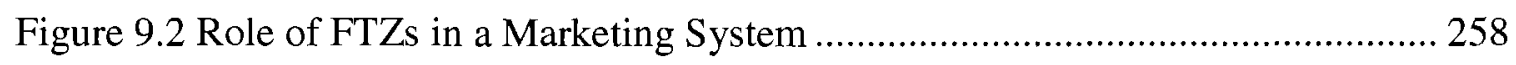




\section{List of Exhibits}

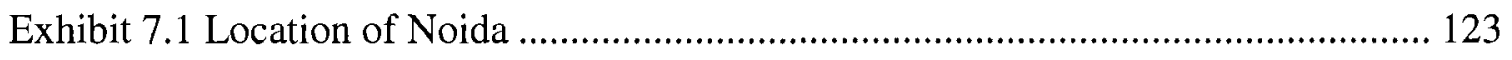

Exhibit 7.2 The Location of Shenzhen in China.................................................. 132

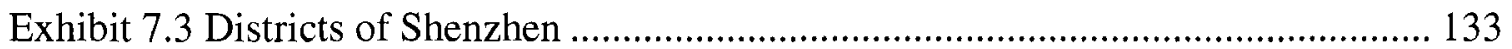

Exhibit 7.4 Location of Jebel Ali Free Zone............................................................ 148 


\section{Chapter 1 INTRODUCTION}

\section{Background}

Free Trade Zones (FTZs) have been growing in recent years, in terms of both frequency and strategic importance (WEPZA 2004). The number of countries with at least one FTZ of any type has increased from about 80 in the 1980 s to 132 today; whereas the number of zones grew from less than 100 in the 1950s to about 2,500 as of 2006 (Papadopoulos 1987, Ettore 1998, WEPZA 2007, ILO 2007). In spite of the rising popularity of FTZs, there is little research in this area by business scholars. Overall, FTZs have received little attention by researchers throughout business and its sub-disciplines, with no more than 30 published studies to date. This is a serious omission, considering the growing importance of FTZs for firms to expand their operations across national borders. The overall goal of the study is to address this gap. (Please note, in addition to the sources cited, background information on free zones is drawn from Malhotra and Papadopoulos [2007], Malhotra, Papadopoulos and Huang [2006], and Papadopoulos and Malhotra [2005a, 2005b, 2005c].)

FTZs are not a new concept; they have been around since ancient times. Free Zones existed in the Phoenician city of Tyre and in $300 \mathrm{BC}$ in the Greek island of Delos, establishing it during those years as one of the wealthiest islands in the world (Haywood 2000). Modern zones, which are quite different from the earlier ones, came into being more recently in the 1960s. One of the first modern FTZ was established in Ireland near Shannon airport. It was set up to prevent layoffs from the advent of jet airliners that did not require refuelling at Shannon. As a counter-measure, the area surrounding the airport 
was converted into an FTZ to attract Export-oriented and Trade-intensive firms (ILO/UNCTC 1988). Influenced by its success, many Asian and Latin American countries adopted the FTZ concept. The main interest for these countries was to promote exports and to attract much-needed foreign direct investment (FDI).

Much of the research on FTZs has been in the domain of developmental (or welfare) and regional economics, where the literature comprises numerous studies. According to Jenkins, Esquivel and Gerardo (1998), economists have concentrated on two main questions:

1. Whether host country's welfare is higher if foreign investment is made inside FTZs in comparison to investment in other parts of the country;

2. Whether welfare is higher after foreign investments in FTZs in comparison to no foreign investment (assuming investment could only be made inside FTZs).

These studies focus primarily on the welfare implications of FTZs. On the other hand, very few studies have looked at the potential benefits of free zones for multinational enterprises.

Table 1.1 shows the percentage of foreign firms operating in FTZs in 12 countries in the early 1990 s. On average, $52 \%$ of these firms were foreign owned, and an additional $19 \%$ of all firms were joint ventures between a domestic and a foreign company. In total, nearly $72 \%$ of all firms operating in these zones were either foreign owned or have a foreign partner. FTZs are important international institutions, where multinational firms have increasingly invested over the years. The potential impact of FTZs on international business strategy makes it imperative that international business researchers and managers understand the role of FTZs. 
Table 1.1

Firm Ownership in FTZs across 12 Countries in the early 1990s

\begin{tabular}{lrccr}
\hline Country & $\begin{array}{l}\text { \# of Firms } \\
\text { Barbados }\end{array}$ & $\begin{array}{r}\text { Foreign Owned } \\
(\boldsymbol{\%})\end{array}$ & $\begin{array}{r}\text { Domestic Owned } \\
(\boldsymbol{\%})\end{array}$ & $\begin{array}{r}\text { Joint Ventures } \\
(\boldsymbol{\%})\end{array}$ \\
\hline Cyprus & 124 & 29.0 & 47.6 & 23.4 \\
Dominican Rep. & 11 & 54.5 & 45.5 & 0.0 \\
Fiji & 357 & 80.4 & 19.6 & 0.0 \\
Jamaica & 119 & 30.3 & 53.8 & 16.0 \\
Jordan & 14 & 92.9 & 7.1 & 0.0 \\
Korea & 15 & 33.3 & 60.0 & 6.7 \\
Mexico & 91 & 37.4 & 33.0 & 29.7 \\
Morocco & 2,634 & 32.4 & 43.2 & 24.4 \\
Philippines & 36 & 94.4 & 0.0 & 5.6 \\
Senegal & 187 & 53.9 & 17.5 & 28.6 \\
Sri Lanka & 9 & 44.4 & 11.1 & 44.4 \\
Total & 139 & 42.4 & 3.6 & 54.0 \\
\hline
\end{tabular}

Source: UNIDO 1995

In light of the above, the intended contribution of the thesis is to help advance international business theory by exploring the role of FTZs from a firm-level perspective, determining the key characteristics of different types of FTZs, and understanding the underlying behaviour of zone tenants (firms operating in zones).

\section{Concept of FTZs}

FTZs are referred to by different names, such as Export Processing Zones (EPZs), Special Economic Zones (SEZs), Freeports, Free Industrial Zones, and so on. Although all of these are FTZs, they are different from each other in many respects. There is lack of consensus in the literature as to which version should be used as an umbrella term. For example, the International Labour Organization (ILO) database refers to zones as EPZs, 
the United Nations Conference on Trade and Development (UNCTAD) uses Free Zones, and the World Economic Processing Zones Association (WEPZA) uses Economic Processing Zones. Use of different terms to refer to zones creates confusion in analyzing data provided by international organizations, and therefore, makes it difficult to compare statistics across zone types. For the purpose of this thesis, I use FTZs, free zones and zones as the interchangeable umbrella terms to refer to all manifestations of this institution. However, I still use specific terms, such as EPZ, SEZ, and others, when referring specifically to these particular types of zones.

There is no universally accepted definition of FTZs, and it is unlikely any one will be agreed upon soon (Jenkins 2000). For this thesis, drawing from the definitions put forth by ILO, World Bank, and WEPZA, FTZs are defined as:

a geographically-restricted place, or a specific industry/company, located within a country, which provides exemption from import and export duties, a liberal regulatory regime, and/or tax and other incentives, which are not available beyond the zone area and are intended to create a relatively barrier-free environment that encourages business to increase imports to, exports from, and/or manufacturing in the host country.

The main concept behind FTZs is that they are an alternative policy framework initiated by governments to promote exports, reduce unemployment, and attract FDI. Contrary to popular belief, liberalization of trade has not eliminated the need for FTZs, rather it has expanded their role (Haywood 2000). With increasing liberalization, FTZs have also increased in number and importance. The statistics presented below highlight the increasing importance of FTZs. These statistics have been compiled from major 
international databanks such as the World Bank, the U.S. Foreign Trade Zones Board, the National Association of Foreign Trade Zones, and various United Nations (U.N.) agencies (e.g. ILO, UNIDO, UNCTAD, and UNCTC). This data was cross-referenced between different sources to address discrepancies among the databases. Currency figures below are in the U.S. Dollars.

- The number of countries with at least one FTZ of any type has increased from about 80 in the 1980 s to 132 as of 2007 (out of approx. 200 nations, i.e. $65 \%$ of the total) (WEPZA 2007).

- The total number of main types of zones grew from fewer than 100 in the 1950 s to about 500 in the 1980s and over 2,500 as of 2006 (Papadopoulos 1987, Ettore 1998, WEPZA 2007, ILO 2007). The current figure would increase to approximately 3,500 if firm-specific zones were included (mainly the U.S. subzones, Mexican maquiladoras, and Philippine ecozones), and to well over 4,000 if the count also included certain other institutions, such as duty-free shops and bonded warehouses at most countries' main ports of entry (these technically are FTZs but are rarely included in such counts).

- The amount of trade channelled through free zones increased from negligible levels 50 years ago to about $\$ 800$ billion in 1997 and $\$ 1.2$ trillion in 2003, and is generally estimated to account for as much as $20 \%$ of total world trade (Papadopoulos 1987, Martin 1998, Ettore 1998, ILO 2004, WEPZA 2004). As just one case in point, the Jebel Ali Free Zone in Dubai, U.A.E. alone hosts over 6,000 companies that handle nearly $\$ 13$ billion in trade annually (Jebel Ali Free Zone Association corporate brochure 2007). 
- According to ILO (2004), exports from EPZs have increased steadily to the point where they now account for the lion's share of exports in countries with strong zone programs (e.g., $60 \%$ for Bangladesh and 87\% for Philippines). In examining EPZs in Africa, Romero (1998:391-392) notes 24 nations had (15) or were planning (9) zone programs as of 1996. Three of the latter had not materialized as of 2004, but 11 nations that had not been included in her original list had in fact implemented new zones, bringing the total to 32 , or more than a two-fold increase in this eight-year period (WEPZA 2004).

- In the U.S., the number of main "general purpose" zones (U.S./FTZ), also known as Foreign Trade Zones, rose from 12 in 1969 to 162 by 1989 and 272 as of 2007 (not all are active at all times, as will be seen in later chapters). Using the same years for comparison, the number of firm-specific sub-zones also rose from one to 54 and then 502. During the same period, the area of several main zones was expanded to accommodate growing demand from the private sector. To obtain an overall measure of zone activity in the U.S., the sums of new main- and sub-zones established, plus main zone expansions, minus only 25 facilities whose license has been revoked or operation terminated for various reasons, for the three time points of 1969, 1989 and 2003, are 16, 388, and 1,054. The amount of trade (imports and exports) handled through the U.S. zones by the 2,285 firms that operate in them, rose from less than $\$ 5$ billion in 1980 to $\$ 410$ billion in 2005 (latest year for which this statistic is available; U.S./FTZB 2002, U.S./FTZB Annual Report 2007). 
The rapid growth in FTZs related activities has undoubtedly attracted considerable research interest at least among scholars in economics. The potential role of FTZs in a broader global strategic plan is discussed below.

\section{Advantages and Strategic Role of FTZs}

Zone advantages to host nations have been discussed at length by researchers in economics, at least insofar as EPZs and SEZs (typically termed as Export-oriented zones, because of their emphasis on promoting exports) in the developing world are concerned. McIntyre, Narula, and Trevino (1996) classify these into direct and quantifiable benefits (e.g., foreign exchange earnings through exports, capital formation through FDI, reduced unemployment) and indirect long-term externalities ("catalyst" and/or "demonstration" effects in the form of improved labour skills, technology and knowledge transfer, building of a competitive infrastructure, regional development, and model testing for national-level liberalization of markets). The advantages of Import-oriented zones that are typically found in developed countries, on the other hand, are less well understood. It can be assumed that the advantages stem from those countries' inherent belief in the value of free market systems and their aim to not only attract foreign customers but also facilitate the operations of their home firms.

Turning to the business perspective, the benefits of FTZs can be many and varied and depend largely on the environment and incentives offered by a zone. For example, the exemption from duties for the duration that merchandise remains in a zone is one of the main benefits of FTZs. While some countries (e.g., Canada) do have "duty-remission" schemes that have a similar duty-free effect on products imported and re-exported after processing, such schemes most often involve a cumbersome bureaucracy unlike that 
found in zones. Many zones also exempt machinery and equipment from duties and other taxes, which can make a significant difference for capital-intensive producers (car makers, for example, are among the biggest users of the U.S./FTZs). The absence of duties can also result in additional savings from lower insurance premiums (since the assessed merchandise value excludes duties). Since both countries and regions within them (notably, states in the U.S.) compete against each other to attract zone tenants, the infrastructure available in free zones most often is subsidized, which further lowers operational costs. Lastly, firms based in any type of zone enjoy considerable flexibilities through reduced red tape (which can be a concern even in developed countries) and by being able to use FTZ-based operations in various distribution functions including labelling, packaging, bulk breaking, and product demonstrations to potential customers.

However, an important benefit not cited in the literature is the broader role of FTZs whether they are viewed individually or as potential networks that can be integrated into the firm's international supply chain and/or global strategic plan. From the standpoint of business decision makers working on global strategic planning, understanding this broader role for FTZs requires recognition of three important facts: (a) in-zone operations may be the only means available for operating in some countries of potential strategic importance to the firm (e.g., when trade and foreign investment legislation in the country's "domestic" territory is overly restrictive); (b) in most developed and many developing countries, many zones specialize in certain sectors (e.g., textiles, electronics, cars) which create industrial clusters and bring about their associated benefits (e.g., sector-tailored infrastructure or legal and consulting services); and (c) countries tend to establish their zones at strategic locations within their territory, further 
enhancing any locational advantage that the country itself may offer (examples include the Colon FTZ in Panama, Shannon in Ireland, Shenzen in China near Hong Kong, and the fact that most, and the most active, zones in the U.S. are in five major "entry-point" states - Florida, California, New York, Washington, and Texas).

Keeping the above points in mind, the strategic role of FTZs can be seen from the following two perspectives:

\section{Individual Zones as Assembly, Distribution, and/or Just-In-Time-Marketing Hubs}

Centralizing operations in barrier-free (and often incentive-enhanced) zones can enable a firm to reduce its operational costs. It can also enable firms to respond quickly to demand in the host country and perhaps other nearby markets (e.g., most international courier firms operate Asian hubs from within Philippine SEZs; Makabenta 2002). This is particularly the case in inventory management. Rather than holding excess inventory, firms can hold base inventories within one or more selected zones enabling quick responses as market conditions evolve - while at the same time taking advantage of the zone's barrier-free environment and facilities (Papadopoulos 1985, 1987). For example, goods can be labelled for specific export markets only when demand in each warrants their export, thus reducing the need for re-labelling and re-transporting them if expected sales at the original target do not materialize. Similarly, in-zone goods that are subject to quotas can be readily imported into a country's domestic territory as soon as the quota is lifted. In addition, faddish products with uncertain demand can be moved to new locations without triggering extra duties or extra red tape each time. In countries where duties are higher for component parts than finished goods (as is the case for several items in the U.S.), the former can be shipped separately or in modular form for assembly at a 
zone before being imported into the domestic market, thus taking advantage of both lower freight costs and lower end-product duty rates.

\section{Zone Networks as Part of Supply Chain and Global Strategic Planning}

Strategic global positioning on both production and marketing sides is important to all firms. However, for all but perhaps a handful of the largest multinational companies, achieving it can be prohibitively costly and is often impeded by trade and FDI obstacles in many countries. In this context, viewing multiple in-zone operations as integral parts of international positioning can supply answers to problems that are otherwise hard to solve (Papadopoulos 1985, 1987). In a simplified scenario, a firm may elect to establish zone operations in as few as two or three countries by taking advantage of the unique characteristics of each. For example, inventory of key input materials in zone/country A, where they are readily available; assembly in $\mathrm{B}$, where labour costs are low and manufacturing incentives are offered; and distribution hub in $\mathrm{C}$, which may be closer to major target markets. Coupled with the advantages mentioned above when viewing zones individually (for example, ability to package and label products for particular markets "at the last minute" as demand warrants), this approach maximizes economies of scale, minimizes costs and risk, and optimizes market responses. All this can be achieved at a considerable advantage over a scenario where the same operations are carried out in the same countries' regular "domestic" territory. In a more complex scenario, several or many in-zone operations can be used to optimize the firm's supply chain as well as marketing and distribution operations. Whatever the case may be, one can envisage situations where goods can be "moved around the world" from their inception as raw and intermediate materials or components to their final release to target buyers in the form of 
finished products, being free of barriers (and perhaps also taking advantage of special incentives) by staying within FTZs throughout the process.

As is apparent from the above discussion, zones can offer both tactical and strategic benefits that go well beyond their "duty-free" characteristic. In fact, it is possible that the apparent staying power of the latter as "the" perceived key benefit of FTZs often obscures the relative importance of their other advantages. This may be a prime culprit behind the lack of interest in FTZs on the part of business researchers who may still be thinking of them as just a "duty avoidance" scheme. For instance, Diamond and Diamond (2003) still use the term "Tax Havens of the World" as the title of their much-used directory of FTZs; this in fact emphasizes this characteristic even more than the "Tax-Free Trade Zones of the World" title of earlier editions. This can clearly affect understanding and appreciation of the role of FTZs, and not just on the part of business academics. For example, even the U.S. Foreign Trade Zone Board has clearly failed to understand the broader logistical and strategic advantages of its own zones, since all its listings of benefits emphasize duty and tax issues. Specific instances of such references can be found, for instance, in the U.S./FTZB (2002), and in McGilvray (2004), who "buries" logistics in the midst of a long list of tax-related benefits.

\section{Conceptualization, Methodological Approach, and Importance of the}

\section{Study}

While research in developmental and regional economics has dealt with FTZs in detail, most of these studies focus on the welfare aspects and cost-benefit analyses of zones in developing countries. To the best of my knowledge, there is no comparative research of zones between those in developed and developing countries. More importantly, there is 
virtually no research from the business standpoint or using the firm as a unit of analysis in the context of FTZs. This creates the research gap which this study is intended to address. The overall research goal is to advance understanding of the role of FTZs from an international business perspective through four specific objectives:

- To identify and compare the key characteristics of various representative types of zones using secondary data.

- To obtain an in-depth understanding of zone and tenant operations using case analysis.

- To explore, describe, and analyze the zone-related behaviour of tenants.

- To compare and analyze differences between the three important types of FTZs Export, Import, and Trade-oriented zones.

The behaviour of firms in relation to FTZs is a matter of internationalization and export target selection (in relation to Import-, or Trade-oriented zones) and/or of the selection of locations for FDI (in relation to FDI/Export-oriented zones). Therefore, the conceptualization of the study and its methodology were grounded on five theory streams: existing research specifically on FTZs (mostly from economics); Dunning's eclectic paradigm for FDI (ownership, location, and internalization advantages); the resource-based view (RBV) of the firm; the FDI location selection literature; and the literature on internationalization (Uppsala school).

The research is conceptualized so as to capture and analyze a variety of zone and tenant characteristics for three main types of zones located in representative regions: Import-oriented (U.S.); Trade-oriented (mostly Europe, also Colon, Panama, and United Arab Emirates); and FDI/Export-oriented zones (developing world). Since there was 
virtually no past similar research to help guide the development of this study, a threephase research methodology was undertaken to obtain a comprehensive view of zone operations and zone tenants, and to enable the results of each phase to inform and enhance the design of the next phase. Following is a brief overview of the three phases. Each phase is discussed in detail later in this thesis.

\section{Phase I}

- Overview: Review of a broad sample of 105 FTZs of various types and in various regions, to obtain basic data on their operations and characteristics.

- Sample: Identified using the databases of the U.S. Foreign Trade Zones Board, the International Labour Organization, and the World Economic Processing Zones Association, the Diamond \& Diamond (2003) list of Tax Havens, and the websites of individual zones.

- Approach: Downloaded/obtained as much information as possible and catalogued and analyzed it to develop an overview of typical zone operations.

\section{Phase II}

- Overview: Identified four zones for in-depth qualitative analysis using the case study method.

- Sample: Four zones included were, the New Orleans Foreign Trade Zone (Importoriented); Jebel Ali Free Zone in Dubai (Trade-oriented); Shenzhen Special Economic Zone in China and Noida Special Economic Zone in India (Exportoriented). 
- Method: In-depth interviews (with pre-designed interview guides, using information from Phase I) with zone officials and tenant representatives, enhanced with documentary information about the zones obtained during the site visits.

- Analysis and use of findings: Data from this phase was combined with the results of Phase I to develop a comprehensive view of zone and tenant operations.

\section{Phase III}

- Overview: Broad based survey of zone tenants, with a sample of 115 firms.

- Sampling: Convenience sampling limited to tenants in two zones - Jebel Ali Free Zone and Noida Special Economic Zone. The sample comprised roughly equal proportions of firms representing each zone.

- Method: Questionnaire based survey with emphasis on collecting firm characteristics, objective data on the firm's zone and other international operations, and, in line with the eclectic paradigm, RBV, internationalization, and other theories noted above, manager perceptions of and attitudes to their tenancy in a zone, objectives for locating in a zone, position of zone operations in relation to global strategy, and so on.

- Analysis: Mainly descriptive statistics, correlation analysis, and multiple linear regressions.

This study is important for six main reasons. First, it will help to fill several of the existing gaps in the FTZ literature. Second, it will be the first study to (a) compare zones and their tenants in a cross-section of zone types and regions, and (b) explore and describe the characteristics and behaviour of zone tenants. Third, it will help determine zone characteristics that may influence firms' operations within FTZs, which would be important for host countries to design successful zone operations and can contribute 
toward broader investment policy considerations. Since work of this type is not available to date, this will be the first time that broad tenant input from various types of zones and regions will be available to policy makers interested in FTZs. Fourth, it will enhance managers' understanding of zone operations and their potential benefits in international business strategy. Fifth, it will contribute useful insights to the research streams that are used to frame this study. Of these, one, economics, has addressed the question of why FTZs exist but not from the business perspective, while the other four (eclectic paradigm, resource-based view of the firm, FDI location selection, and internationalization of the firm) have not dealt with FTZs at all. And last but not least, it will contribute towards developing a basic FTZ theory from the perspective of zone tenants. An additional potential contribution of this study arises from problems encountered in attempting to collect data from firms operating in FTZs, which proved to be extremely difficult. While the difficulties were largely overcome, the nature of the problems themselves provides useful insights into zone operations and will be discussed in a later chapter.

It should be noted at this point that the nature and context of this study had additional benefits for me as a researcher and future academic, in that it enabled me to obtain considerable experience in coordinating a large international project and helping to supervise graduate students. The study is part of a long-term program of research into FTZs that was initiated by my supervisor, Dr. Papadopoulos, and is now coordinated jointly by him and me. Earlier phases of the program included work by two MBA students supervised by Dr. Papadopoulos, whose research I helped to guide - Lihuan Huang, who focused on a detailed analysis of Chinese SEZs, and Nubia Cabezas-Navas, who carried out a website-based analysis aiming to determine broad FTZ characteristics. 
Both projects were designed partly to obtain synergies with, and possible inputs to, the present study. (In a further attempt to expand the scope of the program, Ms. CabezasNavas is presently initiating an FTZ study in Nicaragua under my supervision.) Further, the present study also included Frank Jinyu, an MBA student working under the supervision of Dr. Leslie T. Szamosi at the University of Sheffield City College campus in Thessaloniki, Greece, and Xiaotong Yang, an MBA student working under the supervision of Dr. Melodena Balakrishnan at the University of Wollongong in Dubai. These students worked on the data collection in Shenzhen (China) and Dubai, respectively, under joint supervision and guidance by me and their local professors.

This coordination and supervision work, which involved four graduate students and three professors and spanned six countries, provided me with valuable experience that will be instrumental to the success and future expansion of this and other research studies and programs.

The remainder of this thesis report is structured as follows. Chapter 2 reviews the relevant literature, and chapter 3 discusses the different types of zones, with emphasis on the three important types. In chapter 4, I discuss the conceptual framework, followed by detailed discussion on the three-phase methodology in chapter 5. Chapters 6,7 and 8 present the results for Phase I, II and III. Chapter 9 concludes the study with a general discussion of the main findings from all three phases and suggests implications for policy makers, managers, and research. 


\section{Chapter 2 LITERATURE REVIEW}

\section{Literature Search Method}

The studies selected in this review were identified by a methodological process that combined electronic means with manual search. The use of electronic tools as a way of search was conducted by scanning 'Emerald Insight', 'Ebsco-Host', 'Scholars Portal', 'EDGAR', and 'Econlit' bibliographic databases, and also other internet resources such as 'Google', and other similar search engines. These databases and search engines were used to generate a number of studies which contained (whether in their title, abstract, or full text) keywords that have become associated with FTZs, such as Duty Free Zones, EPZs, SEZs, Tax Havens, Free Zones, and Economic Development zones. The databases covered all possible economic and management journals.

This process generated approximately 110 studies, whose abstracts were then scanned to shortlist those that were relevant to the research topic. This was followed by a manual search of the selected articles to identify books and chapters, conference proceedings, and working papers, which are not normally included in the electronic databases.

Although no time frame was set for selecting the studies, most of the articles belong to the period 1970-2006. This search ensures that most relevant articles, which comprise a representative and a comprehensive body of literature in FTZ, were reviewed for this study. This process helped to identify a multitude of studies in economics, of which the principal ones are used here, and an inventory of relevant works in business 
(defined as those that were written by a business researcher, published in a business journal, and/or dealing with a business theme).

Past research on FTZs can be divided into several streams. Early studies tended to focus on free zones in general as an instrument in international trade (e.g., Diamond 1979, Grubel 1983, Jaywardena 1983, Journal of Commerce 1983, Papadopoulos 1985, 1987). This was a natural tendency since the FTZ concept was relatively new, Exportoriented zones were still in relative infancy, and attention was focused on the "duty-free" advantages of zones at a time when trade barriers were high and the concept itself had not yet evolved to its present multi-faceted form. These early studies tended to focus on three main issues: discussing the advantages of FTZs for host nations and/or international firms (e.g., Diamond 1979, Grubel 1983, Papadopoulos 1985), profiling their growth (e.g., Grubel 1983, Basile and Germidis 1984), and examining the "growing pains" of the nascent concept as more countries started launching new zone programs (e.g., Wall 1976, "Zones of confusion..." 1985).

Over time, however, and particularly as the newer Export-oriented and development-focused zone concepts began taking shape, the emphasis of researchers has tended to become rather polarized. Given their interest in development, economists in both academia and the major international organizations focused more and more on EPZs and SEZs, and business and government researchers in the U.S. focused on that country's unique "foreign" trade zones and their significance on its import trade. In the following sections, I review separately the economics and business literature. 


\section{Economics Perspective}

The economics literature on FTZs can be further sub-divided into two broad areas. The first area focuses on the developmental issues of EPZs from a host-country perspective, while the second includes studies that have attempted to put forth a unifying theory of FTZs. I discuss these separately.

\section{Developmental Issues}

The economics literature depicts EPZs as instruments of economic development, particularly as tools for economic liberalization (Chen 1994, Johansson and Nilsson 1997, Romero 1998, Wei 2000, Sargent and Mathews 2001, Kinunda-Rutashobya 2003). Among others, Madani (1997) and Jenkins, Esquivel and Gerardo (1998) stress that EPZs are a second best policy in comparison to country-wide reforms for economic development. The success of EPZs is due to a theoretical shift away from importsubstitution and self-sufficiency, in favour of greater emphasis on exports and integration with the world economy (World Bank 1992). Studies by economists and leading world organizations consistently show a positive relation between export expansion and economic growth in developing countries (UNCTAD 1983, World Bank 1992, Johansson \& Nilsson 1997, Kinunda-Rutashobya 2003). The studies show the developing countries that have pursued an export-led strategy have grown faster than those that have maintained an import-substitution strategy.

Major developmental objectives of EPZs vary depending on the context and the environment under which it is operating. Chen (1994) classifies zone objectives for host nations into six main categories: FDI attraction, employment generation, export promotion, technology transfer, domestic integration, and regional development. Perhaps 
more effectively, McIntyre, Narula, and Trevino (1996) distinguished between two major groups: direct and quantifiable objectives (e.g., foreign exchange earnings through exports, capital formation through FDI, and reduced unemployment); and indirect longterm externalities ("catalyst" and/or "demonstration" effects in the form of improved labour skills, technology and knowledge transfer, building of a competitive infrastructure, regional development, and model testing for national-level liberalization of markets).

Given the potential benefits, it is not surprising that many developing countries have developed EPZ programs. Arguably, the most successful (and certainly most discussed) zone is the Chinese SEZ in Shenzhen. Since its inception in 1980, this zone area developed from a small town of 20,000 into a modern city of 3.5 million with a GDP per capita of U.S. $\$ 4,000$, and an annual GDP growth rate of $32 \%$. The zone tenants represent a "who's who" of major multinational firms. As an illustration of its global importance, in 1998 Shenzhen accounted for $14 \%, 6 \%$, and $8 \%$ of world output in, respectively, floppy disks, PC motherboards, and hard drives (Wei 2000). At the other end of the scale, Mauritius, a very small country which set up its first EPZ in 1971, has risen to "middle-income nation" status in the World Bank classification (KinundaRutashobya 2003). It has also become one of Africa's leading exporters of merchandise, which replaced sugar as the country's main export. Its export earnings grew at an average annual rate of $70 \%$ in the 1980 s, and its EPZs are credited with reducing unemployment from $20 \%$ in 1971 to less than $2 \%$ in 1994 (resulting in an enviable position where labour to service the zones now has to be imported; Romero 1998, Kinunda-Rutashobya 2003).

However, EPZs have not been without their critics and several researchers have noted a number of potential limitations and problems. Of these, two stand out most 
prominently. The first concerns labour issues, including so-called inadequate wages, job benefits, health and safety standards, job security, and training, the latter also suggesting limited opportunities for zone workers to migrate from unskilled to supervisory jobs (Rondinelli 1987, Romero 1998). For example, analyses by ILO/UNCTC (1988) and others have concluded that the societal impact of EPZs may be negative due to the "shadow price of labour". This is due to the differential opportunity cost from bringing unskilled young females into the workforce for the first time, versus offering the jobs to skilled but currently unemployed men who could technically command higher wages. This is claimed to result in below-market wage rates within zones, since young females comprise the bulk of EPZ labour (ILO 2004). In a similar vein, Jauch (2002, p. 101) posits that the incentives offered to zone tenants in Southern African countries are a "race to the bottom" and "greatly limit the net benefits of the new investment to the national economy". This results in lower labour standards, restricted union rights, and significantly less employment than promised by the country's government when promoting the relevant legislation (in Namibia's case, 400 jobs versus a forecast of 25,000 by the end of the first three years of operation of that country's zones in 1999 ; Jauch [2002], p. 101, 105).

The second major area of concern focuses on negative and/or fewer-than-expected externalities. These include adverse impacts on the host society (e.g., human rights violations in the work environment, encouragement of corruption among government zone managers, and implicit support for the informal economy in some zone programs). It also includes low levels of technology transfer, labour migration to city-based zones, which burdens already weak urban infrastructures, and over-dependence on zone 
investors who may move to other countries when labour costs rise (Rondinelli 1987, ILO/UNCTC 1988, Romero 1998, Jauch 2002).

These two major areas of concern, coupled with poorly thought out policies by host nations, which lead to poor zone management and discourage foreign firms, are commonly used to explain the failure or difficulties of various EPZ programs such as, for example, in Africa (Romero 1998), Russia (Manezhev 1993), North Korea (Noland and Flake 1997), and India (Kundra and Sharan 2000).

However, a number of researchers suggest that many of the issues raised are misstated or exaggerated. Rather they reflect early problematic experiences that are eventually addressed once a country gains experience with the zone concept. For example, Summerfield (1995) argues that using the shadow price of labour to assess EPZs ignores the broader benefits from employing women in zones (e.g., higher status in society and within the household). Kusago and Tzannatos (1998) have shown that the proportions of managerial and clerical staff within Malaysia's EPZs in fact rival the national average (respectively $5 \%$ and $8 \%$ within zones, versus $4 \%$ and $7 \%$ in domestic manufacturing). The authors also compared in- and off-zone wages in five Latin American countries. They found that those in EPZs were actually somewhat higher than the national rates in three countries, somewhat lower in one, and significantly lower only in one instance (Panama). Lastly, concerning employment in the case of Namibia's EPZs, which was mentioned above, the ILO (2004) reports the current number of jobs as 29,000 , or $16 \%$ higher than the initial target of 25,000 that was noted as badly missed by Jauch (2002) using 1999 as the reference year. 
Based on the above, it may be concluded that while disagreements among researchers naturally exist, these have to do more with specific implementation problems than with the EPZ concept as such.

\section{Economic Theory on FTZs}

The development of economic theory on FTZs, which, it will be recalled, focuses exclusively on EPZs, has progressed in two main directions: (1) study of the cost-benefit analysis of FTZs; and (2) study of the welfare impact of FTZs on the host economy. Warr's (1987) analysis of the four zones located in Malaysia, Indonesia, Korea, and Philippines, to determine the relative importance of different sources of benefits and costs, is a pioneering study in the cost-benefit analysis of FTZs (Jenkins, Esquivel, and Gerardo 1998). The study revealed foreign exchange and employment generation to be the two most important sources of benefits. These contribute $75 \%$ to $90 \%$ of the total benefits from the zones in Philippines, Malaysia, and Korea. Purchase of local supplies and raw materials contributed $3 \%$ to $16 \%$ of the total benefits from all four zones, making it the third most important source of benefit. Among the major costs associated with FTZs, infrastructure costs tended to be the largest, followed by administrative and public services costs. Of the four zones, those located in Malaysia, Indonesia, and Korea achieved an internal rate of return of over $15 \%$, while the zone in Philippines showed negative results, due mostly to high infrastructure costs.

The researchers studying the welfare impact of FTZs have tried to address two main questions: (1) whether the host country's welfare is higher with foreign capital invested in FTZs, versus if the same amount is invested in the domestic economy; and (2) does the host nation welfare improve after establishing FTZs (Jenkins, Esquivel, \& 
Gerardo 1998). Hamada (1974) was the first to study the welfare impact of FTZs using a $2 \times 2$ factor model, i.e. a host economy with two factors of production (labour and capital) and two final goods (1 and 2). He concluded that FDI in FTZs is welfare decreasing. Similarly, Hamilton \& Svensson (1982) using a similar framework but under different assumptions concluded that FDI in FTZs reduces welfare relatively more than the same amount of FDI in the domestic economy.

The later studies employ an extension of a $2 \times 2$ factor model. Miyagiwa (1986), using three factors of production (land, labour, and capital) and three goods ( $3 \times 3$ model), concluded that FDI in FTZs used for diversifying production increases welfare. Young and Miyagiwa (1987), incorporating unemployment as another factor, argue that formation of FTZs may be the second-best policy for increasing national welfare.

Apart from the two main research directions, a number of studies have also looked at the impact of FTZs on the firm's FDI location decision. Woodward \& Rolfe (1993), Kumar (1994), and Choi (1995) examined the determinants of location of Exportoriented FDI of the U.S. multinationals. The three studies find the presence of FTZs to have a positive and a significant impact on the firm's choice of FDI location.

The overview of the economics literature indicates a major impact of EPZs on the economic development of developing and under-developed economies. However, the literature on the welfare impact of FTZs on society at large is clearly inconsistent. The research results appear to be highly sensitive to the methodology employed. For example, the use of different equilibrium models under distinct sets of assumptions has lead researchers to conclude contrasting outcomes. In addition, although studies have attempted to put forth a unifying theory for FTZs, the predominant focus of these theories 
has been Export-oriented zones. Kinunda-Rutashobya (2003) rightly argues that the current theories are inadequate and that a more appropriate explanation of the FTZ phenomenon is yet to emerge.

\section{Business Perspective}

As noted earlier, business research on FTZs is scant and comprises only around 30 studies in total. (This total includes six studies published by this researcher and his supervisor between the proposal for this thesis and today.) These studies can be categorized as those having been carried out in earlier versus more recent years of FTZ research.

Starting with the earlier studies, these attempted to outline the basic functioning of FTZs and their role as an integral part of international business (Papadopoulos 1985, 1987, Tansuhaj and Gentry 1987, Cornwell 1989, Tansuhaj and Jackson 1989). Of these, Papadopoulos $(1985,1987)$ reviewed the literature to that time and was the first to examine the concept in the international strategy context. The other earlier studies were focused entirely on the U.S./FTZs. Tansuhaj and Gentry (1987) carried out what was probably the first empirical study on free zones. They examined differences between firms that do and do not use foreign zones in the U.S. They contacted zone operators in U.S /FTZs to distribute questionnaires to their clients. In all, 62 firms participated in the study. They found that the user groups were significantly smaller in terms of sales and number of employees. For instance, $63 \%$ of the users had sales of $\$ 10$ million or less, and $65 \%$ had 100 or less employees. Cornwell (1989) conducted a longitudinal empirical study of zone managers at the U.S./FTZs in June 1983 and December 1986, to determine 
their current and future expectations of zone utilization. Her findings can be grouped under three main headings.

- Characteristics of zones' potential clients: Over 50\% of the managers at both time periods indicated that potential clients to their zones were located in foreign countries, primarily Japan, Canada, and West Germany;

- Product characteristics: 87\% (1983) and 71\% (1986) of the managers indicated that assembled goods would be the most probable products to pass through the zones. In $1983,74 \%$ of the managers indicated products to be primarily low in technology and $47 \%$ indicated that products would be high in technology (multiple responses were allowed, and so the percentages may total more than 100). In 1986, managers held equal expectations for both low and high technology.

- Zone functions: With regard to the likely functions that potential FTZ clients would perform in zones, managers indicated storing as the most probable function in 1983 (84\%) and $1986(80 \%)$.

Surprisingly, in contrast to the findings of the above study, the U.S./FTZs continue to attract predominantly local manufacturers (U.S./FTZB 2004), who are essentially importing intermediate/component goods that are combined to form new products before being sold in the U.S. market.

The studies in more recent years have largely focused on identifying the U.S./FTZ benefits for local firms. Beenhakker and Damanpour (1992) and Mathur (1993) identify three major benefits for firms operating in the U.S./FTZs: (1) tariff deferral on domestic shipped goods, (2) tariff reduction by selecting the lowest tariff in advance, and (3) tariff avoidance on foreign content or goods to be transhipped. Primarily the U.S. importers 
who pay lower duties on finished goods than on the component parts use these benefits. Thus, these firms import component parts in zones and avoid excessive duties, assemble them to final products, and either export or sell these in the U.S. at lower tariffs, leading to what is commonly known as "inverted tariff" benefits.

In another comparative study among users and non-users of the U.S./FTZs, Mathur (1994) was the first to determine whether benefits offered by these zones translated into actual cost savings for the user firms. Relying on secondary data, the author compared 35 user and non-user firms, with total operating costs as the dependent variable, and sales and ratio of cost of sales to total sales as independent variables. Surprisingly, the results showed that the zone user firms had significantly higher total operating costs than the non users, indicating that users are less cost efficient than non users. However, the results need to be interpreted with caution due to the small sample size of the study, and the possible effect of the type of firms that were sampled.

Among the other more recent studies, five are limited to examining specific zones, and two of these adopt essentially an economics perspective (Brenes and Ruddy 1997, Noland and Flake 1997). Two other studies are little more than practical "guides for managers" wishing to invest in Chinese SEZs (Firoz and Murray 2003, Firoz et al. 2003). The fifth study by Jenkins (2006) seeks to provide a better understanding of the factors that affect tenants in an EPZ to source intermediate goods from the local economy. This paper adopts an econometric model and is based on secondary data collected at the Costa Rica EPZ in 1997. The study finds that (1) manufacturing companies are less likely than service firms to purchases intermediate goods from the 
local economy; and (2) capital intensive and older firms (in terms of the number of years spent in the zone) are more likely to purchase local goods.

At a more generic FTZ level, major benefits for businesses includes inexpensive labour, subsidized cost of infrastructure support, reduced tariff barriers for intermediate goods, tax subsidies, and more recently, relaxed pollution laws (McIntyre, Narula, and Trevino 1996). In addition, firms may not be subject to any duties on spoilage or defects during cutting and packaging; and they can also hedge against seasonal prices (Firoz et al. 2003).

In summary, of all business studies, only five are based on empirical research of any type. Of these, three were based on surveys, while the other two relied on secondary data. In addition, four of these five studies focus only on the U.S./FTZs, of which three were conducted in the late 1980s. Considering that the number of the U.S./FTZs has grown from 138 in 1987 to over 270 as of today, there is a definite need of replication studies. Importantly, there have been only one empirical research involving zones in other countries, which too relied on secondary data and were limited to one zone in Costa Rica. While the economics literature has contributed towards developing a theory of FTZs, there is still a need to consolidate the empirical knowledge on FTZs, which is characterized by fragmented and spasmodic efforts to synthesize a general theory. There is also a need to evaluate the theoretical and practical usefulness of FTZs to multinational companies, as the current research focus is mostly limited to the study of FTZs from a host country perspective. 


\section{Chapter 3 TYPES OF FREE TRADE ZONES}

In this study, I propose to compare the different types of FTZs, therefore, it is important to look at these different types in some more detail. As noted in the introduction, the literature is crowded with numerous terminologies used to indicate the different types of FTZs. For instance, Kusago and Tzannatos (1998) list 19 most common used FTZ terms (Table 3.1). Yet, this list does not contain at least two more common terminologies Foreign Trade subzones, and Freeports. However, the list contains both terms that distinctly and specifically apply to certain zone types (e.g., Mexican "maquiladoras") as well as simple variants that are virtually interchangeable and have often been used simply to facilitate written expression. For example, in this thesis I use "FTZ" as well as "free zones" and plainly "zones" to refer to the institution overall, only to avoid repetitive wording. By contrast, Kusago and Tzannatos (1998) appear to consider such terms as "free zone", "industrial free zone", "tax free zone", and "tax free trade zone" as distinct, even though their original users most likely did not have such an intent.

Table 3.1

List of Common FTZ Terminologies

\begin{tabular}{|l|l|l|l|}
\hline 1 & Free trade zone & 11 & Special economic zone \\
\hline 2 & Foreign trade zone & 12 & Tax free zone \\
\hline 3 & Industrial free zone & 13 & Tax free trade zone \\
\hline 4 & Free Zone & 14 & Investment promotion zone \\
\hline 5 & Maquiladoras & 15 & Free economic zone \\
\hline 6 & Export free zone & 16 & Free export zone \\
\hline 7 & Duty free export processing zone & 17 & Free export processing zone \\
\hline 8 & Export processing free zone & 18 & Privileged export zone \\
\hline 9 & Free production zone & 19 & Industrial export processing zone \\
\hline 10 & Export processing zone & & \\
\hline
\end{tabular}


The lack of proper classification of these variants has led to significant confusion. As noted earlier, this is largely visible in the secondary data provided by international organizations, since each computes statistics using different definitions for various zone types. This results in different organizations using the same terms but ascribing different meanings to them, and therefore including different content in each case.

Taking into account these 19 terms but focusing on the more common ones encountered in the literature, along with definitions developed primarily from UNCTAD (1983), Grubel (1983), and Papadopoulos (1987) and updated based on Madani (1997), Romero (1998), Makabenta (2002), and others, following is a broad typology of distinct main zone types (of which some have, and some have not, been mentioned so far).

- Bonded Warehouses (temporary duty-free storage for goods in trans-shipment at international customs entry points);

- Duty-free stores at airports and other border crossings (display and sale of goods exempt from the country's domestic duties and some times other taxes as well);

- Free Transit Zones (geographic "corridors" offered usually by coastal nations to their land-locked neighbours for transporting goods in bond; may include the use of port and related facilities);

- Freeports (facilities allowing a greater range of functions than bonded warehouses, including minor distributive operations such as bulk-breaking and sorting, re-labelling, and/or re-packaging);

- Export Processing Zones (EPZs - fenced geographic enclaves with production facilities oriented to duty-free manufacturing or assembly operations intended for export); 
- Special Economic Zones (SEZs - typically oriented to export manufacturing, like EPZs, but normally with a much broader barrier-free regime, and most often encompassing much larger regions, such as an entire city, province, or state;

- Economic Development Zones (EDZs, - designated regions or cities [e.g., in China and the U.S.] within a country, similar to SEZs but intended to attract business and investment, rather than enhance exports, through an array of special incentives such as tax holidays, grants, and regulatory exemptions aimed at encouraging industrial development or economic revitalization);

- Free Economic Zones (FEZs - region-wide zones similar to SEZs and EDZs but encompassing any economic and commercial activity rather than only, respectively, exports or inward investment);

- Coastal Open Cities, Coastal Economic Open Cities, and other similar terms (generally similar to SEZs, EDZs, or FEZs - used primarily by China and a small handful of other nations to signal relatively minor variations from main zone types);

- Free Banking Zones (FBZs - typically defined at the city or national level, such as "London U.K." or in several Caribbean countries, where restrictions such as government oversight regulations and/or minimum reserve requirements for foreign currency dealings are relaxed, to enable banks and their customers to deal in greater privacy, take part in the market for transnational deposits, and issue and buy international bonds);

- Free Insurance Zones (FIZs - again defined at the city or national level, with London, U.K. also being a prime example, where reserve requirements are relaxed and firms 
are able to compete for insuring uncommon or major risks such as large production facilities, space equipment, works of art in transit, or major personalities);

- Industry-specific Zones (ISZs - zones limited to certain sectors, such as India's "Jewellery Zones"; some times specified as a geographic enclave and other times enabling "zone" benefits regardless of where a firm is located, so long as it belongs in the specified industry);

- Firm-specific Subzones (FSZs - zones specified at the level of an individual facility of a firm, such as a warehouse or factory, commonly attached for administrative purposes to a nearby main zone; the U.S. is the principal practitioner of this type, with over 500 subzones in operation today, but they can also be found in other countries such as Belgium, the Philippines, China, and Mexico);

- Free Trade Zones (FTZs - a term used both generically, as in the present paper, to connote any and all free zone(s), but also to describe zones that offer a wider range of facilities than the individual variants and are oriented to enhancing both imports and exports as well as FDI); and,

- The U.S. version of FTZs, but termed Foreign Trade Zones (U.S./FTZs, to distinguish from the broader use of the same acronym - similar to general FTZs, in that they may encompass any type of facility for either imports or exports, even though in practice most are heavily oriented to imports).

While other minor variants do exist, the above 15 categories capture well the extant distinct types of free zones, and the definitions reflect quite accurately the nature of each and the differences among them. At the same time, the exact terms used are less 
important than the main zone features they are intended to reflect, which can be classified based on six key criteria (Papadopoulos and Malhotra 2005b). Zones may be:

a. Import vs. Export oriented (e.g., Freeports and Bonded Warehouses vs. EPZs and SEZs)

b. Trade vs. Investment oriented (e.g., FTZs vs. free economic or development zones)

c. Enclaves vs. regions (e.g., Freeports, FTZs, and the U.S./FTZs vs. SEZs, FEZs, and EDZs)

d. Service vs. merchandise oriented (e.g., free banking and insurance zones vs. all others)

e. Private vs. public (firm-specific zones in the U.S. and elsewhere vs. all others)

f. Zones of relatively minor logistical vs. major strategic importance (e.g., Bonded Warehouses and Freeports vs. FTZs, EPZs, and SEZs).

Needless to say, these criteria do not necessarily classify free zones in mutually exclusive categories. For example, nothing precludes a country from designating an entire region as a "freeport", even though the traditional definition sees these as fenced-in small-area enclaves. Also, virtually all SEZs, and many EPZs, encourage not only manufacturing and merchandise trade but also trade in services. Nonetheless, this classification does point to the principal motives of the governments that establish or expand FTZ programs and of the firms that choose to invest and/or operate within free zones. It can also be useful in understanding the types of zones existing at any point in time and therefore enabling educated decisions by governments or firms to create or invest in a particular type of zone(s). In the following sections, I discuss important characteristics of three main types of zones. These are: (a) Export-oriented zones (e.g., EPZs and SEZs), (b) Import-oriented zones (U.S./FTZs), and (c) Trade-oriented zones 
(e.g., Free Trade Zones in Europe and Middle East). These three types of zones are important, as they reflect the principal orientations of most zones, and together constitute the bulk of FTZs across the world.

\section{Export-Oriented Zones: Export Processing Zones}

Over the last three decades, there has been conclusive evidence to suggest that an Exportoriented strategy is more successful than the traditional import substitution approach in promoting economic growth (Singer and Gray 1988). It should come as no surprise that this change has been parallel to the growth of EPZs. EPZs have managed to help developing countries enter into international markets by encouraging the growth of nontraditional exports. Initially found in a small number of countries, mainly among the ASEAN (Association of South East Asian Nations), such as Hong Kong (China), South Korea, and Singapore, EPZs now exist in more than 90 countries. ILO/UNCTC defines EPZs as

"a free trade enclave in the customs and trade regime of a country, where foreign manufacturing firms producing mainly for export, benefit from a certain number of fiscal and financial incentives".

This definition highlights gross carelessness on the part of international organisations; as can be seen from Table 1.1 (please see Chapter 1), nearly $30 \%$ of all firms operating in FTZs (of which many are EPZs) are domestic. Yet, the ILO/UNCTC definition clearly states "foreign manufacturing firms", neglecting the importance of such zones to domestic manufacturers.

Different terminologies have been used to represent EPZs. The most popular ones are: Export Processing Free Zones, Free Export Zones, Free Economic Zones, and 
Special Economic Zones. The first EPZ was set up in Kandla, India in 1965, but it was only in the 1970s that the EPZ concept became popular among developing countries. This was largely due to the success of such zones in China, South Korea, Malaysia and other South East Asian countries. Due largely to the success of Shenzhen SEZ in China, a number of countries changed their zone names from EPZs to SEZs. For example, earlier all zones in India were called EPZs, but over the last two years their names have been changed to SEZs. To some extent, it may seem that governments are becoming more conscious about marketing their zones. This shift in zone terminologies can be viewed as one of their attempts to associate themselves with a popular brand name.

As noted earlier, the role of EPZs is typically seen as an instrument for expanding and modernizing the host economy through foreign investment/capital formation, technology transfer, employment generation, and export promotion. Apart from direct benefits, EPZs also create indirect benefits. The most important of these benefits originate due to a "catalyst effect". In this, foreign companies operating in EPZs could encourage local firms to begin to export by showing them how to produce, market, sell, and distribute manufactured goods in the world market. The following sections discuss in greater detail the host-country and firm-level benefits offered by EPZs.

\section{EPZ Benefits for Host Countries}

\section{Increased Exports}

EPZs have played a major role in increasing exports for large numbers of developing countries in Asia, Latin America, and more recently in Africa. Table 3.2 lists contribution of EPZ exports to the countries' total exports. Chinese SEZs account for $88 \%$ of China's 
total merchandise exports. Similarly, in other Asian countries, like Philippines, Vietnam, and Malaysia, EPZs account for more than $80 \%$ of the countries' total exports. Also in

Table 3.2

Contribution of EPZs to Total Exports for 22 Countries

\begin{tabular}{lrrr}
\hline Country & Year & $\begin{array}{r}\text { Zone exports } \\
\text { (mill. U.S. \$) }\end{array}$ & $\begin{array}{c}\text { \% of Total } \\
\text { exports }\end{array}$ \\
\hline Argentina & 2001 & n.a. & 90 \\
Bangladesh & 2002 & n.a. & 60 \\
Brazil & 2003 & 9,042 & 60 \\
China & 2002 & 163,380 & 88 \\
Costa Rica & 2002 & 2.9 & 50 \\
Egypt & 2002 & 132,500 & 28 \\
Indonesia & 2002 & 18.4 & $n . a$. \\
Kenya & 2002 & 1,266 & 80 \\
Macao (PRC) & 2003 & 876 & 80 \\
Malaysia & 2002 & n.a. & 83 \\
Mauritius & 2003 & 1,168 & 77 \\
Mexico & 2003 & 2,205 & 83 \\
Morocco & 2001 & n.a. & 61 \\
Mozambique & 2000 & n.a. & 85 \\
Namibia & 2002 & n.a. & 80 \\
Philippines & 2002 & 22,723 & 87 \\
Senegal & 2002 & n.a. & 80 \\
Sri Lanka & 2002 & 1,195 & 25 \\
Tunisia & 2002 & 6,510 & 80 \\
Uruguay & 2002 & 2,700 & 60 \\
Vietnam & 2001 & n.a. & $80-100$ \\
Zimbabwe & 2001 & n.a. & 80 \\
\hline
\end{tabular}

Source: Compiled from ILO (2003) and IMF (2003) databases.

African countries like Kenya, Mauritius, Mozambique, Namibia, Senegal, and Zimbabwe, EPZs account for nearly $80 \%$ of the countries' total exports. In Argentina and Brazil, EPZs account for $90 \%$ and $60 \%$ of the countries' total exports, thus, also making a 
significant impact among the South American nations. This highlights that the success of EPZs has travelled across the globe, and is not confined to only the Asian countries.

EPZs have also proved to be useful trade tools in promoting non-traditional exports, as indicated by the case of Mauritius that was cited earlier. The zones help in decreasing over-reliance on commodity exports, which are prone to price and demand inelasticity. There are a number of problems associated with shifting domestic exporters towards non-traditional exports. These are due to: (a) lack of adequate knowledge of world markets, and (b) unavailability of managerial expertise and marketing know-how. This is defined by Johansson \& Nilsson (1997) as "idea gaps". The EPZs help to overcome these gaps by encouraging foreign investment into the zones. The presence of foreign companies, advanced technology, and managerial expertise help in transmitting requisite knowledge among local exporters to enter world markets.

An indirect contribution of EPZs towards export growth is due to its "catalyst effect" (Johansson and Nilsson 1997). As noted above, this refers to the growth in total exports of the host country due to the diffusion of knowledge from EPZs to local manufacturers not directly associated with the zone. These local manufacturers obtain sufficient knowledge and expertise to enter into non-traditional exports, increasing the country's presence in world markets. Thus, EPZs contribute both directly and indirectly in increasing total exports.

According to Kinunda-Rutashobya (2003), an Export-oriented strategy is particularly important for developing countries, because of their dependence on foreign countries for most of their key inputs and technologies required for production processes. Despite their efforts and policies, a number of developing countries have yet to realize 
export growth, which according to Kinunda-Rutashobya (2003) is primarily due to their continued dependence on commodity exports.

\section{Increased Employment}

A direct benefit of EPZs can be seen in the increase in employment within the host countries. The number of people employed by EPZs across all countries is nearly 42 million (ILO 2004). Table 3.3 lists the number of people employed across different geographical areas. Of these, Asian countries employ the largest number, due primarily to the Chinese SEZs, which employ nearly 30 million people. Despite the success zones have had in generating employment, they have had their fair share of critics. A prominent critic is the ILO (2004), which claims that: (a) people employed at zones are paid below market rates, (b) employees generally work under unhealthy conditions, (c) workers generally put extra hours for no extra benefits, and (d) most of the jobs are unskilled with minimum opportunities for skill advancement. However, as highlighted earlier with EPZs in Malaysia and those in the Latin American countries, many zones do not suffer from such problems; as a matter of fact, these zones boast a better working environment than in the domestic mainland. Thus, the concerns raised by ILO do not appear to be generalizable across all EPZs, and, where such problems do exist, researchers (Summerfield 1995, Kusago and Tzannatos 1998) argue that this is due primarily to implementation problems rather than to the EPZ concept as such.

\section{Increased Foreign Direct Investment}

EPZs contribute towards economic development of host countries by attracting muchneeded FDI. This investment is made largely in the form of foreign operations inside the zones. As compared to short-term investments such as those in financial markets, which 
can be easily withdrawn, investments in zones are long-term and make an overall contribution towards broader economic development. Another major benefit from FDI in zones is that they assist in knowledge and technology transfer. FDI primarily takes the

Table 3.3

\section{Employment in EPZs in Regions across the World}

\begin{tabular}{lr}
\hline Geographical Area & Employment \\
\hline Asia & $36,824,231$ \\
Central America \& Mexico & $2,241,821$ \\
Middle East & 691,397 \\
North Africa & 440,515 \\
Sub-Saharan Africa & 431,348 \\
North America & 330,000 \\
South America & 311,143 \\
Other Transition Economies & 245,619 \\
Caribbean & 226,130 \\
Indian Ocean & 127,509 \\
Europe & 50,830 \\
Other Pacific Economies & 13,590 \\
Total & $\mathbf{4 1 , 9 3 4 , 1 3 3}$ \\
\hline
\end{tabular}

Source: ILO (2004)

form of advanced technology brought by the multinational companies. A prevalent example of this is the Chinese SEZs (Wei 2000). This enables local employees to gain expertise and knowledge in operating such advanced technologies. To encourage FDI in zones, many host countries have liberalized their policies regarding foreign investment in joint ventures (e.g. China and India).

\section{Protection to Domestic Industry}

Unlike a broader liberalization policy, EPZs confine the open economy concept to certain regions in the country. In addition, per the EPZ concept, foreign firms have to largely export goods manufactured in these zones. Although SEZs and the more recent EPZs do 
allow foreign firms to sell their products in domestic market, there is generally a cap as to how much a firm can sell. This helps protect domestic industry against foreign competition (Firoj et al. 2003).

\section{Improved Industrial Infrastructure}

Zones are an efficient and competitive industrial infrastructure, which provides the host country an industrial set up that it may lack (McIntyre, Narula, and Trevino 1996). In order to market EPZs to foreign companies, the host government's emphasis is on building state-of-the-art infrastructure around the zone. This includes among others: (a) improved roadways, (b) easy connectivity to ports and airports, (c) better housing facilities, (d) better schooling facilities for children of foreign employees residing in zones, and (e) improved telecommunication facilities. This not only enables countries to attract foreign companies but also helps in establishing a modern industrial infrastructure.

\section{Test Run for Broader Policy Reforms}

Successful zones can become a model for country's policy makers towards initiating countrywide economic liberalization (Kundra and Sharan 2000). For example, India had as many as six EPZs before 1991, the year most popularly remembered as the transition year in the India economy. The testing of various tariff and non-tariff policies in these six EPZs provided the government with enough background on which to base their broader economic policies. Failures of certain policies at a zone level can save the policy makers the potential long-term impact of similar failures at a national level. Learning from such success and failures, the then Finance Minister of India, who is the present Indian Prime Minister, Dr. Manmohan Singh, unveiled a number of liberalization policies. The test run at the zone level helped India to progress at a much faster pace towards nation-wide 
economic reforms. In addition to providing a test run ground, EPZs play a significant role in removing structural bottlenecks and opening up external trade (Kundra and Sharan 2000).

\section{EPZ Benefits for Firms}

The main firm level benefits of EPZs are as follows:

- EPZs enable duty free import of raw materials and intermediate inputs. These decrease firms' overall cost of operations, thereby increasing their profit margin (McIntyre, Narula, and Trevino 1996).

- Most of the present EPZs provide long-term tax holidays. This enables foreign firms to cut down their cost of operations and export products at a more competitive price. Such locational benefits contribute towards increased international competitive advantage for foreign firms (Chen 1994).

- Another contributing factor towards increased competitive advantage is the possible presence of a clustering effect at these zones. These zones can be seen as a cluster of similar manufacturing units surrounded by efficient suppliers of raw materials and inputs (Tansuhaj and Gentry 1987). Such facilities enable foreign firms operating in these zones to enjoy greater competitive advantage over their competitors.

- There is considerably less governmental red-tape inside the zones than most of the industrial sectors in the host countries. One of the biggest bottlenecks or a non-tariff barrier to foreign investment in developing countries is the bureaucratic red-tape system. EPZs provide a hassle free mode of investing in economically vibrant developing countries. 
- Notwithstanding criticisms by the ILO, EPZs provide more flexibility to foreign firms in negotiating beneficial labour laws, than does the domestic market.

- EPZs generally have relaxed pollution laws. With increasing pressure on firms in developed countries to comply with strict pollution regulations, EPZs offer a safe haven for many of these firms to set up manufacturing units with relaxed pollution restrictions. Due to the popularity of these zones for firms seeking less restricted manufacturing places, some of these zones are also being termed as "Pollution Havens" (McIntyre, Narula, and Trevino 1996). It seems quite unpleasant to consider that some multinational companies, rather than focusing on technology advancement to improve production processes for reducing harmful emissions, move to developing countries to pollute their environment. Therefore, in the case of "pollution havens", the developing countries are attracting what are popularly termed as "dirty industries".

- Poor infrastructure is a major deterrent for many foreign firms planning to enter developing markets. EPZs on the other hand provide above average infrastructure facilities at subsidized costs, as compared to rest of the country, encouraging multinationals to set up operations (McIntyre, Narula, and Trevino 1996).

\section{Government Initiatives}

As stated earlier, such countries as China and Mauritius have seen unprecedented growth due to the success of their Export-oriented zones. It is important to highlight that government policies was mostly responsible for this success. In the case of China, Firoj et al. (2003) attributes the success of its SEZs to the protectionist policy followed by its government towards mainland investment. The Chinese government had controlled its 
imports, and at the same fostered its exports, meaning that investors could not export goods to China freely. Therefore, the only viable option left was to invest in SEZs, and take advantage of low tax rates and tax holidays. To encourage further investment in zones, the government restricted foreign investment outside the designated SEZs. The restrictive measures along with lucrative investment options in the SEZs led to tremendous increase in foreign joint ventures inside the zones. It is not surprising to note that almost half of the foreign investments in China are confined to these economic zones (Firoz and Murray 2003).

Most developing countries are particular on selecting the right locations for their zones. Their prime focus is to look for zones near areas that are less developed and have high unemployment. The government's policy is to encourage investment in these regions to bring about economic growth. On the contrary, the Chinese government has concentrated on strategically locating its zones in regions that will attract maximum foreign investment. Shenzhen SEZ was located near Hong Kong, to attract large multinational firms operating in Hong Kong. Xiamen and Shentou SEZs were located opposite Taiwan, Zhuai opposite Macao, and Hainan close to Vietnam. This not only helped build and maintain strong foreign relations with these countries (prior to Hong Kong becoming a part of China), but also attracted profitable firms to invest in China (Firoz and Murray 2003). Therefore, with the aid of restrictive investment policies and attractive locations, Chinese SEZs have managed to attract large foreign investment. This has led to a phenomenal increase in Chinese exports from these zones.

Unlike China, the Mauritian government focused on free trade initiatives. One of the factors that made the Mauritian EPZ scheme succeed is the country's ability to 
monitor the incentives offered to companies from time to time (Kinunda-Rutashobya 2003). The government has been adept in making adequate policy changes keeping in mind the performance of EPZs. For example, EPZs were diversified to include high-value added goods such as electronics. The Mauritian rupee had been devalued to encourage exports. Further investment had been encouraged through the establishment of stock exchange markets. Without doubt, the presence of a stable political environment also attracted foreign companies to these zones. The location of Mauritius, which provides excellent sea and air connections with the Far East, Europe, and Asia, and the presence of a highly literate (above 95\%), and bilingual (speaking both English and French) labour force, are added attractions for large number of multinational firms to invest in these zones.

In summary, China and Mauritius have shown how EPZs have transformed these countries into major players in international markets. FDI into EPZs were sourced into manufacturing and exporting of non-traditional export. This helped to remove the overdependence of these economies on commodity exports.

\section{Import-Oriented Zones: U.S. Foreign Trade Zones}

\section{Growth of the U.S. Zones}

(This section draws inputs from earlier work by Malhotra and Papadopoulos (2007) and Papadopoulos and Malhotra (2005b).) The U.S. zones are primarily import-oriented. This can be gauged by a comparison of volume of imports to exports to and from the zones. In 2004, U.S zones imported $\$ 305$ billion worth of merchandise, whereas total exports were worth only $\$ 19.2$ billion. In particular, FTZs in the U.S. are especially important to 
international marketers worldwide, for at least two reasons. First, because of the country's large number of well-established and well-serviced zones (272 general purpose zones, and 502 subzones) that is available to firms that want to do business in and/or from the U.S. Second, because zones in that country, unlike most other similar institutions especially in developing nations, are aimed at facilitating imports to its huge domestic market rather than encouraging exports. "General Purpose" foreign trade zones (GPZs) were initiated by the U.S. Congress in 1934. The first was set up in New York City in 1936, but the concept languished until the mid-1960s at which time the factors mentioned above sparked significant growth. Additional key factors specific to the U.S. were changes in the act that enabled in-zone manufacturing, showrooms, and other facilities, and the 1963 extension of the concept to "subzones", or firm-specific facilities at the plant or distribution centre level. To assemble the information below, an exhaustive comparative analysis was carried out on data obtained from the U.S./FTZB (Foreign Trade Zones Board) (2002, 2004), OECD (2000), UNCTAD (2002a\&b), ILO (2004), and other sources.

Table 3.4 shows the growth of the U.S. zones over the 70 years since enactment of the act. (Please note that the data on zone expansions and terminations were available only up until 2004.) The surge in new GPZs occurred in the 1980s. Since all 50 of the U.S. states and Puerto Rico now have one or more zones, new GPZ growth then abated and has been replaced by expansions of existing facilities and establishment of new subzones. Figure 3.1 juxtaposes the last column over the by-decade, by-zone-type changes to illustrate the 67 -fold cumulative growth of all three types, and shows the data in somewhat greater detail by five-year periods. Throughout, only six GPZs and 19 SZs 
have been terminated, leaving, respectively, 256 and 521 facilities in operation as of 2004. Interestingly, while general zones tend to be stable since they are run as public utilities, SZs are privately operated and so more exposed to environmental volatility. As a result, 18 of the 19 SZ terminations occurred following severe recession periods, specifically in the early 1970s (2), 1980s (4), 1990s (5), and 2000s (7).

Table 3.4

New GP Zones, Expansions, and New Subzones in the U.S.

\begin{tabular}{|l|r|l|l|r|r|r|}
\hline Years & $\begin{array}{l}\text { No. GPZs } \\
\text { established }\end{array}$ & $\begin{array}{l}\text { No. GPZs } \\
\text { expanded }\end{array}$ & $\begin{array}{l}\text { No. SZs } \\
\text { established }\end{array}$ & Total & $\begin{array}{l}\text { \% Growth } \\
\text { By period }\end{array}$ & $\begin{array}{l}\text { Cumulative } \\
\text { Growth }\end{array}$ \\
\hline $1934-69$ & 12 & 1 & 3 & 16 & 0 & 16 \\
\hline $1970-79$ & 41 & 8 & 8 & 57 & $256 \%$ & 73 \\
\hline $1980-89$ & 109 & 45 & 161 & 315 & $453 \%$ & 388 \\
\hline $1990-99$ & 76 & 138 & 273 & 487 & $55 \%$ & 875 \\
\hline $2000-04$ & 24 & 85 & 95 & 204 & $-58 \%$ & 1,079 \\
\hline Total & $\mathbf{2 6 2}$ & $\mathbf{2 7 7}$ & $\mathbf{5 4 0}$ & $\mathbf{1 , 0 7 9}$ & & \\
\hline
\end{tabular}

\section{Figure 3.1}

\section{Cumulative Growth of All Zone Types in the U.S.}

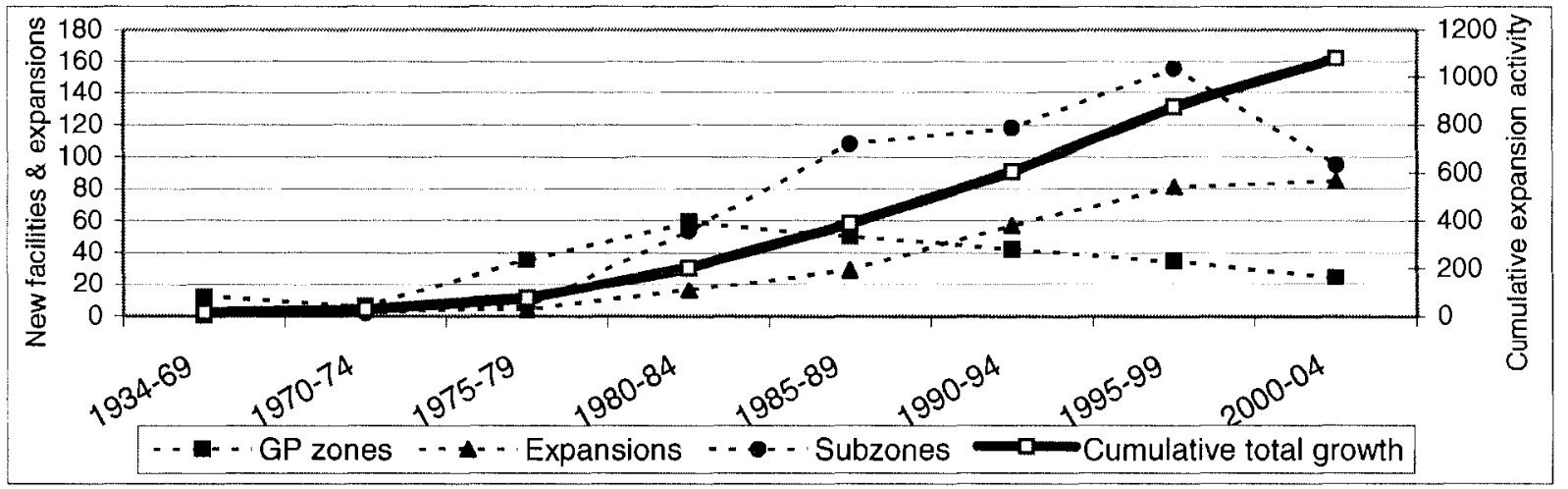




\section{Geographic Distribution and Main Zone Users}

Table 3.5 shows the distribution of GPZs by state and, to the extent that supply follows demand, clearly suggests a concentration around principal ports of entry (first five states)

Table 3.5

Distribution of Establishment of U.S. GP Zones by State

\begin{tabular}{|c|c|c|c|}
\hline State & States & GP FTZs & $\%$ \\
\hline States with 10 or more FTZs: & 5 & 98 & $38 \%$ \\
\hline \multicolumn{4}{|l|}{ Texas (33), Florida (21), California (18), Washington (13), N.Y. (13) } \\
\hline States with $5-9$ FTZs & 13 & 79 & $31 \%$ \\
\hline 7-8 zones: Ohio (8) and Arizona, Illinois, Indiana ( 7 each) & 4 & 29 & \\
\hline 6 each: Alabama, Louisiana, N. Carolina, Pennsylvania, Tennessee & 5 & 30 & \\
\hline 5 each: Alaska, Michigan, N. Jersey, Virginia & 4 & 20 & \\
\hline States with 4 or fewer FTZs & 33 & 79 & $31 \%$ \\
\hline $\begin{array}{l}4 \text { each: Connecticut, Maine, Maryland, Mississippi, Missouri, N. } \\
\text { Mexico, Oklahoma, Oregon }\end{array}$ & 8 & 32 & \\
\hline $\begin{array}{l}3 \text { each: Georgia, Massachusetts, Minnesota, Puerto Rico, South } \\
\text { Carolina, W. Virginia }\end{array}$ & 6 & 18 & \\
\hline $\begin{array}{l}2 \text { each: Colorado, Idaho, Iowa, Kansas, Kentucky, Montana, Nebraska, } \\
\text { Nevada, Vermont, Wisconsin }\end{array}$ & 10 & 20 & \\
\hline $\begin{array}{l}1 \text { each: Arkansas, Delaware, Hawaii, N. Hampshire, N. Dakota, Rhode } \\
\text { Island, S. Dakota, Utah, Wyoming }\end{array}$ & 9 & 9 & \\
\hline Total & 51 & 262 & $100 \%$ \\
\hline
\end{tabular}

and/or in states with substantive industrial activity (the same five plus, for example, Ohio, Illinois, Pennsylvania, and Michigan). Of the states with fewer zones, most are inland or have sparse industrial activity (e.g., Oklahoma, Idaho), and several are near more preferred entry points (e.g., Massachusetts vs. New York and New Jersey).

As of 2002, a total of 2,285 firms operated in GPZs or SZs. A breakdown by sector is available for only 421 SZs. Table 3.6 shows that the lion's share of activity (82\%) in SZs is accounted for by nine sectors (those with five or more entries). Automotive, oil, and consumer products predominate, which helps to explain the geographic concentration in states with significant industrial activity and/or near major port areas, as above (e.g., the oil sector is heavily represented in Texas). While most 
sectors contain only a few subsectors (e.g., "cars" contains passenger cars, trucks, and parts), the "Other consumer" category conceals a large number of industries (27) suggesting that $\mathrm{SZ}$ use is widely distributed. This is buttressed by the number of specific

Table 3.6

Main Sectors and Firms in Subzones

\begin{tabular}{|l|c|c|l|c|c|}
\hline Top sectors in subzones & No. & $\%$ & Top companies with SZ & No. & $\%$ \\
\hline Cars \& related (e.g., parts) & 102 & $24 \%$ & General Motors (automotive) & 20 & $5 \%$ \\
\hline Oil refining & 71 & $17 \%$ & Chrysler (automotive) & 16 & $4 \%$ \\
\hline Other consumer products & 58 & $14 \%$ & Ford (automotive) & 13 & $3 \%$ \\
\hline Pharmaceuticals & 31 & $7 \%$ & Conoccophillips (oil) & 9 & $2 \%$ \\
\hline Computers \& related & 28 & $7 \%$ & Merck (pharmaceuticals) & 8 & $2 \%$ \\
\hline Electronics & 21 & $5 \%$ & Northrop (aerospace) & 8 & $2 \%$ \\
\hline Chemicals & 15 & $4 \%$ & British Petroleum (BP) (oil) & 7 & $2 \%$ \\
\hline Ship Building & 11 & $3 \%$ & Polaroid (opticals) & 7 & $2 \%$ \\
\hline Distribution & 7 & $2 \%$ & Chevron (oil) & 6 & $1 \%$ \\
\hline Other & 77 & $18 \%$ & Hewlett-Packard (computers) & 6 & $1 \%$ \\
\hline Total & 421 & $100 \%$ & Maytag (appliances) & 6 & $1 \%$ \\
\hline & & & Other & 305 & $75 \%$ \\
\hline & & & Total & $\mathbf{4 2 1}$ & $\mathbf{1 0 0 \%}$ \\
\hline
\end{tabular}

companies involved, since the top-13 shown (5+ entries) account for less than one-third of the total. In addition, a more detailed analysis of data for key sectors (auto, oil, electronics and computers, and pharmaceuticals) (not shown in the table) shows that their contribution to new SZ establishment declined precipitously in 2000-04 (38) vs. 19951999 (97), most likely reflecting the negative effects of the September 11 events in the U.S., the dot-com collapse, and the accompanying recession. This suggests that the "dip" in the current period is temporal and may well be reversed in future years, spurring further GPZ and SZ growth. Lastly, the U.S. Foreign-Trade Zones Board is presently 
considering efforts to encourage greater zone use among small and medium-sized firms (McGilvray 2004), which, if successful, may spark further growth.

\section{Business Volume}

Zones employ about 320,000 people and as of 2004 accounted for $\$ 305$ billion in input trade (imports to the zones), higher than in 2002 ( $\$ 204$ billion, or an increase of 49.5\%) and significantly higher than in 1998 (\$157 billion, an increase of 93.6\%). The bulk of inputs $(84 \%)$ are directed to subzones. Perhaps surprisingly, and of strong interest to exporters to the U.S. from Europe, Asia, and other regions, only $35 \%$ of total zone inputs come from outside the U.S. itself. This is because most firms use zones to combine "true imports" from other countries with products already in the U.S. (some of which may have in fact been imported earlier through normal channels with duty paid on them) in the making of finished goods for eventual "re-export" into the U.S. market. Coupled with the fact that most zone users are U.S. firms (Table 3.6), this suggests that zones are in fact under-utilized by those who perhaps ought to be most interested in them: foreign firms wishing to enter the U.S. Furthermore, and consistent with their Import orientation, the U.S. zones account for only $\$ 19.2$ billion (2004) of exports (or re-exports) to other foreign markets. Overall, the data suggests that both GPZs and SZs are used mostly by the U.S. firms serving mainly their domestic market.

In summary, the primary purpose of the U.S./FTZ program is to allow imported goods to be stored, distributed, manufactured, without payment of duties and tariffs until those goods leave the FTZs to enter the domestic market. 


\section{Trade-Oriented Zones: Dubai’s Free Trade Zones}

Trade-oriented zones, also commonly called Free Trade Zones (FTZs [as noted earlier], the term also used generically, to connote any and all free zone[s]), are zones that offer a wider range of facilities than the individual variants and are oriented to enhancing both imports and exports as well as FDI. Most of these zones are located across Europe and in the Middle East. Examples of such zones include the Shannon Free Trade Zone in Ireland, the Colon Free Zone in Panama, and the Jebel Ali Free Zone in Dubai. To enable a better understanding on the working of such zones, this section highlights the Jebel Ali Free Zone, where the survey as part of Phase III of this study was carried out.

\section{Jebel Ali Free Trade Zone}

The Jebel Ali Free Zone, established in 1985 , is home to more than 6,000 companies from over 100 countries, including over 140 Fortune Global 500 companies (Martin 1998, Jebel Ali Free Zone website 2006). It expands across 750 acres of space, and has become one of the largest and the fastest growing FTZ in the world. It also holds a unique distinction of being the only FTZ in the world to hold an ISO 9001: 2000 certification.

Many reasons have contributed to the success of Jebel Ali Free Zone; the important ones are highlighted below.

- The farsighted approach of Dubai's rulers, who decided that an economy founded on oil would not be as successful nor as long lasting as one founded on trade, paved the way towards diversification efforts from the traditional oil and gas exports. This strategy led the government to set up a number of FTZs across the United Arab Emirates (U.A.E., comprising Abu Dhabi, Ajman, Dubai, Fujairah, Ras al-Khaimah, 
Sharjah, and Umm al-Quwain). Exports from FTZs across the Emirates stood at $\$ 6.8$ billion in 2001, an increase from $\$ 4.0$ billion in 1997 (IMF 2003).

- Dubai is strategically located on the world map. It has access to nearly 1.5 billion consumers in countries around the Persian Gulf and the Red Sea (Martin 1998), as well as in South Asia and Africa.

- Jebel Ali possibly offers the longest tax holiday for international companies among all zones. The Emirates government in 2002 allowed a 50-year tax holiday for international companies (Hammoutene 2004). This has led to a huge surge in international companies opening operations in the zone.

- Jebel Ali has created a fully integrated FTZ with air, sea and land transport. It also offers excellent infrastructure facilities and $24 / 7$ customer service. Further, the zone administration is highly efficient and many international applications are approved within a month.

- Jebel Ali encourages both imports and exports of merchandise. Companies operating in zones are among the major re-exporters in the region. It also allows imports of goods into the zones, and subsequent exports within the free zone and to other places in the Emirates at no additional duties.

\section{Summary: Types of Zones and Research on FTZs}

In summary, this chapter highlights the major types of FTZs across the world. As discussed in the chapter, there are more than 19 different terms used to represent the different zones. To help better understand the distinct types of zones, a typology of 15 different zones was developed and presented. Of these, the three most important types of 
zones in terms of orientation are the: (a) Export-oriented zones, (b) Import-oriented zones, and (c) Trade-oriented zones.

Combined, the discussion in Chapters 1,2, and 3 illustrates the importance of FTZs in foreign trade and investment and highlights the significant growth of the institution over the past two decades. In fact, while the number of countries that host FTZs remained stable (at 132) between the time that the proposal for this thesis was being researched in 2005 and today, the number of zones increased considerably even in this short two-year period. For example, general purpose zones in the U.S., which were assumed to have reached a plateau at 256 , increased to 272 . The importance of the FTZ phenomenon would suggest both a need and an opportunity to research it in depth in order to better understand its implications for host countries and international firms. Research in economics has responded with a large number of studies which focus primarily on welfare and regional issues of concern to host countries, but business research remains scant with fewer than 30 studies to date in total. Further, most of the business research is conceptual or deals with analyses of specific FTZs or zone types, and no study has yet examined zones beyond the U.S. empirically (through the use of surveys) or undertaken a comparative analysis of different zone types. This study was developed to address these research gaps, and its conceptual framework and methodology are discussed in the next two chapters. 


\section{Chapter 4 CONCEPTUAL FRAMEWORK}

The guiding principle of the conceptual framework is to gather a comprehensive knowledge of FTZ characteristics and tenant behaviour. In an attempt to provide theoretical and practical insights into the issue to academics and managers, the sections that follow:

- present research questions that will attempt to explain the overall functioning of different zone types; and

- propose a conceptual framework that will help to understand more systematically the zone tenant behaviour.

\section{FTZ Characteristics}

As noted earlier, there is sufficient evidence to suggest that EPZs have helped promote FDI and an Export-oriented industrialization strategy in many countries in Asia, Latin America, and Africa. There has been increasing popularity of FTZs across developed and developing countries. However, a number of studies indicate that many FTZs have realized only limited success. McIntyre, Narula, \& Trevino (1996) found that many EPZs have failed in attracting multinational firms and in the development of host countries' economies. Aggarwal (2005) states that many countries are unable to capture the dynamic and static gains from EPZ operations that they had initially hoped for. The author elaborates that, in China, while the Shenzen SEZ is highly successful in attracting foreign firms, and contributing towards total exports, FTZs in countries such as Sri Lanka and India have been relatively less successful contributing only $25 \%$ and $4 \%$, respectively, towards total exports in the early 2000 s. 
It has also been found that performance of zones varies not only across countries but also across zones in the same country. For instance, in China, while the Shenzen SEZ is a huge success story, the Hainan SEZ has failed to attract firms; in Tunisia, the Bizerte zone is more successful than the Zarzis zone; and in Bangladesh, Dhaka and Chittagong zones are successful, while Ishwardi zone has had no increase in the number of tenants for four years (Aggarwal 2005).

Related to the earlier discussion in previous chapters on social problems related to zones, Romero (1998) points out that in an effort to attract FDI, policy makers have overlooked the social and labour related impact of these zones. The author goes further to state that EPZs have acquired a bad image because of widespread reports of violations of national and international standards. The impact of EPZs on labour and the society at large has attracted increased attention (Romero 1998; Rondinelli 1987). Pay, benefits, working time, occupational safety and health, job security, and labour relations are the major concern areas for EPZs (Romero, 1998). Occupational and safety health standards have attracted considerable public attention due to major accidents in factories operating in EPZs across Asia. In May 1993, a fire in Thailand caused 189 deaths, and in the same year, there were 206 factory fires in China (Romero, 1998). Lower wages to employees in EPZs is the most cited criticism. This is more prominent among female employees, who are mostly employed as unskilled labour. As noted earlier, ILO/UNCTC (1988) and other studies conclude that the social benefits of these zones are negative, primarily because they assign a lower shadow price of employing females than the market wage rate. They argue that the social value of employing women in EPZs has lower value than assigning these jobs to unemployed men in the country. However, Summerfield (1995) 
argues that employing women elevates their status in society and within household. Therefore, providing jobs to women is a social goal that must be considered in making social evaluation of zones.

Rondinelli (1987) highlights the following important limitations with EPZs.

- Jobs in EPZs are unstable, based on temporary contracts, with few or no policies in place to protect interest of employees.

- There is little effort from firms in improving the skill level of employees, therefore, providing limited opportunities to employees to move from clerical or labour jobs to managerial jobs.

- There is little interaction between investing firms and local manufacturers, as firms source raw materials from outside the country, abstaining from developing links with domestic manufacturers.

- Large EPZs promote undesirable migration from rural areas to cities, increasing the burden on the already weak urban infrastructure.

- There is a tendency of employees and even the host country to become overdependent on foreign-owned firms, despite the fact that they may cut back their operations when wages, costs, or international trends change.

Due to the above constraints, it is difficult to estimate the returns that accrue to the host country from foreign investment. The externalities identified by McIntyre, Narula and Trevino (1996), as noted in an earlier chapter, have been further categorized in two main ways by these researchers. First, positive and negative externalities from foreign investment; for instance, multinational firm's activity may lower unemployment (positive externality) but at the same time increase pollution levels (negative externality). 
Second, informal and formal externalities: for instance, spillovers of technology can be formal when firms engage in transferring production technology to domestic suppliers through some sort of contract; and/or informal due to increase competitiveness of the domestic supplier vis-à-vis its domestic competitors as a result of this technology transfer.

On the marketing perspective of FTZs, Tansuhaj and Gentry (1987) in their study on the U.S./FTZs concluded that there is lack of awareness among business firms towards zone benefits, a claim also echoed by Mathur (1994). Mathur (1994) also indicated that the role of FTZs in providing tariff related benefits needs to be better communicated. This indicates the need for zone administrators to promote zone benefits more effectively and also target a wider audience.

Researchers have identified several measures to overcome the above-mentioned shortcomings. The first set of these measures deals with greater responsibility on behalf of the government and foreign-owned firms in developing the regions in and around the FTZs. This includes reinvestment of a part of the funds invested in FTZs for regional development; extending similar benefits and subsidized facilities to local companies in the surrounding regions; encouraging backward linkages between foreign firms and domestic companies; and supporting local state governments in handling increased migration to urban areas (Rondinelli 1987, Manezhev 1993, Yabuchi 2000).

The second set of these measures recommends more effective marketing strategies for FTZs. These include limiting the number of FTZs to sectors that will encourage better payoff and a catalyst-type effect for the economy; improving infrastructure (power, accommodation, transport, and communication); monitoring 
financial incentives on a regular basis to effect timely modifications when incentives no longer correspond to performance; enhancing back-up services such as banking, legal consulting, and telecommunications; and macro-economic adjustments such as the devaluation of currency (Manezhev 1993, McIntyre et al. 1996, Kinunda-Rutsahobya 2003).

Against the above background, it is apparent that the literature is inconsistent in judging the impact and benefits of zones towards the firms and society at large. There is a considerable void in the literature to explain why some zones are more successful than others. Most of the studies have relied entirely on secondary data to arrive at their findings. Further, that too is most often based on either one or two zone analyses, and in most cases the sites have been only Export-oriented zones. There have been very few comparative studies of zones across different countries. In one such study, Aggarwal (2005) compares EPZs from India, Bangladesh, and Sri Lanka. The study is limited in its scope as it concentrates on EPZs only and only in the South Asia subcontinent. Further, it relies entirely on published reports for studying zone operations. There has been no study that compares different zone types. Therefore, while the literature does cite suggestions for zones and tenants, there has been virtually no attempt made to obtain information directly from the concerned people - zone administrators and tenants.

This study will attempt to address this inconsistency and to fill some of the existing gaps in the literature. The first two research phases of the thesis (to be discussed in detail in the methodology section) involve review of a broad sample of FTZs (which will include Export, Import and Trade-oriented zones), and in-depth interviews with zone administrators and tenant representatives. This is the first such attempt to conduct a 
comprehensive comparison of different zone types. In particular, the first two phases, but to a lesser degree the third phase too, of the research will deal with several of the questions that have not been addressed previously, including:

- What are major objectives for establishing different types of zones?

- What are the ownership structures of different FTZs?

- How do zones fund themselves?

- How have different zones evolved over the years?

- What are the main functions performed by different FTZs?

- What are the important strategic benefits offered by different FTZs?

- How satisfied are the administrators and tenants with zone operations?

- What are the types and selection criteria of tenants operating in different FTZs?

- How do FTZs market themselves?

- Do FTZs offer better investment environment than the domestic mainland?

\section{Tenant Behaviour}

As stated earlier, very few studies have focused on zone tenants as the unit of analysis; and those that have, only studied the U.S./FTZs. Despite calls by a number of researchers (Papadopoulos 1985, Tansuhaj and Gentry 1987, Mathur 1993, Mathur 1994) to investigate the role of FTZs in the internationalization process of firms, and more broadly in their overall business strategy, no study to date has attempted to propose or test an integrative FTZ-zone tenant framework.

Although the process by which firms move from domestic-only operations to international business has received much attention (Johanson and Wiedersheim-Paul 
1975, Johanson and Valhne 1977, Dunning 1993), the role of facilitating services at large, such as export trading companies, foreign freight forwarders, custom house brokers, and of particular interest here, FTZs, has received very little attention from business scholars.

"Foreign Trade Zones facilitate a firm's global marketing and logistics system by providing more flexible linkages of in-flows and out-flows of goods from country to country. An integrated network of importing and exporting raw materials, components and finished goods to and from a number of countries with minimum production and distribution costs is a vital key to successful global market expansion." (Jatusripitak, Fahey, and Kotler [1985], Johnson [1986], cited by Tansuhaj and Gentry [1987], p.19-20).

The recent growth of FTZs and the increasing number of firms operating in these zones highlight the importance of studying the role of FTZs from the perspective of zone tenants. All three phases of the research, but more specifically the third phase that involves a broad based survey of zone tenants in three different zone types (Export, Import and Trade-oriented), will help to address this gap in the literature. To obtain a more detailed picture of tenant behaviour, some of the important questions that this study will attempt to answer are:

- What are the key demographics of tenants operating in different zones?

- Why do tenants invest in zones?

- Which information sources on FTZs do tenants use to make their investment decision? 
- How do tenants assess different investment factors inside the zone and in the host country mainland?

- Does the assessment of different factors differ across zone types?

- What are tenants' assessments of their satisfaction with zone investment?

- How does zone satisfaction relate to different investment factors, such as production, financial, economical and legal, and infrastructure?

- Is there a relationship between tenant demographics and zone satisfaction?

- What is the main business functions performed in the zone?

\section{Conceptual Framework}

To help direct a more systematic and focused analysis of tenant behviour, a conceptual framework is proposed. This framework draws from four main theory streams to examine some key relationships between tenant demographics, investment criteria and zone satisfaction. The four theory streams include the existing literature on FTZs; Dunning's eclectic paradigm for FDI (ownership, location and internalization advantages); the resource-based view (RBV) of the firm; the Uppsala internationalization model; and the FDI location selection literature. This framework, whose components are described in the following sections, will help to answer selected questions from those mentioned above, while the complete study will address all of the questions cited (e.g., some of these questions will be answered through tenant in-depth interviews) and provide a more comprehensive analysis of tenant behaviour.

\section{The Eclectic Paradigm}

To appreciate the role of FTZs in an international business setting, it is useful to extend the internationalization theories that can more specifically reveal the motivations, 
interests, and position of FTZs in an international business process. The eclectic paradigm offers a framework for determining the extent and pattern of both, production by domestic companies, and domestic production by foreign enterprises (Dunning 1993). The paradigm lies in the realm of international trade theory that explains the spatial distribution of different kinds of output. The assumptions of the paradigm are that the resources required for ownership and spatial distribution of these outputs are not equally accessible by all firms. This is due to the presence of two market failures: (1) structural market failure, which distinguishes firms in their ability to control and govern multiple and geographically dispersed value-added activities; and (2) failure of intermediate markets to transact intermediate goods at a price lower than those done by hierarchical firms - larger firms with multiple layers (Dunning 1993).

The paradigm includes three important benefits for firms to consider before selecting an international production location. These are Ownership-specific, Locationspecific, and Internalization-specific benefits.

Ownership-specific advantages (O): Ownership-specific assets are termed as “...firms possessing or being able to acquire certain assets not available or not available at such favourable terms, to another country's enterprises" (Dunning, 1993). These assets are resources that are productive to generate future income stream. The tangible assets include natural endowments such as work force and capital. The intangibles include technology information, managerial expertise, marketing and entrepreneurial skills, and organizational systems. The extent to which a firm possesses these sustainable ownership-specific advantages over firms of other nationalities in a given international market, the greater the level of firm's value added activity in the country. 
The size of the firm has often been cited as an ownership-specific asset for them to engage in international expansion (Agarwal and Ramaswami 1992). Hood and Young (1979) document that resources are needed for absorbing the high costs of operating in international markets. Further, empirical evidence indicates a positive relation between firm size and foreign direct investment (Buckley and Casson 1976, Kumar, 1984). Thus, it can be assumed that larger tenants are more likely to have more FTZ-based operations, and because of their large resources are likely to overcome the initial difficulties faster and make best use of resources in the zone. Therefore, it can be proposed that:

Hypothesis 1: Firm size should have a positive impact on zone satisfaction.

Another form of ownership asset in international business is the firm's international experience. Firms without international experience are expected to be selective in their targeting of foreign markets, due to insufficient skills to overcome market uncertainties in new markets (Contractor and Lorange 1988, Agarwal and Ramaswami 1992). Further, firms with greater international experience can handle difficult conditions in new locations better and may have a faster turn-around time in realizing profits. Given this scenario:

Hypothesis 2: Tenant firms in FTZs which have prior experience in operating abroad either directly (though greenfield investments, tie-ups and so on) and/or indirectly (though exports), are likely to fare better in the zones, thus, can be proposed to have a higher zone satisfaction.

Location-specific assets (L): These assets are specific to a particular location, but are available to all firms. The location enjoys advantages to other locations due to possession of such assets. These assets are not only confined to natural endowment benefits, such as 
work force and capital, but also include the cultural, legal, political, institutional environments, market structure, government policies, and legislation. Certain assets owned by firms in their home country, but which are capable of being used in combination with other capabilities and resources such as property rights, also constitute L-specific assets. Other important L-benefit includes cluster effect.

FTZs offer greater L-benefits to firms than the rest of the host country, thus, acting as important antecedents for firms to set up FTZ operations. As noted earlier, following are some of the benefits offered by FTZs: (a) presence of better infrastructure (Manezhev 1993); (b) less red-tape; (c) duty-free imports; (d) no duties or taxes on discarded materials due to spoilage or defects; (e) lower insurance costs (premiums apply to the duty-free value of goods); (f) lower inventory costs through centralized warehousing; (g) flexibility in bulk-breaking, packaging, and labelling for various foreign markets; (h) "generous" (Madani 1997) tax holidays, grants, and other concessions for investors; (i) duty-free imports not only of goods but also of manufacturing equipment; (j) relaxed environmental protection or labour laws (e.g., right to hire or fire workers based on merit within China's SEZs); (k) greater protection against crime or unstable political environments (host authorities normally assume responsibility for security of the zone's perimeter; e.g., Makabenta 2002); and (l) dynamic competitiveness differential (host countries invest more on zones to keep them internationally competitive, and so their advantages are less static than those that the same country's domestic territory might offer). Traditionally in the FDI literature, it has often been shown that inexpensive labour and lower costs attract FDI (Helleiner 1973, Wells 1986, Woodward and Rolfe 1993, Zhang 2000, Hong and Chen 2001, Foster and Alkan 2003). In addition, another major 
benefit of zone operations is the extended tax holidays or reduced tariff structure. There is sufficient empirical evidence to suggest that tax holidays attract FDI (Grubert and Mutti 1991, Woodward and Rolfe 1993, see also de Mooij and Ederveen 2003 for a detailed discussion of the literature on the impact of tax incentives on FDI location). Given the above information:

Hypothesis 3: Higher FTZ L-benefits will lead to higher zone satisfaction.

Internalization benefits (I) and RBV: These benefits accrue due to the firm's decision to add value to its ownership advantages in the international locations by not selling them or their right of use to foreign firms but to internalize their operations in these locations. These advantages are called market internalization advantages, which reflect greater hierarchical efficiency in handling these assets or in exercising monopoly power over the assets under governance (Dunning, 1993). The degree of market internalization will also depend on the favourable environment offered by host locations towards establishing sole or majority-owned ventures.

In a similar vein, the RBV suggests that firms enjoy competitive advantage due to the possession of certain resources or capabilities that are valuable, rare, difficult to imitate, imperfectly mobile, and not easily substitutable (Barney 1991, Peteraf 1993). According to Caves (1971), Hymer (1976) and others, these resources and capabilities include both tangible and intangible assets, such as financial resources, technological capability, management capacity, and international experience. While tangible assets are easier to replicate, intangible assets such as management skills and knowledge are difficult to formalize and replicate and can create sustainable firm-specific competitive advantages (Barney 1991). Prahalad and Hamel (1990) point out that these resources are 
enhanced as they are applied to new businesses or markets. Therefore, firms that do have such resources will be keen to internalize its operations so as to sustain its competitive advantage.

FTZs offer greater I-benefits to multinational firms as its policies are generally more lenient and favourable toward internalizing operations. Many of the FTZs give the right to establish fully-owned or majority-controlled ventures (Martin 1998). They also allow full repatriation of profits and/or capital (Firoj and Murray 2003, Jebel Ali Free Zone website 2006), unlike the case in domestic territory, where this is heavily regulated. Thus,

Hypothesis 4: Higher I-benefits offered by FTZs will lead to higher zone satisfaction.

\section{The Uppsala Internationalization Model}

In a landmark study, Johanson and Wiedersheim-Paul (1975) proposed a "stages model" for internationalization of firms. The study was based on a longitudinal observation of the internationalization path undertaken by four Swedish firms - Sandvik, Atlas Copco, Facit, and Volvo. The underlying assumptions in their study are that a firm first develops in the domestic market before venturing internationally; and the two main obstacles towards internationalization are lack of knowledge and resources. Incremental decisionmaking and increased learning of the foreign markets and their operations can overcome these. Hence, the internationalization process is a gradual stage-wise process rather than large spectacular investment. The four distinct stages of internalization are:

- No regular export activities

- Export via independent representatives (agent)

- Sales subsidiary 
- Production/manufacturing.

The four stages differ in regards to the resources committed by the firm in international activities, and the development of the information channel between the firm and international markets. In a follow-up study to the stage-wise internationalization process, Johanson and Vahlne (1977) developed a dynamic model to represent the incremental internationalization process in which outcomes of one decision constitutes the input for the next.

$$
\Delta I=f(I \ldots)
$$

Where $\mathrm{I}=$ state of internationalization

$\Delta I=$ change state of internationalization

Thus, the present state of internationalization is an important determining factor for the future course of the internationalization process. The authors also define conditions under which firms will decide to increase the scale of operations in foreign markets. The scale increasing decisions are based on the existing risk situation ( $R)$, and the firm's maximum tolerable risk in the market $\left(\mathrm{R}^{*}\right)$. If $\mathrm{R}<\mathrm{R}^{*}$, the firm will incrementally extend its scale of existing operations in international markets. Hence, the conditions under which the firm will decide to increase scale of operations are:

- Decrease in existing market risk situation

- Increase in the firm's tolerable market risk

It can be shown that FTZs decrease existing market risk, encouraging firms to increase scale of operations. 
"...additional commitments will be made in small steps unless the firm has very large resources and/or market conditions are stable or homogenous" (Johanson and Vahlne 1977).

FTZs provide a more stable political, industrial and market environment to firms than the host country. FTZs are also termed as "foreign enclaves", which lie outside the jurisdiction of the host government, avoiding any instability in the host country. The policies in FTZs as already discussed provide a stable and a homogenous environment, thus, firms operating in FTZs will lower their existing market risks. Foreign market risk perception affects management's decision about commitment of resources to a particular market (Ahmed et al. 2002). Therefore, it can be assumed that:

Hypothesis 5: Lower market risk in FTZs will lead to higher zone satisfaction.

\section{Operationalisation of Key Constructs}

As there were no pre-existing measures in the literature for some of these variables, these measures were obtained from FDI and market selection literature. Please note that more details are given on these measures in Chapters 5 and 8.

\section{Zone Satisfaction}

For zone satisfaction, a perceptual measure is used. The measure is based on overall tenant's assessment of satisfaction with the main investment factors (production, finance, economic and legal, political and social, infrastructure, and country and people related factors). The assessment is made on a scale on 1 to 5 , with $1=$ "very dissatisfied" and $5=$ "very satisfied".

\section{Ownership}


Firm size: Size is typically operationalised in terms of either sales or employment (Agarwal and Ramaswamy 1992). For this study, the firm size is measured as the log of total zone tenant employees.

International experience: The internationalization literature cites a number of measures, which include among others, the percent of total earnings attributed to foreign operations, the number of years of experience over all previous foreign operations, and total exports (e.g., please see Agarwal and Ramaswamy 1992, Nachum and Wymbs 2005). For this study, international experience will be measured as log of total exports made by zone tenants.

\section{Location}

For the operationalisation of L-benefits, a perceptual measure is used. The measure is based on tenants' assessment of six main investment factors: production, finance, economic and legal, political and social, infrastructure, and country and people. The measures are assessed on a 5-point bipolar scale, with 1 highlighting an "unfavourable" and 5 a "favourable" assessment.

\section{Internalization}

For internalization benefits, a perceptual measure is used. This is also in line with the suggestion by Agarwal and Ramaswami (1992), who point out that perceptual measures are useful for measuring internalization advantages as the construct has not been properly identified in the international business literature. Adopting the same measure as used by Agarwal and Ramaswami (1992), internalization advantage (the measure is termed as "contractual risk") can be measured as the manager's perception of risk of entering into a

contractual arrangement for sharing firm's resources and skills inside a zone. The 
measure used three items on a 7-point bipolar scale, with $1=$ "zone worse than mainland" and $7=$ "zone better than mainland". The three items are:

- Cost of making and enforcing contracts

- Maintenance of quality of services with a local partner

- Risk of misuse of your proprietary knowledge

\section{Market risk}

As largely prevalent in the literature (Kim and Hwang 1992, Agarwal and Ramaswami 1992, Brouthers 1993, Ahmed et al, 2002), a perceptual measure can be used to measure market risk. For this study, the perceived market risk is measured by adopting Agarwal and Ramaswami's (1992) three items scale. Similar to contractual risk, the market risk was also measured on a 7-point bipolar scale, with $1=$ "zone worse than mainland" and 7 $=$ "zone better than mainland". The three items are:

- Stability of the political, social, and economic conditions

- Risk of repatriating your income

- Risk of expropriation of firms

In summary, this study with the help of three phases will attempt to provide a comprehensive picture of zone characteristics and tenant behaviour. In the next chapter, the methodology for each phase is discussed. 


\section{Chapter 5 METHODOLOGY}

The literature in all pertinent fields was reviewed, and some preliminary groundwork was done to help in designing the methodology for the three phases. The preliminary groundwork included:

(a) Collection and subsequent conversion into a readily usable format of all relevant sampling frames. These include the ILO (2004) listing of EPZs, World Economic Processing Zones Association (2004) (WEPZA) directory on FTZs, UNCTAD (2002) listing of FTZs, the U.S. Foreign Trade Zones Board (2004) listing of all of the U.S. zones, and Diamond and Diamond (2003) list of tax havens.

(b) Identification of a large number of zone websites across the world by reviewing different databases.

The key activities of the research include collection, coding, and cataloguing of website and other secondary information in Phase I; in-depth interviews with zone managers and tenant representatives in Phase II; and a broad based survey of zone tenants in Phase III.

The rationale for a three-phase design and its sequencing stems from the lack of prior relevant research in the literature that could inform this study. While each phase has its own benefits and will contribute on its own, the three together will yield the intended rounded view. Phase I will help guide subsequent phases by identifying key zone characteristics. Phase II will help identify key issues from the viewpoint of zone officials and tenant representatives. Both of Phases 1 and 2 will help guide the broad based survey

in Phase III. The methodologies for each phase are discussed separately in the following sections. 


\section{Phase I: Review of Websites}

As mentioned in Chapter 1, the website analysis part of this study was coordinated with a project carried out by an MBA student (Cabezas-Navas 2007). That project focused on identifying the universe of available zone websites and outlining the broad characteristics of zones where the relevant information was available. The present study focused on a more detailed analysis of zones where websites provided substantial enough information to enable an in-depth content analysis. The synergy between the two studies made it possible to observe the norms for systematic content analysis, which are advocated by Krippendorff (1980).

\section{Content Analysis}

The websites selected for use in Phase I were reviewed for comprehensive information on FTZ characteristics. The internet has become a popular medium for researchers to carry out qualitative analysis (Malhotra, Dixit, and Uslay 2002). There has also been an increase in conducting international comparative studies by reviewing companies' websites (Cho and Cheon 2005). A similar approach is followed for this study, which involved a detailed download of all possible information on the website of each FTZ in the sample.

The content analysis approach that was used is a common methodology when working with qualitative information. Budd, Thorp and Donohew (1967) define content analysis as a research technique for making replicable and valid inferences from data to their context. According to Aikat (1995), content analysis involves a systematic and reliable coding of communication content into a theoretically meaningful set of mutually exclusive and exhaustive categories. In this analysis care was taken to apply the four 
tenets of good content analysis research, objective, systematic, quantitative, and manifest content (Stempel 1989), to explore the information present in FTZ websites. According to Stempel (1989) Objective content is achieved by having the categories of analysis "precisely defined", Systematic content relates to "application of set procedure...for all content", Quantitative content is achieved by "recording of numerical values or frequencies of various defined types of content", and Manifest Content involved coding of content "as it appears rather than as the content analysis feels it is intended".

Major benefits of using content analysis are that a large amount of data can be systematically analysed and that it enables the processing of symbolic forms and unstructured information. The analysis is presented mainly in qualitative and descriptive form. A T-test and/or an ANOVA were done depending on the sample and the parameter for zone comparisons.

\section{Selection of Websites}

A fundamental problem with the websites is the enormous number of possible resources available and the difficulty of locating and tracking them. As a comprehensive listing of all FTZ websites is not available with any one organization, a master list of FTZ websites was compiled from the following sources:

1. The World Export Processing Zones Association website (WEPZA 2006), which lists 132 countries that have zones. The list does not provide any links to the FTZ websites. Nevertheless, this website was useful to identify the countries that have zones, and in some instances the names of the respective zones. 
2. The ILO database (2003) on EPZs, which provides links to a number of FTZ websites. However, as the database has not been updated, a large number of links were not working.

3. The Zonas Francas database on Free Trade Zones in Latin America. (Zonas Francas Net 2006), which provided a rich source of web links to sites of FTZs in that region.

4. The United States Foreign Trade Zone Board website (U.S./FTZB 2006), which provides a list of the U.S./FTZs. The website also provides web links to a number of these zones.

Apart from the above main sources, to locate those websites that were included in the databases but where the cited links were not working, a query was run on several public search engines such as Google, Alta Vista and Vivísimo. In addition, the search engines were used to find zone websites that were not listed in any of the databases.

\section{Coding and Data Collection}

Most of the websites on the internet begin with a "home page", which leads to other web pages via links. A home page is, therefore, the point of entry to a site, from where a user can simply click on the hypertext links that automatically connect to other pages on the internet. For the content analysis, along with the home page, hypertext links were also followed to code for information.

Coding units were used to analyse the content on the websites. To develop the coding units, first a literature review of FTZs was done, which helped to determine some of the basic features of the three zone types. Second, from the FTZ websites, 20 were randomly chosen to find a tentative set of characteristics that was later used to develop the coding units. The zones represented by those 20 sites included the three main Export-, 
Import-, and Trade-oriented zone types. Each of these websites was scanned for words or phrases that related to the demographics of the zones, their business aspects such as administration of the zone, human resources, marketing, and finance (e.g., location, investment offers, glossary of terms, links, and statistics on performance), and, importantly, that addressed the research questions. For each of the types of zones a list of phrases and words was developed using the most frequently used content.

The above two approaches helped to develop the content analysis categories and coding scheme. These categories were then used to develop an excel database where the information from the selected websites was coded.

\section{Phase II: Case Analysis}

The research design for Phase II is a multiple-case study, as the research questions guiding this phase are characterized as one of description and interpretation. The main purpose of this phase and the overall study is to obtain a comprehensive view of FTZ operations and tenant behaviour. Accordingly, case research was deemed most appropriate, following the argument of Rouse and Daellenbach (1999), who suggest that case methodology is helpful in generating sensitive, confidential or consequential data (as required in this study). In addition, the case study was the best method for this phase because of the exploratory nature of the research. Yin (2003) states that for "how" and "why" questions, the preferred research strategy is the use of case studies. This method was also chosen because it allows the researcher to explore unclear situations, resulting from little prior information.

The design of this phase consisted of four cases. The multiple case design is chosen because of its advantages - researchers have indicated that the evidence from 
multiple cases is often more compelling, hence increasing the robustness of the study (Miles and Huberman 1984, Yin 2003). In addition, the multiple case design will enable a between-zone comparison.

\section{Selection of Case Sites}

Data was collected from four different zones, and each was treated as an independent experiment that confirmed or disconfirmed insights as they emerged (per Brown and Eisenhardt 1997). The four zones were: (1) Noida Special Economic Zone in India, (2) Shenzhen Special Economic Zone in China, (3) New Orelans Foreign Trade Zone in the U.S., and (4) Jebel Ali Free Zone in Dubai. All four zones in the remainder of this report will be referred to as either by their complete name, or by their city (e.g., Noida SEZ can be referred to as Noida zone or simply Noida, and so on). As recommended by Eisenhardt (1989), the cases, or zones in this study, were selected for theoretical reasons. The selection criteria required that at least one zone in the case studies represents one of the three types of FTZs, as an important element of this study is a comparison of the three different types of zones. This is also in line with the approach suggested by Harris and Sutton (1986), whereby selecting diverse zones will better serve to build a theoretical model applicable across all zones. In this case, while Noida and Shenzhen are Exportoriented, New Orleans is Import-oriented, and Jebel is a Trade-oriented zone. Another criterion was that the countries selected would possess considerable interest in FTZs, and should have active FTZs. This again is the case for all four countries from which the zones are selected. While the U.S. has the largest network of FTZs in the world, India, China and U.A.E. are also fast emerging as major players in the FTZ arena, with a large network and some well-known zones to boast about. In addition to theoretical reasons as 
cited above, resources available to the investigator, including finance, market familiarity, and access and language ability, also influenced zone selection, though these were secondary considerations.

\section{Collection Procedure}

For all cases, the data was collected through interviews, questionnaires, observations, and secondary sources. The primary source of this data collection involved a series of indepth interviews followed by a leave-behind questionnaire for each interview using the procedures laid out by Eisenhardt (1989) and Yin (2003). The use of multiple sources of data collection methods provides stronger substantiation of constructs, and helps to increase the reliability and validity of the case study (Eisenhardt 1989, Yin 2003). Data was collected from zone administrators and tenant representatives.

\section{Sampling and Fieldwork}

The Phase II data collection was administered locally at each country with the help of coinvestigators. I developed the entire study and research instruments, and coordinated the data collection procedure at the various locations. This approach helped to overcome some of the problems mentioned above in regards to availability of resources, language ability and market familiarity, while also enabling cross-country consistency and local adaptability. The use of multiple investigators also enhanced the creative potential of the study, as team members bring in complementary insights which add to the richness of the data.

The interviews were conducted by myself at Noida and New Orleans, and as noted in Chapter 1, by Frank Jinyu at Shenzhen and Xiatong Yang in Dubai. While the local professors in each case helped to oversee the project and monitor the 
implementation of the fieldwork, I took the lead role in guiding and training the investigators, and also managing the operational details of data collection at each of the sites.

All interviews were conducted in-person, except for those at New Orleans, where officials preferred to be interviewed by telephone. The interviews were conducted during visits (or calls) to the zones that spanned several days. Interviews in all four zones were conducted between September 2006 and May 2007. In most cases the interviews were pre-arranged through either email or telephone. Interviews typically lasted 45 to 60 minutes, although some ran as long as two hours. During zone visits, a daily record of observations was maintained.

\section{Research Instruments}

Two research instruments were used, a guide for the in-person interviews and a structured, self-administered questionnaire to be completed by the interviewees after the end of the in-person component. The design of both instruments was based on the corresponding guide and questionnaire used by D'Souza (1993) and Papadopoulos et al. (1997) in their study of foreign investors' perception of the investment climate in Canada. These instruments were successfully tested by the authors in that study, and in related research in Greece (Kalligatsi 1996) and Poland (Czapor 2000), and were in turn based on extensive reviews of other similar studies in FDI decisions and location choice, thus providing a good base for the present project. The original instruments were slightly modified keeping in mind the comparability of results across the different zone types, its effectiveness in answering the key questions outlined in the previous chapter, insights 
gained from the review of websites and secondary data (Phase I), and the five theory streams used to frame this study.

As recommended by Yin (2003), the interview guide used phrasing beginning with "what, who, where, why, when and how" to direct the questioning process. The interviews began with questions relating to the background of the respondents, and their zones, and/or companies. In the next stage questions relating to the reasons for the set up of the zones or the companies in the zone were asked. In the next section of the interview, among other questions, questions focused on the strategies adopted by zones to attract tenants, and similarly for tenants on why they chose the particular zone. The leave-behind questionnaire focused more on perceptions of the investment climate of the zone through structured bipolar adjective scales.

The application at Shenzhen, which was the first in this study in terms of time sequence served to pre-test the instruments. The pre-test showed no need for modifications except for adding scales to measure perceptions not only of the "zone" but also of the "host country" investment climate in the leave-behind questionnaire. Therefore, these scales are the only part of the Shenzhen study that is not included for when the relevant results are discussed. The guides and questionnaires are included in Appendices A, B, C, and D.

All investigators used the same standard interview guidelines for the interviews and the same questionnaire for the leave-behind. All interviews were conducted in English, except for some in Shenzhen, which were conducted in Chinese. All interviews were audio-taped and transcribed verbatim. 
The leave-behind questionnaires were collected either on the same day or the next day. The questionnaires were used to collect data on the financial performance of the zones and the companies, and to obtain respondents' perceptions on various functions at the zones. Secondary data was obtained through annual and industry reports and internal documents where available.

\section{Data Accuracy}

Several steps were undertaken to ensure the accuracy of the information. First, recall was enhanced by the fact that a number of questions were based on facts and objective events, often accompanied by press releases, such as when the zone was established, reasons for establishing the zone, benefits offered by the zone, and so on. Second, when respondents were unsure of the exact information, such as the month in which the zone was established, they consulted other sources to obtain it. Finally, we could check, for some questions, the informants' responses against various secondary data including press releases and internal documents.

The demographics of the respondents and details on the data analysis are presented along with the results in chapter 7 .

\section{Phase III: Survey}

Phase III of the research involved a survey of zone tenants. The main methodological components of this phase are discussed below.

\section{Selected Zones}

In line with the objectives of the study, three zones were selected as possible sites to run the survey. These were the Noida SEZ (Export-oriented), the Jebel Ali Free Zone (Trade- 
oriented), and the New Orleans Foreign Trade Zone (Import-oriented). (Note: The case analysis at Shenzhen SEZ in China was not part of the original proposal for this thesis and it was understood from the outset that its addition to Phase II would not extend to the survey in Phase III. Shenzhen was added to the previous phase in order to enhance and expand the case analyses by capitalizing on the opportunity presented by the availability of Frank Jinyu, who wished to work on this project for his MBA thesis. By contrast, due to the large size of Shenzhen, the need to translate the questionnaire, the need for central government authorization for running a survey, and other factors, extending Phase III to that zone was not feasible and was well beyond the scope of this thesis.) The New Orleans zone in the U.S., very surprisingly, did not agree to participate in the survey. Although I and my supervisor made numerous attempts to convince the officials, their response remained negative. To overcome this problem, other zones in the U.S. were also contacted. These included zones in Miami and Baltimore. Again, after many attempts, and even after personal meetings and/or extensive telephone conversations with officials at these zones, it was not possible to secure the necessary cooperation to conduct the surveys. Therefore, in agreement with the Thesis Committee, it was decided that the two zones in Noida and Dubai would be appropriate and adequate for the survey. A more detailed account of the problems faced with data collection at the U.S. and other zones is presented in Chapter 9, as it was felt that these difficulties were a systematic and important finding in this study.

\section{Sampling and Fieldwork}

To ensure a high response rate, a number of steps were undertaken. First, Dillman's “Total Design Method" (1978) and his more recent "Tailored Design Method" (2000) 
were used as guidelines. Second, to increase the chance that a sufficient number of usable questionnaires would be completed and returned, the survey was administered with the help of zone officials (a similar approach was used by earlier survey studies on the U.S./FTZs; e.g., see Tansuhaj and Gentry 1987, Tansuhaj and Jackson 1989). The questionnaire was mailed along with two cover letters. One, signed by the researcher and his supervisor on Sprott School of Business letterhead, explained the purpose of the study, requested the respondents' participation, and informed them on standard practices per Carleton University's ethics guidelines. The other, sent on a senior zone official's letterhead, explained that the study had been approved by the zone administration and also requested the tenants to actively participate in the study. Finally, to ensure that the survey would reach the concerned person in each company, the questionnaires were distributed by a zone representative to the companies in the zone. In most cases they were handed to the person in-charge of operations or a senior manager in the zone company.

For the Noida SEZ, the questionnaires were distributed to all 165 companies in the zone. The respondents were asked to hand over the completed questionnaire to the zone office, which is situated inside the zone. Two follow-up letters were sent out at one week intervals following the initial distribution of the survey. In addition to these, I and a zone representative made several visits to the companies to collect some of the surveys by hand.

A similar approach was followed at the Dubai zone. The questionnaire was distributed to 200 companies, which were selected randomly from the list of firms obtained from the zone officials. 


\section{Survey Instrument}

The structured leave-behind questionnaire from Phase II, pre-tested in the first case application at Shenzhen, was used as the base for the instrument in Phase III, with only minor cosmetic and sequencing changes (given under Appendix D). It consisted of seven main sections.

- Section 1 was intended to capture demographic information on the parent company of the zone tenant. Companies which are solely based in the zone and had no other parent company did not fill this section.

- Section 2 asked for background information on the respondent. This included information such as his or her number of years in the zone, level of education, and education background.

- Section 3 asked for demographic information on the zone company. This included information such as, year of establishment of the company in the zone, primary business carried out in the zone, major product groups, and the company's total sales and exports.

- Section 4 measured the zone tenant's assessment on six investment factors concerning the environment in the zone and that of the host country in general: production, finance, economic and legal, political and social, infrastructure, and country and people factors. An additional "market factor" was also added for the assessment of the general country environment. Each factor included a set of items measured using a 5-point bipolar adjective scale, with 1 highlighting an "unfavourable" and 5 a "favourable" assessment. 
- Sections 5 and 6 measured the zone tenants' assessment of the importance of the seven investment factors for investing in the zone and in the country, and their level of satisfaction with these factors. Five-point scales were used here as well, anchored by the terms "not important" / "very important" for Section 5 and "very dissatisfied" / "very satisfied" for Section 6. To prevent excessive questionnaire length, the approach of Papadopoulos et al. (1997) was used whereby these two sections of questions were asked at the factor rather than individual item level. In other words, the scales in Section 4 were asked for each of 56 individual items appearing grouped under the headings that represented the seven investment factors. Having thus established in the minds of respondents what the detailed "content" of each factor is, the importance and satisfaction scales in Sections 5 and 6 were measured only at the level of the seven summary factor headings as in the previous section.

- Section 7 measured contractual and market risks by comparing the zone to the mainland on a scale of 1 to 7 , with $1=$ "zone worse", and 7 = "zone better".

\section{Data Analysis}

Due to the exploratory nature of this research, large emphasis was put on a detailed and descriptive analysis of the data. In addition, Ordinary Least Squares (OLS) multiple linear regressions were run to test the impact of investment factors and contractual and market risks on tenants' assessment of zone satisfaction. OLS is a preferred estimator as it assumes normality for random error terms, which, due to the property of normal distribution (any linear function of normally distributed variables is itself normally distributed), means that beta coefficients will also be normally distributed (Gujarati 2003). This makes the task of hypothesis testing using OLS straightforward. OLS is 
preferred over Maximum Likelihood Estimation (MLE) as it is more robust to a small or a finite sample size, whereas MLE will be biased at small sample sizes. This property is important for this study, due to the difficulty in collecting large samples.

The next three chapters present and discuss the results from each of the three phases. Following these chapters which deal with the findings of each phase separately, the final chapter concludes with a general discussion on results from all three phases, and suggests implications for policy makers, managers, and research. 


\section{Chapter 6 PHASE I RESULTS: WEBSITE ANALYSIS}

This chapter presents the results from Phase I of the study, which involved a content analysis of FTZ websites. The chapter begins with a brief description of the sample, followed by the results from the inter-coder reliability tests. The next section presents the main findings from the content analysis, followed by a discussion of the main findings.

\section{Sample}

The comprehensive search explained in the previous chapter generated a universe of 280 available FTZ websites. Of these, websites which merely mentioned the name and location of the FTZ were discarded; furthermore, those websites that were either under construction or not accessible were also discarded. The result was a sample of 105 usable FTZ websites. This final sample is substantially greater than the $50 \mathrm{FTZ}$ websites that were initially targeted during the thesis proposal stage.

As will be seen when discussing the main findings, the distribution of zones represented by these websites generally corresponds to the distribution of the population of FTZs in terms of geographic location and zone type.

\section{Tests for Inter-Coder Reliability Agreement}

As suggested in the content analysis literature (e.g., Krippendorff 1980), the judgements of two coders (in this case the researcher and an MBA student) for 20 websites were compared to determine inter-coder reliability. Table 6.1 shows the reliability coefficients for the main categories of content analysis. Coefficients above $85 \%$ are considered satisfactory (Kassarjian 1977, Gross and Sheth 1989) and those obtained in this study are 
Table 6.1

Inter-Coder Reliability Test

\begin{tabular}{llc}
\hline Variables & Operational Definition & Inter-Coder Reliability \\
\hline $\begin{array}{l}\text { Demographics } \\
\text { Type }\end{array}$ & What is the type of zone - Export, Import or Trade & $97.1 \%$ \\
$\begin{array}{l}\text { Country status } \\
\text { Area }\end{array}$ & Whether developing or developed & $100.0 \%$ \\
Year & The are of the zone & $100.0 \%$ \\
Proximity & Which year was the zone established? & $100.0 \%$ \\
Zone Tenants & Whether the zone was near an airport, major city port, or a border & $92.0 \%$ \\
Firms & & \\
Industries & The number of firms operating inside the zone & $98.0 \%$ \\
Zone Benefits & The different industries operating inside the zone & $96.2 \%$ \\
$\begin{array}{l}\text { Number } \\
\text { Type of benefit }\end{array}$ & The number of different benefits offered by the zone & \\
& Different types of benefits offered, such as: duty deferral, no duties, & $92.4 \%$ \\
Marketing Tools & value added tax, 100\% ownership, 100\% repatriation etc... & $88.0 \%$ \\
Number & Number of different marketing / public relation tools used & \\
Type of tools & $\begin{array}{l}\text { Different types of marketing tools used, such as: case studies, overview } \\
\text { of the zone, use of videos, client log-in, set-up steps etc... }\end{array}$ & $88.1 \%$ \\
\hline
\end{tabular}

considerably higher. Consistent with the procedures of Schneider and Schneider (1979), and Gross and Sheth (1989), disagreement among the coders was settled via discussion and consensus.

\section{Main Findings}

The analysis was done keeping the following points in mind.

1. By virtue of the design of Phase $I$, the analysis was not intended to review the population (or a sample) of all zones, but to review those that have websites. The website-based search was necessary since there is no other comprehensive listing or information source that provides detailed, or even basic, data on all individual FTZs. Therefore, from the perspective of this study the web provides the best and only source of individual and comparative information across different types of zones. 
2. The same is true from the perspective of investors. Some firms may be interested specifically and only in one or a small handful of zones (e.g., a firm that does business in the Middle East and has heard of the Dubai zone), in which case they can contact the zone(s) directly and request information. However, those firms that have a broader interest in investing in zones, and wish to further explore the FTZ possibility, have no alternatives but to obtain consulting advice (which, in addition to its cost, will also be limited to a handful of zones for the same reasons), or to start with a webbased search that will enable them to obtain and compare information across many FTZs.

3. In today's competitive and technology-oriented world, it can be reasonably assumed that better-run and larger organizations are more likely to not only have "a" website but also to have well organized and effective websites that provide substantive information to visitors. This is likely to also apply to FTZs.

4. The systematic search used in this study identified a population of 280 websites, of which 105 can be considered as reasonably good in providing information on each individual zone, at the least, and as containing sufficient data to enable cross-zone comparisons. Therefore, while the findings from the sample being used here may not be generalizable to the entire population of FTZs, it seems reasonable to assume that it offers a good representation of better performing and/or more competitive zones that proactively strive to attract foreign investors. This is a very important consideration, since the main intent of an FTZ website is to provide information that will help attract potential investors and other users to the zone. Therefore, the findings are extremely important not only for the purposes of this study but also from 
the perspective of the individual firm as well as that of zone operators who may wish to compare their FTZ to others in developing their competitive strategies.

In the following section, the main findings from the content analysis are discussed under 11 main headings.

\section{Zone Analysis by Country}

Table 6.2 shows the breakdown of zones across the five continents of North and South America, Asia, Europe, and Africa. A number of observations are noteworthy. First, North America accounts for most FTZs (32\%), all of which are located in the U.S. This observation highlights a more general statistic: the U.S. accounts for the largest number of zones in the world if both general purpose zones (272) and subzones (502) are considered. This finding is in line with the breakdown of zones given in the ILO (2003) database, which shows the U.S. to have the largest number of zones in the world (even though the ILO figure for the U.S. at 336 under-represents reality by a wide margin).

Table 6.2

Zones Analysis by Continent

\begin{tabular}{lcc}
\hline Continent & Number & Percentage \\
\hline North America & 34 & $32 \%$ \\
Asia & 32 & $30 \%$ \\
South America & 21 & $20 \%$ \\
Europe & 14 & $13 \%$ \\
Africa & 4 & $4 \%$ \\
Total Zones & $\mathbf{1 0 5}$ & $\mathbf{1 0 0 \%}$ \\
\hline
\end{tabular}

Second, Asia accounts for $30 \%$ of all zones in the analysis, reflecting the true representation of the distribution of zones worldwide (ILO 2003). Third, there are a low 
percentage of zones in Africa. This is surprising because Africa has recently begun rapidly developing new FTZs. This may be due to the fact that most zones in Africa do not have websites at all, or that they may be lacking in useful detail.

Apart from the U.S., the other predominant countries in terms of number of zones in the sample are: India (8\%), Iran (7\%), Argentina (5\%) and China (5\%). In terms of countries with zones in different continents: India, China, Iran, and South Korea (also at $5 \%$ ) are the major countries with zones in Asia. Colombia (5\%), Dominican Republic (4\%) and Ecuador (3\%) together have the majority of zones in South America while Kenya (2\%) has the majority in Africa and Belarus (4\%), Latvia (3\%) and Spain (3\%) in Europe.

It is interesting to note that while most of the zones had information on their host country, much of this information was very brief and was limited to the location of the zones in the country. For example, it was observed that many of the U.S. zones did not have any information on the home country. If a host country had other zones, the website usually highlighted this fact and provided some useful information on them. Very few zone websites tried to explain the reasons that lead to the zone's creation. An exception to this was the Noida SEZ website that provides detailed information behind the government's incentive to set up the SEZs.

\section{Zone Analysis by Type}

Although there are no international rules for naming zones, most of the FTZ names have two main parts. The first denotes on most occasions the name of the city, port, or province where the zone is located. The second part implies the type or function of the zone, for example, terms like Export Processing, Special Economic, Free Trade, Industry, 
or Industrial Park, accompanied by the word "zone". Some examples of complete zone names are Iksan Free Trade Zone, Shenzhen Special Economic Zone, and Dubai Airport Free Trade Zone. In the case of the U.S./FTZs, in addition to their name, the Foreign Trade Zones Board requires that they cite their serial number, for instance, the Hawaii Foreign Trade Zone is also named FTZ No 9.

Through the content analysis the zone's main functions, their orientation, if mentioned, and their main focus (imports, exports or overall trade) was noted. Based on this information, the zones were categorized as Export-, Import-, or Trade-oriented. As expected and as alluded to in Chapter 3, there was a clear association between the functional part of the zone's name and its orientation. Export-oriented zones have the following suffixes - Export Processing, Special Economic, and Free Economic. All three of these are primarily oriented towards exports with one difference being that Special and Free Economic Zones are generally larger in size and more flexible in allowing exports to domestic host country markets. The Trade-oriented zones are labelled Free Trade Zone or Free Zone, while the Import-oriented zones are labelled Foreign Trade Zone.

As Table 6.3 shows, each zone type was equally represented in the sample. In the sample, all import zones are located in the U.S. The geographic distribution of Export zones is as follows: India has six zones, Belarus, Iran, and South Korea each have four zones, and Dominican Republic has two zones. Similarly, for Trade zones, the top five countries are China and Colombia with four each, and Iran, Argentina, and Ecuador with three each. The fact that the Import zones are primarily limited to the U.S. is not 
Table 6.3

Zone Analysis by Type

\begin{tabular}{lcc}
\hline Type of Zone & N & Percent \\
\hline Export & 35 & 33.3 \\
Import & 34 & 32.4 \\
Trade & 36 & 34.3 \\
Total & $\mathbf{1 0 5}$ & $\mathbf{1 0 0}$ \\
\hline
\end{tabular}

surprising given that the focus of American zones is to encourage domestic manufacturers to import intermediate goods free of duties, and manufacture finished goods at cheaper prices, making them more competitive in their domestic market. For Export zones, the predominance of developing countries is understandable given that their focus is to encourage foreign investment and increase foreign exchange reserves.

\section{Year of Establishment}

Out of the 105 zone websites, only 64 mentioned the zone's year of establishment. This highlights that a number of websites had very limited or no background information on the zones, as the "year of establishment" should be a very basic information to be shown on the websites. Table 6.4 categorizes the zones into two groups, those established before or in $1990(39 \%)$, and those established later $(61 \%)$. Thus, from the investors' perspective, they may feel that there has been an increase in the number of new zones established in the recent years. This may also point to an increased market oriented focus for new and upcoming zones. This finding supports the pervasive belief that FTZs are becoming increasingly important, at least to host countries. 
Table 6.4

Year of Establishment of the Zones

\begin{tabular}{lcc}
\hline Year Established & Frequency & Percent \\
\hline Before or in 1990 & 25 & 39.06 \\
After 1990 & 39 & 60.94 \\
Total & $\mathbf{6 4}$ & $\mathbf{1 0 0 . 0 0}$ \\
\hline
\end{tabular}

Table 6.5 shows a breakdown of these zones by type. There appears to be an increase in the growth of Export and Import zones after 1990 (as will be perceived by an investor). This should be expected given the increasing number of developing countries that are aggressively establishing Export- and Trade-oriented zones (e.g., India and U.A.E.). This is also reflected in the overall FTZ population trend. While Import zones have been used for a long time, with the first one being set up in 1936 (in the U.S.), Export zones have only been in use since the early 1970s.

Table 6.5

Year of Establishment by Type of Zone

\begin{tabular}{lccc}
\hline Type of Zone & $\leq \mathbf{1 9 9 0}$ & $\mathbf{> 1 9 9 0}$ & Total \\
\hline Export & 7 & 15 & 22 \\
Import & 9 & 6 & 15 \\
Trade & 9 & 18 & 27 \\
Total & $\mathbf{2 5}$ & $\mathbf{3 9}$ & $\mathbf{6 4}$ \\
\hline
\end{tabular}

The lesser number of websites of Import zones after 1990 may also suggest a more general finding that indicates that the setting up of new Import zones in the U.S. has decreased over the years. As shown in Figure 3.1 (Chapter 3), the number of new general purpose zones established show a declining trend after the 1980s. One possible 
reason for this trend is that most states in the U.S. already have five or more zones and so the U.S. market may be getting saturated.

\section{Zone Analysis by Developed and Developing Countries}

Countries were grouped as developed or developing using the World Bank classification (World Bank 2007), which categorizes countries into Low, Middle and High Income. All countries in the High Income category were grouped as developed, while those with Low and Middle income were grouped as developing countries. In line with the earlier results, Table 6.6 shows that the there are substantially more Export zones in developing countries than in developed countries. In the sample, 88\% (31 out of 35) of Export zones and $86 \%$ (31 out of 36) of Trade zones are located in developing countries. This may suggest that (1) developing countries are becoming more aggressive in offering incentives for firms that prefer both to manufacture and export and those that prefer only to store their products for export or sales at a later time; and (2) the actual difference between the Export and Trade zones may be diminishing as countries try to offer all facilities and incentives in any given zone.

Table 6.6

Zone Analysis by Development of Country

\begin{tabular}{lcccc}
\hline Country Development & \multicolumn{2}{c}{ Type of zone } & \multicolumn{2}{c}{ Total } \\
& export & import & trade & \\
\hline Developed & 4 & 34 & 5 & 43 \\
Developing & 31 & 0 & 31 & 62 \\
Total & 35 & 34 & 36 & 105 \\
\hline
\end{tabular}


The sample also shows Import zones to be a U.S. only phenomenon. Among the developed countries, apart from the U.S., South Korea (High Income by the World Bank 2007 classification) with five zones and Spain with three zones had the largest number of FTZ websites.

\section{Zone Area}

Only 47 of the 105 zone websites give the area of the zone. In general, the land area of a zone can be as small as three hectares (Hawaii Foreign Trade Zone in the U.S.) and as large as 100,000 hectares (Aras Free Zone in Iran). To give a reasonable idea of the size of the zones, a football field is about 0.47 hectares, Central Park in Manhattan is 341 hectares and Manhattan itself is 5,130 hectares.

Table 6.7 shows the mean area of the zones by type and the total mean for the 47 zones. The mean area of all zones is 191 hectares. The mean area for the Import Zones (343) is substantially more than that of Export Zones (133) and Trade Zones (162).

Table 6.7

Mean Area of Zones in Hectares

\begin{tabular}{llc}
\hline Type of Zone & $\mathbf{N}$ & Mean \\
\hline Export & 15 & 133 \\
Import & 10 & 343 \\
Trade & 22 & 162 \\
Total & $\mathbf{4 7}$ & $\mathbf{1 9 1}$ \\
\hline
\end{tabular}

ANOVA $-F$ value $(3.18), p=0.051$

Table 6.8 shows the top five zones by area. It is interesting to note that the top five only include Trade and Export establishments. Two of these zones are from China - 
Table 6.8

Top Five Zones in terms of Area

\begin{tabular}{lllc}
\hline Name & Country & Type & Area in Hectares \\
\hline Aras Free Zone & Iran & Trade & 100,000 \\
Shanghai city Waigaoqiao Free Trade Zone & China & Trade & 52,200 \\
Aqaba Special Economic Zone & Jordan & Export & 37,500 \\
Clark Special Economic Zone & Philippines & Export & 33,000 \\
Shenzhen Special Economic Zone & China & Export & 32,800 \\
\hline
\end{tabular}

Shanghai City Waigaoqiao Free Trade Zone at 52,200 hectares, and Shenzhen Special Economic Zone at 32,800 hectares. The fact that the mean area of Export and Trade zones is smaller than that of Import zones could be due to a great variation in the area and size of Export and Trade zones around the world, whereas the U.S. has more or less standard areas for its general purpose sites.

In a further analysis, an ANOVA was carried out to see if the difference in the area of the zones was significantly different across the types. The result was not significant at the $p=0.05$ level, but it is significant at $p=0.10$. In addition, the area means across different years of establishment (before or in and after, 1990), and across developing and developed countries were compared. Again the results were not significant.

An interesting finding regarding the zone area is that for some, the total area can be distributed among several separate land sites. For instance, the Bourgas Free Zone, which is located on the Bulgarian Black Sea coast, is spread across three sites - next to a sea port, a railway station, and an airport. A similar trend is seen for the U.S. general purpose zones where sites are licensed out to individual contractors. 


\section{Zone Proximity to Major Cities, Ports, Airports, and/or Borders}

Zone proximity to major cities, ports, airports, and adjoining borders is an important incentive to attract investment. This information helps to show the strategic advantages that zones can offer due to their favourable location. Table 6.9 gives a breakdown of zones that are close to important places/landmarks. For this analysis, only those FTZ websites which specifically mentioned the proximity to these locations were considered.

Table 6.9

Zone Proximity by Type

\begin{tabular}{lcccc}
\hline Zone Proximty to & Export & Import & Trade & Total \\
\hline Airport & 17 & 19 & 19 & 55 \\
Port & 14 & 15 & 23 & 52 \\
Major City & 11 & 4 & 10 & 25 \\
Border & 3 & 1 & 3 & 7 \\
\hline
\end{tabular}

Out of 105 zones, 87 mentioned on their website whether they are close to these landmarks. The fact that $83 \%$ of the zones recognize that location is important information for prospective clients is a noteworthy finding. This highlights that the majority of the sampled zones recognize the strategic advantages associated with a favourable location. Such advantages for firms include access to good transportation facilities, close proximity to important markets and international trade routes, and more broadly the possible role that the zone may play in supporting the global logistics of companies.

The table shows that $63 \%$ (55 of the 87 zones) are close to an airport and $60 \%$ (52) are close to a port. In addition, $29 \%$ (25) of the zones are close to a major city, and 
only $8 \%$ (7) are close to a border. Thus, it seems that close proximity to a port and an airport are more important locations for a zone than proximity to a major city or an adjoining country. Furthermore, since ports and airports are likely located in or near major cities, the fact that the sampled websites stress the ports and airports more frequently than the city itself suggests that operators believe that proximity to good transportation facilities is more important than being near a major urban centre.

When the data is split by zone type, the above relation still holds for all three types. All FTZ websites mention their proximity to ports and airports more frequently than their proximity to a major city or adjoining border.

On further examination of the data, it is seen that $13 \%$ (11) of the zones are close to at least three of the four important landmarks (Table 6.10). Two examples of such zones are:

1. The El Pedregal Free Zone (Trade zone) in El Salvador, which was established in 1993 and is located in Rosario La Paz, 10 minutes from El Salvador's International Airport, and 35 minutes away from the capital city of San Salvador on the second most important highway in the country. Distances between this zone and the main seaports are two hours from Puerto Acajutla at the Pacific and eight hours away from Puerto Santo Tomas de Castilla at the Atlantic. (El Pedregal website 2006)

\section{Table 6.10}

Zone Proximity to Number of Landmarks

\begin{tabular}{lc}
\hline Zone Proximty to & No. of Zones \\
\hline 3 Landmarks & 11 \\
2 Landmarks & 33 \\
1 Landmark & 43 \\
Total & $\mathbf{8 7}$ \\
\hline
\end{tabular}


2. The Andhra Pradesh SEZ (Export zone) in India, which was established in 2007, is located $55 \mathrm{~km}$ south of Vishakapatnam city (a major port city in India). It is $45 \mathrm{~km}$ from the city's airport and $50 \mathrm{~km}$ from its port. (Andhra Pradesh SEZ website 2006).

In addition, $38 \%$ (33) of the zones in the sampled websites are close to at least two landmarks and $49 \%$ (43) to only one. There was not a single zone that was close to all four important landmarks. Very few zones mentioned the exact distance of their zone from these important landmarks.

A number of zones, especially those next to ports, cite the location advantages on their websites. These zones suggest the significance of their locations by pointing out their proximity to major trade routes, large markets, and important resources. For example, the Colon Free Zone in Panama states on its home page (Colon Free Zone website 2006),

"The Colon Free Zone is a gigantic entity at the Atlantic gateway to the Panama Canal, dedicated to re-export an enormous variety of merchandise to Latin America and the Caribbean."

In addition, the zone stresses the fact that nearly all trade routes pass the Colon Free Zone.

Another such interesting example is the Clark SEZ in Philippines, which states on its home page (Clark SEZ website 2006),

"Clark possesses a location so strategic and unique. The American military forces maintained it as its largest air base outside of the U.S. Mainland.”

This was one of the very few zone website examples where one can see a lot of emphasis being put in creating a strong and an attractive message. This highlights the strategic 
perspective of the zone. In addition, this site was one of the very few examples where important trade locations and their distances from the zone were mentioned.

Other such examples include the Djibouti Free Zone, which sells itself as the gateway to Africa, and the Jebel Ali Free Zone (which is discussed in detail in Chapter 7). As mentioned earlier, these examples are restricted to few zones and that also to those near ports.

\section{Number of Firms in a Zone}

Only $47(45 \%)$ of the FTZ websites provided information on the number of tenants. Contrary to expectations, the Import zones in the U.S. were the least forthcoming in offering this information, while Export and Trade zones were substantially more open in sharing it. Most zones do not provide information on the type of tenants such as - how many are domestic and foreign owned, industry background, main operations, and so on.

The mean number of tenants per zone was 85 (Table 6.11). The Trade zones on average had more tenants than Export and Import zones. Although the difference was not statistically significant based on an ANOVA test, it does seem to have practical significance: such information might suggest to investors that more firms are attracted to Trade zones suggesting a better investment climate or perhaps beneficial industrial clustering effects. The larger average number of firms at Trade zones may also be due to their closer proximity to ports than other zone types (as seen in Table 6.9), which enables firms easier access to other international markets.

The variation in the number of firms operating in the zone was vast, ranging from one to 6,000. The Jebel Ali Free Zone in Dubai and the Dalian Free Trade Zone in China reported the highest number of firms in the sample at 6,000 and 2,183. During a further 
Table 6.11

No. of firms in the zone

\begin{tabular}{lrr}
\hline Zone Type & N & Mean \\
\hline Export & 22 & 76 \\
Import & 6 & 67 \\
Trade & 19 & 100 \\
Total & $\mathbf{4 7}$ & $\mathbf{8 5}$ \\
\hline ANOVA - F value $(\mathbf{0 . 2 4}), \mathbf{p}=\mathbf{0 . 7 9}$
\end{tabular}

analysis, it was found that the average number of firms across zones in developed and developing countries was similar at 84 and 85 respectively. This implies that for the sampled zones, development of the host country may not be an important factor in attracting firms.

\section{Ownership of Zones}

A total of 79 websites provide information on zone ownership. Table 6.12 gives a breakdown of ownership by zone type. It shows two interesting findings. First, 71\% (56 of 79) of the zones are government owned. From an investor's standpoint, this may indicate that zones in general may also suffer from the same operational and bureaucratic inefficiencies as do other governmental organizations. Alternatively, this may also suggest that the private companies are either not allowed to or stay away from setting up zones, probably due to long gestation period involved in FTZ projects. The in-depth interviews did show evidence that governments in general do not allow private companies to operate FTZs. This trend seems to be changing as can be seen in India, where the government has recently allowed private companies to set up and operate zones. 
Table 6.12

Zone Ownership by Type

\begin{tabular}{lcccc}
\hline Ownership & Export & Import & Trade & Total \\
\hline Nongovernment & 3 & 7 & 13 & 23 \\
Goernment & 25 & 12 & 19 & 56 \\
Total & $\mathbf{2 8}$ & $\mathbf{1 9}$ & $\mathbf{3 2}$ & $\mathbf{7 9}$ \\
\hline
\end{tabular}

Pearson Chi-Square $\mathbf{- 0 . 0 2 7 3 5 6}$ (significant at $\mathrm{p}=\mathbf{0 . 0 5}$ )

Second, the government ownership of Export zones at 89\% (25 of 28) is significantly more than those among Import zones at 63\% (12 out of 19) and Trade zones at 59\% (19 out of 32). This may be because Export zones, which are predominantly in developing countries, were normally built with an overall goal to develop cities or regions. Such an objective would hardly interest a private firm.

When zone ownership was analysed by developed or developing countries, no significant differences were found. Similar to the above results, it was found that zones were predominantly owned by governments across both developed and developing countries.

\section{Benefits Offered by Zones}

The literature cites a number of zone benefits that range from duty free exports and corporate tax holidays to cheap labour and better infrastructure. For this analysis ten such benefits were studied (shown in Table 6.13). Most of these benefits are financial such as duty deferral, zero tax on exports, zero tax on inventory, tax holidays, and $100 \%$ repatriation of profits. Others are mainly operational specific, such as cheap labour, storage, and manufacturing facilities. 
Table 6.13

Zone Benefits

\begin{tabular}{lcccc}
\hline Benefit & Export & Import & Trade & Total \\
\hline Duty deferral & 24 & 31 & 24 & 79 \\
No duties on exports & 13 & 29 & 20 & 62 \\
No tax on inventory & 5 & 18 & 6 & 29 \\
Tax holidays & 17 & 4 & 5 & 26 \\
Storage facilities & 0 & 17 & 1 & 18 \\
Manufacturing & 0 & 16 & 2 & 18 \\
Cheap labour & 5 & 8 & 3 & 16 \\
100\% ownership & 6 & 0 & 7 & 13 \\
Domestic sale & 3 & 7 & 3 & 13 \\
100\% repatriation of income & 4 & 0 & 5 & 9 \\
\hline
\end{tabular}

In terms of the most cited benefits, "duty deferral" topped the list with 79 zones mentioning it on their websites. Duty deferral refers to a benefit whereby firms can defer payment of duties on imported goods until they are sold in the domestic market. If these goods are exported to an international market, the firms will have to pay no tax.

The second most important benefit is "no duties on exports" which again highlights that most of these zones would be viewed primarily as places to save duties. There is a substantial drop from the number two to number three incentive (from 62 to 29 zones), which is "no tax on inventory". The other incentives seem less important as much fewer zones cite them on their websites. It seems from these findings that an investor will very likely feel that the zone predominantly offers "duty free" benefits.

Table 6.14 shows the top five incentives for different types of zones. In line with the above results, the top incentive for all three zones is duty deferral. While the second most important incentive for Export zones is tax holidays, this does not appear in the top five for Import zones, and it appears at only the fifth position for Trade zones. Tax 
Table 6.14

Top Five Benefits by Type

\begin{tabular}{lc}
\hline Export & No. of Zones \\
Duty deferral & 24 \\
Tax holidays & 17 \\
No duties on exports & 13 \\
100\% ownership & 6 \\
Cheap labour & 5 \\
Import & \\
Duty deferral & 31 \\
No duties on exports & 29 \\
No tax on inventory & 18 \\
Storage facilities & 17 \\
Manufacturing & 16 \\
Trade & \\
Duty deferral & 24 \\
No duties on exports & 20 \\
100\% ownership & 7 \\
No tax on inventory & 6 \\
Tax holidays & 5 \\
\hline
\end{tabular}

holidays are benefits whereby the firms are not required to pay any corporate tax on their profits for a designated number of years. For instance, at the Noida SEZ the corporate tax holiday is for 10 years, while at Jebel Ali Free Zone, it is for 50 years. This may suggest that Export zones find this to be an important incentive to attract foreign and domestic companies to set up manufacturing units.

Another major difference between the zone types is that "cheap labour" appears in the top five incentives only for the Export zones. This provides further proof to the earlier finding that that Export zones promote themselves as good places to set up manufacturing units. 
It is interesting to note that for Import zones "allowing manufacturing" is an important incentive, though this does not appear among the top five for Export and Trade zones. This may be because most of the Import zones are primarily used for storage facilities and also these zones require special permission from the U.S./FTZB to allow manufacturing at their sites, therefore, promoting this incentive on their website will help to differentiate their zones from the others. The Export zones may not feel the need to highlight this benefit, because investors may already know that manufacturing is a key component for these zones.

In a further analysis (Table 6.15), the mean benefits across the different zone types were compared to better understand which types cites more benefits on their websites. The first observation that stands out is the low mean of benefits cited. Zones on average cite only three incentives on their websites. Thus, a prospective investor may feel largely unsatisfied with the information on zone incentives. This may turn away a number of potential investors.

Table 6.15 Number of benefits offered by the zone

\begin{tabular}{lcc}
\hline Zone Type & N & Mean \\
\hline Export & 35 & 2.31 \\
Import & 34 & 3.82 \\
Trade & 36 & 2.22 \\
Total & 105 & 2.77 \\
\hline
\end{tabular}

ANOVA - F value (9.22), $p=0.00$ 


$\begin{aligned} & \text { Multiple Comparisons } \\
& \text { Dependent Variable: } \\
& \text { Bonferroni }\end{aligned}$
\begin{tabular}{llccc} 
(I) type of zone & (J) type of zone & Mean Difference (I-J) & Std. Error & Sig. \\
\hline export & import & -1.51 & 0.42 & 0.001 \\
& trade & 0.09 & 0.41 & 1.000 \\
import & export & 1.51 & 0.42 & 0.001 \\
& trade & 1.60 & 0.42 & 0.001 \\
trade & export & -0.09 & 0.41 & 1.000 \\
& import & -1.60 & 0.42 & 0.001 \\
$*$ & The mean difference is significant at the .0167 level. & & \\
\hline
\end{tabular}

Interestingly, Import zones with a mean value of 3.82 cite significantly more benefits on their websites than the Export zones (mean value of 2.31) and Trade zones (mean value of 2.22). The ANOVA and the subsequent post-hoc Bonferroni test (significant at 0.0167 level, computed by dividing 0.05 by 3 , to control for the Bonferroni inequality) confirms the significant difference (Table 6.15). This may not suggest that Import zones offer more benefits, but it does highlight that Import zones are better than Trade and Export zones at stressing these benefits on their websites.

\section{Marketing or Promotional Tools Used by Zones}

One of the main purposes of the websites is to promote the zone as a complete entity. It is interesting to see how FTZs through their websites promote or market themselves and it is here that marketers can promote a zone's strategic and tactical advantages in addition to purely financial ones. According to the Black (2002) some of the important public relations tools that can be used on a website are annual reports, newsletters, intranet access for staff and stakeholders, and links to other relevant websites. In addition to these, other important tools included testimonials of companies already established at the 
zones, cost calculators, and flash demonstrations of the facilities at the zones. The final list of promotional tools was:

- Zone Overview: This gives information on the zone location, its infrastructure, services available, and so on.

- Other Important Links: These are links to institutions like government ministries and central banks that are related to the operation and management of the zones. These links simplify the information gathering process for prospective zone users.

- News: This can be news on new projects or new country regulations that benefit the zone. Some zones even have an electronic newsletter which is sent to subscribers by email.

- Set up Steps: This gives information on how to set up a business at the zone. Some can be as detailed as to mention the full name of the office where the applications should be submitted along with the information that needs to be presented. Others simply list what information to present with the application.

- Search Tool: This feature makes the search process very convenient, especially for those zones that present detailed information on the facilities and regulations. By using this tool, the browser can quickly search the entire document in order to find the needed information.

- Flash Demonstration: These are media files with video and/or sound demonstration of zone facilities. They are not very common; it is more common to find pictures of various areas and features of the zone. 
- Client Login: This provides access on the website to the zone's intranet. This tool makes the websites a reference point for current and future zone users.

- Links to Other Zones: These are links to promote other zones in the region or in the country.

- Annual Reports: These are links to annual reports of the zones, and/or any other financial information such as total sales, exports, and imports.

- Cases: These are case studies of companies operating at a zone. These cases allow prospects to learn of the benefits these companies have gained by operating at a zone. For example, the Greater Detroit Foreign Trade Zone website shows the following case:

"BASF Corporation has been operating a foreign trade subzone since late 1995 to import raw materials and manufacture vitamins. The company's main intention for utilizing its subzone status is to reduce manufacturing costs, remain competitive in both domestic and international markets, and realize savings in Customs duties."

- Cost Calculator: This is a tool that allows hypothetical calculations of costs of a business operating in a zone and shows the savings a company can achieve. This is a quick tool to show the impact of different financial incentives on firm's overall costs.

- Information on the Host Country: This provides general information on the host country such as the government background, population, per capita income, infrastructure set up, and other macro level information that may be important for tenants to consider before deciding to invest in a zone. 
Table 6.16 shows the number of zone websites that use these tools. It also shows the breakdown by zone type. The table shows that the most commonly used promotional tool is the "zone overview" (64 zones). In line with the earlier results on zone proximity to landmarks, this finding also highlights that a large number of zones recognize and promote the strategic benefits they may offer. In a similar vein, information on the host country (21 zones) and other zones (17) also communicate to the investor the possibility of using other zones in a manufacturing or a distribution network. The availability of additional zones in a country at strategic locations can encourage firms to manufacture in remote zones with low costs of production, and then assemble and store final goods at locations near ports and/or airports. From these zones, the final goods can be easily shipped to distant markets.

Table 6.16

Zone Promotional Tools

\begin{tabular}{lcccc}
\hline Tool & Export & Import & Trade & Total \\
\hline Zone Overview & 17 & 28 & 19 & 64 \\
Other links & 17 & 20 & 12 & 49 \\
Link to news & 17 & 6 & 13 & 36 \\
Set up Steps & 15 & 8 & 10 & 33 \\
Information on the country & 14 & 0 & 7 & 21 \\
Search tool & 10 & 1 & 7 & 18 \\
Information on other zones & 3 & 11 & 3 & 17 \\
Company login & 9 & 3 & 5 & 17 \\
Flash demos & 5 & 3 & 4 & 12 \\
Cost Calculator & 0 & 11 & 0 & 11 \\
Case studies & 2 & 5 & 2 & 9 \\
Annual report & 2 & 3 & 2 & 7 \\
\hline
\end{tabular}


The additional frequently used promotional tools are "other links on the website" (49 zones), "links to news" (36 zones) and "set up steps" (33 zones). The least used tools are "cost calculator" (11 zones), "case studies" (9 zones) and "annual reports" ( 7 zones). It is not surprising to find that only seven websites list the annual reports. It was found during the web analysis and during secondary data search that it was very difficult to find any financial information on the zones. The host country government normally publishes a collective report on financial information for all zones, which in most cases are not elaborate enough to get any useful data.

Interestingly none of the Import zones gave any information on the U.S., while it was an important tool used by many of the Export and the Import zones. Also, cost calculators were shown exclusively by Import zones and not by the other zone types. Besides these, most of the top five tools were very similar across all three zone types (Table 6.17).

In a further analysis, the mean number of tools used by each website across zone types was calculated. Table 6.18 shows that on average, Export zones offer more promotional tools on their website with a mean of 3.43 than Import and Export zones with means of 2.91 and 2.42 respectively. However, the difference did not come out to be significant. Nevertheless, it seems that the average mean of 2.91 promotion tools per zone is relatively low to make much of an impact on the investors.

\section{Zone Operations}

Very few zone websites listed the sectors that the firms operated in, and in general very little information was available on the zone's tenants. Table 6.19 shows different tenant 
Table 6.17

Top Five Promotional Tools by Zone Type

\begin{tabular}{lc}
\hline Export & No. of Zones \\
Zone Overview & 17 \\
Other links & 17 \\
Link to news & 17 \\
Set up Steps & 15 \\
Information on the country & 14 \\
Import & \\
Zone Overview & 28 \\
Other links & 20 \\
Information on other zones & 11 \\
Cost Calculator & 11 \\
Set up Steps & 8 \\
Trade & \\
Zone Overview & 19 \\
Link to news & 13 \\
Other links & 12 \\
Set up Steps & 10 \\
Information on the country & 7 \\
\hline
\end{tabular}

Table 6.18

Number of Marketing Tools on the Website

\begin{tabular}{lcc}
\hline Zone Type & $\mathbf{N}$ & Mean \\
\hline Export & 35 & 3.43 \\
Import & 34 & 2.91 \\
Trade & 36 & 2.42 \\
Total & 105 & 2.91 \\
\hline
\end{tabular}

ANOVA - F value (1.79), $p=0.17$

operations for those zones that gave the information on their websites. Interestingly, the most cited sector of operations is services with 30 zones. This is somewhat misleading as this high number is due predominantly to the Trade zones which have a large number of service firms. These firms are generally in the banking and the insurance sectors, which 
may be more vital for Trade zones than the Export and Import zones. This may be because the goods are in constant transit at the Trade zones thus, it is essential to access insurance and banking facilities at close proximity. Besides services, other important sectors are information technology and electronics (26 zones), heavy industry manufacturing ( 20 zones, with major focus on automobiles), and textiles ( 20 zones).

Table 6.19

Zone Operations in Different Sectors

\begin{tabular}{lcccc}
\hline Sector & Export & Import & Trade & Total \\
\hline Services & 8 & 3 & 19 & 30 \\
I.T. and Electronics & 13 & 3 & 10 & 26 \\
Heavy industry manufacturing & 9 & 4 & 7 & 20 \\
Textiles & 12 & 0 & 8 & 20 \\
Agriculture & 11 & 1 & 6 & 18 \\
Chemicals and Pharmaceuticals & 9 & 2 & 4 & 15 \\
Gems and Jewellery & 7 & 0 & 2 & 9 \\
\hline
\end{tabular}

It is also interesting to note that when we look at the top three sectors for each zone type, the top sector is different (Table 6.20). While information technology and electronics is the most important sector for Export zones, services and heavy industry manufacturing are the most important for Trade and Import zones respectively. It may be important to mention here that it was the U.S. or the Import zones again that offered the least information on the tenants and their sector of operation. This is surprising considering that one would associate transparency and willingness to promote with the U.S. based organizations more than organizations in the developing countries, where most of the Export and Trade zones are located. 
Table 6.20

Zone Operations by Type

\begin{tabular}{lc}
\hline Export & No. of Zones \\
I.T. and Electronics & 13 \\
Textiles & 12 \\
Agriculture & 11 \\
Import & \\
Heavy industry manufacturing & 4 \\
Services & 3 \\
I.T. and Electronics & 3 \\
Trade & \\
Services & 19 \\
I.T. and Electronics & 10 \\
Textiles & 8 \\
\hline
\end{tabular}

\section{Discussion}

The results from Phase I can be discussed under three main headings.

\section{Availability and Depth of Information}

The website analysis suggests that in general zone websites are few in number (280 out of over 2,000 zones); that very few (105 of 280) provide anything but basic coordinates for the zone (e.g., address, locations, or "contact"); and that even those sites that can be considered "good" overall provide limited information. Unlike corporate websites, many of which have a well organized home page with links to different information such as corporate background, sales offices, annual reports, and so on, the zone websites were much more disorganized, sometimes with information presented in a haphazard manner. Although there are some good examples such as the Jebel Ali Free Zone, Noida SEZ, Colon Free Zone, and Shannon Free Zone websites, they are limited in number. In addition, the websites rarely gave any financial information. Also, information on tenants 
was difficult to find, and most zones gave very little background on the type of tenants and their country of origin. Again one of the very few exceptions to this was the Jebel Ali Free Zone, which provides detailed information on its tenants.

\section{Demographic Characteristics}

The results also reveal that an investor will feel that FTZs are spread across the globe, with a greater concentration in Asia and North America (the U.S. in particular). This finding seems to match the overall distribution of zones worldwide. International organizations such as WEPZA (2007) and ILO (2004, 2007) report that Asia has the largest number of zones, closely followed by North America.

Also, the results show that a good number of countries have a combination of both Trade and Export zones. This seems to suggest that host countries may be inclined to offer investors a wider array of benefits. This finding is in line with the results reported by Kumar (1994) and Choi (1995) who find that the presence of FTZs in a location is significantly related to increased FDI. This may also point to the fact that the differences between different zones may be diminishing somewhat, in line with the claim made by Papadopoulos and Malhotra (2007).

The results also indicate that FTZs may be viewed as highly varied entities in terms of their size and structure. The zone areas and number of tenants in a given zone vary tremendously, not only across different countries, but also across zones in the same country. This suggests that there is no standard structure to FTZs; and may explain why some zones in the same host country do well while the others fail. Thus, there seem to be no standardised policies among many host countries towards the setting up of FTZs. This 
is clearly visible in countries in South East Asia where zones are sanctioned more on political grounds rather than on economic or business grounds.

\section{Financial and Strategic Advantages}

An important finding from this analysis is that zones recognize the existence of both financial and strategic advantages. The results showed that for 79 and 62 zone websites, respectively, "duty deferral" and "no duties on exports" were by far the most cited financial benefits. This does show that an investor will mostly likely associate "duty free" as the most predominant financial benefit across zones. However, the results (broken down by zone types) also suggest that these benefits do differ slightly across the three zone types.

The strategic character of zones is highlighted by the following results. First, 87 zone websites cite location advantages, that is, they specifically mention whether they are located next to ports, airports, major cities, and/or borders. Second, $63 \%$ and $60 \%$ of the zones mention they are close to ports and airports respectively, thus highlighting to a potential investor their proximity to transportation facilities. Third, 64, 21 and 17 zone websites emphasise "zone overview", "information on country" and "information on other zones" respectively as important promotional tools. All three results suggest that a potential investor will be exposed to the strategic benefits that zones can provide. These will include, among others, the proximity of zones to important and large markets, their potential role in a global and/or a regional distribution system and their role in supplying important business resources such as storage, manufacturing facilities, warehouse and showrooms that will help firms to accelerate their internationalisation process. This finding supports the views of Papadopoulos (1987), Tansuhaj and Gentry (1987) and 
Tansuhaj and Jackson (1989) that zones offer much broader strategic advantages to firms than merely short-term financial gains. As Papadopoulos (1987, p.117) suggests: "When the specific advantages of individual zones are pooled together, they can be viewed as a means for establishing a strong global competitive position"

It does seem from the results that zones do recognize their advantage, which were largely ignored by the development and regional economists. 


\section{Chapter 7 PHASE II RESULTS: CASE ANALYSIS}

This chapter begins with a discussion on the data analysis, followed by a description of the sample. The case profiles for the four zones are presented next. Following this, the principal findings of Phase II are presented, and the chapter concludes with a discussion on the main findings.

\section{Data Analysis}

As noted earlier, the research design for Phase II is a multiple-case study. Data was collected from four different zones, and each was treated as an independent experiment that confirmed or disconfirmed insights as they emerged (per Brown and Eisenhardt 1997). As a reminder, the four zones were: (1) Noida Special Economic Zone in India,

(2) Shenzhen Special Economic Zone in China, (3) New Orelans Foreign Trade Zone in the U.S., and (4) Jebel Ali Free Zone at Dubai in U.A.E.

Table 7.1 shows the breakdown of interviews and leave-behind questionnaires collected from the four zones. As is evident, in some cases the respondents did not return the leave-behind questionnaire or simply refused to fill it out. On further examination, it was found that this was mainly because a number of respondents refused to divulge any financial or sales information on their operations in the zone (this is discussed in more detail in Chapter 9). In cases where the respondents refused to fill out the questionnaires, more time was spent during the interviews to cover as many questions as possible from the leave-behind questionnaire. Due to differences in quality and quantity of material received from different zones and from other sources such as the internet, in some instances there is a slight variation in the information on each zone. In addition, because a 
Table 7.1

Number of Interviews and Leave-Behind Questionnaires

\begin{tabular}{lccccc}
\hline & Dubai & New Orleans & Noida & Shenzhen & Total \\
\hline $\begin{array}{l}\text { Zone Officials } \\
\text { Interviews }\end{array}$ & 2 & 3 & 3 & 2 & $\mathbf{1 0}$ \\
$\quad$ Leave-behind Q're & 2 & 1 & 3 & 1 & 7 \\
$\begin{array}{l}\text { Zone Tenants } \\
\text { Interviews }\end{array}$ & 2 & 2 & 6 & 15 & $\mathbf{2 5}$ \\
$\quad$ Leave-behind Q're & 2 & 1 & 4 & 6 & $\mathbf{1 3}$ \\
\hline
\end{tabular}

few zone administrators refused to answer certain questions, some of the information may be missing on these zones. It was felt, considering the exploratory nature of this research, and also because there has been no research of such kind in the FTZ literature, that all relevant and important findings be presented, even if some information was not available for one or two zones.

In spite of the above difficulties, in total 35 interviews and 20 leave-behind questionnaires were collected, in both cases considerably more than initially proposed targets of 15 each. Therefore, the realized sample provided a wealth of information for the analysis.

All audio taped interviews were transcribed, and together with the leave-behind questionnaires and secondary data, were gathered in Ottawa for the analysis. In line with the suggested approach by Eisenhardt (1989) and Yin (2003), the data was analyzed by first understanding individual cases and then comparing across cases. As a first step, all transcribed interview responses were entered into a database indexed by case, interview number, interview type, and question number. Next, responses to the same questions were gathered to enable easier comparison within and across cases. 
In order to guide the analysis of the data, initial categories were established in accordance with the questions mentioned in Chapter 4 (under the "FTZ Characteristics" section). Subsequently, the data analysis followed principles common to the exploratory nature of qualitative research, for example, noting patterns and making contrasts and comparisons (Miles and Huberman 1994). Cross-case analysis was used to develop conceptual insights. The cases were compared on the main themes/questions. This is again in line with Eisenhardt's (1989) recommendation, that is, to preempt any danger that investigators may reach false conclusions due to information processing biases, a good tactic is to select categories or themes and then to look for comparison across cases. In addition, tables and figures were created to facilitate further comparisons to develop emerging patterns and theoretical logic. To ensure that the ideas were consistent with the data, frequent checks were made with the original interviews.

\section{Sample Description}

\section{Zone Profile}

Table 7.2 shows that two of the zones (Shenzhen SEZ and Noida SEZ) are Export oriented, while New Orleans is Import oriented, and Jebel Ali zone is Trade oriented. All four zones are government owned. Except for New Orleans, which was established in 1946, the other three zones were established in the 1980s. A detailed profile of each zone is presented in the next section. 
Table 7.2

Zones Selected for Case Studies

\begin{tabular}{llllcl}
\hline Zone Name & Type & City & Country & Year Est. & Ownership \\
\hline Jebel Ali Free Zone & Trade & Dubai & UAE & 1985 & Government \\
New Orleans Foreign Trade Zone & Import & New Orleans & U.S. & 1946 & Government \\
Noida Special Economic Zone & Export & Noida & India & 1985 & Government \\
Shenzhen Special Economic Zone & Export & Shenzhen & China & 1980 & Government \\
\hline
\end{tabular}

\section{Respondent Profile}

The data was collected from both zone administrators and tenant representatives. Table 7.3 shows that 32 out of the 35 interviews were with senior or middle-level managers in the zone or in their organizations. In terms of specific designations the most prominent were Directors, Presidents, General Managers, and Deputy Managers. The respondents came from a mix of functional areas, which included marketing, production, finance and engineering.

Table 7.3

Respondent Profile

\begin{tabular}{lccccccrrr}
\hline & \multicolumn{2}{c}{ Dubai } & \multicolumn{2}{c}{ New Orleans } & \multicolumn{2}{c}{ Noida } & \multicolumn{2}{c}{ Shenzhen } \\
& Official & Tenant & Official & Tenant & Official Tenant & Official & Tenant & Total \\
\hline $\begin{array}{l}\text { Designation } \\
\quad \text { Senior Management }\end{array}$ & 2 & 1 & 3 & 1 & 2 & 4 & 1 & 1 & $\mathbf{1 5}$ \\
$\quad$ Middle Management & & 1 & & & 1 & 2 & 1 & 12 & 17 \\
$\quad$ Junior Management & & & & 1 & & & & 2 & $\mathbf{3}$ \\
$\begin{array}{l}\text { Time with Zone } \\
\quad 0-2 \text { years }\end{array}$ & & & & & & & & 2 & $\mathbf{6}$ \\
$\quad 2-5$ years & 1 & 1 & 1 & 1 & 2 & & & 11 & $\mathbf{1 5}$ \\
$\quad>5$ years & 1 & 1 & 2 & 1 & 1 & 4 & 2 & 2 & $\mathbf{1 4}$ \\
$\quad \begin{array}{l}\text { Worked in other Zones } \\
\quad \text { Yes }\end{array}$ & & & & & & & & & $\mathbf{0}$ \\
$\quad$ No & 2 & 2 & 3 & 2 & 3 & 6 & 2 & 15 & $\mathbf{3 5}$ \\
\hline
\end{tabular}


Further, the majority of the respondents had relatively good experience at the zone; most of them had spent more than two years at the zone (29 out of 35). Among these, a good number (14) had worked at the zone for more than five years. Interestingly, none of the respondents had ever worked at another zone.

In summary, the respondent profile suggests that data was collected from people holding responsible positions who had good knowledge about the working of the zone. Thus, the data is rich and very suitable to meet the objectives of this phase.

\section{Case Profile of Noida Special Economic Zone}

\section{Background on Indian SEZ Program}

Over the last 15 years, India has progressively opened up its economy. Through an easing of licensing (import and industrial), quantity controls, reduction in tariffs, and by liberalizing its export policies the country is gradually moving towards free trade. This has resulted in an increase in exports to U.S. $\$ 88,026$ million in $2004-2005$, a $124 \%$ increase since $1999-2000$, and FDI inflows to nearly U.S. $\$ 4,268$ million in the year 2004, a 49\% increase over the previous year (Confederation of Indian Industry Report 2006, Indian Ministry of Statistics website 2007).

The introduction of EPZs, and later SEZs, has been an important government initiative to achieve its goals of attracting FDI and increasing exports. Although India only recently established SEZs, it had set up the first EPZ in the world - the Kandla Export Processing Zone at Gujarat in 1965, which was followed by the Santacruz EPZ in 1973. The EPZs never really made an impact. The respondents noted that this was due to inadequate policies such as limited power of zone authorities, absence of single window 
facility within the zone, stiff custom procedures, bureaucratic restraints, and inadequate infrastructure. In order to revamp the EPZs, from 1991 to 2000, the government liberalized its policies towards EPZs, eased controls, simplified procedures, passed more powers to zone authorities, increased fiscal incentives, and improved zone facilities (Confederation of Indian Industry Report 2006). In 2000, a new policy was initiated under which the existing EPZs were converted into SEZs (e.g., in 2003, the Noida EPZ was converted into an SEZ), and new SEZs were allowed to be set up in the public, private, or the joint sector (Confederation of Indian Industry Report 2006).

By 2005, 11 SEZs were operational, while an additional 42 SEZs had been approved (Confederation of Indian Industry Report, 2006). Figure 7.1 shows that exports from SEZs saw a steady increase in the initial years before accelerating after the year 2002 ; as a matter of fact, total exports from all SEZs increased by $16.4 \%$ from $2000-01$ to 2003-04 (Confederation of Indian Industry Report 2006). Despite the recent increase in exports from SEZs, their share in the total exports of the country has only increased from $4.2 \%$ in $2000-01$ to $5.1 \%$ in $2004-05$ (Figure 7.2 ).

\section{Salient Features of Noida SEZ}

India established the Noida SEZ in 1985. It is situated in the northern part of the country, at a distance of $24 \mathrm{~km}$ from New Delhi (capital city of India) (Exhibit 7.1). It is spread across 310 acres of land, and is the first land locked SEZ in India. It is connected to a super-highway that passes through New Delhi on one side and goes up to Agra (deep into the state of Uttar Pradesh, also more famously known as the city which houses the Taj Mahal). 
Figure 7.1

\section{Trend in SEZ Exports}

(Million U.S. \$)

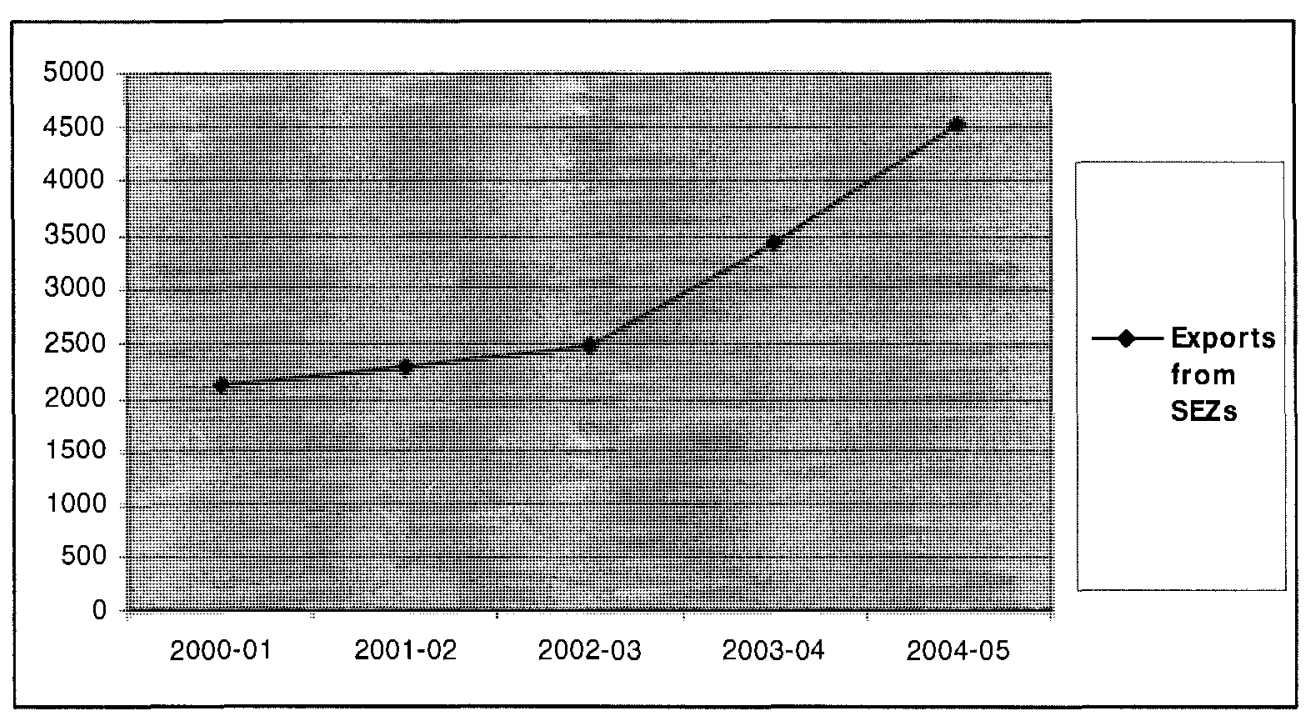

Source: Confederation of Indian Industry Report 2006

Figure 7.2

SEZ Exports as \% Share of Total Indian Exports

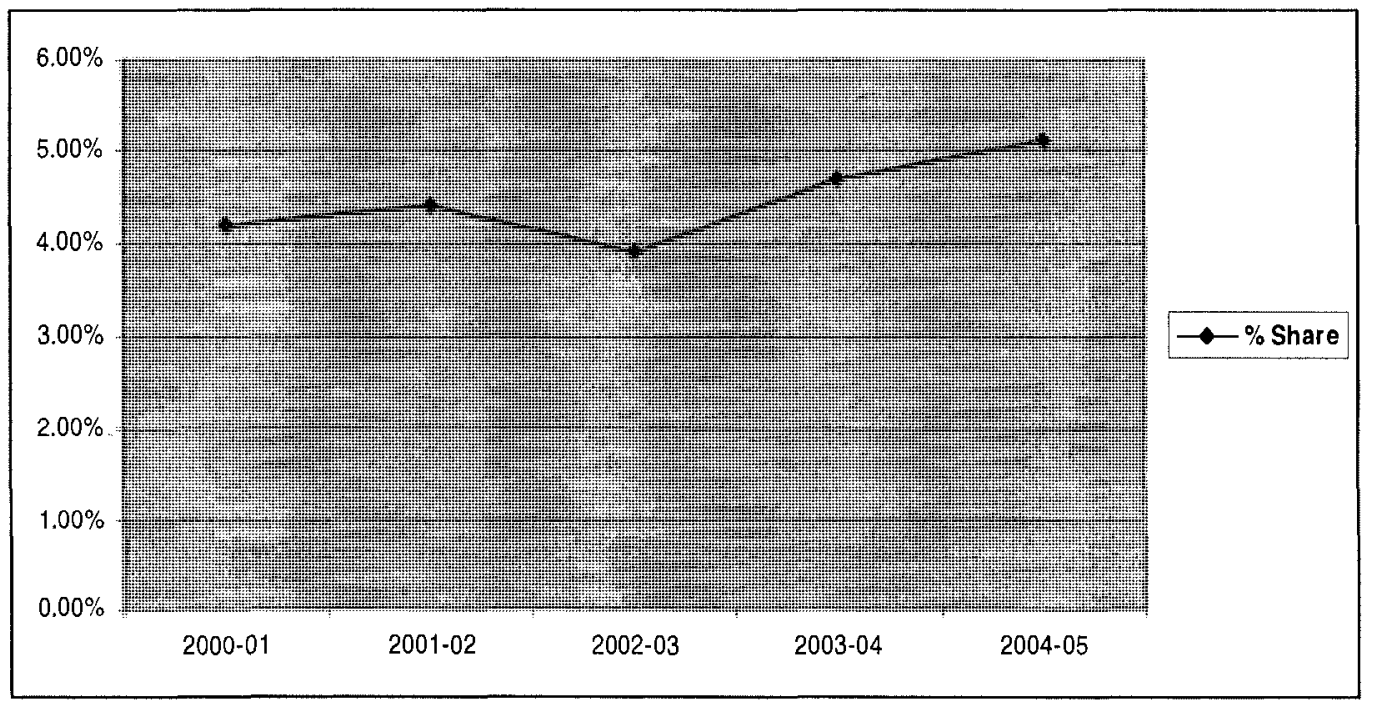

Source: Confederation of Indian Industry Report 2006 
Noida SEZ is the second most successful SEZ in India after the Santa Cruz SEZ in Mumbai. As indicated in Figure 7.3, it contributes $23 \%$ to the total SEZ exports from India. However, it receives only $12.7 \%$ of the total FDI to SEZs, far behind Vishakhapatnam SEZ which receives nearly 40\% of FDI (Noida SEZ website, 2007).

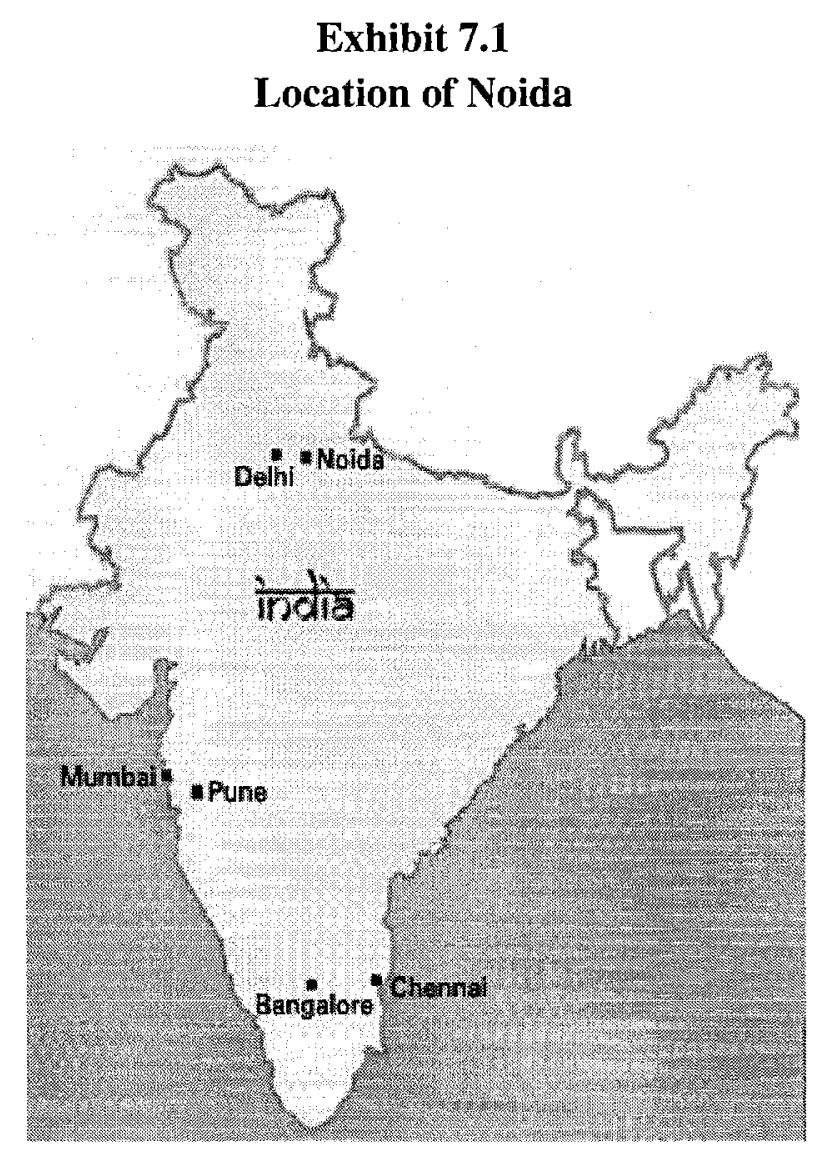

Source: Google Images

Table 7.4 shows the growth of exports from Noida SEZ during the period 2001-02 to 2005-06. It also breaks down the export figures across nine major sectors. The table highlights that exports from the Noida SEZ have increased by $471 \%$ during this period. 
Figure 7.3

Composition of Exports from Indian SEZs

(2004-05)

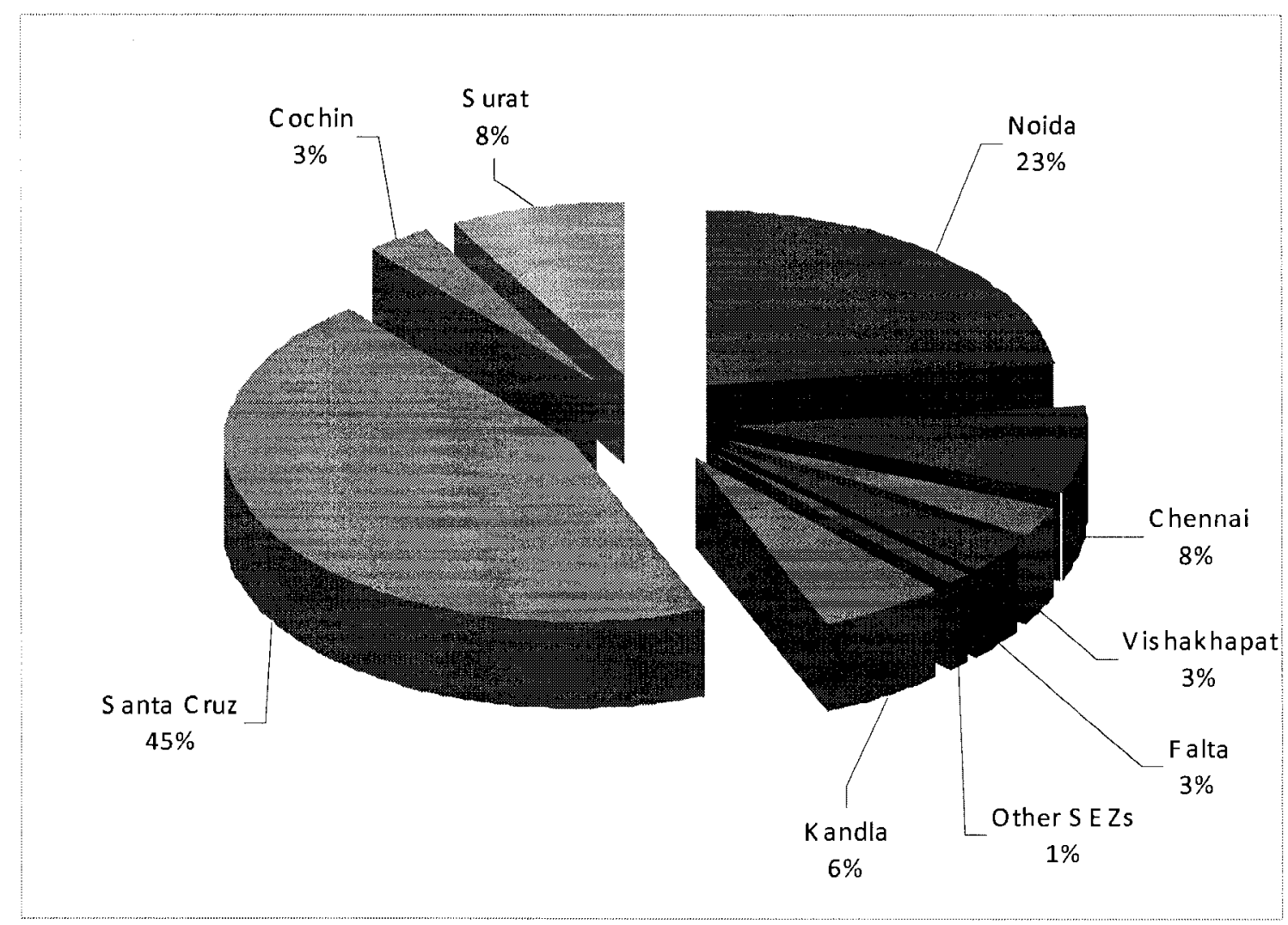

Source: Noida SEZ website 2007

This helps to show that the transformation from an EPZ to an SEZ and the increased focus from the government have yielded positive results.

Figure 7.4 shows the percentage contribution from the nine sectors to the zone's total exports for the year 2005-06. The top three sectors include: gems and jewellery (which accounted for $81.4 \%$ of total exports from Noida in 2005-06), software (5.9\%), and engineering goods (5.1\%). The Noida SEZ is dominated by firms dealing in gems and jewellery, but in the last five years, there has been a steady increase in the number of software firms operating in the zone. 
Table 7.4

Growth of Exports from Noida SEZ by Sector

(Million U.S. \$)

\begin{tabular}{lrrrrr}
\hline Product sector & $\mathbf{2 0 0 1 - 0 2}$ & $\mathbf{2 0 0 2 - 0 3}$ & $\mathbf{2 0 0 3 - 0 4}$ & $\mathbf{2 0 0 4 - 0 5}$ & $\mathbf{2 0 0 5 - 0 6}$ \\
\hline Textile/Garments & 29.47 & 24.33 & 24.22 & 28.52 & 23.44 \\
Hardware & 21.75 & 18.18 & 22.96 & 23.36 & 19.48 \\
Software & 46.86 & $\mathbf{4 3 . 9 3}$ & 52.95 & 116.79 & 82.37 \\
Engineering goods & 29.11 & 33.79 & 40.29 & 57.04 & 71.67 \\
Gem \& Jewellery & 74.13 & 84.51 & 195.91 & 757.02 & $1,131.33$ \\
Chemical \& Pharmaceuticals & 5.08 & 5.85 & 5.54 & 4.18 & 7.56 \\
Leather products & 2.46 & 1.30 & 1.34 & 1.48 & 1.92 \\
Plastic/Rubber/Synthetics & 7.07 & 5.62 & 7.74 & 3.44 & 3.48 \\
Trading \& Miscellaneous & 28.05 & 31.87 & 43.55 & 57.04 & 53.00 \\
& & & & & \\
Total & $\mathbf{2 4 3 . 9 9}$ & $\mathbf{2 4 9 . 3 7}$ & $\mathbf{3 9 4 . 4 9}$ & $\mathbf{1 , 0 4 8 . 8 6}$ & $\mathbf{1 , 3 9 4 . 2 5}$ \\
\hline
\end{tabular}

Source: Compiled from Noida SEZ website 2007 and Confederation of Indian Industry Report 2006

Figure 7.4

\section{Exports from Noida SEZ: Sector Contribution}

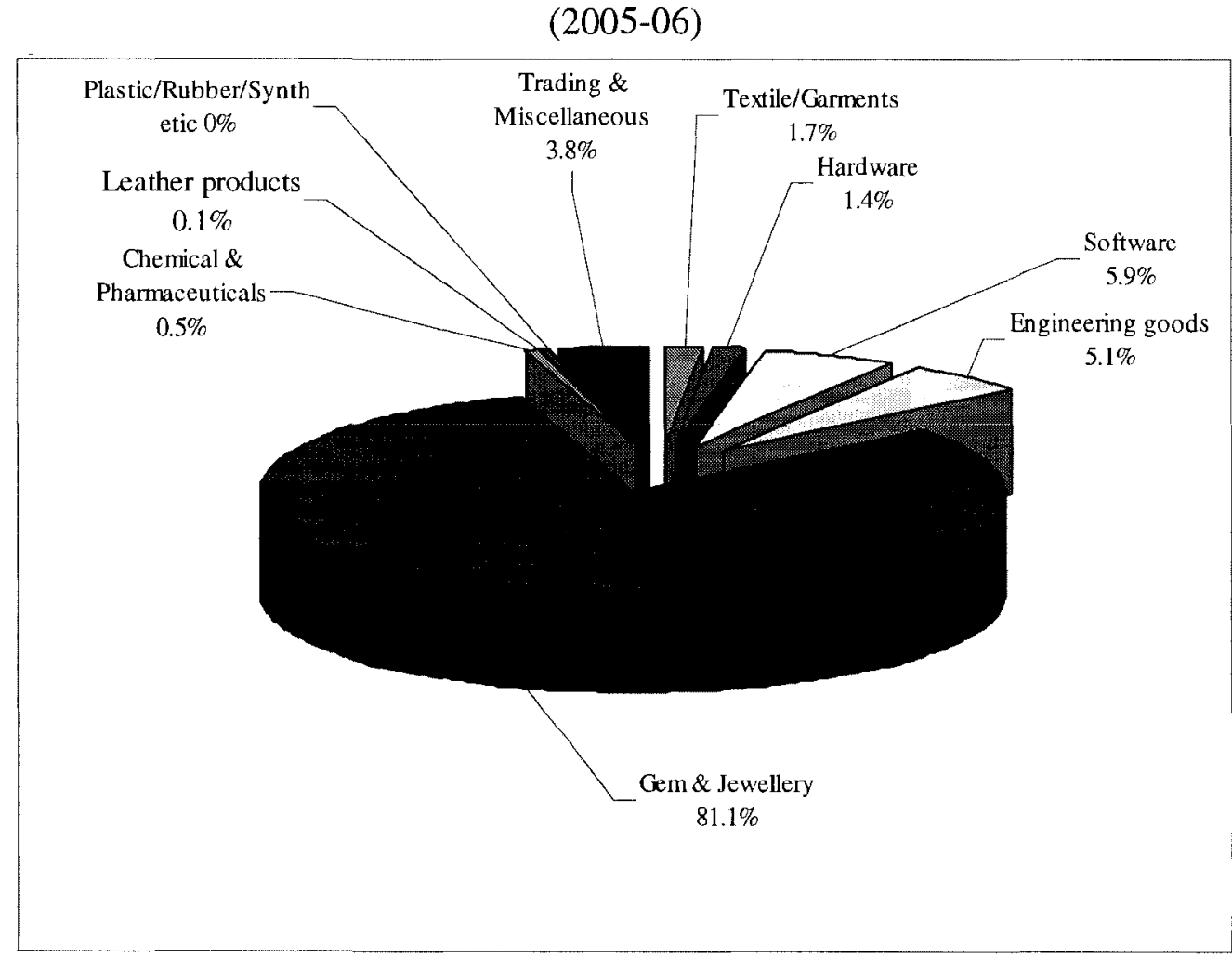

Source: Compiled from Noida SEZ website 2007 and Confederation of Indian Industry Report 2006 
Figure 7.5 shows the percentage of exports from Noida to different countries. U.A.E accounts for the lion's share of Noida's exports at $81.5 \%$, followed by the U.S. at $5.8 \%$. This is an interesting statistic, as it is unlikely that the small U.A.E. population will absorb all exports from Noida. This suggests that exports from Noida are channelled into U.A.E's strategically located FTZs; from here the goods maybe re-exported to different countries. This provides reasonable evidence in support of the argument that firms can combine advantages from individual zones to formulate a global business strategy.

\section{Figure 7.5}

\section{Exports to Different Countries from Noida SEZ}

(2005-06)

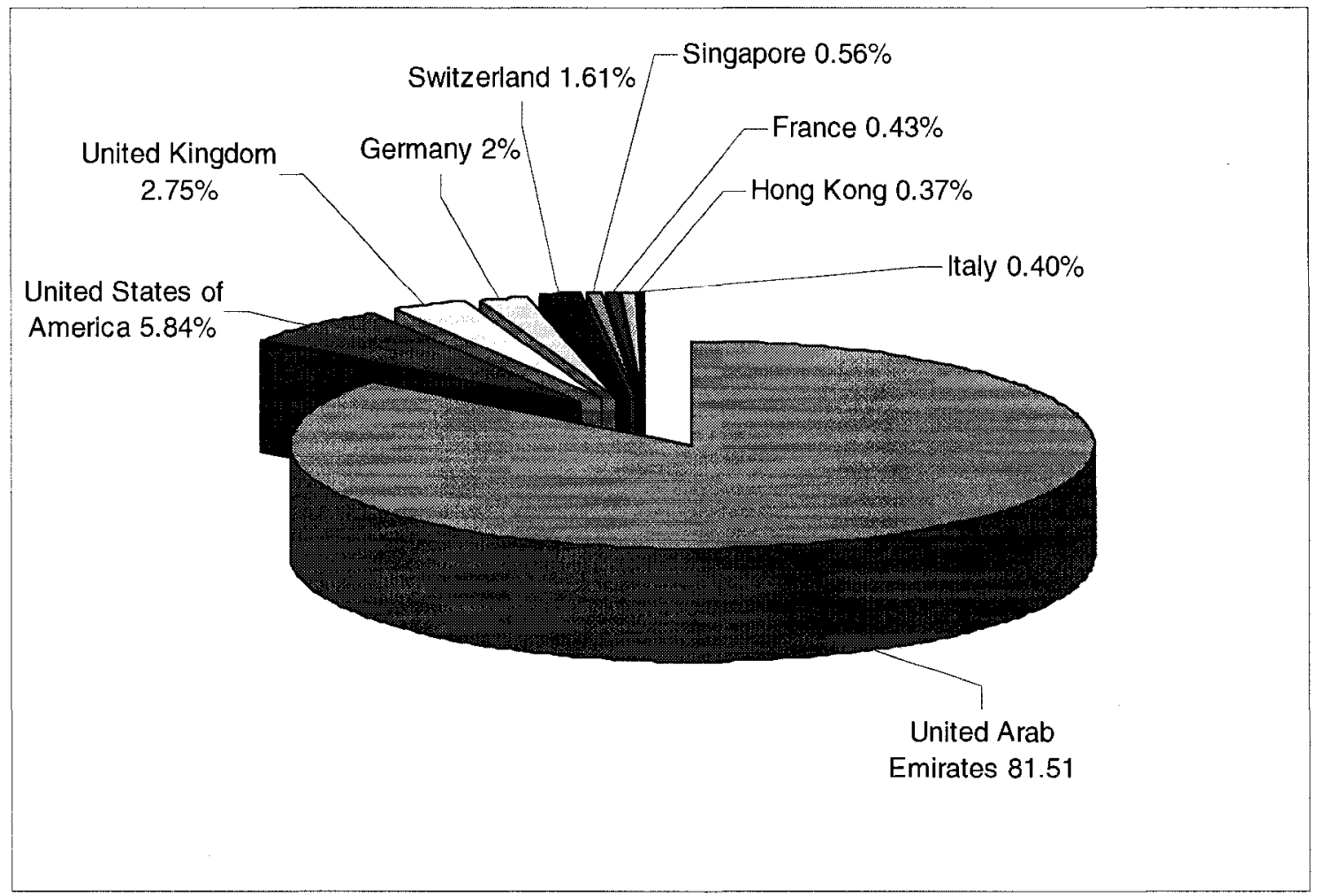

Source: Compiled from Noida SEZ website 2007 and Confederation of Indian Industry Report 2006 
The tenants in the zone import mainly raw materials which accounts for $99 \%$ of the total imports, valued at U.S. $\$ 1,116$ million for the year 2005-06. Given that Noida's exports for the same year were U.S. $\$ 1,394$ million; its export surplus for the year was U.S. $\$ 278$ million.

Noida has also experienced a recent increase in new applications from companies to set up units. The zone's main problem at the present moment is the lack of land space. It has applied to the central and state governments to obtain more land. In 2005-06, it had 156 companies that were in operation, another 270 that had been approved, and 44 that were under implementation (Table 7.5 shows the breakdown across sectors).

Table 7.5

Breakdown across Sectors of Units in Production, Approved, and Implemented (2005-06)

\begin{tabular}{lccc}
\hline Sector & In production & Valid approvals & Under implementation \\
\hline Textile/Garments & 16 & 34 & 8 \\
Electronics Hardware & 20 & 30 & 3 \\
Electronics Software & 18 & 29 & 4 \\
Engineering & 34 & 54 & 10 \\
Chemical/Pharma. & 2 & 4 & 1 \\
Leather \& Sports goods & 3 & 8 & 2 \\
Gems \& Jewellery & 35 & 58 & 8 \\
Plastic/Rubber/synthetics & 4 & 10 & 1 \\
Food \& Agro products & -- & 1 & 1 \\
Miscellaneous & 24 & 42 & 6 \\
Total & $\mathbf{1 5 6}$ & $\mathbf{2 7 0}$ & $\mathbf{4 4}$ \\
\hline
\end{tabular}

Source: Noida SEZ's Internal Documents 2006

Noida SEZ, per 2006 figures, provides jobs to 22,298 employees, of whom 20,378 are men and 1,920 are women. The zone claims to offer inexpensive skilled manpower, 
abundant managerial and technical talent, fully developed infrastructure, uninterrupted power supply, efficient telecom facilities, and local transport services. One of the most attractive features, as claimed by the officials and tenants during interviews, was the single window clearance system. Under this system, applications for setting a unit in the zone are approved under one window and in a time span of only 15 days. Thus, the companies save time and money as they are not required to go to different departments to get approvals, such as customs, electrical, water, and utilities. Another attractive feature of Noida is the on the spot custom clearance. Again, under normal conditions, custom clearance could take up to several months. It also offers satellite data link communication facilities for companies. It offers lucrative financial benefits, most importantly the 15 years tax holiday, which is broken down as follows: $100 \%$ corporate tax exemption for the first five years, and 50\% exemption for the next ten years thereafter. Other financial benefits include (Noida SEZ website 2007):

- Duty free import of capital goods, raw materials, and components.

- Exemption from central excise duty and levies on goods brought from the domestic tariff area (area in India outside the SEZs).

- Exemption of taxes on purchase of goods from the domestic market.

- Exemption from payment of service tax.

- No restriction on foreign share holding and $100 \%$ convertibility of export earnings at market rates.

- Unrestricted remittance of profits and dividends.

- Sub-contracting of production in domestic tariff area or abroad.

- No separate license required for import. 
- Facility to retain up to $100 \%$ of export earnings in a foreign currency account.

Noida SEZ's range of benefits, which comprise mainly of financial, but also includes infrastructure benefits, shows its initiative in offering much beyond the duty free benefits.

\section{Case Profile of Shenzhen Special Economic Zone}

\section{Background on Chinese SEZ Program}

(This section draws partly from Huang (2006), the MBA project that I helped to guide, in addition to the interviews and secondary data collected for the present study.) The creation of an economic area in China was initially proposed by the China Merchants Steam Navigation Company, which suggested that an area in the Guangdong province, close to Hong Kong, be set aside to facilitate business cooperation between the regions. The government initiated the SEZ program by setting up four zones in Shenzhen, Zhuhai, Shantou, and Xiamen, in the year 1980. The fifth SEZ was later set up in Hainan in 1988. All of China's SEZs are located physically close to Hong Kong, Macao, and Taiwan. Proximity was the major reason behind the decision-making of designating the provinces of Guangdong, Fujian, and Hainan for the location of SEZs (Wong \& Chu 1985). This is reflected by the fact that Shenzhen is contiguous to Hong Kong, an industrial and financial centre with a per capita GNP of U.S. $\$ 4,000$ in 1980 (Wong \& Chu 1985). While Zhuhai shares a border with Macao, a well-developed recreational location, Shantou is geographically close to both Hong Kong and Taiwan. Xiamen is the closest mainland town to Taiwan, and Hainan is also geographically close to Hong Kong, but is also easily accessible from Taiwan, Singapore, and Japan. 
Among the initial four SEZs created in 1980, Shenzhen was the biggest. It had an area of 328 square $\mathrm{km}$ when it was established, which was about "one-third the size of Hong Kong and more than one-half the size of Singapore" (Ge 1999). Compared with the Shenzhen SEZ, the other three zones were much smaller. Zhuhai SEZ was about 6.8 square $\mathrm{km}$ while Shantou SEZ had an area of only 1.6 square $\mathrm{km}$. An area of 2.5 square $\mathrm{km}$ was set aside in Fujian province for the Xiamen SEZ (Wall et al. 1996). The establishment of the Hainan SEZ in 1988 gave birth to the largest SEZ in the world. The Hainan SEZ occupied the whole province with an area of 33,907 square $\mathrm{km}$ or $3,339,700$ hectare (Hong Kong Trade Development Council 1990).

State-owned and collective enterprises were the original dominant businesses in all five SEZs, and their investments supported the initial development of the zones (Wall et al. 1996). In addition, the preferential loans and related aid drawn from international financial institutions were another important source of funding (Zhai 1999). In respect to foreign investments, capital from Hong Kong accounted for the largest percentage of the total investments in most SEZs. The second most important source was the Taiwanese investment, except in the case of Zhuhai, where Macao came second (Wall et al. 1996).

Looking at the development of China since 1979, there is no doubt that these five SEZs have contributed in a big way towards the country's economic development. In the last 25 years, these zones have demonstrated remarkable progress in a number of areas.

The share of the national GDP of the five SEZs together has increased from merely $1.36 \%$ in 1985 to $3.97 \%$ in 2002 . Considering that these zones only had less than one percent of China's population, this was a remarkable achievement. The performance of Shenzhen SEZ in terms of GDP growth has surpassed the other zones: the GDP of the 
Shenzhen SEZ in 2002 had increased by more than 828 times compared to that of 1980. Zhuhai and Xiamen have also been successful, with a growth rate of $154 \%$ and $100 \%$, respectively. In addition, the growth rate of the collective GDP of the five SEZs (32.4) surpassed that of the country (10.7) by about $20 \%$ points.

With regard to international trade, the volume of exports from SEZs saw a slow start in the earlier years, but picked up quickly since the late 1980s. In 1989, these zones had collectively amassed U.S. $\$ 3.85$ billion worth of exports (Shenzhen alone accounted for U.S. $\$ 2.17$ billion), which was $10 \%$ of the national figure (Yuan, 1993). Table 7.6 shows that the share of exports from the five SEZs to that of national exports increased from $12 \%$ in 1980 to $21 \%$ in 1995 and to $23 \%$ in 2002 . Another important success parameter has been that these five SEZs have helped to foster technology transfers mainly through the importation of machinery and equipment, introduction of managerial skills, and on-the-job training of the labour force (Yuan 1993). In addition, the spill-over effects brought by these zones have also facilitated advanced technology flow to the nonzone areas.

Table 7.6

Exports from SEZs and their Share of the Total National Exports

(Million U.S. \$)

\begin{tabular}{rrrrrrrr}
\hline Year & Shenzhen & Zhuhai & Shantou & Xiamen & Hainan & Total & \% of Total Exports \\
\hline 1980 & 11 & 13 & 251 & 140 & - & - & - \\
1988 & 1,849 & 421 & 619 & 576 & 290 & 5,744 & 12 \\
1995 & 20,527 & 2,115 & 2,128 & 3,479 & 923 & 31,168 & 21 \\
2002 & 46,557 & 7,634 & 1,570 & 15,187 & 819 & 73,769 & 23 \\
\hline
\end{tabular}

Sources: Compiled with data from (National Bureau of Statistics of China 2005; Shenzhen Statistic Bureau 2005; Statistic Bureau of Hainan Province 2004; Xiamen Statistic Bureau 2003; and Zhuhai Statistic Bureau 2005) 


\section{Salient Features of Shenzhen SEZ}

Shenzhen is a sub provincial city located in a south coastal area of Guangdong province (Exhibit 7.2), facing Hong Kong across the Shenzhen River to the south. The city "connects Dongguan and Huizhou cities to the North, Pinghai Peninsular across the Daya Bay to the east, and Lingding Ocean of Zhuhai Port to the west" (Zhai 1999 p.291). The city covers an area of 2,020 square $\mathrm{km}$, in which 328 square $\mathrm{km}$ belong to the SEZ (Shenzhen Government Website 2007).

There are six county-level districts in Shenzhen, namely Luohu, Futian, Nanshan and Yantian districts, which are in the perimeters of the Shenzhen SEZ, and Bao'an and Longgang districts outside the zone (Zhai 1999). Exhibit 7.3 is a map of the administrative regions of Shenzhen city. The shaded region in the exhibit shows the area under the Shenzhen SEZ.

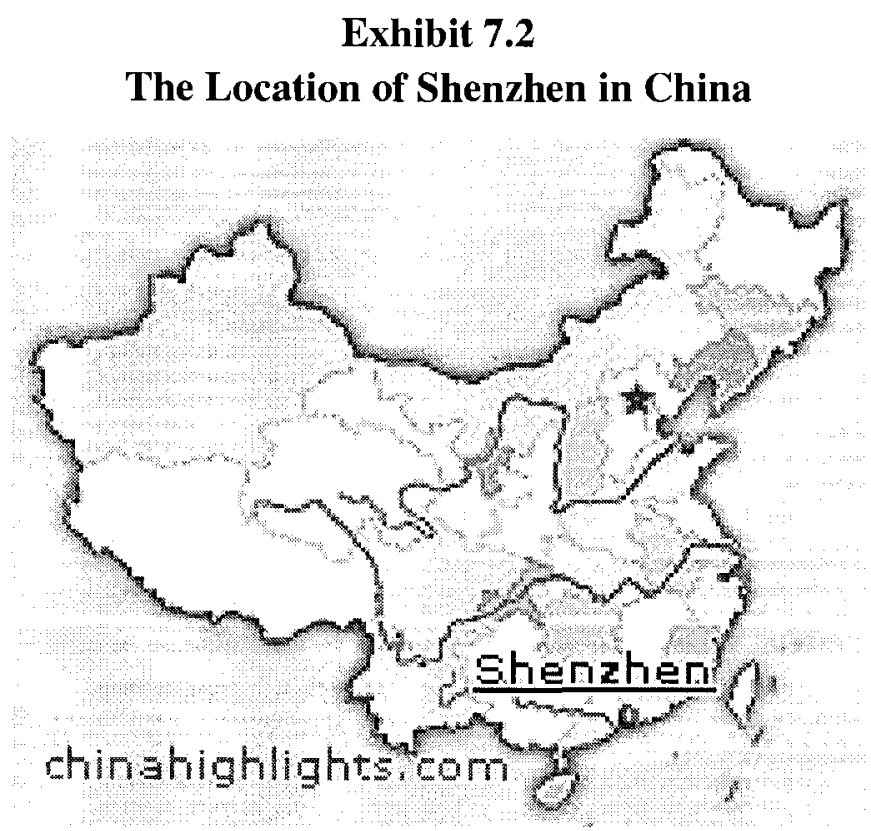


Exhibit 7.3

Districts of Shenzhen

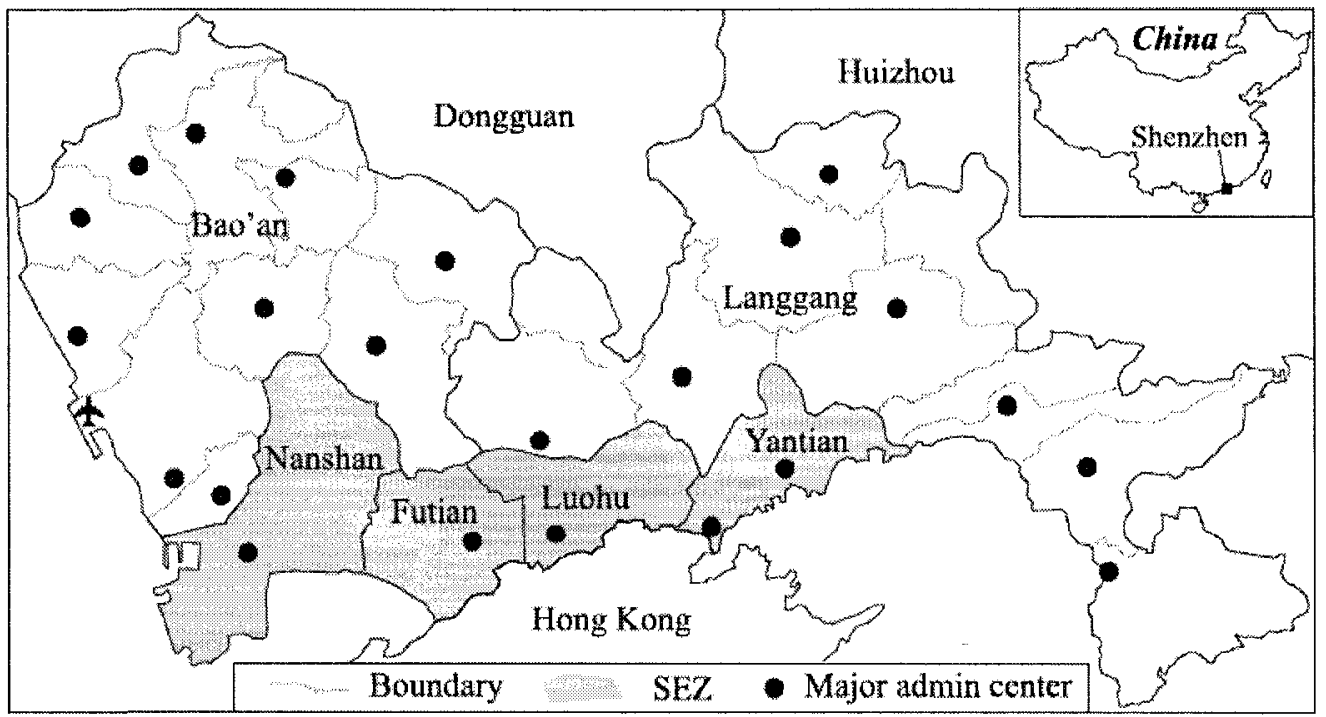

Source: Wang \& Meng 2004

To attract foreign investment to Shenzhen SEZ, the infrastructure facilities of the city have been completely upgraded. Shenzhen owns a well-developed three-dimensional (sea, land and air) transportation network. The completion of Daya Bay Nuclear Power Station has largely relieved Shenzhen's power shortage and enhanced its attractiveness to foreign investment (Mackerras, Taneja and Young 1994). Shenzhen also has an advanced communication system, and one of the two stock exchanges in the country, the other being in Shanghai (Sen 2003).

Table 7.7 lists the real GDP and per capita GDP of Shenzhen SEZ in selected years from 1979 to 2004. Shenzhen SEZ's GDP growth pattern illustrates three distinct phases: the initial phase of construction from 1979 to 1984, the taking off period from 1985 to 1989 , and the acceleration phase from 1989 onwards. 


\section{Table 7.7 \\ Real and Per Capita GDP of Shenzhen SEZ}

(1979-2004)

\begin{tabular}{ccc}
\hline Year & GDP (in million U.S. \$) & Per Capita GDP (in U.S. \$) \\
\hline 1979 & 26 & 80 \\
1980 & 36 & 110 \\
1981 & 65 & 186 \\
1982 & 109 & 266 \\
1983 & 173 & 331 \\
1984 & 308 & 461 \\
1985 & 513 & 633 \\
1986 & 548 & 603 \\
1987 & 736 & 704 \\
1988 & 1,144 & 852 \\
1989 & 1,522 & 1,148 \\
1990 & 2,259 & 1,148 \\
1992 & 4,175 & 1,672 \\
1994 & 8,095 & 2,568 \\
1995 & 10,470 & 3,076 \\
1997 & 14,869 & 4,029 \\
1999 & 18,895 & 4,723 \\
2002 & 29,466 & 6,056 \\
2004 & 45,695 & 7,799 \\
\hline
\end{tabular}

Source: Compiled from the Shenzhen Government website 2007

Shenzhen SEZ's remarkable achievement has attracted worldwide attention. In 2004, the real GDP of Shenzhen SEZ reached U.S. \$45,695 million with an average annual growth rate of approximately 53\% during the period from 1979 to 2004 . While the national economy expanded at an annual average rate of $9.6 \%$ from 1981 to 1993 , Shenzhen SEZ grew at an astonishing $40 \%$ per annum over the same period, surpassing the former with more than 30\% points (Ge 1999). Such phenomenal economic growth has rarely been found in any other region around the world. 
Figure 7.6 plots Shenzhen's exports and imports in selected years from 1990 to 2004. The total of exports and imports increased from U.S. $\$ 16.8$ million in 1979 to U.S. $\$ 147$ billion in 2004 (Table 7.8). As indicated by Table 7.8, the expansion in imports surpassed that in exports leading to trade deficits in initial years, but Shenzhen now enjoys a trade surplus.

Figure 7.6

Value of Shenzhen's Exports and Imports

(Million U.S. \$)

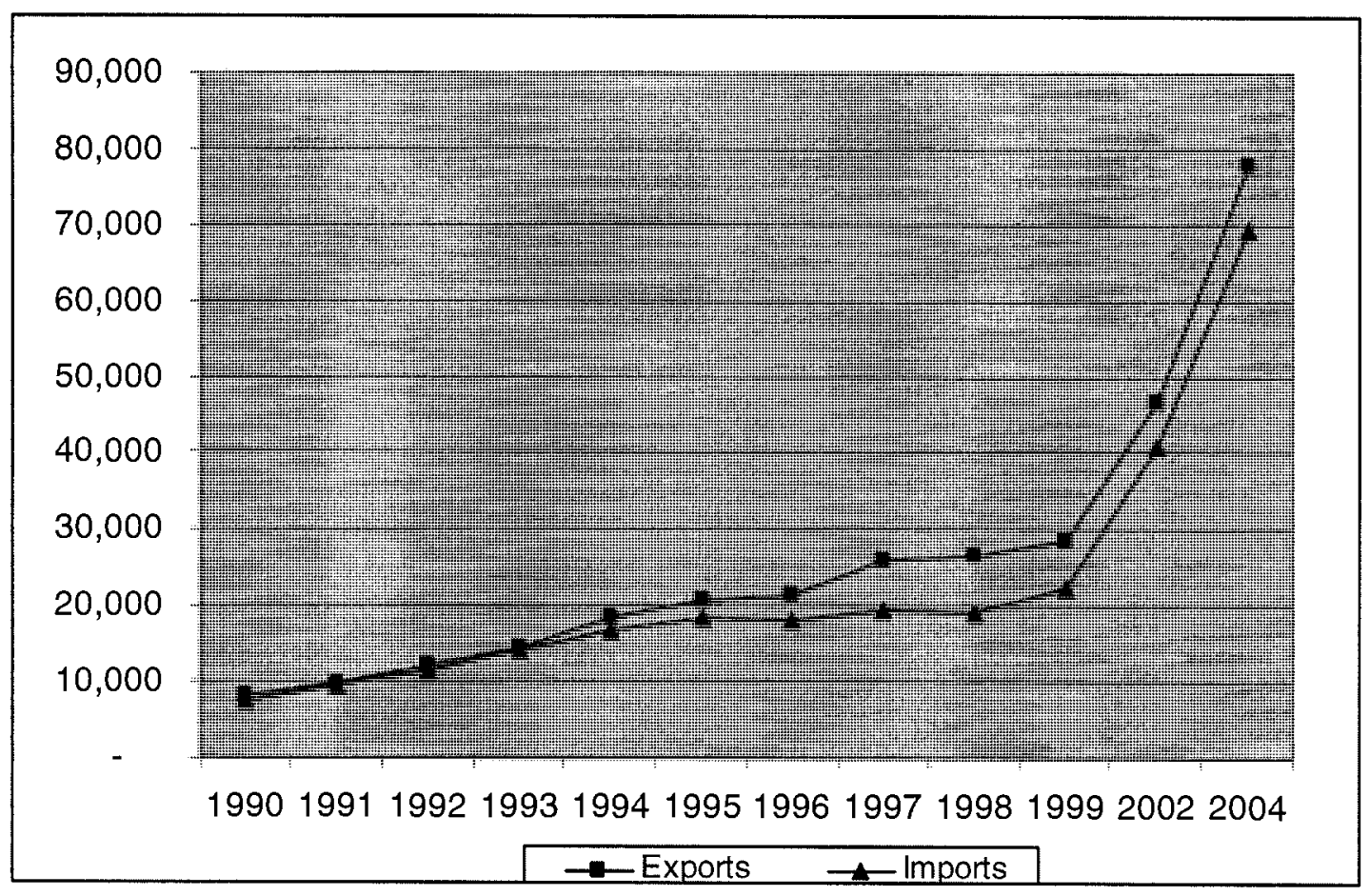

Source: Compiled from the Shenzhen Government website 2007

FDI into Shenzhen SEZ has increased from U.S. $\$ 177$ million to U.S. $\$ 3,191$ million in 2002, and accounted for $6 \%$ of total FDI into China in 2002 (Table 7.9). These numbers show the prominent role that Shenzhen SEZ plays in the growth of the Chinese economy. 
Table 7.8

Value of Shenzhen's Exports and Imports

\begin{tabular}{rrrr}
\multicolumn{4}{c}{ (Million U.S. \$) } \\
\hline Year & Export & Import & Difference \\
\hline 1979 & 9 & 7 & 2 \\
1980 & 11 & 6 & 5 \\
1981 & 17 & 11 & 7 \\
1982 & 16 & 9 & 7 \\
1983 & 62 & 724 & $(662)$ \\
1984 & 265 & 807 & $(542)$ \\
1985 & 563 & 743 & $(180)$ \\
1986 & 726 & 1,121 & $(396)$ \\
1987 & 1,414 & 1,144 & 269 \\
1988 & 1,849 & 1,593 & 256 \\
1989 & 2,174 & 1,578 & 596 \\
1990 & 8,152 & 7,550 & 602 \\
1991 & 9,862 & 9,614 & 248 \\
1992 & 12,000 & 11,575 & 425 \\
1993 & 14,218 & 13,986 & 232 \\
1994 & 18,309 & 16,674 & 1,636 \\
1995 & 20,527 & 18,242 & 2,285 \\
1996 & 21,208 & 17,846 & 3,362 \\
1997 & 25,618 & 19,391 & 6,228 \\
1998 & 26,396 & 18,878 & 7,518 \\
1999 & 28,208 & 22,219 & 5,989 \\
2002 & 46,557 & 40,674 & 5,883 \\
2004 & 77,864 & 69,437 & 8,427 \\
\hline
\end{tabular}

Source: Compiled from the Shenzhen Government Website 2007

Note: The figures in parentheses are negative

Shenzhen SEZ has developed into arguably the most successful FTZ in the world, and has become a success story that other zones across the globe are trying to imitate. 
Table 7.9

FDI Inflows to Shenzhen SEZ

\begin{tabular}{lrc}
\hline Year & Shenzhen (in mill. U.S. \$) & Share of National FDI \\
\hline 1985 & 177 & $11 \%$ \\
1986 & 361 & $19 \%$ \\
1987 & 265 & $11 \%$ \\
1988 & 259 & $8 \%$ \\
1989 & 271 & $8 \%$ \\
1990 & 349 & $10 \%$ \\
1991 & 335 & $8 \%$ \\
1992 & 322 & $3 \%$ \\
1993 & 672 & $2 \%$ \\
1994 & - & - \\
1995 & 1,310 & $3 \%$ \\
1996 & 2,050 & $5 \%$ \\
1997 & 1,660 & $4 \%$ \\
1998 & - & - \\
1999 & - & - \\
2000 & - & - \\
2001 & 2,590 & $6 \%$ \\
2002 & 3,191 & $6 \%$ \\
2003 & - & - \\
2004 & - & - \\
\hline
\end{tabular}

Source: Compiled from the Shenzhen Government website 2007

\section{Case Profile of New Orleans Foreign Trade Zone}

\section{Background on the U.S. Foreign Trade Zone Program}

The U.S. government set up Foreign Trade Zones to offer special customs advantages to domestic firms engaged in international trade-related activities. The primary reason was to offer a level playing field to domestic companies who compete against overseas producers that receive customs advantages (National Association of Foreign Trade Zones Report 2003). This supports the argument that the U.S./FTZs, unlike SEZs or EPZs, were 
created for domestic manufacturers and not to attract foreign investments. There are at present 272 general purpose zones and 502 approved subzones (U.S./FTZB 2007). However, the 2005 annual report on the U.S.FTZs states that only 158 general purpose zones and 256 subzones were active during that year, that is, the remaining zones did not receive any clients for that year. This suggests that, perhaps facilitated by the legal regime governing U.S. zones, both tenants and zone operators may be seeing them as transient facilities (unlike, for example, SEZs, where company investments are seen as more permanent).

The general purpose zones were set up for different activities, and are generally located within 60 miles from a U.S. customs port of entry (National Association of Foreign Trade Zones Report 2003). These zones may consist of one or multiple sites such as, a stand-alone building, an industrial park, a water port, or an international airport. The most common activities at these zones are storage, inspection, and distribution, while other activities such as processing or manufacturing require special approval from the Foreign Trade Zone Board. The general purpose zones and subzones are similar on legal grounds, but generally subzones are set up for individual companies' manufacturing operations. As the formation and expansion of the U.S./FTZs were already discussed in Chapter 3 ("Import-Oriented Zones"), this section concentrates on some key statistics on the U.S. zones.

Designation as a Foreign Trade Zone is granted by the U.S./FTZB, which is an independent agency reporting to the U.S. Department of Commerce. The other federal agency involved in the zone program is the Bureau of Customs and Border Protection, Department of Homeland Security (formerly the U.S. Customs Service). The Customs 
Port Director where the U.S./FTZ is located is the local representative of the Foreign Trade Zone Board.

Several key indicators, such as the dollar value of shipments to and of exports from zones, number of jobs associated with zones, and number of private firms actively engaged in zone activities, suggest that the Foreign Trade Zone program is clearly benefiting the U.S. economy and strengthening its international economic competitiveness. The total value of shipments into general purpose zones and subzones amounted to U.S. $\$ 410$ billion (2005), in comparison to U.S. $\$ 305$ billion for the previous year (2004, Table 7.10). Out of the total shipments received in 2005, general purpose zones received only U.S. $\$ 69$ billion in merchandise, while total shipments received at subzones were U.S. \$341billion (Table 7.10). This shows that nearly $83 \%$ of zone activity took place at subzone facilities, which is the general trend over the past 15 years.

\section{Table 7.10}

Value of Shipments into Foreign Trade Zones

\begin{tabular}{lcc}
\multicolumn{3}{c}{ (Billion U.S. \$) } \\
\hline Merchandise Received & FY 2005 & FY 2004 \\
\hline General purpose zones & 69 & 48 \\
Subzones & 341 & 258 \\
Total & 410 & 306 \\
\hline Source: U.S./FTZB Annual Report 2007 &
\end{tabular}

Exports from the U.S./FTZs amounted to U.S. \$23 billion (Figure 7.7). These do not include certain indirect exports involving the U.S./FTZ merchandise that undergoes further processing in the United States at non-zone sites prior to export. Approximately 340,000 persons were employed at nearly 2,500 firms that operated in the zones during 
Figure 7.7

Foreign Trade Zones: Merchandise Received

(General Purpose Zones and Subzones)

$(1985-2005)$

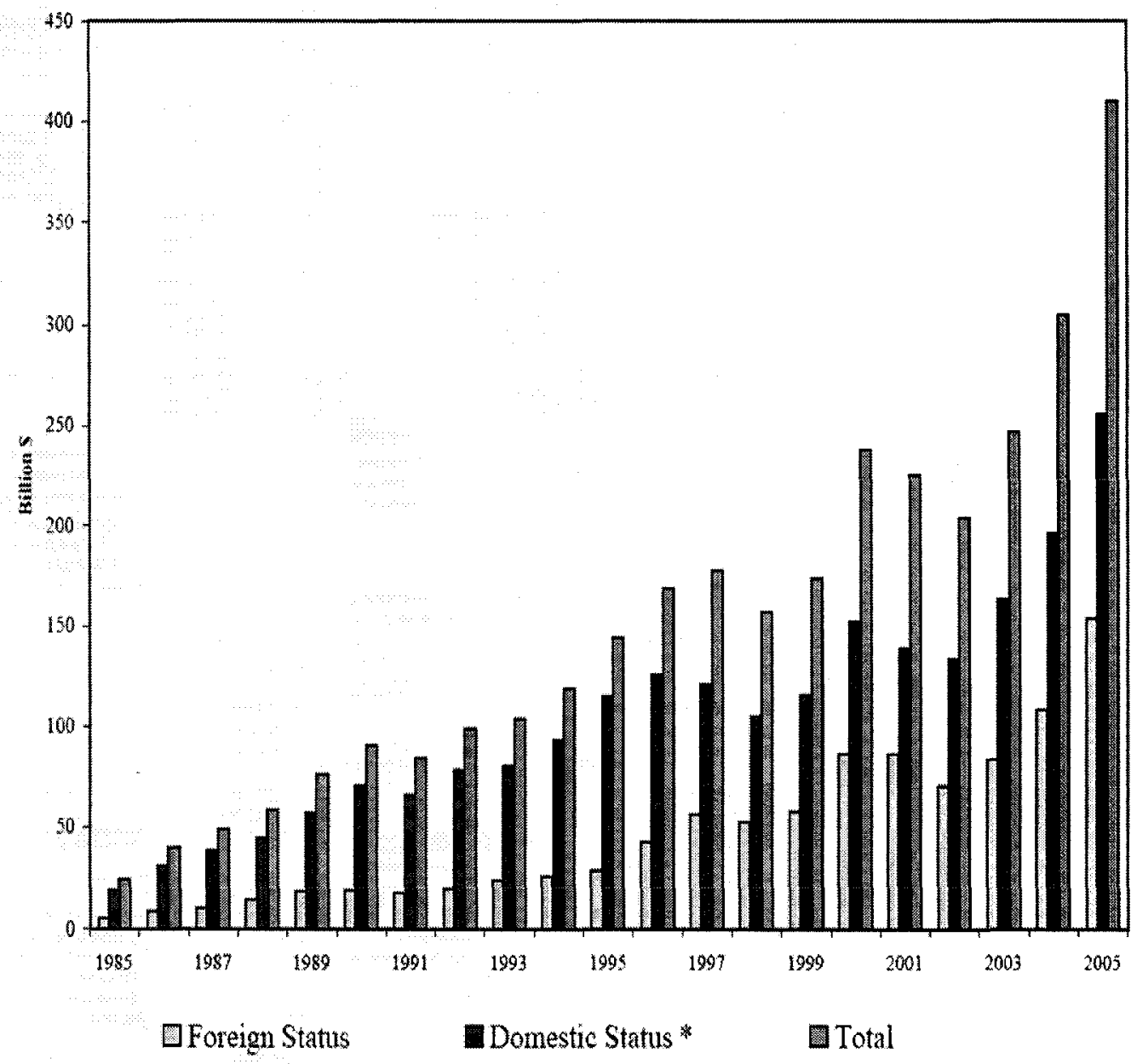

Source: U.S./FTZB Annual Report 2007

*Domestic Status merchandise is mainly merchandise of domestic origin, but includes some foreign-origin goods on which customs entry and duty payments have been made prior to their entering the zones. 
Figure 7.8

Foreign Trade Zones: Exports

(General Purpose Zones and Subzones)

$(1985-2005)$

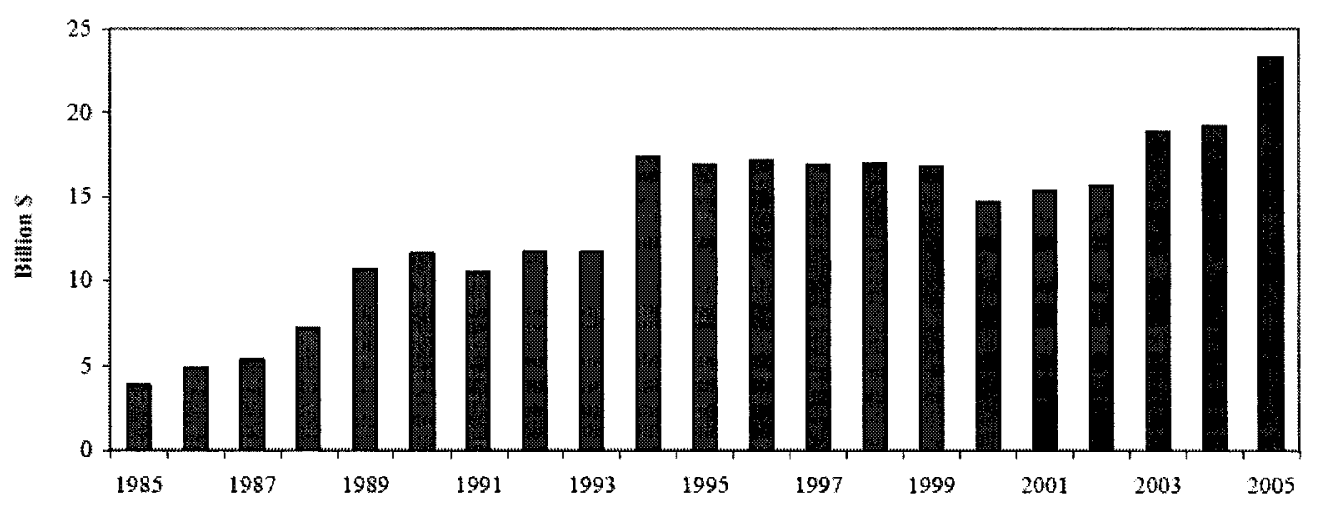

Source: U.S./FTZB Annual Report 2007

2005 (U.S./FTZB Annual Report 2007). The principal foreign-origin products received at zones that account for most zone manufacturing activity included the oil refining, automotives, pharmaceuticals, and electronics. Nearly $62 \%$ of the merchandise received at zones in 2005 involved domestic status merchandise. The high level of domestic status merchandise received at zones demonstrates that the U.S./FTZ operations tend to include domestic companies that combine foreign inputs with substantial domestic inputs.

Per the National Association of Foreign Trade Zones, zones in Texas top the lists of volume of merchandise received, employment generated, exports to foreign countries, and number of firms engaged, among the states in the U.S. On average, the zones in the U.S. engage much fewer firms at a given time, around 10 to 15 , in comparison to EPZs and SEZs. 


\section{Salient Features of New Orleans Zone}

The New Orleans Foreign Trade Zone is also referred to as Foreign Trade Zone \# 2, as this was the second zone to be set up in the U.S. It was established in 1946. The New Orleans zone is presently operated by the Board of Commissioners of the port of New Orleans, Louisiana, also known as the Grantee of zone \# 2. The Port of New Orleans has been an important international port for more than a century (Port of New Orleans website 2007). The Port of New Orleans is in the midst of one of the most active port complex in the world - Louisiana's Lower Mississippi River (Wilkipedia 2007). It is also the fifth biggest port in the U.S., when compared on volume of cargo handled (Port of New Orleans website 2007, Wikipedia 2007); and it is served by "six class-one railroads" (Port of New Orleans website 2007). This gives port users fast and economical connections to places within and outside the country.

In stark comparison to other zones around the world, the U.S./FTZs have more than one site. For instance, the New Orleans zone presently has seven sites spread across the city (Port of New Orleans website 2007).

- Site 1: (3 acres), located on the north bank of the Mississippi River in New Orleans. This is an "open yard space" operated by the Port of New Orleans.

- Site 2: (76 acres), located on the Inner Harbor Navigation Canal and the Mississippi River Gulf Outlet, operated by Dupuy Storage and Forwarding Company.

- Site 3: (573 acres), also known as the New Port Industrial Park, located on the Mississippi River Gulf Outlet at Bayou Bienvenue. 
- Site 4: (4 acres), located adjacent to the Louis Armstrong International Airport, operated by the Lacour Warehousing, Inc.

- Site 5: (182 total acres), six general purpose operators manage 37 warehouse sites in the Metro New Orleans area.

- Site 6: (136 acres), located at the Arabi Terminal and Industrial Park.

- Site 7: (216 acres), located at the Chalmette Terminal and Industrial Park.

Sites 6 and 7 have only been added during the last fiscal year (2006-07).

Additionally, New Orleans has 5 manufacturing subzones as follows:

1. ExxonMobil Corporation

2. Murphy Oil

3. Northrop Grumman Avondale Operations

4. ConocoPhillips Company

5. Trinity Yachts

It is interesting to note that a number of sites are run by private operators, an arrangement very different from what we see in other zones. The Port of New Orleans has designated a manager which overlooks the contract arrangements with these operators. The operators are responsible for attracting clients to their sites. Most of these seven sites are currently used as warehouse facilities; most of the clients are operational only for a brief part of the year. That is, they may bring in goods to store at the facility for a given month in the year, and then may not come back, or only come back the following year. It is rare to find clients that are operational throughout the year at these sites. 
Operators essentially handle the marketing and promotion of their sites. The U.S./FTZ Board seeks expansion in zone activities through established regional economic development, and does not employ an outside sales effort or media reach.

The New Orleans zone is still reeling with the aftermath of hurricane Katrina, as it lost many clients in the last two years following the hurricane. The zone primarily provides warehousing facilities for primary metals, such as copper and zinc. Thus, the composition and operation of the zone remains uncertain in the face of a cyclical primary metals world trade.

New Orleans zone served 75 business firms during fiscal year 2005. Of these only 38 used the zone on a continuous basis, employing up to 164 persons, 75 of whom were full-time employees ((Port of New Orleans website 2007). The number of business firms was drastically reduced in the following year due to the hurricane. During the interviews, it was realized that apart from two sites, the remaining sites had from zero to very few business clients.

\section{Case Profile of Jebel Ali Free Zone}

\section{Background on Dubai's Free Trade Zone Program}

Dubai's main goal to develop free trade zones was to attract foreign direct investment. With the success of the Jebel Ali Free Zone, which started its operation in 1985, several other free zones have so far been established in Dubai, each catering to very special sectors and economic activities, namely, the media, car and automotive, information technology, jewellery, and metals industries. The Dubai authorities have provided zone tenants with modern transport and telecommunication facilities, and global markets for 
goods and services. Businesses locating in these zones enjoy tax cuts, business incentives, and world-class resources and facilities that are otherwise not available in the regular domestic mainland. In addition, those in the free zones can also enjoy the favourable features of the host country.

Today, apart from Jebel Ali Free Zone, several other free zones have been or are being established in Dubai, catering to specialized types of businesses. For example, located within the Dubai International Airport is the Dubai Airport Free Zone, established in 1996, which attracts firms dealing in high-value, low-volume products that need immediate access to markets (Dubai Chamber of Commerce and Industry 2004). The Dubai Media City, established in 2001, is partner to about 500 media companies and professionals, while the Dubai Internet City, established in 2000, hosts companies in information technology and technology-related services (Dubai Chamber of Commerce and Industry 2004). The Dubai Cars and Automotive Zone, established in 2000, deals in re-exporting used cars and vehicles, while more recently, the Dubai Metals and Commodities Centre has been established for businesses in metal and related activities (Dubai Chamber of Commerce and Industry 2004). The modern and highly efficient telecommunication facilities of Dubai provide the ideal environment to attract international companies to these zones.

Dubai Chamber of Commerce and Industry controls the functioning of all free zones in the country. According to its latest report released on Dubai's Free Zones in 2004, the key trade statistics are:

1. Majority of the imported products into the free zones are either directly re-exported or eventually re-exported after some processing. 
2. Total trade from free zones in 2002 totalled U.S. $\$ 19$ billion, which is an increase of more than $300 \%$ over the 1995 value of U.S. $\$ 6$ billion.

3. Imports into free zones totalled U.S. $\$ 10.49$ billion in 2002 , while exports for the same year were U.S. $\$ 8.81$ billion, leading to a trade deficit of U.S. $\$ 1.68$ billion.

4. Jebel Ali Free Zone continues to dominate foreign trade among the free zones.

5. In 2002, Japan topped the list of suppliers of products to the free zones, accounting for $14 \%$ of total imports. Other major suppliers were China $(9 \%)$, the U.S. (8\%), South Korea (7\%), and United Kingdom and Malaysia (6\%, each). Germany, India, France and Belgium completed the list of the top 10 suppliers.

6. In 2002, Saudi Arabia topped the list of major destinations of the free zones' exports/re-exports receiving almost $15 \%$ of the total value. Iran ranked second (13\%), followed by Hong Kong, Kuwait, and India.

7. Trade routes from Japan and to Saudi Arabia were the busiest. Iran and the U.S. followed.

8. The highest trade surpluses were from Asian markets.

9. The largest trade deficit is recorded for Japan, followed by China, South Korea and Malaysia.

10. Automatic data processing machines and accessories, transmission/communication apparatus, non-industrial diamonds, motor vehicles and parts and accessories, petroleum oils and oils from bituminous minerals and raw cane sugar in solid form comprise the major imports. 
The above statistics highlight two main aspects. First, the free zones in Dubai have grown both in number and importance in its positive impact on Dubai's overall economy. Second, point one above highlights the view that the Dubai zones are largely used by companies for trade-related activities, and not for manufacturing like the Export zones, or primarily for import like the Import zones in the U.S.

\section{Salient Features of Jebel Ali Free Zone}

Jebel Ali Free Zone is the first and the biggest free zone in Dubai. Inside the zone is the Jebel Ali Port, the largest man-made port in the world (Jebel Ali Free Zone website 2007). The port is equipped with world-class shipping facilities that can handle "large container ships, car carriers, bulk carriers, and other general and specialized cargo vessels" (Jebel Ali Free Zone website 2007). A network of modern roads and highways, feeder vessels, and airport connects the port to domestic, Middle Eastern, South Asian and African markets (Jebel Ali Free Zone website 2007). The zone, set up in 1985, is spread across 140 square $\mathrm{km}$, and is strategically located close to prime markets in Saudi Arabia, Oman, Iran, Pakistan, India, and on a principal trade route to China (Exhibit 7.4).

In 1996, Jebel Ali Free Zone became the first free zone in the world to be awarded the ISO 9001:2000 certification (Jebel Ali Free Zone website 2007). The certification implies that the zone has adopted quality management systems, and has consistent business procedures. Jebel Ali, which started in 1985 with just 19 companies, is now a successful zone with nearly 6,000 companies from over 140 countries around the world (Dubai Chamber of Commerce and Industry 2004). It also boasts a sizable multinational workforce, and is host to over 125 of the Fortune Global 500 companies. 


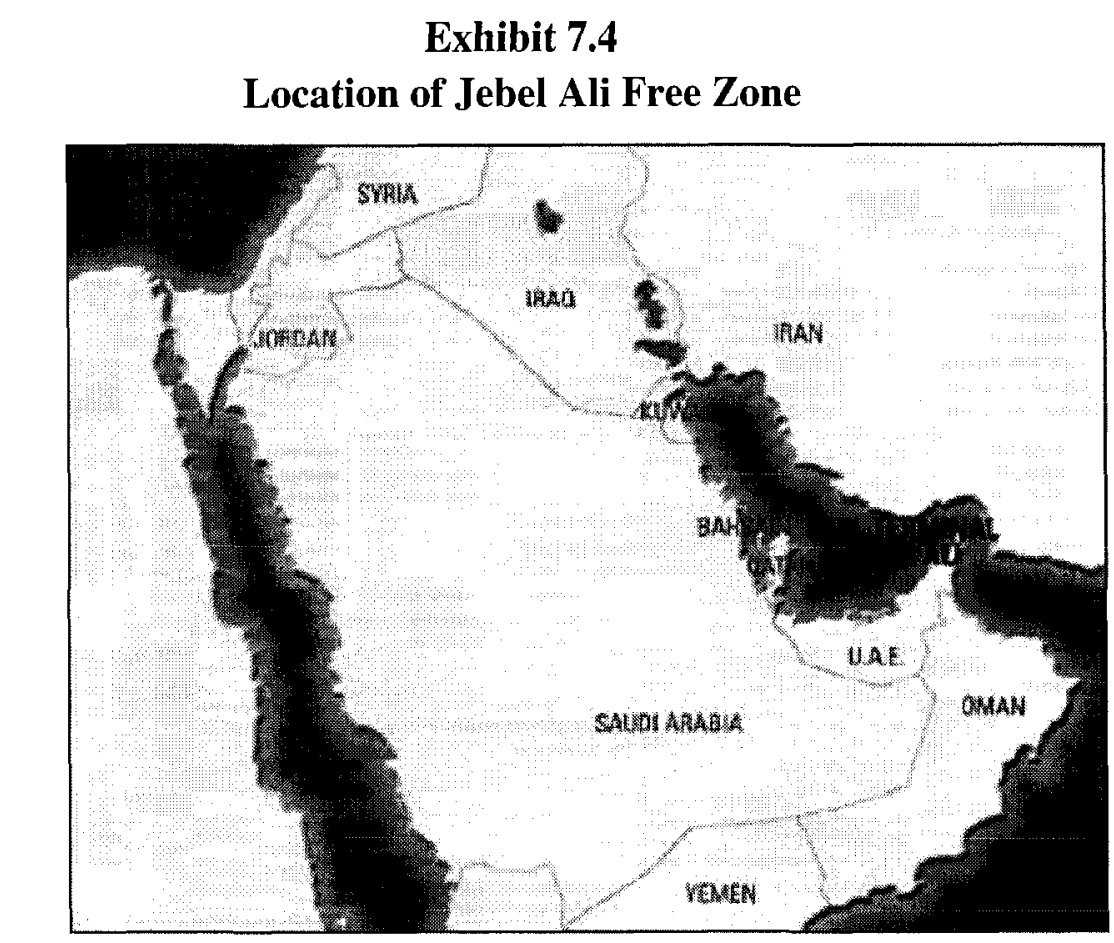

Source: Google Images

Figure 7.9 provides a breakdown of company demographics at the Jebel Ali Free Zone for the year 2006. The figure shows that Middle East accounts for nearly half of the companies that operate in the zone, that is, nearly 3,000 companies come from the surrounding regions. Similar to the Shenzhen SEZ, the Jebel Ali zone too highlights the importance of location to nearby countries. Another interesting observation from this figure is the large share of European companies (at 21\%) in the zone. This would highlight that the Jebel zone is strategically located for a number of European companies to store and later sell their products to a vast Middle East and South Asian markets in close proximity to the zone. It should be noted that Asia in the figure signifies all countries after excluding the Middle Eastern countries. 
Figure 7.9

Company Demographics at Jebel Ali Free Zone

(2006)

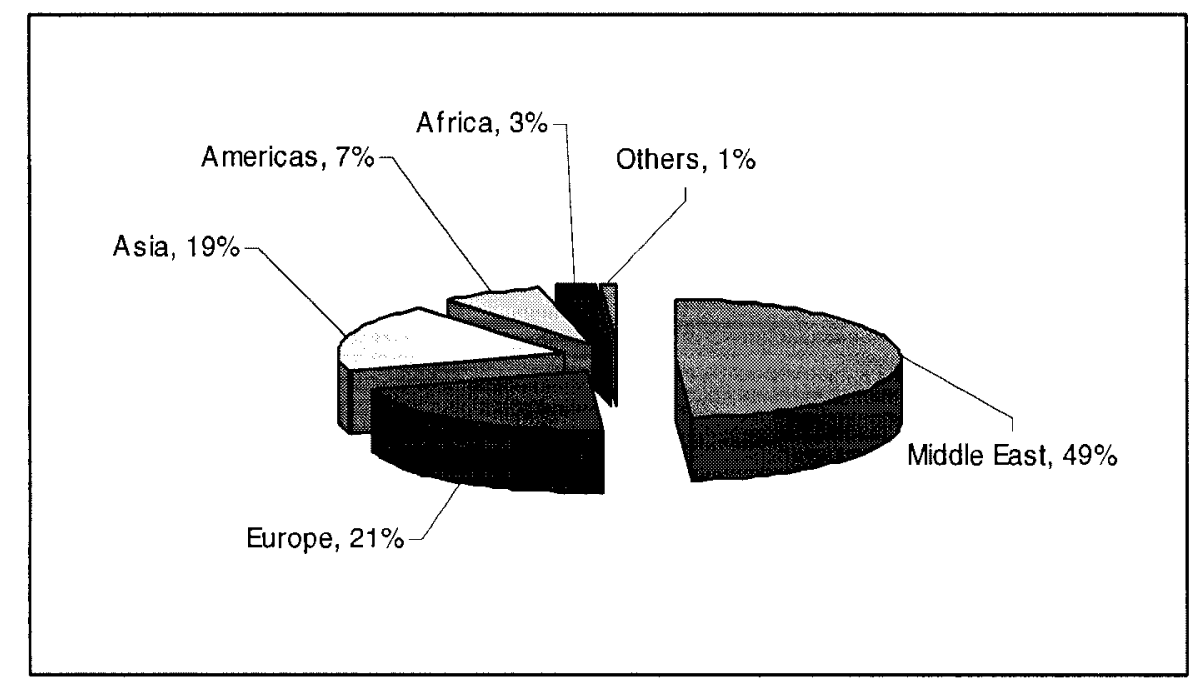

Source: Jebel Ali Free Zone Association corporate brochure 2007

Figure 7.10, which shows the breakdown of activities at the zone, again strongly supports the fact that the Jebel zone is primarily a Trade oriented zone, where $77 \%$ of the activities are trade related.

In terms of trade, Jebel Ali continues to dominate foreign trade by free zones in Dubai, accounting for more than $80 \%$ of the total value of goods traded with the rest of the world. The presence of newly specialized free zones has actually lead to Jebel Ali's share declining from nearly $90 \%$ in 2001 to about $84 \%$ in 2002 (Dubai Chamber of Commerce and Industry 2004). Nevertheless, it is expected to remain the key zone in Dubai. The zone recorded U.S. $\$ 13$ billion in trade volume for the fiscal year ending 2006 (Jebel Ali Free Zone Association corporate brochure 2007). 
Figure 7.10

\section{Activities at Jebel Ali Free Zone}

(2006)

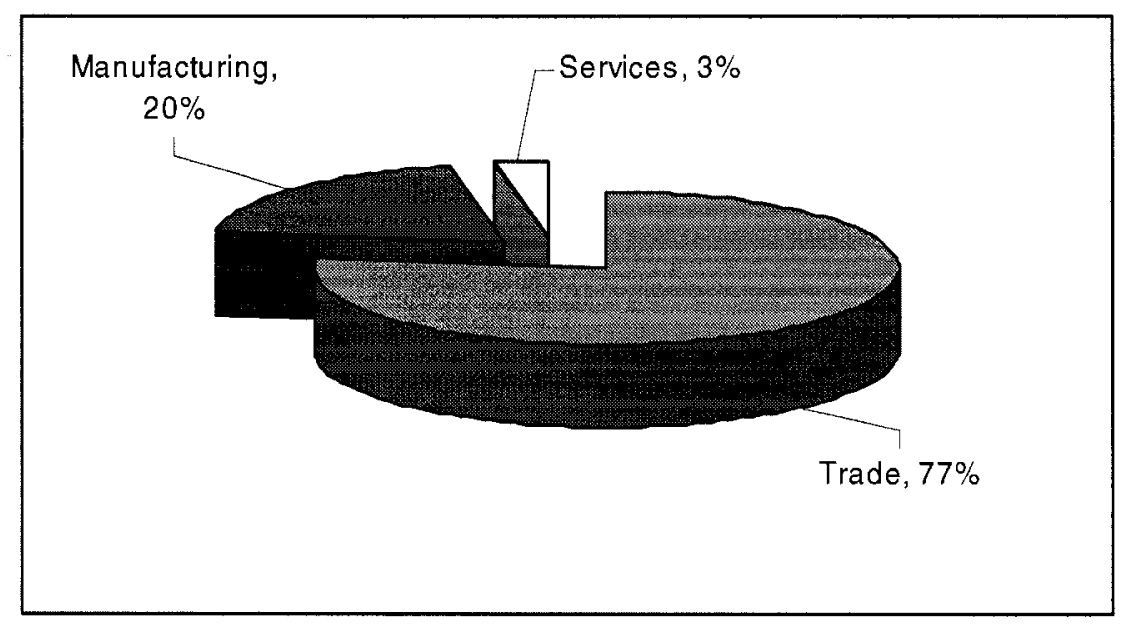

Source: Jebel Ali Free Zone Association corporate brochure 2007

\section{Principal Findings}

The findings are presented under ten main themes. The results are based on the analysis of data originating from five main inputs: in-depth interviews, leave-behind questionnaires from zone officials and zone tenants, and secondary information collected from the zones. As noted earlier, the ten themes relate to and answer the research questions that were put forth during the conceptualisation of this phase (please see Chapter 4 under the "FTZ Characteristics" section). The summary findings below are supported, where necessary and useful, by citing direct quotations from the interviews.

\section{Zone Establishment}

Table 7.11 presents the main reasons for establishing the four zones, and leads to a number of interesting general observations. 
Table 7.11

Reasons for Establishing Zone

\begin{tabular}{|c|c|c|c|c|}
\hline Factors & Dubai & New Orelans & Noida & Shenzhen \\
\hline Attract Investment & $\checkmark$ & $\sqrt{ }$ & $\sqrt{ }$ & $\sqrt{ }$ \\
\hline Generate Employment & & $\sqrt{ }$ & 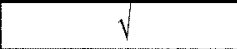 & \\
\hline Promote Exports & $\sqrt{ }$ & & $\sqrt{ }$ & $\sqrt{ }$ \\
\hline Help to Improve Local Skills & & & $\sqrt{ }$ & $\sqrt{ }$ \\
\hline Encourage Linkages with Local Firms & & & & $\sqrt{ }$ \\
\hline Development of Backard Areas & & & $\sqrt{ }$ & \\
\hline Accelerate Economic Development & $\sqrt{ }$ & & $\sqrt{ }$ & $\sqrt{ }$ \\
\hline Other Reason - 1 & Promote Trade & Source of raw materials & Skill transfer & Attract advanced technology \\
\hline Other Reason - 2 & Avoid laws & & Meet financial crisis & Help HongKong to return \\
\hline
\end{tabular}

First, there seems to be some variation across the zones in the reason for which they were established. As noted through the interviews, the Dubai zone was greatly influenced by the need to promote trade through the Jebel Ali Port. A senior Dubai zone official cited a need to set up a place where the laws of the land will not apply as another important reason to set up the zone. The Shenzhen zone was partly influenced by the need to associate Hong Kong to the Chinese mainland. As noted by one respondent:

"Meanwhile, this action was a preparation for the return of Hong Kong to the motherland."

By initiating closer trade links with Hong Kong in the 1980s, the Chinese government laid the path for a smoother transfer of Hong Kong to the Chinese mainland in the later years.

On the other hand, the Noida zone's primary motive was to overcome the financial crisis in India during the mid 1980s. During the early 1980s, India was under 
tremendous foreign debt, and had very little reserves. As one Noida administrator claimed,

"During that time India had a bad exchange problem, that is the foreign exchange.

So it was set up primarily to overcome the exchange problem, as this would then bring in the much needed foreign exchange."

New Orleans, as with most of the U.S. zones, was primarily set up to facilitate domestic firms to import raw materials and intermediate goods.

Another apparent difference is the reason to develop backward areas, which cane out as an important reason for setting up Export-oriented zones - Noida and Shenzhen. This observation is in line with the developmental economics literature which has carried out extensive research that tries to determine whether setting up Export zones in developing countries leads to economic development of surrounding regions. As noted in the literature review, there is no firm consensus on the results.

Second, the main reasons to establish zones seem to match with their types. For instance, Dubai being a Trade oriented zone was set up for firms that would use the Jebel Ali Port for trading goods. A large number of companies store goods at the zone and reexport to different countries across the world. Similarly, the Export zones, Noida and Shenzhen, were developed to attract investment, generate employment, promote exports, and accelerate economic development. Finally, the New Orleans zone, as already mentioned above, was established for the import of goods for domestic manufacturers. Thus, the reasons above would appear to confirm the assumption that zones have different orientations. 


\section{Ownership Structure}

All four zones are government owned and in most cases report to the country's ministry or department of commerce. This is in line with the website analysis (Phase I) results, which showed that $71 \%$ of zones were government owned. While the ultimate ownership is same across the four zones, it is interesting to note the reporting structure at the four zones.

The Noida zone has a typical bureaucratic hierarchical structure. The senior officials of the zone report to the Ministry of Commerce, which ultimately reports to a cabinet minister with the central government. The top official at the zone is the Development Commissioner (DC). There are two joint DCs, who report to the main DC, and below them are the deputy DCs, who manage different departments, such as customs, imports, exports, administration, and security. The commissioners comprise the entire management cadre at the zone, and below them are the upper and lower division clerks, who work in different departments.

The New Orleans zone, as like the other zones in the U.S., directly reports to the Foreign Trade Zone Board, which is housed within the U.S. Department of Commerce. The board consists of the Secretary of Commerce and Secretary of Treasury. An Executive Secretary administers the day-to-day activities of the board and supervises the board staff. The board itself has quite a flat structure. It appoints a general manager for each zone that is associated with a port in the region, in this case, the Port of New Orleans. The general manager monitors the sites and the contracts with private operators.

The Dubai zone operates under a holding company, Dubai World, which is in

turn, wholly owned by the Dubai government. Dubai World was founded in 2006 and 
currently holds a vast portfolio of businesses such as The Palm Islands, The World Islands, Jebel Ali Free Zone, Dubai Ports World, Dubai Waterfront, and Kerzner Hotels. Within the Jebel Ali zone, there are many different departments - strategy, human resources, marketing and public relations, finance and so on. The chairman of Dubai zone is also the executive chairman of Ports, Customs, and Free Zone Corporation.

The Shenzhen zone also, ultimately reports to the central government. But its reporting structure is more complex, with some departments in the zone reporting to the Shenzhen Municipality, while others report directly to the authorities in the central government. Like the Dubai zone, Shenzhen too has many departments.

Based on the above information, some interesting observations emerge. Of all four zones, the one in New Orleans, followed closely by the Dubai zone, has a more flat and less complex structure of reporting. The zones in Shenzhen and Noida seem more bureaucratic with many different levels of reporting. This is in line with Hofstede's dimension of power distance which measures the extent to which the less powerful members of organizations and institutions accept and expect that power is distributed unequally (Hofstede 1980). While India and China have scores of 77 and 80, the U.S. has a score of 40 on the power distance index (www.geert-hofstede.com). The higher score implies a high power distance. The power distance is not available for U.A.E., but is for the Arab world, which, however, may be misleading as U.A.E. has a more equal working environment than other Arab countries, due to its large immigrant working population.

Another observation that was noted was the disinclination of the respondents at the Shenzhen zone to provide information on their reporting structure, while other respondents from the remaining zones were more forthcoming. In addition, the Dubai 
zone had the most complete portfolio of business departments, followed by the Shenzhen zone. New Orleans had the least number of departments; it only had one General Manager and a few staff members, who in fact were shared with the Port of New Orleans.

\section{Zone Funding}

Table 7.12 highlights some of the avenues of funding for the zone operations. As can be seen, the Shenzhen respondents were disinclined to give any information on the funding and simply referred us to the online documents. Surprisingly, there is no separate site on the Shenzhen zone, but there is information about the zone on the Shenzhen Government website. This site does publish financial numbers, but reports them for the entire Shenzhen region, which besides the zone includes other prominent areas (as already discussed in the case profile). Therefore, there were no means to separate the numbers for the Shenzhen zone for most of the reported figures.

\section{Table 7.12 \\ Zone Funding}

(For financial year ending in 2006; Values in Million U.S. \$)

\begin{tabular}{|c|c|c|c|c|}
\hline Activity & Dubai & New Orleans & Noida & Shenzhen \\
\hline Total investment from foreign countries & 1,633 & & 33 & \\
\hline Zone's annual budget & & 1.4 & 1.29 & \\
\hline $\begin{array}{l}\text { In percentage terms, the budget is covere } \\
\text { the government }\end{array}$ & & & $100 \%$ & \\
\hline investor fees & $100 \%$ & & & \\
\hline other sources & & $100 \%$ & & \\
\hline Zone running in profit & Yes & Yes & Yes & Yes \\
\hline
\end{tabular}


The Dubai zone gets a large amount of investment (U.S. \$1,633 million) from foreign countries, expected from the large number of multinationals that trade through the zone. The number for the Noida zone is much less at U.S. \$33 million, which is largely supported by the Non-Resident Indian population living abroad.

The annual budget could only be collected from New Orleans and Noida. Interestingly, both New Orleans and Noida have similar budgets at U.S. \$1.4 and U.S. $\$ 1.29$ million respectively. The lack of financial information on the zone seems to support the results from the Phase I analysis, where it was found that the websites very rarely published any financial numbers. Such observations may lead to an assumption that the host countries seem somewhat reluctant to divulge any financial information to the public. It is mostly available exclusively with the respective government ministries, which are careful to only publish, if they do, collective information on all zones. This reluctance of the host countries to divulge information on the zones proves, why there are virtually no comprehensive databases on the zones, and those that do exist report a large amount of incorrect information (this is further elaborated in Chapter 9).

Table 7.12 leads to two more noteworthy observations. First, all four zones are presently running in profit. This finding helps to give some indication to the possible reason for the recent increase in the number of zones across the world, and also highlights the increasing interest by business firms to use these zones.

Second, the table shows that in general, zones have different sources for funding their budget. While the Dubai zone relies entirely on investor fees, the Noida zone relies on the government to meet its budget requirements. A stark contrast between these two zones is that while the Noida zone subsidises the rent for companies (it is cheaper to rent 
space in the zone than outside), the Dubai zone charges a premium for companies to rent space. As noted by a Dubai tenant,

"The zone authority seems to increase the rent so often, it is becoming increasingly expensive."

\section{Zone Evolution and Fit with the Country's Economic Strategy}

Table 7.13 presents some important characteristics of the zones. It can be seen that Shenzhen is by far the biggest of all four zones (at an area of 327.5 square $\mathrm{km}$ ), and is actually one of the biggest zones in the world. While the Dubai zone too, is quite a large zone at 100 square $\mathrm{km}$, both New Orleans and Noida zones are much smaller at 4.81 square $\mathrm{km}$ and 1.25 square $\mathrm{km}$, respectively.

Table 7.13

\section{Main Zone Characteristics}

\begin{tabular}{lllll}
\hline Characteristics & Dubai & New Orleans & Noida & Shenzhen \\
\hline Area (sq. km) & 100 & 4.81 & 1.25 & 327.5 \\
Distance from closest big city (km) & 35 - Dubai mainland & in New Orleans & 24 - New Delhi & 25 - center of Hong Kong \\
Total no, of employees (all firms in the zone) & 125,000 & & 22,928 & \\
$\quad$ Of which, \% of female workers & $9 \%$ & & $8.30 \%$ & \\
$\begin{array}{l}\text { Approx. composition of the zone workforce today } \\
\quad\end{array}$ & $14 \%$ & $5 \%$ & $20 \%$ & \\
$\quad$ Managerial and Professional & $30 \%$ & $10 \%$ & $20 \%$ & \\
$\quad$ Supervisory and Skilled & $21 \%$ & $10 \%$ & $50 \%$ & \\
$\quad$ Clerical & $35 \%$ & $75 \%$ & $10 \%$ & \\
$\quad$ Semi-skilled and Unskilled & & & $\$ 78$ & \\
Monthly wage of unskilled workers (per month) & $\$ 204$ & 1 & 100 & \\
Number of Employees in zone administration & 650 & &
\end{tabular}

Most of the zones have evolved substantially since their inception. The Noida zone started with a land area of 0.16 square $\mathrm{km}$ in 1985 , and grew in size by more than 
six times. In addition, where only 25 firms were operational at the Noida zone in 1980s, it now has more than 160 firms, with a large list of potential applicants. The Noida zone has evolved into the second most successful zone in India.

Shenzhen portrays one of the biggest success stories of any region in the world. The success of this zone, in terms of increase in exports and FDI, has already been highlighted in the case profile and in the literature review.

The Dubai zone, portraying a similar trend, has increased the number of firms from 1,920 in 2000 to nearly 6,000 in 2006 , which is an annual increase of $37 \%$ in the given time period. In addition, it has seen a growth in facilities (custom offices, warehouses, storage facilities, and so on) from $9.3 \%$ in 2000 to $17.4 \%$ in 2006 , and an increase from 34,458 employees to 125,000 employees in the same time period. Their vision for the next five years is to expand the size of the zone to 140 square $\mathrm{km}$. Influenced by its great success, a number of countries, such as Malaysia, Senegal, and Djibouti have hired the Dubai zone authority as consultants to help them develop their own free zones.

The New Orleans zone has a much longer history, having being set up in 1946. The fact that this zone has survived for so long is a testimonial to its success. The zone respondents attribute the success of the zone to the addition of three new petroleum refinery subzones, which ship and import bulk quantities of petroleum. Although the setback by the hurricane Katrina has set the zone back by some years, they remain hopeful for an early revival. Overall, most of the respondents (both tenants and officials) across the four zones were convinced that their zones have been relatively successful over the years. 
Table 7.13 also shows the number of employees across the zones, which leads to some interesting observations. One is the low percentage of female workers in the zone (9\% and $8 \%$ for Dubai and Noida zones respectively). In addition, most of the zones have a low percentage of managerial and professional staff, at $14 \%, 5 \%$ and $20 \%$ for Dubai, New Orleans, and Noida respectively. One surprising element is a very large percentage of semi-skilled and unskilled workers in New Orleans (75\%) in comparison to Dubai (35\%) and Noida (10\%). One would expect, since the Noida zone is primarily a manufacturing zone, that it would have a high percentage of unskilled workers. This finding, however, is consistent with the respondents' claim at Noida that more and more technology-oriented firms are setting up base at the zone.

Another interesting observation is the presence of only one staff member for the New Orleans zone administration. This seems to support the earlier observation that the U.S. zones support a very flat organization structure.

In terms of the zone's fit with the overall host country's economic strategy, for three of the four zones, the responses seem to suggest an important and critical fit. As remarked by a Noida respondent,

"In my view, it has an important role to play in increasing investment and encouraging exports. It has and continued to play an important role in increasing the foreign exchange reserves of India. Over the last few years, the emphasis and role of zones in the general strategy has gained more critical importance. You must have heard how new zones are being sanctioned, and there is a renewed interest among the government officials to increase its presence in SEZs. They have opened the zones to private companies. As for Noida SEZ, it has a 
prominent role to play in the overall strategy of the government towards the SEZs."

As noted by a Shenzhen respondent,

"... when our country established this special zone, the purpose was to build up a new economy model. The purpose was to make it become an international metropolis. Shenzhen is the first place that our country conducted an economic reform. The strategy is to use it as a window to attract investments, meanwhile, for companies to go to international markets"

As remarked by a Dubai respondent,

"Jebel Ali zone was set up to create a zone that would not be bound by the laws of the land, and to promote Dubai as a center of world trade. After the success of Jebel, we are aggressively getting into new zones."

The only exception was this response from New Orleans.

"Well, we're just part, part of the puzzle. There are 250 general purpose foreign trade zones, and more than 450 subzones in the United States. We have five other subzones and seven of the general purpose, well actually one general purpose zone. I don't know how they measure that, but any event. So we're a very small percentage of the overall."

\section{Main Functions}

Table 7.14 shows the zone officials' assessment of the importance of different activities on a scale of 1 to 5 , where 1 stands for "not at all important" and 5 for "very important". As might be expected, the Noida zone rated 5 or very important for manufacturing and exports; New Orleans rated 5 for manufacturing, exports, imports, and warehousing; and 
Table 7.14

Importance of Different Activities

\begin{tabular}{lccc}
\hline Activity & Dubai & New Orleans & Noida \\
\hline Manufacturing / Processing & 4.5 & 5.0 & 5.0 \\
Assembly & 4.5 & 1.0 & 2.0 \\
Exports & 5.0 & 5.0 & 5.0 \\
Imports & 5.0 & 5.0 & 3.0 \\
Warehousing & 3.5 & 5.0 & 1.0 \\
Distribution/Logistics & 5.0 & 4.0 & 1.0 \\
Retailing & 1.5 & 1.0 & 1.0 \\
\hline
\end{tabular}

Scale: $1=$ "Not at all important" to 5 = "Very important"

Dubai rated exports, imports and distribution at 5. These ratings seem to agree not only with the orientation of the zones but also withthe tenants' responses to their activities at the zone.

The table also highlights some noteworthy differences across the zones. First, while the Dubai and New Orleans zones rate distribution/logistics at 5 , Noida rates it at 1 . This difference may be due to the location of the zones. While both Dubai and New Orleans are located next to famous ports, the Noida zone is in a land locked area with no close proximity to a port. As a matter of fact, several of the tenants mentioned this as a major setback for the Noida zone. Further, the emphasis of the Dubai zone on distribution can be gauged by this comment,

"We screen out those applications which would not carry out any goods movement through the port."

The above finding also helps to show the relative influence of location on the activities performed at the zone. 
Second, while warehousing comes out as very important for New Orleans, and somewhat important for Dubai, it has no importance for the Noida zone. This is in line with the responses from the tenants at the Noida zone who indicated that increasing number of new firms at the zone are either into software development or business process outsourcing, which require no warehousing activities.

Another difference is that while both Dubai and New Orleans rate 5 activities as very important (4 or above), Noida rates only two. This shows that both New Orleans and Dubai offer a larger range of activities than Noida. Finally, it is clear from the table that retailing is not considered important. This seems to support a general trend across the zones, because as found during Phase I, retailing hardly appeared on the websites as a possible zone function.

It is interesting to compare export and import figures across the zones. The Shenzhen zone had exports of U.S. $\$ 649.64$ billion (an increase of $37.6 \%$ over the previous year) and imports of U.S. $\$ 499.38$ billion (both figures are for the year 2006, as reported in the Shenzhen Government Website 2007). Both figures are substantially more than the corresponding numbers for the other zones. Dubai zone had exports and imports of U.S. $\$ 8.89$ billion and U.S. $\$ 10.49$ billion respectively (for the 2002 financial year, as reported in the Dubai Chamber of Commerce and Industry 2004) while the Noida zone reported exports of U.S. $\$ 1.39$ billion and imports of U.S. $\$ 1.12$ billion (for the 2006 financial year, as reported in the Confederation of Indian Industry Report 2006). For the New Orleans zone, total exports from both general purpose sites and the subzones were U.S. $\$ 0.075$ billion, while the imports to the zone were U.S. $\$ 4.23$ billion (for the year 2003, U.S./FTZB FTZ\#2 Annual Report 2006). In line with the Export orientation of the 
zones, both Noida and Shenzhen zones support a trade surplus with exports exceeding imports. Similarly, for the New Orleans zone, the very large difference between imports and exports provides further proof that the U.S. zones are Import-oriented. Regarding the Dubai zone, it is interesting to note that according to a Dubai zone official, it is likely that the negative trade balance may be because trade in services are not factored into this equation, and according to him, the Dubai zone enjoys a significant positive trade in services.

\section{Financial and Strategic Incentives}

Table 7.15 presents the main financial incentives for tenants across the zones (analyzed through leave-behind questionnaires for zone officials). Two prominent observations emerge from the table. First, all four zones offer duty free imports and exports for all types of products. This again seems to suggest that the basic and the most critical financial incentive for all zones is the duty free benefit. This finding further supports the more general finding from the website analysis, where duty benefits appeared as the most citied on the zones' websites.

Another interesting observation is the differences in incentives across the zones. While Dubai, Noida and Shenzhen offer corporate income tax holidays (50 years for Dubai, 15 for Noida, and varies across industries in Shenzhen, but on average for 15 years) and allow repatriation of profits, New Orleans does not offer tax holidays and allows only restricted repatriation of profits. This again is in line with the orientation of the zones, where the Export- and Trade- oriented zones encourage firms to set up manufacturing units by offering tax benefits and allowing them to repatriate their income. These differences seem to support the Phase I findings, where tax holidays appear among 
Table 7.15

Zone Incentives

\begin{tabular}{|c|c|c|c|c|}
\hline Incentives & Dubai & New Orleans & Noida & Shenzhen \\
\hline \multicolumn{5}{|l|}{ Duty free imports } \\
\hline Raw materials & $\sqrt{ }$ & $\sqrt{ }$ & $\sqrt{ }$ & $\sqrt{ }$ \\
\hline Intermediate goods & $\checkmark$ & $\checkmark$ & $\sqrt{ }$ & $\sqrt{ }$ \\
\hline Finished goods & $\sqrt{ }$ & $\sqrt{ }$ & $\sqrt{ }$ & $\sqrt{ }$ \\
\hline Equipment & $\sqrt{ }$ & $\sqrt{ }$ & $\sqrt{ }$ & $\checkmark$ \\
\hline Machinery & $\sqrt{ }$ & $\sqrt{ }$ & $\sqrt{ }$ & $\checkmark$ \\
\hline \multicolumn{5}{|l|}{ Duty free exports } \\
\hline Intermediate goods & $\sqrt{ }$ & $\sqrt{ }$ & $\sqrt{ }$ & $\checkmark$ \\
\hline Finished goods & $\sqrt{ }$ & $\sqrt{ }$ & $\sqrt{ }$ & $\checkmark$ \\
\hline \multicolumn{2}{|c|}{ Exports to the country's domestic territory $\sqrt{ }$ with conditions } & $\sqrt{ }$ & $\sqrt{ }$ & $\sqrt{ }$ \\
\hline Tax exemptions on investments & $\sqrt{ }$ & No & $\sqrt{ }$ & $\sqrt{ }$ \\
\hline Tax holiday & $\sqrt{ }$ & No & $\sqrt{ }$ & $\sqrt{ }$ \\
\hline $\begin{array}{l}\text { Tax Holiday Length } \\
\text { Investors to repatriate }\end{array}$ & 50 years & No & 15 years & $\sqrt{ }$ \\
\hline $\begin{array}{l}\text { Profits } \\
\text { Investment capital }\end{array}$ & $\begin{array}{l}\sqrt{ } \text { unrestricted } \\
\sqrt{\text { unrestricted }}\end{array}$ & $\begin{array}{l}\sqrt{ } \text { with conditions } \\
\sqrt{\text { with conditions }}\end{array}$ & $\begin{array}{l}\text { unrestricted } \\
\text { unrestricted }\end{array}$ & $\begin{array}{l}\sqrt{ } \text { unrestricted } \\
\sqrt{\text { unrestricted }}\end{array}$ \\
\hline
\end{tabular}

the top five benefits for Export and Trade oriented zones, while it does not appear in the top five for Import zones.

In a further analysis, a comparison was made on the basis of in depth interviews of tenants and officials, to see whether there is any difference in the incentives cited by both. For the Noida zone, while tax holidays came across as the most important benefit per the officials, duty free imports appeared as the most important to the tenants. The reason for this was the high import and export duties levied on products in India in the 1980s and early 1990s. As noted by one tenant in Noida,

"The main reasons were as I mentioned earlier duty free imports. Exports at that time were very difficult as raw materials costs were very high due to high duties on imported products." 
The other important benefits per the Noida officials were duty free imports and exports, $100 \%$ repatriation of income, and better infrastructure inside the zone. For the Noida tenants, tax holidays appeared as the second most important benefit. The other important benefits cited by tenants were more strategic in nature, such as the proximity to an airport and large cities, and fast access to super highways.

For the New Orleans zone, there was clear and conclusive agreement across both tenants and officials that duty free import was the most important benefit. Interestingly, both officials and tenants did not suggest any other benefit.

For the Shenzhen zone, tax holiday was cited as important by both officials and tenants. Another benefit that came across from both parties was the availability of "every conceivable service" inside the zone, which included among others, financial, insurance, and administrative services. Also, a number of domestic manufacturers cited the presence of multinationals in the zone as an incentive to set up operations. One more benefit cited by tenants, but not mentioned by officials for obvious reasons was the presence of fair business practices in the zone. As commented by one respondent,

"We do not need to deal with some under-table activities from the customs and public section."

While the officials at the Shenzhen zone did not cite many non-financial benefits, the tenants cited a number of strategic benefits, such as proximity to Hong Kong, presence of large Chinese market, and access to suppliers within or around the zone. As remarked by two Shenzhen tenants, 
"As I have said before, first, because we are implementing a "close to customers" strategy. Second, the whole market in china is really attractive to us. I mean the population is a foundation for manufacturing firms."

"It is because of the location. Hong Kong is a developed market and Shenzhen just neighbours it."

For the Dubai zone, both officials and the tenants were unanimous and in full agreement on their most important benefits $-100 \%$ ownership of business and location of the zone. As noted by one tenant,

"As a trading company in Dubai, one has to have a local partner with maximum ownership, while in the zone one can have $100 \%$ ownership. Also, the location of Jebel allows us easy access to international markets."

As remarked by a Dubai official,

"Most of the companies at the zone do trading. Location is crucial for them."

The above analysis leads to an important finding that for both officials and tenants, financial incentives are very important for investing in the zone. In addition, while the officials rarely mention strategic benefits, the tenants considered them very important. This is further supported by the results from Phase III (shown in Chapter 8), where it was found that non-financial variables were more important in determining tenants' satisfaction with the investment climate at the zone.

\section{Type and Selection of Tenants}

Table 7.16 gives the breakdown of foreign and domestic tenants at each zone. As shown, Dubai has significantly more companies than Noida and New Orleans. Although Shenzhen is expected to have more firms than Dubai, the data is available for the whole 
Table 7.16

Domestic and Foreign Firms at the Zones

(Year 2006)

\begin{tabular}{lrcrc}
\hline Type & Dubai & New Orelans & Noida & Shenzhen \\
\hline Domestic Companies & na & 7 & 160 & na \\
International Companies & na & 0 & 5 & na \\
Total Companies & 6,000 & 7 & 165 & na \\
\hline
\end{tabular}

Shenzhen area and not for the zone. The breakdown for the entire Shenzhen area is 130,000 domestic firms and 22,000 foreign firms. Considering that first, most of the developed area in Shenzhen is in the zone, and second, most of the foreign firms would likely invest in the zone, these figures may be considered to offer a reasonable assumption of firms operating in the Shenzhen zone.

While the absence of any domestic firms is not a surprise for New Orleans, as the Import zones primarily benefit the domestic manufacturers, the low number of foreign companies at the Noida zone does come as a surprise. One of the reasons for this can be the location of the zone. As the zone does not have any access to a port, this may deter firms to operate at the zone. Another possible reason could be that the Noida zone was an EPZ till very recently which meant limited possibility for foreign firms to sell goods to the domestic market. Considering that Noida has very recently been converted to an SEZ, which means more flexibility in selling to the domestic market, this may encourage more foreign firms to invest in the zone. This finding is in line with the intention of the government at the time of establishing the zone, which was to encourage domestic manufacturers to enter into exports and shift from an emphasis on import substitution to export oriented growth. This feature of the Noida zone is in line with the suggestions by 
developmental economists, who have advocated for these zones to benefit domestic companies.

Of the 165 companies that operate in the Noida zone, $95 \%$ are in manufacturing while 5\% are in trading. This is in contrast to the Dubai zone, where $70 \%$ of the firms in the zone are traders. For New Orleans, the seven firms consist of manufacturers of ships and large petroleum refineries.

Another interesting aspect that comes from this table is the stark difference in the number of firms reported by the National Association of Foreign Trade Zones, which reports 88 firms at the New Orleans zone, while the actual active number of firms is only seven. While the Board lists all companies that have used the zone at least once during the financial year as a client, the actual number of active firms that continue to operate at the zone is much less.

Important differences were found across the zones on the tenant selection process. While the Noida zone had a similar policy of selection for all industries, the Shenzhen zone had different screening process for firms in different industries. Therefore, a firm in one industry may get a sanction faster than a firm in another industry. This point is well highlighted in the following remark by a Shenzhen official,

"First of all, we need to identify if it is foreign or domestic company. For foreign investors, we have requirements of minimal investment capital, and the business it wants to run must be permitted by the country. For domestic investors, it depends on the types of businesses they want to invest in. Some of the industries are not allowed to enter. So, there is no simple answer. If a domestic and a foreign company want to set a company dealing in the same business, which is allowed to 
enter, which one might get it earlier - probably the domestic one. Since the foreign company has to go through a process to get the government approval.”

The Noida zone has arguably the fastest selection process across the zones. The officials noted that the turnaround time for the application was 15 days, after which another two weeks were taken to allocate a space to the tenants at the zone. This is primarily due to their policy of a "single window clearance" which means that all sanctions and licenses are approved at once by a single authority. This was mentioned as an important incentive by tenants in the zone. As one Noida tenant noted,

"Again it was very simple and easy, especially with a single window clearance. It makes it quite easy to get all government permissions."

Because of the different policies followed by the Shenzhen zone, the tenants had mixed responses to the process of setting up operations. Two contrasting comments are shown below:

"...this would be more complicated. I personally am not satisfied with the efficiency and effectiveness of the local government. Many things need to be improved. It depends on the company itself and the industry it is in. For the companies in logistics business, it might be easier since it is in an industry supported by the local government."

"That is not difficult. Especially help from the government. Hotel business is one of the industries that the government encourages to operate in Shenzhen."

The Dubai zone is quite similar to Shenzhen in its screening process, as it screens out those applications which are not likely to use the Jebel Ali port for the movement of goods. 
At the New Orleans zone both officials and tenants were in agreement that the process of application and selection is quite cumbersome and complex due to the large quantity of paper work required. As noted by one tenant,

“...the language is too abstruse or difficult. If anybody wants to set up a subzone now they will still have to hire a consultant. With somebody without experience, I don't think they could do it."

Thus, the above observations lead to a surprising finding, the Noida zone is the easiest among the four zones to set up operations and the New Orleans zone has the most complex process.

\section{Zone Promotion}

The information obtained on the promotional or marketing tools adopted by the zones led to some interesting findings. First, apart from Dubai no other zone had a separate department allocated solely to marketing and promotion. It was interesting to note that the Dubai zone regularly conducted research surveys, most of which were web based and the respondents could easily fill them online. Other zones too reported on getting feedbacks from tenants on zone operations, but it was not as systematic as the process followed by the Dubai zone.

Second, when officials were inquired whether the zone carried out any marketing or more specifically promotion activities, responses were varied. While the Noida officials seemed adamant that not only did the zone have no promotion or marketing strategy, in their view there seemed no need to promote the zone as the zone was already filled to capacity and there was a huge list of applications in the pipeline. Some of the comments from Noida officials were, 
"Again I will state that the emphasis on marketing is less as most of the zones including Noida SEZ are filled."

"At present there is no specific marketing strategy that the zone has. Also as the zone is doing very well, I think the ministry does not feel the need to do so."

Similar to Noida, New Orleans too had no specific promotion or marketing program. As one official noted,

"We have information on our website, in our directory about the foreign trade zone, and people call me quite frequently, and that's how we have contacts with potential operators and users so there is marketing going on, but it's not exactly what you would call an active targeted marketing program."

In contrast to the above two zones, Dubai and Shenzhen officials stress that they are quite particular on promoting the zone both in national and international markets. It comes as no surprise that bothse zones receive good media coverage in trade magazines and international trade fairs and conferences. As noted by a Shenzhen official,

“Take my job for example, we have conferences in different countries organized by the municipality of Shenzhen every year to promote relevant businesses."

Third, when officials were asked what they felt were the possible sources from where the tenants may receive information on the zone, most pointed to a similar set of sources. Information on the websites was cited as an important source. Surprisingly, of the four zones, only the Dubai and Noida zones have a dedicated website. Both of these websites provide rich information on the benefits and operations of the zones. The Shenzhen and New Orleans zones do not have a dedicated website, while the former has web pages on the Shenzhen Government Online website, the latter only has one web page 
on the Port of New Orleans website. There is enough information on the Shenzhen zone on the Shenzhen Government portal; however, the New Orleans zone's web page gives very little information.

Other important sources cited by the officials were brochures, trade magazines and personal inquiries. On searching through secondary information, it was found that print media especially trade magazines do cover information on these zones. Interestingly, in India, due to strong opposition by farmers against the use of their land for setting up zones, the SEZs were getting daily coverage, albeit not for the right reasons.

In a similar question asked to the tenants, it was revealed that word of mouth through the trade (e.g., suppliers, competitors) was the primary source of information. Other important sources cited were websites, trade journals, and meetings with zone administrators. Interestingly, tenants at Shenzhen and New Orleans also referred to the role of consultants or hired agents for giving them information on the zones.

Fourth, in terms of competition from domestic and international zones, it was found that while the tenants felt there was competition, the officials did not. For instance, Noida tenants felt that the Santa Cruz SEZ in Mumbai and the Chinese zones were major competitors due to their proximity to a port. As commented by Noida tenants,

"Yes probably the Santa Cruz Special Economic Zone, as although all benefits are very similar, that zone is very close to an international port."

"Probably the Chinese, because again they are much larger and are located close to major ports." 
Chinese tenants felt that zones in India are a threat to Shenzhen because of Shenzhen's special treatment to some industries. As noted by a tenant at Shenzhen,

"I have mentioned several ones, such as Vietnam and India. They are more attractive to many investors form different industries."

Similarly for New Orleans, while the officials did not feel there was any competition, because different zones had their own strengths, the tenants felt zones in the Gulf were a major threat.

Based on the above findings, it seems that most zones do not have a well defined marketing strategy. The likely reasons could be (a) because zones do not feel threatened by other zones and so they do not see the need to aggressively market themselves; (b) government's control over the zones reduces the fear of competition; and (c) because Noida, Dubai and Shenzhen seem to be operating at full capacity with a long list of applicants, so the officials do not feel the need to attract new businesses. These findings are in line with the Phase I results which suggest that on average most zones use very few promotional tools on their websites.

\section{Zone versus Mainland}

Table 7.17 shows the zone officials' assessment of the investment climate across six main factors for both zone and the country. The six factors were production, finance, economic and legal, political and social, infrastructure, and general view of the country and people. Under each factor a number of items were listed, which are measured on a 5-point scale, 
Table 7.17

Officials' Assessment of Investment Climate in Zone and Country

\begin{tabular}{|c|c|c|c|c|c|c|}
\hline \multirow{2}{*}{ Factors } & \multicolumn{2}{|c|}{ Dubai } & \multicolumn{2}{|c|}{ New Orleans } & \multicolumn{2}{|c|}{ Noida } \\
\hline & Zo & Co & Zo & Co & Zo & Co \\
\hline \multicolumn{7}{|l|}{ Production } \\
\hline Cost of energy & 4.0 & 4.0 & 2.0 & 2.0 & 4.0 & 2.0 \\
\hline Manufacturing costs & & & 4.0 & 3.0 & 4.0 & $\mathbf{2 . 0}$ \\
\hline Labour costs & 4.0 & 4.0 & 4.0 & 4.0 & 3.5 & 1.5 \\
\hline Availability of skilled labour & 3.0 & 4.0 & 1.0 & 1.0 & 4.0 & 4.5 \\
\hline Availability of expert managers & 5.0 & 5.0 & 3.0 & 3.0 & 4.0 & 4.5 \\
\hline Labour productivity & 3.0 & 4.0 & 3.0 & 2.0 & 4.0 & 3.5 \\
\hline Technology level & 4.0 & 4.0 & 4.0 & 3.0 & 4.5 & 4.0 \\
\hline Transportation quality & 4.0 & 3.0 & 3.0 & 3.0 & 4.5 & 4.0 \\
\hline Communication quality & 4.0 & 4.0 & 3.0 & 5.0 & 4.5 & 3.5 \\
\hline \multicolumn{7}{|l|}{ Finance } \\
\hline Tax structure & 5.0 & 5.0 & & & 4.5 & 3.5 \\
\hline Tax advantages & & & & & 5.0 & 2.5 \\
\hline Inventory tax & 5.0 & 4.0 & & & 5.0 & 3.5 \\
\hline Insurance cost & 4.0 & 4.0 & & & 3.0 & 3.0 \\
\hline Subsidies & & & & & 4.0 & 2.0 \\
\hline Duties on imports & & 5.0 & & & 4.0 & $\mathbf{2 . 0}$ \\
\hline Duties on exports & & & & & 5.0 & 3.0 \\
\hline Repatriation of profit and capital & 5.0 & 5.0 & & & 3.5 & 3.5 \\
\hline \multicolumn{7}{|l|}{ Economic and Legal } \\
\hline Bureaucratic bottlenecks & 5.0 & 4.0 & 3.0 & 1.0 & 5.0 & 2.5 \\
\hline Setting up operations & 5.0 & $\mathbf{2 . 0}$ & 4.0 & 2.0 & 5.0 & 3.0 \\
\hline Obtaining licenses & 5.0 & $\mathbf{3 . 0}$ & 3.0 & 2.0 & 5.0 & 3.5 \\
\hline Obtaining work permits for expatriates & 5.0 & 3.0 & 1.0 & 1.0 & 5.0 & 5.0 \\
\hline Legal system & 5.0 & 3.0 & 1.0 & $1.0^{*}$ & 1.0 & 1.0 \\
\hline Restrictions on ownership & 5.0 & 1.0 & 5.0 & 5.0 & 3.5 & 4.5 \\
\hline \multicolumn{7}{|l|}{ Political and Social } \\
\hline Government attitude to foreign investment & 5.0 & 5.0 & 5.0 & 4.0 & 5.0 & 5.0 \\
\hline Public's attitude towards foreign investment & 5.0 & 5.0 & 5.0 & 4.0 & 5.0 & 5.0 \\
\hline Quality of life style & 2.0 & 2.0 & 4.0 & 3.0 & 4.0 & 4.0 \\
\hline Crime level & 5.0 & 5.0 & 5.0 & 5.0 & 4.0 & 3.0 \\
\hline \multicolumn{7}{|l|}{ Infrastructure } \\
\hline Container handling facilities & 5.0 & 5.0 & 5.0 & 5.0 & 5.0 & 5.0 \\
\hline Warehouse facilities & 5.0 & 4.0 & 4.0 & 5.0 & 5.0 & 4.0 \\
\hline Banking facilities & 5.0 & 4.0 & 3.0 & 4.0 & 4.5 & 4.5 \\
\hline Transport facilities & 5.0 & 4.0 & 5.0 & 5.0 & 4.5 & 4.5 \\
\hline Communication facilities (Internet, phone) & 5.0 & 5.0 & 4.0 & 4.0 & 5.0 & 5.0 \\
\hline Housing facilities & 4.0 & 4.0 & & & 2.5 & 4.5 \\
\hline School facilities & 5.0 & 5.0 & & & 1.5 & 4.0 \\
\hline \multicolumn{7}{|l|}{ General View of Country and People } \\
\hline General zone and country outlook & 5.0 & 5.0 & & & 4.5 & 4.5 \\
\hline Likeability of the people & 5.0 & 5.0 & & & 4.5 & 3.5 \\
\hline Trustworthiness of the people & 5.0 & 5.0 & & & 4.0 & 3.5 \\
\hline Friendliness of the people & 5.0 & 4.0 & & & 5.0 & 4.5 \\
\hline Industriousness of the people & 5.0 & 5.0 & & & 4.0 & 3.5 \\
\hline
\end{tabular}

Scale: $1=$ "low or poor" to $5=$ "high or good"; $\mathrm{Zo}=$ zone environment; $\mathrm{Co}=$ country Environment; Bold numbers $=$ difference of two or more between zone and country values; $*=$ "particularly surprising" finding, discussed in text; Blank cells $=$ respondent did not answer 
where 1 meant a "low or poor assessment" and 5 a "high or good assessment". The comparison was possible for only three zones, as the leave-behind questionnaires for Shenzhen officials did not have these items for the country (explained earlier in the Chapter 5).

As the sample of officials were low, no statistical test was carried out, but to highlight important differences between the zone and the country, a difference of two or more was considered substantial, and those ratings have been highlighted in bold in the table.

The Noida zone officials reported the maximum number of items which were substantially different across the zone and the country. Most of these were positive differences in favour of the zone. As expected, tax advantages, subsidies, import duties, and export duties were much more favourable inside the zone than outside. Along with financial factors, production factors such as cost of energy, manufacturing costs, labour costs were found to be favourable inside the zone than outside. Among the items that were more favourable outside the zone than inside, were housing and school facilities. This is understandable as the Noida zone does not offer these facilities inside the zone. The positive sentiment of the officials was supported by the tenants, "Yes, it is better, in terms of infrastructure, duty free benefits, and tax benefits."

One of the reasons that the Noida zone outscored the other zones in terms of more favourable differences between the zone and the mainland can be attributed to the huge difference between the functioning of the zone and the functioning of the government departments outside. While this difference may be substantial in a low income country 
like India, this may not be much of a problem in more developed countries like U.A.E. and the U.S.

For the Dubai zone, most of the substantial differences were in the economic and legal items. For example, obtaining licenses and work permits were considered much easier inside the zone than outside. This is understandable as immigrants form a large proportion of the working population in Dubai. Another difference for Dubai was the restriction on ownership; while businesses in most industries are not allowed to establish $100 \%$ owned firms in the Dubai mainland, this restriction does not apply in the zone.

Interestingly for New Orleans, the officials felt that the communication system was substantially worse in the zone than the mainland. This is not surprising considering the zone has no central office in contrast to the other three zones. Despite this negative difference for the zone, the officials do feel that the zone offers substantially better investment climate in terms of less bureaucratic bottlenecks and ease of setting up operations. However, it is interesting to note that the New Orleans officials reported the least number of items for which the investment climate in the zone is substantially better than outside. This is further highlighted by the very low score given to "legal system" both in the zone and outside. The above sentiment was also found to be highlighted by the tenants at the zone, as one of the New Orleans tenant expressed when asked whether zone offered a better investment climate,

"No, I think it would be about the same. Right, whether you're in a zone environment or not I think our business in the way it's operated, it would basically be the same." 
A highly surprising finding for New Orleans was the poor score given to "legal system" in the zone and country. Although this finding can not be generalized as the response comes from only one official, nevertheless, it does suggest a highly disgruntled worker. This is further highlighted with poor scores for "obtaining work permits" (which is somewhat understandable given the difficulty to get work visas for the U.S.), "availability of skilled labour", and "cost of energy".

\section{Zone Satisfaction}

Tables 7.18 and 7.19 show zone officials' and tenants' assessment of satisfaction with six main investment factors - market (e.g., market size, market potential), production (e.g., cost of energy, manufacturing costs), finance (e.g., tax advantage, insurance cost), economic and legal (e.g., obtaining licenses, bureaucratic bottlenecks), political and social (e.g., government's attitude to foreign investment, public attitude to foreign investment), and infrastructure (e.g., warehouse facilities, banking facilities). Apart from the market factor, the detailed list of items for each factor is given in the previous table.

A look at the overall mean scores shows a stark contrast between the assessment by officials and tenants. While Dubai tenants give the lowest mean ratings among all zones across all factors at 3.3, followed by Noida at 3.6, Shenzhen at 3.8, and New Orleans at 4.5 , these results are completely opposite to the findings for zone officials where New Orleans had the lowest rating and Dubai had the highest ratings. This highlights a strong difference in opinions between the officials and tenants suggesting the need for the zones to develop a market orientation to better understand their clients.

Table 7.18 shows that only infrastructure out of the six factors are rated highly by all four zones ( 4 or above). While both Dubai and Shenzhen officials seem quite 
Table 7.18

Assessment of Investment Factors: Zone Officials

\begin{tabular}{lrcrc}
\hline Factors & Dubai & New Orleans & Noida & Shenzhen \\
\hline Market & 5.0 & 3.0 & 4.5 & 3.0 \\
Production & 3.5 & 4.0 & 4.5 & 3.0 \\
Finance & 4.0 & 3.0 & 5.0 & 4.0 \\
Economic and Legal & 4.5 & 3.0 & 3.5 & 4.0 \\
Political and Social & 4.5 & 3.0 & 2.5 & 4.0 \\
Infrastructure & 5.0 & 4.0 & 4.5 & 4.0 \\
\hline Mean Score & $\mathbf{4 . 4}$ & $\mathbf{3 . 3}$ & $\mathbf{4 . 1}$ & $\mathbf{3 . 7}$ \\
\hline
\end{tabular}

Scale: 1 = "very dissatisfied" to $5=$ "very satisfied"

Table 7.19

Assessment of Investment Factors: Zone Tenants

\begin{tabular}{lcccc}
\hline Factors & Dubai & New Orleans & Noida & Shenzhen \\
\hline Market & 3.0 & 4.0 & 3.7 & 4.2 \\
Production & 3.0 & 5.0 & 3.5 & 3.2 \\
Finance & 4.0 & 5.0 & 3.5 & 4.0 \\
Economic and Legal & 2.0 & 5.0 & 4.0 & 3.8 \\
Political and Social & 4.0 & 4.0 & 3.0 & 4.0 \\
Infrastructure & 4.0 & 4.0 & 4.0 & 3.8 \\
\hline Mean Score & $\mathbf{3 . 3}$ & $\mathbf{4 . 5}$ & $\mathbf{3 . 6}$ & $\mathbf{3 . 8}$ \\
\hline
\end{tabular}

Scale: 1 = "very dissatisfied" to 5 = "very satisfied"

satisfied( 4 or above) with four out of the six factors, the New Orleans officials seem quite satisfied with only two factors. There is no factor that has been consistently rated low across the zones. Of all zones, Dubai officials have the highest mean rating at 4.4 , followed by Noida at 4.1, Shenzhen at 3.7, and New Orleans at 3.3. Interestingly, the lowest rating was given by Noida officials for political and social factors in India (2.5). Based on personal interviews, a possible reason that emerged was because the state and the central governments belong to different parties, therefore, the zone officials find it 
difficult to get their issues resolved. For instance, despite the request by the zone officials for an increase in land space, there has been no decision on this over the last two years.

The low mean rating by zone tenants for Dubai can be understood by this comment,

"They keep changing their policies very frequently. It is difficult to get any information; most of the staff is uneducated on the policies."

Interestingly, in the assessment by tenants, apart from New Orleans, no other zone has a rating of 5 for any factors. The dissatisfaction among tenants can also be gauged by some of the comments for suggested improvements in the zone. As a Noida tenant noted,

"There is a need for more space in the zone, so if need be companies can expand their operations. Also, there is a need for better interaction with government officials."

As noted by Shenzhen tenants,

"For example, the reconstruction of road you see just in front of our company has been going on for months. As I know it should have been completed months ago." "...in the past, all costs here, like land, water and so on, were very cheap. But after years of development, it seems that the city lacks many resources, such as space and energy ... Also, other cities in China are developing very fast; even labor seems not efficient any more. Among all this, I think land is a very serious problem here."

Despite the above differences, many of the tenants expressed strong interest in further expanding their operations in the zone and had well developed plans for the next three to five years. Some of the comments by the tenants, 
Noida tenants:

"We are planning to recruit more than 300 new people in the next five years."

"We have increased expenditure in the zone over the last two years by U.S. $\$ 1.4$ million. We intend to keep increasing the expenditure in the same proportion over the next five years."

Shenzen tenants:

"We are absolutely expanding businesses in the coming years. As I told you, we are growing with an annual $20 \%$ growth for the past years. There is still a lot of potential in China for us."

"We are definitely expanding. Our purpose is to be one of the top 5 mobile phone vendors in the world. Our current rank is no. 7 , so we still have things to do, haha....."

\section{Discussion}

The results of Phase II provide insights into the views of both tenants and officials on the working and the main characteristics of the four zones. It was interesting to note that a number of findings from Phase II seem to support the Phase I findings. For instance, it seems very clear that the zones do not have a well planned or thought out marketing strategy. Zones in general do not feel the need to market themselves, largely because they do not see any immediate competition. The thought of competing against zones either in the same country or in other countries seemed a far-fetched thought for most of the zone officials, however, the tenants thought otherwise. Most tenants felt that the zones had real competition from both domestic and international zones. 
Another finding from this phase that supports the finding from Phase I was the lack of financial information on the zones and tenants. It was difficult to get financial information from the officials and tenants as most of the respondents cite such information as confidential. This issue is discussed in more detail in Chapter 9.

The results also indicate that contrary to common belief and published reports by international organizations, large percentage of tenants operating in the zones are domestic firms. To highlight the point, below is the definition of EPZ given on the ILO website,

"EPZs are industrial zones with special incentives set up to attract foreign investors, in which imported materials undergo some degree of processing before being re-exported".

The definition suggests that the EPZs are set up mostly for foreign investors. The results from Phase II suggest that this is not the case as all four zones have a larger percentage of domestic firms than foreign ones. This suggests that the FTZs are generally established to benefit both domestic and foreign companies. This argument was supported by Noida officials who pointed out that the prime reason for establishing the Noida SEZ was to encourage domestic companies to become larger exporters. This finding does contradict a major critique of FTZs which says that the zones make the host countries over-dependent on foreign firms, and that these firms may cut back their operations any time (Rondinelli 1987).

There are generally no restrictions to the kind of firms that can set up a unit in these zones. However, different types of zones tend to favour firms with different primary functions. For instance, for Export-oriented zones, a general condition is that all 
firms need to be positive foreign exchange earners at the end of every year (the firm has to export more than it imports and sells to the domestic market). This requirement will tend to favour firms that are primarily exporters. Similarly, Trade zones by virtue of their locations and incentives favour trading companies.

It was also seen that most of the tenants in the zone enjoyed long term contracts with domestic suppliers. This is not surprising considering that many of the companies were domestic. This finding seems to contradict another primary critique of FTZs that states that foreign tenants in general source raw materials from outside the country, abstaining from developing links with domestic manufacturers (Rondinelli 1987). It could be seen that while tenants did source a large portion of raw materials from outside the country to avail of duty benefits, many tenants had long term domestic suppliers for low value goods and services. It was noted during the interviews that one of the primary incentive of Shenzhen SEZ was the availability of a large number of domestic suppliers and service companies.

Finally, the results of this phase also indicate that the government authorities played a major role in the designing and success of these zones. Therefore, the success of a zone relies heavily on the policies initiated by the government. 


\section{Chapter 8 PHASE III RESULTS: SURVEY ANALYSIS}

This chapter presents the results for Phase III of the study, which involved a survey of tenants at two zones. This chapter consists of five main sections. The first section presents the profile of the sample, followed by a section that summarizes the responses on the descriptive elements of the survey. The third section presents results on the investment assessment of the tenants across the two zones. The fourth section presents results for different association tests and regressions analysis; and the chapter is concluded with a discussion of the main findings.

\section{Sample}

As noted earlier in Chapter 5, for Noida, the questionnaires were distributed to all 165 companies. The final usable questionnaires received were 52 , resulting in a response rate of $31.5 \%$.

For the Jebel Ali zone, questionnaires were distributed to 200 companies, which were selected randomly from the list of companies obtained from the zone officials. In the early stages of data collection at Jebel Ali, it became apparent that an adequate response rate might not be achieved at this zone. In order to address this problem, a handful of surveys were collected from the neighbouring Dubai Airport zone. Both Jebel Ali and the airport zones are very similar. At the airport zone, 60 questionnaires were randomly distributed. The final usable questionnaires received from both zones were 63 , resulting in an overall response rate of $24.2 \%$. The samples from both Jebel Ali and the airport zones were compared, and there was no significant difference between the two. 
Therefore, the two samples were combined, and I refer to them as the "Dubai zone" to avoid confusion.

The combination of the above led to a final combined sample of 115 questionnaires with a collective response rate of $27.1 \%$. It may be noted that this response rate is much higher than the average reported for cross-national industrial surveys, which are as low as $6 \%$ and rarely exceed $20 \%$ (e.g., Dawson and Dickinson 1988, Jobber, Mirza and Wee 1991, Ghosal and Nohria 1993, Kopp 1994, Cullen et al. 1995, Harzing 2000). In addition, the response received for this phase is substantially higher than what was achieved in the earlier empirical papers on the U.S./FTZs. For example, Tansuhaj and Gentry (1987) received only 62 completed surveys from tenants after distributing the questionnaires across all zones in the U.S.

This final sample is slightly less than the initially proposed target of 150 . However, it must be noted that this is the largest zone tenant survey to date, the first survey outside the U.S., and also the first survey across Export and Trade oriented zones. Therefore, it is felt that the realized sample was adequate given the descriptive / exploratory nature of this study.

\section{Descriptive Analysis}

\section{Respondent Characteristics}

The respondents had a mean of 10 years of experience in the workforce and a mean of four years at the zone. Respondents were mostly well educated, with $66 \%$ having an undergraduate degree and $31 \%$ a graduate degree. 


\section{Parent Company's Home Country}

For the Noida zone, $86 \%$ of the 52 firms were from India, $10 \%$ from North American, and $4 \%$ from Europe. This is in contrast to the breakdown of the parent company's home country in the Dubai zone. European firms account for the largest percentage at $34 \%$, while U.A.E. firms account for 29\%, rest of Asia 28\%, North America 7\%, and Central America accounts for $2 \%$. Five firms did not mention the parent company's home country.

The above analysis clearly highlights that while the Noida zone is dominated by firms with headquarters in India, the Dubai zone has a vast number of international firms from different continents, with Europe accounting for the largest share. This finding is in line with the Phase II finding, where zone officials and tenants at the Dubai zone point to using the zone primarily for distribution and logistics. On the other hand, the Noida zone, being in a land-locked area, does not offer an easy distribution facility to international companies.

\section{Year of Establishment of Zone Companies}

Table 8.1 shows the year distribution for when the firms were established at the zone. Most of the firms at both zones are relatively new with $47 \%$ of the firms in Noida and $60 \%$ in Dubai being established during the period 2001-06. Another interesting finding is the relative increase in new firms being established at both zones, with the Dubai zone experiencing a steeper increase. 
Table 8.1

Year of Establishment of Zone Companies

\begin{tabular}{lcc}
\hline Year & Noida & Dubai \\
\hline $1980-1990$ & $13 \%$ & $6 \%$ \\
$1991-2000$ & $40 \%$ & $34 \%$ \\
$2001-2006$ & $47 \%$ & $60 \%$ \\
\hline
\end{tabular}

\section{Primary Business Operation}

It is interesting to look at the primary business operations across both zones. As might be expected, the most important function performed by the companies at the Noida zone is manufacturing, with $94 \%$ mentioning manufacturing as one of their primary businesses. This is in contrast to the Dubai zone where $79 \%$ of the firms mention trade as one of their primary businesses. In Noida, $25 \%$ of the firms mentioned trade, while only $9 \%$ of the Dubai firms mentioned manufacturing as one of their primary businesses, respectively.

Another noteworthy difference was that while only $11 \%$ of the Noida firms mentioned service as one of their primary businesses, the percentage for Dubai firms was much higher at $52 \%$. The total percentage for this analysis will exceed 100 , as this was a multiple response question.

A further analysis compared the parent company's business operation with their operation at the zone. Interestingly, it was found that $96 \%$ of the parent companies of the firms in Noida with manufacturing as their primary business also carried out manufacturing at the zone. Similarly, for the Dubai zone $83 \%$ of the parent companies with trade as their primary business carried out trade at the zone. This finding shows that firms retain their same main operations at the zone, which highlights the possibility that 
firms chose the zones that encourage similar operations that match their primary business function. This further supports the notion that FTZs play a strategic role for many firms.

\section{Zone Company Demographics}

Table 8.2 reports the mean values for different zone company characteristics for the year 2005-06. Of the six demographic variables, four report significant mean differences across the zones. The number of employees in the Noida zone with a mean value of 178 is significantly more than in the Dubai zone with a mean of 101 employees. This result is understandable as firms in the Noida zone are primarily into manufacturing, thus, requiring more employees than those in Dubai which are predominantly into trading.

Table 8.2

\section{Zone Company Demographics}

(For Fiscal Year 2005-06)

\begin{tabular}{lccc}
\hline Variable & $\begin{array}{c}\text { Noida } \\
\text { Mean }\end{array}$ & $\begin{array}{c}\text { Dubai } \\
\text { Values }\end{array}$ & $\begin{array}{c}\text { Mann-Whitney U } \\
\text { p-value }\end{array}$ \\
\hline Number of Employess & 177.71 & 100.57 & $\mathbf{0 . 0 0 0}$ \\
Total Sales from Zone (USD Million) & 4.86 & 54.94 & $\mathbf{0 . 0 1 7}$ \\
Total Exports from Zone (USD Million) & 4.26 & 5.27 & 0.707 \\
Total Imports to Zone (USD Million) & 2.53 & 5.04 & 0.499 \\
Percentage of Total Exports to Domestic Market & 1.94 & 37.73 & $\mathbf{0 . 0 0 0}$ \\
No. of Countries to which Co. Exports & 6.88 & 8.08 & $\mathbf{0 . 0 3 8}$ \\
\hline
\end{tabular}

Given that 150 of the Fortune 500 companies and a large number of international companies are operating at the Dubai zone, it comes as no surprise to see that the mean sales from the Dubai firms (U.S. \$54.94 million) are significantly more than that for the Noida firms (U.S. \$4.86 million). 
The Dubai firms export on an average $37.73 \%$ of their total exports to the domestic market, while the Noida firms only export $1.94 \%$ (the difference is significant with $\mathrm{p}$ value $=0.000$ ). This seems to suggest that firms in the Noida zone are predominantly oriented towards exports, while firms in the Dubai zone also sell to the domestic market. This may be due to two main reasons. First, as expected, given that the Noida SEZ is an Export-oriented zone with favourable policies, more firms will be inclined to export than to sell to the domestic market. As mentioned earlier, one of the conditions for firms at the Noida SEZ is that they have to show a net positive foreign exchange earning at the end of every year. Second, as a predominantly large percentage of firms in the Noida zone are Indian owned, their main purpose in setting up operations in a zone is to export. A number of these firms have manufacturing units in the domestic mainland of India which produces goods for the domestic market.

Finally, the mean number of countries to which the Dubai zone based firms export to is 8.08 , significantly more than for firms from the Noida zone at 6.88 . Although the difference is statistically significant ( $p$ value $=0.038$ ), the actual difference in the mean is not too large for practical purposes. This is also because more international firms operate in the Dubai zone than those in the Noida zone; therefore, the Dubai firms may target more international export destinations.

\section{Assessment of Zone Investment Climate}

In this segment a detailed analysis of zones' investment climate is presented. This is based on the responses for sections 4 to 6 of the questionnaire (please see Chapter 5 under "Survey Instrument"). As a reminder, the first of these sections contained a detailed list of investment climate characteristics for assessing the zone and the country 
environment. These characteristics are related to production, finance, economic and legal, political and social, infrastructure, and general view of the country and people. The next two sections in the questionnaire asked the respondents to assess the importance of these investment factors, and their satisfaction with them. As explained earlier in Chapter 5, the assessments were done only at the factor level, so as to avoid an excessively long questionnaire.

The analysis below is presented in the order that the three sections appear in the questionnaire. For each of these sections, first, a comparison of Dubai and Noida respondents is done on their assessment of the zone environment; which is then followed by a comparison of the respondents' assessment of the zone and the country environment. Both parametric and non-parametric tests were performed to ascertain the robustness of the results, and both gave identical results. For the tables below, only the parametric tests are reported.

\section{Investment Assessment - Comparison of Zone Climate}

Table 8.3 shows the comparison of zone investment climate as assessed by Noida and Dubai tenants. All items are rated on a five point scale where 1 represents "unfavorable" and 5 represents "favorable" assessment. The mean scores for each item are reported and the difference across means is tested using independent-samples T-tests. As mentioned earlier, the non-parametric tests were also performed, in this case the Mann-Whitney U test, and both tests gave similar results.

The first important observation that can be made from the table is that the overall mean scores for both zones (3.73 for Noida and 3.45 for Dubai), as well as many/most of the individual item scores are not high. Considering that the middle value for a 5-point 
Table 8.3

Comparison of Zone Investment Climate

\begin{tabular}{|c|c|c|c|}
\hline Factors & Noida & Dubai & Diff. \\
\hline \multicolumn{4}{|l|}{ Production } \\
\hline Cost of Energy & 2.62 & 2.65 & -0.03 \\
\hline Manufacturing Costs & 3.37 & 3.61 & -0.24 \\
\hline Labour costs & 3.26 & 3.13 & 0.13 \\
\hline Availability of skilled labour & 3.47 & 2.76 & $0.71 *$ \\
\hline Availabaility of Expert managers & 3.66 & 3.02 & $0.64 *$ \\
\hline Labour productivity & 3.63 & 3.00 & $0.63 *$ \\
\hline Technology level & 3.72 & 3.44 & 0.29 \\
\hline Transportation quality & 3.64 & 2.73 & $0.90 * *$ \\
\hline Communication quality & 3.77 & 3.51 & 0.26 \\
\hline Customs procedures & 3.79 & 3.21 & $0.58 *$ \\
\hline Inventory control & 3.83 & 3.45 & 0.38 \\
\hline \multicolumn{4}{|l|}{ Finance } \\
\hline Tax structure & 4.02 & 3.83 & 0.19 \\
\hline Tax advantages & 4.13 & 4.30 & -0.17 \\
\hline Inventory tax & 3.83 & 3.23 & 0.60 \\
\hline Insurance cost & 3.37 & 2.97 & 0.40 \\
\hline Subsidies & 3.08 & 3.10 & -0.01 \\
\hline Import duties & 4.00 & 3.68 & 0.32 \\
\hline Export duties & 4.13 & 3.67 & 0.46 \\
\hline Repatriation of profit and capital & 3.64 & 3.71 & -0.08 \\
\hline \multicolumn{4}{|l|}{ Economic and Legal } \\
\hline Bureaucratic bottlenecks & 3.33 & 3.25 & 0.08 \\
\hline Setting operations & 3.81 & 3.73 & 0.08 \\
\hline Obtaining licenses & 3.70 & 3.75 & -0.05 \\
\hline Obtaining work permits & 3.97 & 3.73 & 0.25 \\
\hline Legal system & 3.70 & 3.41 & 0.29 \\
\hline Ownership restrictions & 3.71 & 3.20 & 0.51 \\
\hline Political and Social & & & 0.00 \\
\hline Govt. attitude to for. invst. & 4.27 & 4.27 & 0.00 \\
\hline People's attitude to for. invst. & 4.09 & 4.14 & -0.05 \\
\hline Quality of life style & 3.82 & 2.12 & $1.70 * *$ \\
\hline Crime level & 3.34 & 3.77 & -0.43 \\
\hline \multicolumn{4}{|l|}{ Infrastructure } \\
\hline Proximity to bigger city & 4.33 & 3.55 & $0.78 * *$ \\
\hline Proximity to industry clusters & 4.33 & 3.57 & $0.76 * *$ \\
\hline Proximity to ports, railways \& airports & 3.74 & 3.63 & 0.12 \\
\hline Container facilities & 3.86 & 4.08 & -0.22 \\
\hline Warehouse facilities & 3.95 & 4.09 & -0.14 \\
\hline Banking facilities & 3.86 & 4.02 & -0.16 \\
\hline Transport facilities & 3.61 & 3.25 & 0.36 \\
\hline Communication facilities & 3.91 & 3.93 & -0.02 \\
\hline Housing facilities & 2.81 & 2.53 & 0.28 \\
\hline School facilities & 2.76 & 2.30 & 0.47 \\
\hline \multicolumn{4}{|l|}{ General View of Country and People } \\
\hline Zone and country outlook & 4.10 & 4.10 & 0.00 \\
\hline Likeability of people & 4.25 & 3.77 & $0.48 *$ \\
\hline Trustworthiness of people & 4.11 & 3.49 & $0.62 * *$ \\
\hline Friendliness of people & 3.96 & 3.80 & 0.16 \\
\hline Industriousness of people & 3.80 & 3.36 & $0.44 *$ \\
\hline Overall Mean Scoret & $\mathbf{3 . 7 3}$ & 3.45 & $0.28 *$ \\
\hline
\end{tabular}


scale is 3 , the above scores suggest that the tenants do not assess the investment climate at the zones very favourably. In addition, the overall assessment by Noida tenants for their investment climate was significantly better than that for Dubai; therefore, it may be assumed that Noida tenants are relatively happier with their investment climate.

More specifically, at the factor level, the table shows a number of significant differences. Production factor shows availability of skilled labour, availability of expert managers, labour productivity, transportation quality, and customs procedures receiving significantly higher assessment for the Noida zone than for the Dubai zone. This is a further proof to the assumption that Export-oriented zones offer greater encouragement for firms to set up manufacturing units than Trade zones. Another explanation for items such as availability of skilled labour (mean scores of 3.47 for Noida and 2.76 for Dubai) and expert managers (mean scores of 3.66 for Noida and 3.02 for Dubai), and labour productivity (mean scores of 3.63 for Noida and 3.00 for Dubai) to be rated low by Dubai tenants could be because of the difficulty that U.A.E. has in recruiting manpower. U.A.E. predominantly relies on new and existing immigrant population to take up new positions in the job market. India, with a vast pool of well educated and trained manpower, faces no such difficulty. Regarding customs procedures, Noida being an Export-oriented zone has simplified the customs procedures to attract exporters to the zone. Another interesting observation among production factors was the low scores given to cost of energy by both zone tenants (mean scores of 2.62 for Noida and 2.65 for Dubai), which implies that both zones have high costs of utilities such as power, electricity and water.

There were no significant differences across the two zones for finance factor items which included, among others, tax structure, tax advantages, inventory tax, 
andinsurance costs. This is in line with the Phase I finding which shows that four of the top five incentives (mainly financial) promoted on the Trade and Export zone websites are similar. These were duty deferral, tax holidays, no export duties, and $100 \%$ ownership.

One major difference, as seen in both Phases I and II, between the Export, Trade, and Import zones is the availability of corporate income tax holiday. While the Export zones generally offer attractive tax holidays, both Trade and Import zones (in particular) do not usually offer this incentive. In this analysis, surprisingly, Dubai with a mean score of 4.30 has a higher rating than Noida with a mean of 4.13. Although the difference is not significant, it is worth noting that Dubai offers a 50 year tax holiday as compared to Noida's 15 years. Dubai may be a specific case in point in terms of Trade zones offering tax holidays as the whole of Dubai is a tax free city.

There were again no significant differences between the zones on the economic and legal factor, which included items such as bureaucratic bottlenecks, setting up operations, obtaining licenses, and work permits. One noteworthy observation for these items is that in most cases for both zones, the assessment has been somewhat favorable. Out of the six items, Noida tenants rated five items above 3.5, while Dubai tenants rated three of the six items above 3.5; the remaining items were rated above 3 for both zones. This may imply that the zones offer relatively good economic and legal conditions inside the zone.

Political and Social factor showed one significant difference for the item "quality of life style." Somewhat surprisingly, the Noida zone was rated higher (3.82) than the Dubai zone (2.12). This may have more to do with the overall environment at both 
places. While New Delhi offers a more relaxed and flexible working culture, Dubai tends to be much more restrictive, especially for immigrants given the strict Shariah laws prevalent there.

Infrastructure items offer a number of interesting observations. The Noida zone was rated significantly better for its proximity to a big city (mean scores of 4.33 for Noida and 3.55 for Dubai) and industry clusters (mean scores of 4.33 for Noida and 3.57) for Dubai) than the Dubai zone (both highly significant at $\mathrm{p}<.01$ ). Possible explanations for this may be, first, the close proximity of Noida to a number of big cities, such as Delhi (distance of $24 \mathrm{~km}$ ), Gurgaon (which is a new hub for Information Technology and Multinational firms in India) at a distance of $35 \mathrm{~km}$, and Faridabad (a major industrial city, formerly called the "Manchester of India" due to its tremendous growth in the 1980s), at a distance of $40 \mathrm{~km}$. This is not the case for the Dubai zone. Further, the close proximity to these major cities offers access to industry clusters (Technology cluster in Gurgaon, Jewellery cluster in Delhi and Faridabad, Garment cluster in Faridabad) for firms operating inside the Noida zone. Another interesting observation among the infrastructure items is the low scores for school and housing facilities; both zones do not offer such facilities to tenants.

General view of Country and People has a number of items with significant differences in assessment across both zones. A more general observation is the relatively better scores on all items by both zones (all five items were rated above 3.5 by Noida tenants, while three were rated above 3.5 for the Dubai tenants). Noida is again rated significantly better than Dubai for items - "likeability of people", "trustworthiness of people" and "industriousness of people." This may be due to the fact that most of the 
tenants inside the Noida zone were Indian, and most of the respondents were local, while for the Dubai zone a large number of respondents were immigrants. Therefore, this may be a case of giving a lower assessment to people in a different country.

\section{Investment Assessment - Comparison of Zone and Host Country Climate}

Table 8.4 shows the comparison of the investment climate at the zone and country as assessed by Noida and Dubai tenants for the six main factors. This comparison would be very meaningful as it will show whether the zone environment and the country mainland environment are assessed differently. This would also provide us with good indicators for why the tenants would prefer zones over the country mainland. In addition, it will show important incentives that might influence tenants' decision to invest in a zone over the country mainland.

Again, all factors are rated on a five point scale, where 1 represents "unfavorable" and 5 represents "favorable" assessment. The mean scores for each item are reported and the difference across means is tested using paired-samples T-tests. This test is used because the comparison is within the same sample and not across two independent samples as in the previous table. As mentioned earlier, the non parametric tests were also performed, in this case the Wilcoxon Ranked Sign Test, and both tests gave similar results.

Please note that the means for the zone investment in Tables 8.3 and 8.4 may differ as some items which were mentioned for the zone investment may not have appeared for the country investment in the questionnaire, or vice versa (as these items may not be relevant for the country, or vice versa). Also, some respondents may have not 
Table 8.4

Comparison of Zone and Host Country Climate

\begin{tabular}{|c|c|c|c|c|}
\hline \multirow[b]{2}{*}{ Factors } & \multicolumn{2}{|c|}{ Noida } & \multicolumn{2}{|c|}{ Dubai } \\
\hline & Zo & Co & Zo & Co \\
\hline \multicolumn{5}{|l|}{ Production } \\
\hline Cost of Energy & 2.69 & $2.21 * *$ & 2.81 & 3.04 \\
\hline Manufacturing Costs & 3.34 & $2.76 * *$ & 3.57 & 3.62 \\
\hline Labour costs & 3.19 & $2.81 *$ & 3.16 & 3.53 \\
\hline Availability of skilled labour & 3.57 & 3.71 & 2.79 & 2.76 \\
\hline Expert managers & 3.69 & 3.86 & 2.97 & 3.00 \\
\hline Labour productivity & 3.71 & 3.37 & 3.03 & 3.06 \\
\hline Technology level & 3.79 & 3.88 & 3.57 & 3.71 \\
\hline Transportation quality & 3.50 & 3.64 & 2.72 & 2.90 \\
\hline Communication quality & 3.69 & 3.74 & 3.42 & 3.53 \\
\hline Customs procedures & 3.86 & 2.76 & 3.06 & 2.94 \\
\hline Inventory control & 3.85 & 3.61 & 3.29 & 3.04 \\
\hline \multicolumn{5}{|l|}{ Finance } \\
\hline Tax structure & 4.07 & $2.43 * *$ & 3.96 & $3.23 * *$ \\
\hline Tax advantages & 4.23 & $2.41 * *$ & 4.36 & $3.86 *$ \\
\hline Inventory tax & 3.86 & $3.11 * *$ & 3.13 & 3.00 \\
\hline Insurance cost & 3.38 & 3.19 & 3.00 & 2.77 \\
\hline Subsidies & 3.17 & 2.69 & 3.13 & 3.06 \\
\hline Import duties & 4.11 & $2.09 * *$ & 3.57 & $2.96 *$ \\
\hline Export duties & 4.20 & $2.67 * *$ & 3.55 & 3.18 \\
\hline Repatriation of profit and capital & 3.59 & 3.09 & 3.68 & 3.32 \\
\hline \multicolumn{5}{|l|}{ Economic and Legal } \\
\hline Bureaucratic bottlenecks & 3.43 & $2.03 * *$ & 3.19 & $2.71 * *$ \\
\hline Setting operations & 3.93 & $2.75 * *$ & 3.79 & $2.94 * *$ \\
\hline Obtaining licenses & 3.88 & $2.78 * *$ & 3.73 & $3.02 * *$ \\
\hline Obtaining work permits & 4.11 & $3.08 * *$ & 3.69 & $2.93 * *$ \\
\hline Legal system & 3.85 & $2.73 * *$ & 3.36 & $2.69 * *$ \\
\hline Ownership restrictions & 3.68 & 3.35 & 2.93 & 2.73 \\
\hline \multicolumn{5}{|l|}{ Political and Social } \\
\hline Govt. attitude to for. invst. & 4.26 & 4.05 & 4.30 & 4.37 \\
\hline People's attitude to for. invst. & 4.09 & $3.72 * *$ & 4.17 & 4.17 \\
\hline Quality of life style & 3.84 & 3.56 & 2.30 & 2.27 \\
\hline Crime level & 3.39 & $2.93 *$ & 3.70 & 3.07 \\
\hline \multicolumn{5}{|l|}{ Infrastructure } \\
\hline Container facilities & 4.05 & $3.50 *$ & 3.92 & 4.00 \\
\hline Warehouse facilities & 4.00 & $3.21 * *$ & 4.11 & $3.53 * *$ \\
\hline Banking facilities & 3.92 & 4.08 & 3.83 & 3.71 \\
\hline Transport facilities & 3.68 & 3.80 & 3.16 & 3.33 \\
\hline Communication facilities & 3.98 & 4.03 & 3.93 & $3.58 *$ \\
\hline Housing facilities & 2.84 & $3.71 * *$ & 2.59 & 2.95 \\
\hline School facilities & 2.84 & $3.66 * *$ & 2.58 & $3.15 * *$ \\
\hline \multicolumn{5}{|c|}{ General View of Country and People } \\
\hline Zone and country outlook & 4.10 & 3.85 & 4.19 & 4.10 \\
\hline Likeability of people & 4.27 & $3.85 * *$ & 3.76 & 3.65 \\
\hline Trustworthiness of people & 4.12 & $3.62 * *$ & 3.60 & $3.33 * *$ \\
\hline Friendliness of people & 3.98 & $3.67 *$ & 3.84 & 3.62 \\
\hline Industriousness of people & 3.85 & 3.88 & 3.36 & 3.16 \\
\hline Overall Mean Score & 3.75 & $3.26 * *$ & $\mathbf{3 . 4 3}$ & $3.26 * *$ \\
\hline
\end{tabular}


answered a particular item in the country scales because it may be irrelevant for their business operation.

A general finding from this table is that the zone environment is assessed significantly better than the country mainland (as shown by the overall mean scores) by both Noida and Dubai tenants. The difference between the overall mean scores for both Noida and Dubai is significant at $\mathrm{p}<.01$. This suggests that both Noida and Dubai zones offer significantly better investment climate than the host country mainland.

Further, out of 34 significant differences (combining both zones) in Table 8.4, 31 (91\%) has the zones getting a more favorable assessment. Out of these 31 significant differences $13(42 \%)$ are highly significant at $p<.001$ (not shown in the table). This provides additional support to the above finding.

In terms of specifics, the production factor shows cost of energy (mean scores of 2.69 for Noida and 2.21 for country), manufacturing costs (mean scores of 3.34 for Noida and 2.76 for country), and labour costs (mean scores of 3.19 for Noida and 2.81 for country) to be more favorable inside the Noida zone than outside in India. Production items for Export zones, as also found earlier in the previous table, are an important incentive to attract tenants. As expected, given the earlier findings, none of the production factors were significantly different across the Dubai zone and the rest of U.A.E. This provides further proof to the difference between Export and the Trade oriented zones in attracting manufacturing units to their sites.

Tax structure, tax advantages, and import duties were rated more favorably for the Noida and Dubai zones than for their respective countries' mainland. This is in line with the FTZ literature and also the findings from Phases I II, which report financial incentives 
to be a major attraction for tenants to invest in the zones. Interestingly, for the Noida zone, inventory tax and export duties were are also significantly better inside the zone than outside. Reduction of export duties, which is an important attraction for Export zones, may not be that important for Trade zones, and this might explain why this was not significant for the Dubai zone.

A very interesting and important finding from Table 8.4 is the importance of the economic and legal factor. Prior research on FTZs has predominantly stated financial incentives as the most important benefit for zone tenants. This table shows that five of the six items under the economic and legal factor were assessed significantly better (all five items were highly significant at $\mathrm{p}<.01$ ) inside the zones than outside. This is true for both zones. The results show that the zones have significantly less bureaucratic bottlenecks, offer easier and faster processes for setting up operations and obtaining work permits and licenses, and have more efficient legal systems. Most of these benefits were also highlighted during the interviews.

Political and social factor highlights two main significant differences for the Noida zone. The zone has a more favorable attitude towards foreign investment and has a lower crime rate than the country's mainland. This is expected, given that the majority of the tenants are exporters, and so the zone offers a favorable and encouraging atmosphere for foreign investment. The higher security at the zone means that the crime level is curtailed to a minimum. Some of the officials during the interview mentioned security as an important benefit for operating in the zone. It is interesting to note the high scores given to both zone and country by Noida and Dubai tenants for "government attitude towards investment." This highlights the interest of the government to encourage foreign 
investment in the country. This interest would invariably be highlighted in governments' promotion of these zones. As noted earlier during the case studies, both countries have shown an increased emphasis on expanding the number, and the operations, of the zones.

The table also shows that both of the Dubai and Noida zones offer better warehouse facilities. Other significantly better infrastructure facilities at the zone include container facilities for the Noida zone and communication facilities for the Dubai zone. Most of these facilities are given at a subsidized rate inside the zones. As mentioned during the discussion of the previous table, both zones do not offer any schooling or housing facilities, so understandably, both of these were assessed poorly inside the zone in comparison to outside. As a matter of fact, these were the only significant differences that were in favour of the country.

Finally, the general view of the country and people factor was also assessed to be favourable inside the zones than outside. Both zones reported that people were more trustworthy and friendly inside the zone than outside. A possible reason could be the banning of any unions inside the zone; therefore, the tenants rarely face any labour related problems. In addition, the zones offer a closely knit environment for most workers. During the visits to the zone, it could be seen that the workers gathered around the cafeteria during lunch and tea times. The atmosphere inside the zone, at times, appeared to resemble the one seen in universities, with common cafeteria, playgrounds, and seminar rooms.

In summary, a very important finding from the above results is that non-financial factors such as production, infrastructure, economic and legal, political and overall attitude of the workers were significantly better inside the zone than the host country 
mainland. Therefore, the notion in the FTZ literature that zones predominantly offer financial incentives is somewhat contradicted by these findings.

\section{Factor Importance}

Table 8.5 shows the comparison of tenants' assessment towards the importance of the six factors for investing in the zone.

\section{Table 8.5}

Comparison of Factor Importance across Zones

\begin{tabular}{lcc}
\hline Factors & Noida & Dubai \\
\hline Production factors & 4.16 & $3.49 *$ \\
Finance factors & 3.89 & 4.07 \\
Economic and legal factors & 3.88 & 4.00 \\
Political social factors & 3.43 & 3.72 \\
Infrastructure factors & 4.18 & 4.34 \\
Country and people & 3.68 & 3.77 \\
\hline Independent-samples T-test sig. at: ${ }^{*} \mathrm{p}<.05$
\end{tabular}

It is interesting to see which factors received the highest and the lowest mean scores. A noteworthy observation here is that both zone tenants assessed the infrastructure factor as the most important, with mean scores of 4.18 and 4.34 for Noida and Dubai respectively. Another important observation is that the finance factor comes at number three in terms of importance for the Noida zone and at number two for the Dubai zone. This further supports the finding above in Table 8.4, that financial bencfits, as claimed in the extant literature, is not the only important factor.

Overall for Noida, the production factor received the second highest mean score, followed by finance, economic and legal, country and people, and political and social. 
For the Dubai zone, economic and legal factor received the third highest score, followed by country and people, political and social, and production.

Interestingly, while the production factor was ranked as high as second for Noida, it was ranked last for Dubai (this factor accounted for the only significant difference between the two zones). Given that most of the tenants are traders at the Dubai zone, this result comes as no surprise. Also worth noting is that "country and people" and "political and social" factors were rated lower by both zones, highlighting the relatively lesser importance of these in comparison to others.

Table 8.6 shows the comparison of tenants' assessment of factor importance for both zone and country.

Table 8.6

Comparison of Factor Importance between Zones and Host Country

\begin{tabular}{lcccc}
\hline & \multicolumn{2}{c}{ Noida } & \multicolumn{2}{c}{ Dubai } \\
Factors & $\mathbf{Z o}$ & Co & Zo & Co \\
\hline Production factors & 4.13 & 4.00 & 3.55 & 3.59 \\
Finance factors & 3.92 & 4.10 & 4.09 & 4.15 \\
Economic and legal factors & 3.87 & 3.90 & 3.96 & 4.00 \\
Political social factors & 3.35 & $3.93 *$ & 3.75 & 3.88 \\
Infrastructure factors & 4.20 & 4.25 & 4.27 & 4.33 \\
Country and people & 3.73 & $4.08 *$ & 3.69 & 3.88 \\
Paired-samples T-test sig. at: ${ }^{*}$ * $<.05$ & \multicolumn{4}{|l}{}
\end{tabular}

In terms of significant differences, Noida tenants gave "political and social" and "country and people" factors a significantly higher importance for investment in the country vis-à-vis the zone. This is likely given that both factors play a more important role for investment inside the country mainland. Their importance is underscored in the 
zone as these factors have lesser impact inside the zones than outside. The political influence is minimal inside the zones as the governments encourage foreign investment in to zones.

Table 8.6 also shows that tenants at both zones consider the infrastructure factor as first in terms of importance, for investment in the zone and country. It is interesting to note that for Dubai, the same order of factor importance is seen for both zone and the country. The order in decreasing importance is: infrastructure, finance, economic and legal, political and social, country and people, and production. This goes to show that Dubai as a whole is an important location for Trade related investment, a point supported by the low rating of production factors. For the Noida zone, the order is slightly different; the notable difference is the rating of production factors at the second place for the zone, and at the fourth place for the country. However, there is no significant difference between the two mean scores.

\section{Factor Experience/Satisfaction}

Table 8.7 shows the comparison of tenants' satisfaction with the six factors for the zone environment. The ratings were on a scale of 1 to 5 , where 1 represents "very dissatisfied" and 5 represents "very satisfied."

One immediate observation from the table is the slightly high scores given to each factor for both zones. All factors received a rating above 3.5. However, none of the factors for both zones received a rating of more than 4.0. This shows that while the tenants may be somewhat satisfied with the zones on each of the six factors, they are not anywhere near being "very satisfied." There is no significant difference between the 
Table 8.7

Comparison of Factor Experience across Zones

\begin{tabular}{lcc}
\hline Factors & Noida & Dubai \\
\hline Production factors & 3.87 & 3.55 \\
Finance factors & 3.72 & 3.59 \\
Economic and legal factors & 3.74 & 3.67 \\
Political social factors & 3.70 & 3.77 \\
Infrastructure factors & 3.84 & 3.73 \\
Country and people & 4.00 & 3.86 \\
\hline Independent-samples T-test sig. at: ${ }^{*} \mathrm{p}<.05$ &
\end{tabular}

scores for Dubai and Noida. Thus, the tenants at both zones have a similar satisfaction level. The scores across the six factors also seem to follow a narrow range, with Noida getting the highest score for "country and people" at 4.00 and "political and social" with the least score at 3.70. Similarly, the Dubai zone received the highest rating for "country and people" at 3.86 and the least rating for "production factors" at 3.55. Given the narrow range, one can assume that the tenants have a similar satisfaction towards all six factors.

Table 8.8 shows the comparison of tenants' assessment of their satisfaction with the factors for the zone and the country overall. Of immediate importance is again the lack of very high scores (no factor for the zone and the country has a score of 4 or more), suggesting that the tenants are not "very satisfied" with the investment climate both in the zone and in the overall country. In addition, the satisfaction scores for most of the factors are very similar across the zone and the country. This is highlighted by the fact that only two significant differences are found.

The Noida tenants show a significant higher satisfaction with the political and social infrastructure inside the zone than outside. This further supports the earlier results 
Table 8.8

Comparison of Factor Experience between Zones and Host Country

\begin{tabular}{lcccc}
\hline \multirow{2}{*}{ Factors } & \multicolumn{2}{c}{ Noida } & \multicolumn{2}{c}{ Dubai } \\
& Zo & Co & Zo & Co \\
\hline Production factors & 3.97 & 3.92 & 3.62 & 3.57 \\
Finance factors & 3.82 & 3.82 & 3.61 & 3.83 \\
Economic and legal factors & 3.82 & 3.74 & 3.62 & 3.83 \\
Political social factors & 3.74 & $3.33^{*}$ & 3.79 & 3.93 \\
Infrastructure factors & 3.92 & $3.67 *$ & 3.72 & 3.81 \\
Country and people & 3.97 & 3.92 & 3.81 & 3.88 \\
\hline
\end{tabular}

Paired-samples T-test sig. at: *p<.05

that the Noida zone offers better infrastructure and is less influenced by political and social factors then the overall country.

\section{Tests of Association and Regressions}

The above section points out significant differences across the two zones, and between the zone and the host country. In this section, first, the correlation analysis between the items under each factor and the overall satisfaction (factor satisfaction) is presented. This is important as this analysis will help determine significant associations between tenants' assessment of each item, and his or her assessment of overall satisfaction with zone investment. This will help show which items may be considered important that may significantly impact tenants' satisfaction. The correlations are run for all factor items for both Noida and Dubai zones.

Second, on determining the significant items, these are then considered for multivariate regressions. The dependent variable is the overall satisfaction score with zone investment. Multivariate regressions will help show which items may significantly 
impact the tenants' overall satisfaction with zone investment by controlling for other variables.

\section{Correlation between Factor Items and Overall Satisfaction}

As mentioned earlier, the tenants were asked to rate the six factors based on how satisfied or dissatisfied they were. This question was asked at the factor level. The scores on all six factors were combined to give the overall satisfaction measure. To check for the reliability of this measure, the Cronbach's alpha was computed. The alpha value was 0.82 which exceeds the benchmark of 0.7 (Nunnally 1978). The factors were then subjected to exploratory factor analysis to compute the factor loadings and the explained variance. The factor loadings ranged from 0.65 to 0.86 , which are comparable to figures obtained in many marketing studies (e.g., Edison and Geissler 2003, Volckner and Sattler 2006). In addition the explained variance was 0.54 , which exceeds the 0.5 benchmark (Fornell and Larcker 1981). These values are shown in Table 8.11 along with the results for other measures which are discussed in the next section. The mean scores for the overall satisfaction measure was calculated, and as a robust check, the overall scores were also calculated by regression using exploratory factor analysis. The correlations were run with both scores, and both yielded similar results. Table 8.9 shows the Pearson correlations of the factor items with the mean scores of the overall satisfaction measure.

The table shows a number of important general observations. First, all six factors scem to be relatively important, as one or more items from each factor for both zones are found to be significantly associated with tenants' satisfaction. Second, all significant items are positively associated with tenants' satisfaction, thus, a better assessment of these factor items are positively related to higher overall satisfaction. Finally, 
Table 8.9

Pearson Correlation between Overall Satisfaction and Factor Items

\begin{tabular}{|c|c|c|c|}
\hline \multirow{2}{*}{$\begin{array}{l}\text { Factors } \\
\text { Production } \\
\end{array}$} & \multicolumn{3}{|c|}{ Overall Satisfaction } \\
\hline & Noida & \multicolumn{2}{|l|}{ Dubai } \\
\hline Cost of Energy & 0.1471 & 0.0726 & \\
\hline Manufacturing Costs & 0.1355 & & \\
\hline Labour costs & -0.0402 & 0.1909 & \\
\hline Availability of skilled labour & $0.3567 *$ & 0.1418 & \\
\hline Expert managers & $0.4061 * *$ & 0.3081 & \\
\hline Labour productivity & 0.2233 & 0.2362 & \\
\hline Technology level & $0.3704 *$ & $0.4064 *$ & * \\
\hline Transportation quality & $0.4490 * *$ & 0.1732 & \\
\hline Communication quality & 0.2052 & 0.1311 & \\
\hline Customs procedures & $0.4427 * *$ & 0.2827 & \\
\hline Inventory control & $0.4683 * *$ & $0.5202 *$ & ** \\
\hline \multicolumn{4}{|l|}{ Finance } \\
\hline Tax structure & $0.3623 *$ & -0.0403 & \\
\hline Tax advantages & 0.1673 & -0.2317 & \\
\hline Inventory tax & 0.1735 & -0.1984 & \\
\hline Insurance cost & 0.0518 & 0.3429 & \\
\hline Subsidies & 0.1518 & 0.2540 & \\
\hline Import duties & 0.1449 & 0.0315 & \\
\hline Export duties & 0.1120 & -0.0919 & \\
\hline Repatriation of profit and capital & $0.3571 *$ & $0.4283 *$ & * \\
\hline \multicolumn{4}{|l|}{ Economic and Legal } \\
\hline Bureaucratic bottlenecks & 0.1909 & $0.3502 *$ & \\
\hline Setting operations & $0.4326 * *$ & -0.0175 & \\
\hline Obtaining licenses & $0.3471 *$ & 0.0396 & \\
\hline Obtaining work permits & $0.4191 *$ & 0.0072 & \\
\hline Legal system & $0.4629 * *$ & 0.1728 & \\
\hline Ownership restrictions & 0.3226 & -0.0170 & \\
\hline \multicolumn{4}{|l|}{ Political and Social } \\
\hline Govt. attitude to for. invst. & 0.0534 & $0.3097 *$ & \\
\hline People's attitude to for. invst. & 0.1517 & $0.3563 *$ & \\
\hline Quality of life style & $0.3675 *$ & -0.2585 & \\
\hline Crime level & -0.2707 & -0.0670 & \\
\hline \multicolumn{4}{|l|}{ Infrastructure } \\
\hline Proximity to bigger city & 0.2712 & $0.3348 *$ & \\
\hline Proximity to industry clusters & $0.3616 *$ & 0.1798 & \\
\hline Proximity to ports, railways $\&$ airports & $0.3268 *$ & 0.2436 & \\
\hline Container facilities & $0.5371 * *$ & 0.2979 & \\
\hline Warehouse facilities & $0.4799 * *$ & 0.2819 & \\
\hline Banking facilities & $0.5737 * *$ & 0.2425 & \\
\hline Transport facilities & $0.5178 * *$ & $0.3254 *$ & \\
\hline Communication facilities & $0.4382 * *$ & 0.1372 & \\
\hline Housing facilities & 0.2431 & 0.2540 & \\
\hline School facilities & 0.3030 & 0.2078 & \\
\hline \multicolumn{4}{|l|}{ General View of Country and People } \\
\hline Zone and country outlook & 0.2819 & $0.2917 *$ & \\
\hline Likeability of people & 0.2624 & 0.1322 & \\
\hline Trustworthiness of people & $0.4494 *$ & 0.1960 & \\
\hline Friendliness of people & $0.4812 * *$ & 0.1501 & \\
\hline Industriousness of people & $0.3747 *$ & 0.2698 & \\
\hline
\end{tabular}

**Correlation is significant at the 0.01 level (2-tailed).

*Correlation is significant at the 0.05 level (2-tailed). 
infrastructure items (given that for both zones infrastructure items reported the most number of significant items in number and in proportion among all factors) come out as possibly the most important that may influence higher tenants' satisfaction. This finding becomes even more important when combined with the findings from Tables 8.5 and 8.6, which report infrastructure items to have the highest mean score among all factors in terms of factor importance. Thus, this finding may have a major implication for zone policy makers to focus on improving infrastructure at the zones.

Regarding specific results for the production factor, availability of skilled labour and expert managers, technology level, transportation quality, customs procedures and inventory control are found to be significantly positively associated with Noida tenants' overall satisfaction with the zone. For the Dubai zone, technology level and inventory control were the only two production items to be significantly correlated with overall satisfaction. It is interesting to note that while six production items significantly associate with overall satisfaction for the Noida zone, only two production items were significant for the Dubai zone. This provides further support to the argument that there seems to be greater importance for tenants at Noida to have favourable production factors, which seems to be less important for tenants at Dubai.

Surprisingly, finance items did not seem to have much of an association with tenants' overall satisfaction. Only two out of the eight items were found to be significantly correlated. Repatriation of profit and capital was significantly associated with satisfaction at both zones. This result seems to suggest that the freedom to repatriate its income to its home country is an important feature that tenants may look for in a zone. 
This is an important distinguishing feature between zones and the host country mainland, as in many developing countries, firms are obligated to re-invest a large part of their income. Tax structure was also significantly associated with overall satisfaction for Noida tenants. As Dubai has a tax free regime for the entire city, this may have underscored the favourable tax structure in the zone. The lesser importance of finance items in its association with overall satisfaction is in line with findings reported in Tables 8.4 and 8.5 .

Economic and legal factor seems to play a very important role in determining tenants' satisfaction at Noida. Ease of setting operations, obtaining licenses and work permits, and a better legal system were found to be significantly associated with satisfaction. For Dubai zone, bureaucratic bottlenecks came out as a significant item. This highlights the relative greater importance of economic and legal items for tenants' satisfaction at the Noida zone than for tenants at the Dubai zone. A possible reason for this may be a far better economic and legal system in U.A.E. than India, thus, increasing its importance for Noida tenants while underscoring its importance for Dubai tenants.

Governments' and peoples' attitude towards foreign investment seems to play a role in Dubai tenants' satisfaction with the zone. Interestingly, quality of life style is shown to be significantly associated with Noida tenants' assessment of zone satisfaction.

A large number of significant infrastructure items for Noida zones are not surprising considering that India faces a severe infrastructure problem. Therefore, this finding seems to suggest that the Noida zone's good infrastructure may be a very attractive feature to tenants at the zone. As the table shows, Noida's proximity to big cities, industry clusters, ports, railways, and airports significantly correlates with tenants' 
satisfaction. In addition, other facilities such as container, banking, transport, and communication is also found to be significantly associated with Noida tenants' satisfaction. Proximity to bigger city and transport facilities were significantly correlated with Dubai tenants' overall satisfaction.

Among the items under general view of country and people, for Noida tenants, trustworthiness, friendliness, and industriousness of people seems to be important for their satisfaction, while for Dubai tenants, a positive zone and country outlook is positively significantly related to their satisfaction.

The above analysis was important as it helped to locate only those items from a large list that are significantly correlated to overall satisfaction. This helped to reduce the list of items to a more manageable number, thereby helping zone administrators to formulate a more focused strategy.

\section{Regression Results}

While the correlations do show the association of different investment items with overall satisfaction, it will be interesting to see which items may be useful to predict positive overall satisfaction while controlling for others. To look more closely at these relationships a number of multiple regressions are run. Further, these regressions will be used to test the hypotheses put forth in Chapter 4.

Before the regressions were run, a principal components analysis was carried out of the significant correlated items from Table 8.9. This was useful as these items were found to be significantly associated to overall satisfaction. Further, this approach of selecting only those items significant with overall satisfaction helped to reduce the number of items to be factor analyzed from 44 to 28 . This is in line with the suggestions 
made by Catell and Jaspers (1967), Browne (1968), and Linn (1968), that generally the criteria for deciding the number of components is more accurate when the number of variables is small (10 to 15 ) or moderate (20 to 30 ), and grossly overestimated when variables are large (40). In addition, this approach is similar to the one followed by Tansuhaj and Gentry (1987) in their study to determine the differences between users and actusers of the U.S./FTZs on importance of zone benefits.

Data reduction by principal components is useful in this study as the sample size is not very large. Empirically reducing the number of variables into logical components will enable running the regressions, while at the same time maintaining reasonable power to detect significance. Also, as the principal components will have little or no correlations among themselves, there will be little problem of multicollinearity among the variables (Field 2006). In addition, this will help create reliable measures that can be used for future empirical research on FTZs. Principal components analysis was preferred over other factor analysis techniques as this is a "very common and a psychometrically sound procedure" (Stevens 1996).

All items were subjected to principal components analysis with varimax rotation. To maintain a high degree of item reliability given the sample size, Steven's (1996) recommendation of testing each loading for significance at alpha $=.01$ (two-tailed tests) was followed. Based on Steven's (1996; p. 371) table of critical values for a correlation coefficient, given the sample size of 115 , the cut-off limit for significant factor loading was set at 0.50 . This led to including only those items that had high reliability (this also falls in line with Hulland's [1999] recommendation of considering items with loadings 
above 0.50 ). This also seems a popular approach with many marketing studies (e.g., White, Varadarajan and Dacin 2003).

Based on the commonly used scree test proposed by Cattell (1966), three components were selected (Figure 8.1). As Figure 8.1 shows, after the third component, the magnitude of the successive eigenvalues drops levels off. The principal components analysis extracted three components (18 items) with item loadings ranging from 0.51 to 0.88 (Table 8.10 ). The explained variance at $59 \%$ exceeded the $50 \%$ benchmark (Fornell and Larcker 1981). The Cronbach's alpha values for all three components were 0.79, 0.81 , and 0.86 , respectively, well exceeding the 0.7 benchmark (Nunnally 1978). Thus, the three components seem very reliable and internally consistent.

\section{Figure 8.1}

Scree Plot from Principal Components Analysis of Investment Items Scree Plot

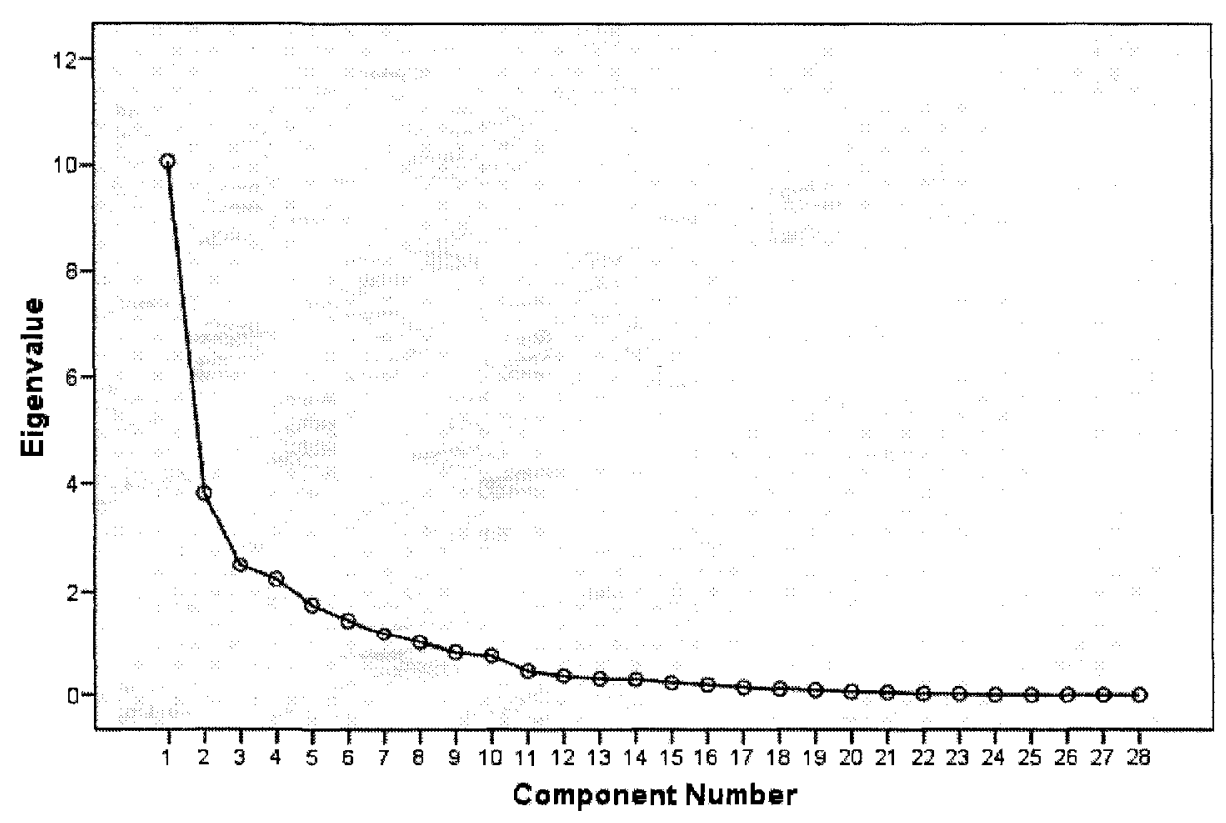


Table 8.10

Principal Components Analysis of Investment Items

(Varimax Rotation; Entries in Table are Rotated Factor Loadings)

\begin{tabular}{lccc}
\hline & \multicolumn{3}{c}{ Components } \\
Items & $\mathbf{1}$ & $\mathbf{2}$ & $\mathbf{3}$ \\
\hline Availability of skilled labour & 0.74 & & \\
Availability of expert managers & 0.77 & & \\
Technology level & 0.74 & & \\
Proximity to bigger city & 0.61 & & \\
Proximity to industry clusters & 0.72 & & \\
Customs procedures & & 0.59 & \\
Inventory control & & 0.52 & \\
Bureaucratic bottlenecks & & 0.65 & \\
Setting operations & & 0.79 & \\
Obtaining licenses & & 0.73 & \\
Obtaining work permits & & 0.51 & \\
Legal system & & 0.81 & \\
Container facilities & & & 0.72 \\
Warehouse facilities & & & 0.86 \\
Banking facilities & & & 0.63 \\
Transport facilities & & & 0.84 \\
Communication facilities & & & 0.89 \\
Transportation quality & 35.99 & 13.62 & 8.95 \\
\hline Cronbach's alpha: & 35.99 & 49.61 & 58.56 \\
Explained Variance (\%): & & & \\
Cumulative Variance (\%): & & & \\
\hline
\end{tabular}

Component one has five items with factor loadings ranging from 0.61 to 0.76 . Specific items loading on component one included: availability of skilled labour, availability of expert managers, technology level, proximity to bigger city, and proximity to industry clusters. These five items seem to address the availability or proximity of important resources such as manpower, technology, and industry clusters. These items were grouped as "Resources." 
Component two has seven items with factor loadings ranging from 0.51 to 0.80 . Specific items included: customs procedures, inventory control, bureaucratic bottlenecks, setting operations, obtaining licenses, obtaining work permits, and legal system. These items seem to relate to the administrative aspects of the zone operations. Procedures, bottlenecks, and systems set by the zones are important for the tenants. Simple and flexible administrative systems and policies are important to tenants, and as seen in the earlier results, these issues are associated with tenant satisfaction. These items collectively were termed as "Operations."

Component three has six items with factor loadings ranging from 0.72 to 0.88 . Container, warehouse, banking, transport, and communication facilities, along with transport quality comprise the six items for component three. These items were grouped as "Facilities."

Apart from the above three components, market risk, and contractual risk were also considered as independent variables for multiple regressions. As stated in chapter 4 (under the "Tenant Behaviour" section), both market and contractual risk assessment inside the zone vis-à-vis outside in the country mainland may influence a tenant's satisfaction with zone operations (Hypotheses 4 and 5). As a reminder, assessment of market and contractual risk were measured using three items on a 7-point bipolar scale, with $1=$ "zone worse than mainland" and $7=$ "zone better than mainland". The three items were:

\section{Contractual Risk}

1. Cost of making and enforcing contracts.

2. Maintenance of quality of services with a local partner. 
3. Risk of misuse of your proprietary knowledge.

\section{Market risk}

1. Stability of the political, social, and economic conditions.

2. Risk in repatriating your income.

3. Risk of expropriation of firms.

To check for the reliability of these measures, the Cronbach's alpha was computed (Table 8.11). The alpha values were 0.76 and 0.81 for contractual and market risk respectively. These values exceed the benchmark of 0.7 (Nunnally 1978). The factor loadings for the items in both constructs ranged from 0.73 to 0.90 , and the explained variance were $68 \%$ and $72 \%$ respectively.

Table 8.12 shows the results for 12 different multiple regressions. All regressions were controlled for the type of zone by including a zone dummy, where 0 was coded for the Noida zone and 1 for the Dubai zone. As indicated by the F-statistic, with the exception of Models 1 and 2, the remaining models were a significant and substantive predictor of tenant satisfaction with zone investment. Also, the table shows that the addition of more variables marks a substantial improvement in the model. The first seven models differed in the independent variables that were entered into the model. To check for individual effects and to take into consideration the sample size, a number of different regressions were run.

All models report that the zone dummy is not significant, thus the impact of independent variables on the tenant satisfaction does not differ by zone type. Models 1 and 2 show the effect of tenant size (depicted as the log of number of employees in the firm in the most recent fiscal year) and tenant export (depicted as the log of the total 
Table 8.11

Reliability Tests

\begin{tabular}{lc}
\hline Items & Loading \\
\hline Market Risk & \\
Stability of the political, social, and economic conditions & 0.77 \\
Risk of repatriating your income & 0.91 \\
Risk of expropriation of firms & 0.87 \\
Cronbach's alpha: & 0.81 \\
Explained Variance (\%): & 72.49 \\
Contractual Risk & \\
Cost of making and enforcing contracts & 0.88 \\
Maintenance of quality of services with a local partner & 0.84 \\
Risk of misuse of your proprietary knowledge & 0.74 \\
Cronbach's alpha: & 0.76 \\
Explained Variance (\%): & 67.73 \\
Overall Satisfaction & \\
Production factors & 0.70 \\
Finance factors & 0.75 \\
Economic and legal factors & 0.86 \\
Political social factors & 0.71 \\
Infrastructure factors & 0.72 \\
Country and people & 0.65 \\
Cronbach's alpha: & 0.83 \\
Explained Variance (\%): & 54.20 \\
\hline
\end{tabular}

export by the zone tenant in million U.S. $\$$ in the most recent fiscal year). Both effects are not found to be significant, thus firm size and exports by firms from the zones seem not to impact tenant satisfaction. Therefore, these results do not support Hypotheses 1 and 2. Although the hypotheses are not significant, these results highlight an important finding. This is discussed in the next section.

Model 3 shows that country risk has a significant positive impact on tenant satisfaction. Thus, tenants who report that zones are better than the mainland in terms of forming and maintaining contracts have a higher satisfaction with the zone. This result supports Hypothesis 4. Similarly, Model 4 shows that tenants who report that zones have 
$\frac{n}{n}$

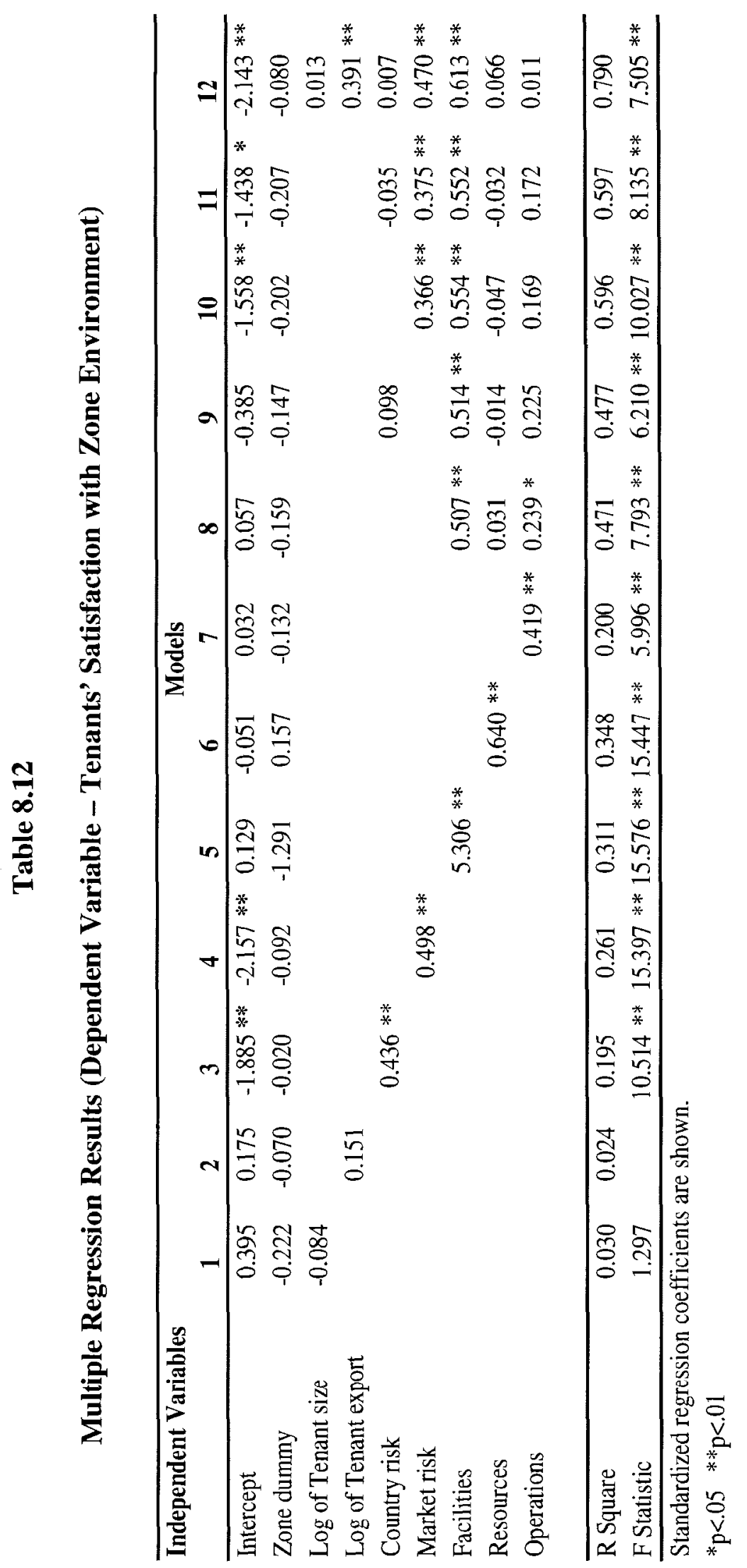


lesser market risk in comparison to country mainland have higher satisfaction. This result supports Hypothesis 5. These results are in line with the previous findings, as both zones allow $100 \%$ ownership, the laws for hiring and firing employees are not as stringent in the zone as outside (both zones do not allow trade unions), and there is less interference from political and social elements.

Models 5, 6, and 7 report that "facilities", "resources", and "operations" are significant predictors of tenant satisfaction. Thus, each of these components individually has a significant impact on tenant's assessment of how satisfied they are with the zone environment. These results support Hypothesis 3 that location benefits at the zone will lead to higher tenant satisfaction. The three variables, "facilities", "resources", and "operations" give the zone a location specific benefit. Thus, this finding suggests that these location benefits positively impact tenants' satisfaction with the zones.

Models 8 to 12, where multiple independent variables are considered together, report some interesting observations. First, when we control for more variables, two variables that consistently remain significant are market risk and "facilities." Thus, it can be safe to assume that these two are the most important variables to impact tenant satisfaction, per the models considered. Therefore, tenants' positive assessment of the various facilities such as container handling and warehousing, and a more positive assessment of market risk inside the zone than outside, because of lesser influence of political and social risks, lesser risk in repatriating income and expropriation of firms, lead to a significant positive assessment of satisfaction with zone investment. Interestingly, Model 12 reports tenant exports to be positively significant, although it was 
not found to be significant in Model 2; this may be a case of "over fitting" as the sample size for model 12 is small given the missing values on tenant exports and size.

\section{Discussion}

The results of Phase III suggest that among both zones, tenants at the Noida zone generally give a higher assessment to investment factors than the tenants in Dubai. This may seem to suggest that tenants at the Noida zone are generally happier with the zone facilities than the Dubai tenants. Further, results show that in general Noida tenants report greater significant positive differences between the zone environment and the country environment. The fact that Dubai tenants do not report many significant differences between zone and country environment may be one of the reasons they seem to assess the zone facilities less positively than the Noida tenants. This finding has important implications for Dubai zone authorities, as they need to reassess their incentives and the operations in the zone in order to increase its attraction to zone tenants.

The results also indicate that finance factors are not the only important incentives that may lead to high zone satisfaction; as a matter of fact, other factors, in particular infrastructure items may be more important. This result is in line with the findings of Tansuhaj and Gentry (1987) and Tansuhaj and Jackson (1989), who report that financial factors were relatively less important for the U.S./FTZ users, while logistics benefits were more important. This finding has strong implication for zone administrators, who need to highlight and promote other incentives besides financial in attracting new tenants and satisfying existing clients. This suggestion is also supported by the finding that infrastructure factors received the highest score in terms of factor importance for investing in the zones. 
The results also suggest that production factors are important for Noida tenants, but are relatively less important for Dubai tenants. This finding strongly supports the claim that both zones are different in terms of their orientation. The Noida zone, being an Export zone, is production-centric, where it encourages tenants to manufacture and export products; the Dubai zone, on the other hand, is trade-centric; thus, the focus is not so much on production but on storage and re-export of goods.

The results do not support Hypotheses 1 and 2. Although it may be assumed that larger firms and more international firms may acclimatize to new locations better, and may utilize resources better, the results do not support these claims. A possible reason for firm size and international experience not making a difference is because of the highly investor friendly conditions in the zone vis-à-vis the mainland. As the findings of this phase indicate that tenants assess the internal environment in the zone to be better than the host country on a large number of investment variables, even small and medium sized firms are equally likely to make the best possible use of resources inside the zone. This result is important for two main reasons. First, it shows that FTZs are a great investment location for small and medium sized firms seeking to expand into international markets. This is because the less risky and more productive environment in the zone does not seem to discriminate small firms from larger and more resourceful ones. Second, from the perspective of zone administrators, this result warns the administrators not to focus entirely on larger and more international firms.

The results support Hypotheses 3, 4 and 5. The finding that location factors, in particular "facilities", and to lesser extent "operations", and "resources" significantly impact zone satisfaction, is an important result for zone administrators, as they can 
formulate a more focused strategy involving these factors. In addition, it also highlights that clients most likely to operate in these zones are likely to have operations that will value these incentives more than others. This will help administrators segment their market and design a more focused marketing strategy to target these specific clients.

It is clear from the regression results that among the investment variables, "facilities" was the most significant in predicting zone satisfaction. This result is in line with the Phase I finding, which reports that most zones are located close to ports or airports, indicating that firms prefer to locate in zones that provide good transportation and distribution facilities.

Finally, the results also indicate that the lower perception of market risk in the zone than outside is an important determinant for zone satisfaction. In line with the Uppsalla internationalization model, this suggests that firms can use FTZs as important international locations to accelerate their internationalization process. The lower market risk in an FTZ will lead to faster turn around time for firms, that is, they will break-even sooner. 


\section{Chapter 9 CONCLUSION AND IMPLICATIONS}

The guiding principle of this study was to generate a comprehensive knowledge of FTZ characteristics and tenant behaviour. There has been an increasing popularity of FTZs across developed and developing countries. Conversely, a number of studies indicate that many FTZs have realized only limited success. The literature on FTZ is relatively small and somewhat inconsistent in its findings. Most of the studies have relied entirely on secondary data and that, too, is most often based on either one or two zone analyses. Most of the existing literature consists of studies in economics, and there is a dearth of business research on this subject. Furthermore, only a handful of the business studies are empirical, and most have studied U.S. zones only. Therefore, while the literature does cite suggestions for zones and tenants, there has been virtually no attempt made to obtain information directly from the concerned people - zone administrators and tenants recently or beyond the U.S.

This study addresses some of these inconsistencies on FTZs and fills some of the existing gaps in the literature. The study examined the main characteristics of FTZs and analysed the behaviour of tenants inside the zone by carrying out a three-phase study. Phase I involved a content analysis of 105 websites; Phase II included in-depth case studies of four different zones across the world; and Phase III involved a survey of 115 tenants across the two zones in Noida and Dubai.

The results of each of the three phases have already been discussed individually along with possible explanations of the findings. In the following section, the main findings from all three phases, along with the information obtained through the background research, are summarized and compared with the literature on FTZs and, 
more broadly, in international business. After this, the limitations of the study are discussed, followed by a discussion on the implications of this research to policy makers, managers, and to research in general. (Note: To stress the different arguments put forth, and to avoid the need to shift through the chapters, some of the important results are restated in the following sections.)

\section{General Discussion}

\section{FTZs Present across the Globe}

FTZs are present across the globe and are not restricted to one area or continent. Phase I findings show that the zones are spread across the five continents of North America, South America, Africa, Europe, and Asia. From a sample of 105 zones, the U.S. accounted for the largest number.

It was also seen that most countries do not resort to setting up only one type of zone, but have a mix of different types. The combination of Trade and Export zones is most common, as can be seen in China and Iran. The existence of different types of zones in a given country highlights the focus of the host countries to attract a larger breadth of firms. Although Phase I finds that a large proportion of these zones are in developing countries, their presence also seems to have increased among newly developed and developed countries. Among the developed countries, apart from the U.S., South Korea and Spain were the top developed countries in terms of the number of zones (per Phase I results). These findings are in line with the reports from International Labour Organization (ILO database 2003), which shows that zones are spread across developing, developed, and transitional economies, and across all continents. Although the findings 
from this research suggest that zones are present across a large number of countries, the extant research on FTZs has predominantly focused on zones in the U.S. and China, with very few researchers looking at zones in other countries.

\section{FTZs Growing Rapidly}

All three phases support the claim that the number of zones are increasing, as also is the number of firms in them. Phase I showed that $61 \%$ of the 105 zones sampled were established after 1990. Phase III shows that for both Noida and Dubai zones, the number of firms established have increased over the last three decades, with $47 \%$ and $60 \%$ of the firms in Noida and Dubai, respectively, having established operations only after 2001. These findings further highlight the importance of these zones to both host countries and firms. These findings help to alleviate some of the claims made by FTZ critics, who argue that increase in wages and reduction in tax breaks will eventually lead to closing down of zones, as firms will shift to other locations where wages remain low and incentive packages are more generous (Wilson 1992, Sklair 1993, Willmore 1995, Johansson and Nilsson 1997, Ver Beek 2001).

A possible explanation for the increase in the number of zones and firms operating in them is the continuous changes made by the host countries in improving incentives and upgrading the status of the zones by offering higher value-added services. For instance, the Indian zones, although started off as EPZs that allowed limited access to domestic markets, soon modified their restrictive policies by converting all EPZs to SEZs. Similarly, at the Shenzhen SEZ, the focus shifted from just being a low cost manufacturing zone to one that fosters technology transfers through the import of machinery and equipment, introduction of managerial skills, and on-the-job training of 
the labor force (Yuan 1993). This explanation falls in line with the findings from the Sargent and Matthews (2004) study, where they examine the role of technology as well as other factors as an explanation for the continued survival of the Mexican EPZs. They find that while it is likely that the early entrants into a zone are often concentrated in low value-added activities, as the zone gains in industrial experience, the FTZ tenants evolve towards a higher value-added, technology-intensive "manufacturing paradigm."

Interestingly, the increase in the number of zones over the last decade resembles a similar increase in the Free Trade Agreements or Regional Trade Agreements across the globe. The Regional Trade Agreements have increased considerably since 1990. In 1999 alone, 194 Free Trade Agreements were notified to the World Trade Organization (World Bank 2000). The increase in global free trade and the reduction of trade barriers would suggest that the FTZs should ideally lose importance, but the recent trend suggests the opposite. This phenomenon is termed by Papadopoulos and Malhotra (2007) as the "FTZ paradox". They suggest that contrary to popular belief trade and investment barriers may not be falling nearly as "globally", or at least not at the national level in all countries, as is commonly thought. They further state that:

"Lower barriers are very real among the developed Triad nations, whose key features include broader and highly successful free trade agreements (e.g., European Union [EU] and North American Free Trade Agreement [NAFTA]). However, in the context of developing nations (DCs), EPZs may in fact be "the", or at least "one of the", major instrument(s) through which barriers are being reduced - rather than being an add-on that offers perhaps minor and temporary 
free-er trade advantages while the host countries' national economies themselves are being broadly liberalized." (p. 153)

Thus, given the findings from this study, it seems safe to conclude that FTZs which continue to change and modify their policies will go on to grow and attract an increasing number of tenants.

\section{FTZs Control Important Information}

A systematic and recurring finding from this study was the general reluctance of zone officials and tenants to respond to surveys. During this study a number of FTZs in the U.S. were contacted, as were other zones in Asia and South America. A general finding with a number of these zones was that while the officials showed an initial interest on receiving an introductory email and/or a phone call, they quickly changed their stance on realizing the complete scope of the study. The quick turnaround by the zone authorities on learning the objectives of the study casts some suspicion over their refusal. Another general observation was that for most zones, the administrators seemed unwilling to share any financial information on the zone, and refused to offer any help in carrying out the survey.

More specifically, three zones in the U.S. and one in South America initially showed some interest in the study. Having received initial interest, the complete scope of the study was explained along with the need to interview officials and tenants and to run a survey at the zones. The administrators of these zones insisted on getting approvals before they could help in the studies. After some weeks, when no response was obtained from the zone officials, repeated attempts were made to contact them. A number of these 
officials never returned phone calls or repeated emails. Those that were finally reached simply refused to help, citing different excuses.

A very interesting case in point was regarding a zone in Miami. After I made an initial contact with a general manager, and on receiving his interest, my supervisor made a personal visit, while at a conference in Miami, to meet with the person. He explained to him the details of the study, and the manager agreed to help us. After this, we made several attempts to move the study forward at the zone by trying to contact him through emails. He never replied to any of them. When we spoke to him over the phone, he said he would reply. After waiting for more weeks, we tried to call him, but the secretary would not let our calls through. We didn't hear back from him.

In addition to such zones, even those where the study was eventually carried out, there was great difficulty in getting cooperation to carry out the research. Both officials and tenants refused to give any financial information on the zones or the zone operations. This finding was observed right through all three phases. Phase I results show that very few zones give any financial information on the websites. In addition to these, very little information is available on tenants, therefore, making it impossible to run a survey without the active help from zone administrators. The Shenzhen SEZ, one of the largest FTZ in the world, does not have a dedicated website. Important information on the Shenzhen SEZ is concealed in the collective numbers of the Shenzhen province. Similarly, other zones, too, do not have a publicly available annual report. The reports, if they exist, are directly sent to their respective ministries, which in turn publish combined reports for zones all across the country, and these too only contain export and import 
figures; virtually no information is available on the operations and the financials of the tenants.

The tenants reported very little financial information, either during the in-depth interviews or in the survey. Repeated visits and calls to the tenants to get information on their exports and sales figures were turned down. The common excuses cited were:

"We do not have permission from headquarters to share such information." "Headquarters does not allow us to fill out surveys."

"The survey will need to be sent to headquarters to get their approval."

"The only person who could answer these questions is on vacation."

Even when for some tenants the headquarters was contacted, the office refused to entertain any calls. Despite getting a cover letter from a senior zone administrator requesting the tenants to comply with the survey, the tenants did not disclose any financial information. This finding was systematic across all zones. When the "annual reports" of tenants, if they were publicly listed, were checked, no reference was made to their operations at the zone. Thus, it seemed impossible to get such information on the tenants.

The above findings are very important, as they help to answer why most of the reports by international organizations many contain misleading statistics on FTZs. The ILO, which prepared the principal database on EPZs in 2003 by collecting information via a questionnaire sent to all countries which have an EPZ, is a prime example of this. For instance, the ILO database cites only 34 zones for the Philippines, which misses that country's 133 Ecozones (Makabenta 2002) and excludes Mexico's maquiladoras altogether (there were 353 as of almost a decade ago, formally classified as EPZs by the 
World Bank; Madani 1997). And yet, against these omissions, that database includes "336 industrial parks" in the U.S., which is patently wrong in several ways - including that there are no "EPZs" in that country since all its zones are Import-oriented. As well, the number cited does not come close to the true figures for zones in the U.S. (256 main and 521 sub-zones in 2003). The same database also cites the number of firms in Albania's EPZs at 2,422 - a rather fantastical figure given the country's size and one that makes suspect the "world totals" of firms in zones (in comparison with tiny Albania, the number of in-zone firms in Egypt, a country with a successful long-standing EPZ program, is reported as 829 ).

Another major database (UNCTAD 2004) claims to show zone imports and exports for 83 countries over a 23-year range to May 2003 - but the vast majority of cells in the table are blank due to lack of data, making it impossible to use in calculating world totals (e.g., imports and exports for 2000 are shown for only 29 and 21 countries, respectively, and exports by rather major contributors such as China are not included). Lastly, although the U.S./FTZB states the number of firms operating in the U.S./FTZs, as realized through the findings of this study on New Orleans zone, these numbers are quite misleading. The number of firms quoted on the U.S./FTZB website for the New Orleans zone is 88 , while it was found through this study that there are only 7 active firms operating at the zone.

The control of information among government organizations (all zones contacted and the ones where the study were carried out were government owned) is well documented in earlier research. Sunstein (1986) states that government secrecy has been a frequent source of public concern over the decades and that the practice of withholding 
information by government organizations is nothing new. A number of possible reasons may account for this control of information. First, most of the countries have statutes that regulate the flow of important government information to foreign nationals. In an international study such as this, on important government institutions, the FTZs, the administrators may have felt apprehensive about disclosing information to researchers working in a foreign country.

Second, Desai, Foley and Hines (2006) in their study on tax havens (such havens include the FTZs), found that the firms most likely to use these havens are those where their multinational parents are either in industries characterized by extensive intra-firm trade, or which operate in industries with low foreign tax rates. This evidence suggests that multinationals employ havens to reallocate taxable income from high-tax to low-tax jurisdictions through intra-firm trade and transfers of intangible property (Desai, Foley and Hines 2006). Also, the fact that multinationals in industries with low foreign tax rates are more likely to operate in tax havens indicates that "haven affiliates do not merely serve to relocate profits away from high-tax locations, but also that firms with low foreign tax rates benefit from using tax havens to defer, or otherwise avoid, parent country's taxation of their foreign incomes" (Desai, Foley and Hines Jr. 2006). This throws further light on why possibly many zone tenant headquarters refuse to divulge any sensitive information.

Lastly, globalization is characterized by the free flow of data, commodities, and people across porous borders, leading to a strong impetus for the theft of information. Industrial espionage is a thriving industry (Richardson and Luchsinger 2007). McDermott (1994) states that "corner cutting organizations often engage in corporate theft, and it is 
normally accepted as part of their marketing mix". Richardson and Luchsinger (2007) note that one of most common tactics used by corporate spies is by misrepresenting themselves as engineers, business persons, and so on. In the wake of such recent developments, and in a world of intense competition, zone tenants whose important motive to operate in an FTZ is to gain competitive advantage, are highly likely to hold back on sharing sensitive information.

In view of the above, it may be concluded that it will be extremely difficult to get reliable sensitive information such as financial numbers on FTZs, and that it will continue to pose problems for researchers to get hold of such information either in person or through secondary databases. Considering the odds, as outlined above, the data collection in the present study may be considered a "fortunate" outcome and suggests that the sampling procedures that were followed were effective.

\section{FTZs Follow a Lifecycle Theory}

The findings from three phases of this study lend support to the lifecycle theory of EPZ evolution (infancy, growth [adolescent], maturity [middle-age], and decline [old-age]) that was proposed by Fujimori (1978) and are supported by Chen (1994). The findings can also be viewed from the perspective of the International Life Cycle phenomenon (Vernon 1966).

Phase II results hint that while the Dubai, Shenzhen, and Noida zones are in the growth stage of their lifecycle, the New Orleans zone seems presently to be in its mature stage. The number of tenants at the Dubai, Noida and Shenzhen zones is increasing, and they also have a pending list of new applicants. On the other hand, the New Orleans zone is seeing a steady decline in its operations. This is further supported by the fact that while 
the New Orleans zone was set up in 1946, the other three zones were established more recently in the 1980s. This finding was further supported by the interviews with zone administrators and tenants at the New Orleans zone, who were not sure as to how the zone is likely to move forward and do not have any specific plans to revamp the zone.

Based on background research on both Noida and Shenzhen zones, it can be stated that both appeared, at one stage, to be moving into the maturity stage. The Noida SEZ, which was earlier an EPZ, was not doing well, similar to the other zones in India. The EPZ policy was deficient by several factors like limited power of zonal authorities, absence of single window facility within the zone, rigid custom procedures for bonding and bank guarantees, restrictive FDI policy, procedural constraints, and severe infrastructural deficiencies. To revamp the zones and address these limitations, the government of India decided to convert all EPZs to SEZs in year 2000. This led to wideranging measures to restructure the zones; the zones liberalized their policies, relaxed the severity of controls, and simplified procedures. Several measures were also taken to improve the quality of governance of the zones. This strategy helped to revamp the growth of the Noida SEZ and prevented it from moving to the maturity stage. Similar strategies by the Shenzhen SEZ helped to retain its growth which included setting new priorities to distinguish the zone in becoming a dominant center in high-tech industries, international finance, and commercial transaction (Liu and Li 1993).

On the whole for FTZs, given the results from Phase I which suggest that a large proportion of zones that were sampled were established after 1990, it would seem that FTZs collectively are at present in a growth stage, with more and more countries starting to join the bandwagon. 
Another interesting finding was that while both Trade and Export zones have seen an increase in growth, Import zones in the U.S. have noticed a decline in the number of new FTZs being set up. Further, Phase I results find that nearly 86\% of Trade and Export zones are being established in developing countries. These trends show that FTZs are possibly experiencing the International Product Life Cycle phenomenon as proposed by Vernon (1966). In this phenomenon, it is noticed that while the manufacturing of new products begins in the developed countries, over time, due to increased manufacturing capabilities of developing and third-world markets, and the low cost of production at these sties, manufacturing of these products gradually shifts to the developing markets. A similar phenomenon is seen in FTZs, where the initial zones were established in developed countries (the U.S. established the Foreign Trade Zone program in 1936, Ireland established the Shannon Free Zone in 1959). The findings of this study suggest that the production of these zones has now shifted to developing countries. Thus, given the findings above, one can conclude with caution that FTZs, similar to products, follow a lifecycle phenomenon.

\section{FTZs Primarily of Three Main Types}

An important claim made in this study was that there are primarily three main types of FTZs - Export-, Import-, and Trade-oriented zones. This is in contrast to the literature which is replete with numerous terminologies to denote variants of FTZs. For instance World Bank's Kusago and Tzannatos (1998) list no less than 19 different terminologies to describe FTZs. Such a large list of variants of FTZs results in terminological confusion and impedes understanding of the concept (Makabenta 2002, Malhotra, Papadopoulos and Huang 2007). In addition, this lack of proper classification of different FTZs has led 
to significant confusion in the secondary data provided by international organizations, since each computes statistics using different definitions for various zone types. From a business perspective, FTZ typology or classification scheme provides the basis for understanding and targeting different types of FTZs.

In this study, the three phases provide ample support to the existence of three main types of FTZs. Phase I results show that there are some important differences in the top five incentives for the three zones, as shown on their websites. While the second most important incentive for Export zones are tax holidays, this does not appear in the top five for Import zones, and it appears at only the fifth position for Trade zones. Another major difference between the zones is the "cheap labour" incentive, which appears only for Export zones and not for Trade and Import zones.

Phase II results shows that while the Noida zone officials rated 5 or very important for manufacturing and exports; New Orleans rated 5 for manufacturing, exports, imports, and warehousing, and Dubai rated exports, imports and distribution at 5. These ratings seem to agree with the orientation of the zones. Also, while warehousing comes out as very important for New Orleans, and somewhat important for Dubai, it has no importance for the Noida zone. In addition, on comparing the export and import figures for the four zones, in line with the Export orientation of the zones, both Noida and Shenzhen zones support a trade surplus, while the New Orleans zone has a high trade deficit providing further proof that the U.S. zones are Import-oriented.

Further support was obtained through the Phase III results which show that the primary business function of the companies at the Noida zone is manufacturing (94\% of the firms), while $79 \%$ of the firms in Dubai mention trade as one of their primary 
business. In Noida, $25 \%$ of firms mentioned trade as one of the primary businesses, while only $9 \%$ of Dubai firms mention manufacturing. In addition, it could be seen that the Noida tenants gave a significantly higher assessment for the availability of skilled labour, availability of expert managers, labour productivity, transportation quality, and customs procedures than the Dubai zone tenants. This is further proof to the assumption that Export-oriented zones offer greater encouragement for firms to set up manufacturing units than Import zones.

Based on the above results and more such findings reported in the earlier chapters, it may be safe to suggest that FTZs can be classified as one of the three main types. It should also be noted that while the orientations and some of the main incentives and benefits and characteristics differ across the three zone types, there are also a number of similarities across them, as shown in the results. So although this classification may not be mutually exclusive, it does point to the principal motives of the governments that establish or expand FTZ programs and of the firms that choose to invest in and/or operate within free zones, and it can be useful in understanding the types of zones existing at any point in time and therefore enabling educated decisions by governments or firms to create or invest in a particular types of zones.

\section{FTZs Offer More than Just Duty Free Benefits}

Researchers have focused predominantly on "duty exemption" as the key advantage of FTZs for business firms. This may be a result of little business research in this area, thereby limiting the understanding of FTZ benefits from the firm's perspective. It is clear from the findings of this study that there are indeed many and multi-faceted benefits of FTZs, in line with the claims made by a small handful of researchers who have 
considered the broader FTZ benefits for business (Papadopoulos 1987, Tansuhaj and Gentry 1987, McIntyre, Narula, and Trevino 1996, Malhotra and Papadopoulos 2007).

\section{Strategic Perspective}

The findings from all of the phases stress the strategic perspective of zones. The infrastructure facilities are found to be significantly better inside the zones. The legal framework is substantially different inside the zones, and as seen through the results, it is assessed better inside. The political environment is less volatile inside the zone, and it has minimal impact inside compared to outside. A number of these zones offer strategic geographic locations. The Jebel Ali zone lies at the centre of major trade routes, and this advantage was cited by respondents as key to their decision to invest in the zone.

Results from Phase II and in particular from Phase III provide evidence to the fact that zones offer many more benefits. For instance, based on zone officials' assessment for the Dubai zone, most of the substantial differences between environment inside the zone and outside were related to hiring of immigrants (for example, obtaining licenses and work permits were considered much easier inside the zone than outside). Similarly, the New Orleans zone officials feel that the zone offers a substantially better investment climate in terms of lesser bureaucratic bottlenecks and ease of setting up operations. Similarly, Noida zone officials reported that tax advantages, subsidies, import duties, and export duties were much more favourable inside the zone than outside. Along with financial factors, production factors such as cost of energy, manufacturing costs, and labour costs were found to be more favourable inside the zone than outside. These findings help to highlight the difference in infrastructure facilities inside and outside the zone. 
Similar results were obtained from zone tenants' assessment of zone environment vis-à-vis outside. It was seen that for the Noida zone, production factors such as cost of energy, manufacturing costs, and labour costs were found to be more favorable inside the zone than outside. Similarly, tax structure, tax advantages, and import duties were rated more favorably for both Noida and Dubai zones then the host country mainland. A very interesting finding is the importance of infrastructure facilities. The results also show that both Dubai and Noida zones offer better warehouse facilities. Other significantly better infrastructure facilities at the zone include container facilities for the Noida zone and communication facilities for the Dubai zone. Finally, the general view of the country and people was also assessed to be more favourable inside the zones than outside. Both zones reported that people were more trustworthy and friendly inside the zone than outside.

The results of correlations between zone satisfaction and investment factors also show the predominant impact of other factors besides duty free benefits on tenants' assessment of satisfaction with zone investment. The results show only two finance items to have a significant association with tenant overall satisfaction. In contrast, economic and legal factors seem to play a very important role in determining tenant satisfaction. For instance, at Noida, ease of setting operations, obtaining licenses, work permits, and a better legal system are found to be significantly associated with satisfaction. For the Dubai zone, bureaucratic bottlenecks came out as a significant factor. A most noteworthy result was the large number of significant infrastructure items. Noida's proximity to big cities, industry clusters, and ports, railways and airports significantly correlated with tenant satisfaction. Other facilities such as container, banking, transport, communication were also found to be significantly associated with Noida tenant satisfaction. Proximity to 
bigger city and transport facilities were significantly correlated with Dubai tenant overall satisfaction.

Another very interesting finding from Phase II is that, given the high exports from the Noida SEZ to the Dubai free zone (82\% of total exports from the Noida SEZ go to U.A.E.), it may be gathered that the Noida zone acts as a producer of goods, and the Dubai zone stores and then re-exports these goods to different countries. This synergy of activities across two different zone types highlights the benefits that can accrue by viewing zones as networks; therefore, suggesting that firms can benefit by pooling together specific advantages of different zones located across the globe. This will help firms to establish a stronger global presence.

In addition to the above findings, Phase III regression results also show a similar story. Most of these results are in line with important business strategy theories. Some of the important results from regression analysis and their association with these theories are shown below:

- Country risk has a significant positive impact on tenant satisfaction. Thus, tenants who report that zones are better than the mainland in terms of forming and maintaining contracts have a higher satisfaction with the zone. This result is in line with Dunning's (1993) internalization benefits, which suggest that multinational firms prefer to locate at places offering possibilities to internalize operations to keep their competitive advantage in-house. The findings from this study suggest that most FTZs give the right to establish fully-owned or majority-controlled ventures and also allow full repatriation of profits and/or capital. 
- Tenants who report that zones have lesser market risk in comparison to mainland have higher satisfaction. This result is in line with the Uppsala internationalization model (Johanson and Wiedersheim-Paul 1975, Johanson and Vahlne 1977), and Ahmed et al. (2002) findings, which suggest that market risk perception affects management's decision about commitment of resources to a particular market. It is noteworthy that market risk remained significant across all models, suggesting that this may be one of foremost factors influencing tenant satisfaction, thus, can be expected to lead to attraction of new tenants.

- Zone facilities emerged as a consistent significant factor in predicting tenant satisfaction. This result is in line with both Porter's (1998) cluster theory and Dunning's (1993) location advantages. In line with these theories, these assets are specific to a particular location, but are available to all firms, and the FTZs enjoy advantages to other locations in the home country and foreign countries due to possession of such assets. Contrary to the notion of comparative advantage of nations, these assets are not only confined to natural endowment benefits, such as work force and capital, but also include the cultural, legal, political, infrastructure, and cluster environments. In addition to these theories, this finding also confirms the results of Tansuhaj and Gentry (1987) and Tansuhaj and Jackson (1989) on a study of users and non-users of the U.S./FTZs. They, too, report distribution and logistic facilities to be important criteria in their decision to use the zone, while the financial incentives were found to be relatively less important. 


\section{Cluster Effect}

The above results seem to suggest that FTZs can be considered as, what Porter (1998) calls, "clusters" - "critical masses - in one place - of unusual competitive success in particular fields." (p. 78). FTZs offer unique competitive advantages to firms in terms of knowledge, relationships, and incentives, thus their similarity to clusters. FTZs can be considered as geographic concentrations of interconnected companies and institutions. They include an array of linked industries and other entities, such as suppliers of inputs (e.g., at Shenzhen SEZ, most of the domestic companies at the zone are suppliers of specialized inputs for either multinationals and/or domestic exporters), and providers of specialized infrastructure. Similar to clusters, FTZs also include governmental and other institutions, such as customs and commerce departments, trade associations (e.g., association of Jewellery traders at the Noida SEZ), freight forwarders and logistic companies, and financial institutions (e.g., presence of large number of financial and insurance services at the Jebel Ali Free Zone in Dubai). Similar specialized facilities can be seen at other zones such as Shannon Free Zone in Ireland, Santa Cruz SEZ in Mumbai, and Colon Free Zone in Panama.

The above results provide sufficient support to contradict the common notion among many researchers and international organizations that zones merely provide duty free benefits. This is important because understanding the zones as strategic assets can lead to long-term investments in zones, and also help firms in integrating them in the their overall business strategy. 


\section{FTZs Lack Marketing Strategy}

The results also point to a conspicuous absence of marketing strategies for zones. Phase I results show that prominent promotion tools used by zone websites were zone overview, useful links to other websites, links to news, and set up steps. While these tools may be somewhat useful, they can be hardly be looked at as promotional tactics by zones. Beneficial tools such as successful case studies of tenants were very rarely seen on websites. In addition, no competitive or comparative information vis-à-vis the other zones or the host country mainland was given on the websites. Most of the U.S. zones did not have a dedicated website and only shared a page on their associated port website. Most of the websites, leaving aside a very few such as the Jebel Ali Free Zone, Noida SEZ, and Shannon Free Zone, did not have very appealing or attractive website designs. In most cases it was very difficult to find information on the websites. Further, it was found that the mean number of promotional tools used by each zone across the different types of zones were as low as 2.42 for Import zones and only as high as 3.43 for Export zones. This can hardly be called effective promotion through websites. Most of the websites gave very limited information on the zone, a number of them citing only a contact number for additional information.

In combination with this, the findings from Phase II suggest a very similar picture. Apart from Dubai, no other zone had a separate department allocated solely to marketing and promotion. Also, apart from Dubai, no other zone had a proper systematic procedure for marketing research, whereby they could conduct satisfaction surveys of tenants. No attempt was ever made by any zone to collect information on non-users of the zones in an effort to convert them to use the zones. In addition, when officials were 
inquired whether the zone carried out any marketing or more specifically promotion, responses were varied. While the Noida officials seemed adamant that not only did the zone have no promotion or marketing strategy, in their view there was no need to promote the zone. Similar to Noida, New Orleans also had no specific promotion or marketing program.

The lack of market orientation on the part of zones seems to be well highlighted in the different possible sources of information on the zone cited by officials and tenants. While officials cited websites, brochures, trade magazines, and personal inquiries as important sources; the tenants stated word-of-mouth through the trade (e.g., suppliers, competitors) as the primary source of information on the zones. A similar finding was reported by Tansuhaj and Jackson (1989). This contrast can have strong implications for zones (discussed separately under implications).

An important reason for the lack of interest in developing a marketing strategy came out of the in-depth interviews. When asked about the competition the zones faced from other domestic and/or international zones, the overwhelming response across all zone officials was that they felt no competitive threat. However, the tenants did not feel the same way; many tenants felt there was serious competition by other zones. For example, Noida tenants cited Santa Cruz SEZ in Mumbai and SEZs in China, New Orleans tenants cited FTZs in the Middle East and Shenzhen tenants cited Indian zones as threats. Another possible reason for no interest in marketing the zone could be the overpowering influence of the government. The fact that in India, China, the U.S. and U.A.E., most zones are owned by government, there is little interest for them to encourage competition among their own zones. 
These findings are in line with those from Tansuhaj and Gentry (1987), Tansuhaj and Jackson (1989), and Mathur (1993), who reported that the users of Foreign Trade Zones were more aware than non-users of zone benefits, and that despite the rapid increase of the U.S./FTZs during the early 1980s, the U.S. firms were virtually unaware of the zone program due to ineffective marketing of the Foreign Trade Zones. This lack of a marketing strategy by zones leads to unnecessary negative perception of the quality of services offered by zones (Tansuhaj and Jackson 1989). In a similar vein, Papadopoulos and Malhotra (2007) state that possible reasons for a lack of marketing strategy for zones are "limited financial resources, a lack of relevant skills, a jaundiced view of marketing and other capitalist practices (Klein and Nason 2001)" (Page 155).

The results from this study help to cautiously conclude that zone marketing is virtually non-existent and occasionally might be limited to only promotion (perhaps arising from the common misconception that equates marketing only with its promotion component [Malhotra, Papadopoulos and Huang 2007]). It completely ignores the other parts of the marketing mix, including marketing research and market segmentation (to enable effective targeting of potential zone tenants).

\section{Limitations of the Study}

The study had several limitations arising mainly from the research design and the realized samples. Although several steps were taken to address them for the purposes of this thesis, they do affect the generalizability of the findings and at the same time they point to approaches that may be used in future research to advance our knowledge in this field.

First, since there was virtually no past research on which to build the survey phase of the study, the methodological design could not draw on previously tested approaches 
specific to the study of FTZs. Instead, by necessity several aspects of the methodology were determined as the study unfolded and/or by borrowing from related areas of research. Earlier studies on foreign investment location decisions were used to help develop the main research instruments for the cases and survey in Phases II and III, respectively. More importantly, the three-phase design and the implementation of the phases sequentially made it possible for the findings at each stage to help inform the next. While this broadened the scope of the overall study and required more time and effort than might have been possible otherwise, the pre-test of the instruments and the results suggest that the interview guide and questionnaire were appropriate and that the study enabled the development of a comprehensive understanding of the nature and operations of FTZs. In future studies of this type it may be possible to use these instruments as the base for further refinements. In general, a sequential phase-based design appears to be an effective approach for research in areas where there are no prior studies to draw on.

Second, the analysis for Phase I was deliberately limited to a purposive sample of those zones that have reasonably good websites. It could be argued that a random sample drawn from the population of existing zones might have been more appropriate and might have produced different results. Although this argument has obvious merit and a broader sample might have been better, the information available from the different databases and other sources does not make this possible, at least for now. For example, the only source that provides information on large numbers of zones is Diamond and Diamond (2003) but this focuses more on providing technical data for potential tenants (e.g., the square footage of average lots for lease or whether a zone operates on the $110 \mathrm{~V}$ or $220 \mathrm{~V}$ system in terms of its electrical supply) rather than the strategic and financial information that 
was sought in this research. For this latter type of information, the only available sources are databases such as those of the ILO (2004) or the U.S./FTZB (2007), and these simply point to the available websites. Therefore, these websites are the main information source not only for this study but also for potential investors. As well, as was noted when discussing this part of the methodology, a reasonable assumption may be made that zones that have websites, and especially those with reasonably effective website designs, are more likely to be those that are better organized or, at least, more determined and aggressive in attracting tenants - and therefore that they are of greater interest for a study of this type. In other words, although the sample was not random, the zones that were included seem to provide a good representation of those that would also be of more interest to investors. Future studies are likely to be faced with the same limitations until better FTZ information sources are developed. In addition, it should be noted that, considering the sampling problems encountered during the present study, traditional mail survey approaches are unlikely to work well in the FTZ environment and may be faced with extremely low response rates.

Third, during the case studies in Phase II it was not possible to both conduct the in-person interviews and collect the "matching" leave-behind questionnaire in all cases. As outlined in Chapter 7, for various different reason some of the respondents agreed to the personal interview but could not, or refused to, fill out and return the structured questionnaire. The reluctance of several interviewees to report "in writing" on their operations probably reflects the types of confidentiality and related concerns that were discussed earlier in this chapter. In future studies that might, perhaps, focus only on a case-based research design and therefore have more time and resources available for this 
phase alone, it may be possible to generate a fuller set of both interviews and structured questionnaires. In this study, however, even with this limitation, as was noted in Chapter 7, the number of completed interviews and leave-behind questionnaires was not only much higher than the original target during the proposal stage but also large enough to make complete case studies possible and to provide a wealth of information on the four zones that were included in this phase. Considering the difficulties with other methods of data collection (e.g., a random mail survey as discussed above), the case approach seems to be appropriate for generating in-depth information on selected zones.

Fourth, the research findings draw on a narrow sample of only four zones for Phase II and only two zones for Phase III, and the overall sample size for Phase III is relatively small. Ideally it would have been nice to include the Shenzhen and New Orleans zones in Phase III as well, but for the reasons outlined earlier this was not possible. Specifically concerning Shenzhen, which was not part of the originally planned case studies, its inclusion was an "addition to" the original plan for Phase II rather than an "omission from" Phase III, and so this in fact is an enhancement rather than a limitation. Concerning the New Orleans FTZ, as well as the other U.S. zones where an effort to apply the survey was made, the unfortunate reality was that the numbers of tenants operating in these zones are significantly lower than these zones claim on their websites and that the zone managers refused to permit or facilitate the survey even for the few tenants they do have. The result of these problems was that the initial intent of conducting the survey at three zones representing the three main types (Import, Export, Trade) was not accomplished and only two zones, one SEZ and one FTZ, in only two countries, were sampled. Therefore, clearly the findings cannot be generalized to other 
types of zones (mainly U.S.-based Import-oriented FTZs) or countries, except with great caution and with appropriate qualifiers. On the other hand, the zones where tenants were surveyed are significant and fairly representative institutions located at critical regions, and the total realized sample, while relatively small overall, is in line with other industrial surveys and represents a better response rate than most such studies achieve.

Overall, therefore, the study had several limitations which must be kept in mind when interpreting and using the results - but, at the same time, the combination of findings from Phases I, II, and III provided highly useful results, and, together with the insights gained from the extensive review of the available literature (mainly from economics), helped to achieve the original overall goal of enhancing our understanding of FTZs.

\section{Implications}

While it is believed that the findings from this study have implications beyond its immediate setting, it is important to bear in mind that this was an exploratory study and that the application of these results in practice must proceed cautiously. In this section, implications for policy makers, managers, and research are discussed separately.

\section{Implications for Policy Makers}

The importance of FTZs can be gauged by their increasing number around the world. Given this scenario, this study is opportune in its timing and objectives to suggest useful policy lessons. These are outlined below:

1. A successful FIZ operation depends critically on a set of economic and institutional factors. The Chinese SEZs, Indian SEZs, and the Dubai zones have benefited greatly 
from continued capital flow, and for the large part, the inflow has been policy influenced. Compared with other zones (that have not been successful, such as those in Russia, and in African nations), incentive packages offered in these zones are not only attractive to investors or tenants, but also have a high degree of flexibility as well. These zones offer a favourable overall investment environment, including a strong infrastructure, simplified legal frameworks, and reduced bureaucracy. A strong implication for other zone policy makers is to develop a comprehensive strategy that does not only rely on offering tax incentives and low-cost labour. The results from this study provide strong support for developing such a strategy, as the results show that it is not only the tax or financial incentives, but factors such as infrastructure, distribution, political and social environment, and presence of market and contractual risk that are strongly correlated to tenant satisfaction with zone investment. In this respect this is supposedly the first research to actually study how investors perceive the attractiveness of the zones versus the zone officials.

2. It was also realized through the study that the location of the zone also matters. Establishing a zone in an isolated area simply to achieve regional development and disregard investors' needs can lead to zone failure (Papadopoulos 1987, Makabenta 2002). In addition, setting a zone in regionally underdeveloped places will likely increase start up costs not only for the zone but also for tenants, and therefore curb its subsequent expansion.

3. One of the most important implications of this study is for policy makers to seriously consider developing a marketing strategy. Given the results from this study, where it was found that there exist certain discrepancies in the expectations of the tenants and 
the officials, a market orientation is necessary for zones to survive in a world of mushrooming FTZs. For instance, while officials believed that the most important source of information on the zones was the website, tenants expressed word-of-mouth through trade as the most important source. Considering that tenants rely on their suppliers or, logistic or distribution companies with whom they may have tie-ups, it is imperative for zone managers to consider these third-parties. Therefore, it is important for zones to find ways to enhance the operations of these third parties rather than compete against these middlemen. This is a common problem in the U.S./FTZs, where zones end up competing against large freight forwarders and distribution companies (Tansuhaj and Jackson 1989). A comprehensive overall strategy as suggested above can help the U.S. zones overcome this competition.

Most often it is assumed that zone marketing is only limited to promotion. However, it was found that zones carried out few promotional activities. The website analysis revealed that there is major scope for improvement in many of these websites. There is a need to give more information on the type and number of tenants that operate in the zone. Also, greater stress should be given to case studies of successful firms. Contact information of tenant associations could be provided to encourage non-users to contact them. A link to the zone website should be available on home pages of relevant country websites, such as the host country's Ministry of Commerce, Finance, and External Affairs sites. It is surprising to note that embassies and high commissions of these host countries have very little information on the zones. Embassies may be a very good place to promote the zones. 
4. The analogy made earlier in this chapter on the growth of FTZs to the growth of regional trade agreements bring with it an important caveat for the policy makers. Bhagwati (2002) created the term "Spaghetti Bowl Syndrome" to exemplify the problems associated with the rise of regional trade arrangements around the world. He used it to discuss the problems in European Union and Africa.

a. “... spaghetti bowl: a messy maze of preferences of preferential trade arrangements (PTAs) formed between two countries, with each having bilaterals with other and different countries, the latter in turn bonding with yet others, each in turn having different rules of origin for different sectors, and so on...".

Although the FTZs may not face the specific problem outlined above, a rise in the number of zones in countries will create another quite similar problem for the policy makers. The problem deals with the allocation of resources. A random increase in the number of zones in its periphery (like the case of India which has initiated a process to sanction more than $100 \mathrm{SEZs}$ ) will lead to inadequate allocation of resources to each of these zones. Further, this study suggests that zones with good location attributes and a comprehensive strategy do well over a period of time. A scenario where zones are set up, thinking that the mere presence of these will bring in tenants can easily backfire; because it is one thing to set up a zone but quite a different proposition to make it successful over time.

5. Further to the suggestion of an existence of a cluster effect at the zone, an important implication for policy makers may be to follow Porter's (1990) diamond framework to develop a comprehensive strategy for zones. In line with the diamond framework, 
the four determinants of competitive advantage (factor conditions, demand conditions, firm strategy, structure and rivalry, and related and supporting industries) can be used as a policy framework. The suggestions for each of these factors in context to the FTZ are described below (shown in Figure 9.1):

Figure 9.1

\section{Porter's Diamond Framework Applied to FTZs}

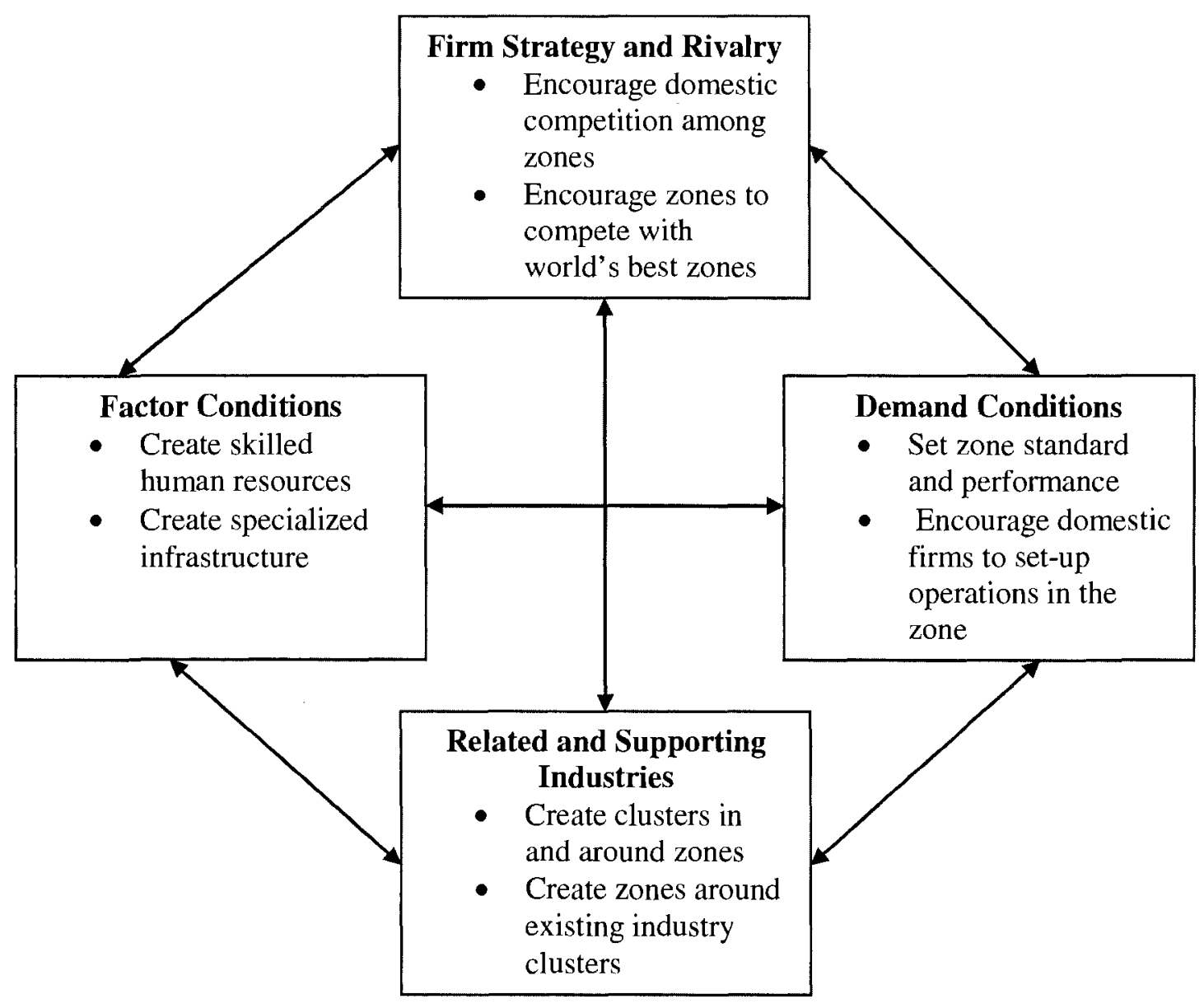


- Factor conditions: The zone administrators should focus on creating and upgrading skilled human resources in and around the zone, developing strong infrastructure, and creating specialized institutions. The Noida SEZ is a case in point. Noida has a number of good educational and technical institutes. It has two prominent MBA institutes that are ranked among the top ten in India. It comes as no surprise that a large number of new companies setting up in the Noida SEZ are technology related firms. Also, the presence of fast lane highways near the zone encourages firms to establish the zone as its base.

- Demand conditions: Zone administrators could affect demand conditions through regulations that affect zone standards and the process by which zones are set up, such as those governing zone performance, zone safety, and the operating practices of zones. The immense variance in different zones within one country highlights the lack of proper regulations on setting up zones. The website analysis shows great variations in the size of zones across the world. This phenomenon is also true for zones within a country (as seen for Chinese SEZs). It has been often cited while the Shenzhen SEZ is a successful zone in China, the other SEZs in China have not done well. The same scenario can be seen in Bangladesh, India, and the U.S. In addition, it may be imperative to create a strong internal demand for zone operations. A strong demand among domestic firms to use the zone will influence zones to improve their processes and standardize their services across all zones in the country. Such a strategy will create zones with a strong competitive advantage, in turn making them attractive to foreign companies. 
- Related and supporting industries: Policy makers can initiate the creation of clusters in and around the zones. Although most clusters often emerge and begin to grow naturally, the government could initiate clusters through investments to create specialized factors such as university technical institutes, training centers, data banks, and specialized infrastructure. This can have implications on the location decision of the zone. It is normally seen that most successful clusters are formed around a concentration of specialized expertise. For instance, the presence of the famous Jebel Ali Port initiated the U.A.E. government to create a zone around the port, as it enables the zone to make use of the specialized services and structures already existing at the port. Similarly, the jewellery zones in India are normally located in and around the areas which have related suppliers and supporting industries for manufacturing jewelleries, in addition to trained workers.

Another strong implication is for host countries to set up the type of zones that are most likely to reinforce existing or nascent industry cluster than in trying to create zones around new expertise. Again a case in point is the creation of a number of port and airport zones in U.A.E. to harness its strategic location in the world map. A similar approach has been followed by the Colon Free Zone. Maquiladaros in Mexico is another such example, which has now become a specialized cluster for the production of automotive parts.

- Firm Strategy, Structure, and Rivalry: A common and systematic finding across all four zones was that the zone administrators did not feel any competition existed either from domestic or international firms, although the 
tenants felt otherwise. The policy makers should encourage not only competition among domestic zones but also encourage zones to compete with international ones. Such an approach will push zones to further improve their processes and systems to stay competitive. Possibly the countries could encourage private companies to set up zones; this will increase competition and thereby the quality of all zones.

6. Last but not least, the life cycle framework (as discussed above) could also help administrators reassess where their zones are and decide on future strategies. Zones such as the one in New Orleans and others in the U.S. could benefit from such a policy framework.

\section{Implications for Managers}

This study both supports the known importance of FTZs to both international and domestic firms and also puts forth new implications for managers. These are listed below:

1. One of the most important implications of the study is to inform managers that FTZs are not merely instruments that provide duty free benefits or tax advantages, but also offer better specialized infrastructure, better legal and political environments, and less market and contractual risks. This finding will help to expand the use of zones to a much wider audience.

2. This study finds support for suggestions by Papadopoulos (1987), Tansuhaj and Jackson (1989), Tansuhaj and Gentry (1987), and Mathur (1993) that strategicallylocated zones can be used as centralized distribution hubs, thereby enabling firms to reduce their total inventories while still being able to respond quickly to the needs of several nearby markets. This strategy was highly prevalent at the Jebel Ali Free Zone, 
where a large number of international firms use the zone as an important distribution hub for the movement of goods to nearby Asian and other European markets. This explains why a large number of Fortune 500 companies are present at this zone.

3. For many small and medium-sized enterprises that do not have the kind of resources owned by large multinationals, FTZs can provide a cost-efficient instrument in their effort to expand into international markets. The findings from this study, that the tenants assess contractual and market risks, and political and legal risks, to be significantly less inside the zone than outside, should be an encouragement to many small firms to effectively use FTZs to expand to countries which were otherwise difficult places to expand given the high risks in the country mainland. For some countries, presence of zones could mean the difference in whether a firm decides to target that country or not. This is especially so in countries where the overall legal or political environment and/or its infrastructure are considerably worse than those of its zones, which is the case in a number of developing countries.

4. Most FTZs allow $100 \%$ control in setting new operations without the need to find local partners. For firms that wish to retain their competitive advantage by internalizing their operations, FTZs may offer a suitable option to set up 100\% subsidiaries, thereby avoiding the risks of sharing competitive resources.

5. Per the Uppsala internationalization model (Johanson and Wiedersheim-Paul 1975, Johanson and Vahlne 1977), firms can rapidly internationalize by either decreasing the existing risk in international markets and/or by diversifying risks. FTZs offer both options; the results of this study suggest that zones are perceived to have less market and contractual risk, as well as political and legal risk, thus, this should encourage 
rapid internationalization of firms, as they will be able to break-even faster due to little effort being put towards handling these risks.

In addition, by setting up operations at strategically located zones such as Jebel Ali and/or Shenzhen (both zones are at close distance to important international markets; e.g., Jebel Ali is close to a huge middle-east market, while Shenzhen is close to Hong Kong), firms can diversify their risks. This is possible because goods kept in these zones can be redirected from one market to another at little cost and without being subjected to import formalities. As Papadopoulos (1987) suggests, "This can be a useful strategy especially for exporters of fad items whose sales may fall far short of expectations in a given market, or to high technology firms that face short product life cycle."

6. The results from the tenant survey suggest that firms attribute similar importance to different investment factors whether investing in a zone or a country. Therefore, the firms planning to invest in zones should adopt a similar international market selection model as what might be adopted for country selection. This point also highlights that firms need to be careful before selecting a zone, rather than relying on unsystematic selection process, a systematic selection process should be adopted for zone selection, akin to the selection of international markets.

7. A common finding among zone tenants across the zones was that firms were primarily located in a single zone, and operated in no other zones. It was realised through this study that firms could greatly benefit by adopting a zone network strategy. By understanding the locational distribution of zones around the globe, firms can integrate a network of free zones into international operations. For example, a 
firm can locate its manufacturing unit in a zone at a location that offers low costs of production (mostly likely an Export zone), from where the goods can be transferred to a Trade zone that can act as a distribution hub, from where the goods can be transferred to an Import zone and finally sold in that market or nearby markets. During this entire process, the firm will enjoy low cost of operations, and benefit from financial incentives and specialized infrastructure. Also, through this strategy goods can move from resource extraction to final destination without being subjected to local conditions in host countries. Such a strategy can be extremely useful for both large and small and medium-sized enterprises.

8. This study provides managers with good understanding of the three main types of zones. It tells managers the kind and type of tenants operating at these zones, the benefits offered by them, the relative assessment of different investment factors at these different zones, the underlying policies behind the setting up of these zones, and the likely problems that may be faced at these zones.

This background of the three main types of zones can substantially help managers to design a zone based strategy. Before selecting a zone, managers should distinguish among zones on their orientation, and determine zones whose characteristics are suitable to their firm's nature and objectives. To do this, first, it is necessary to examine a number of zones to distinguish those that may support the firm's international strategy. Second, similar to a portfolio analysis when selecting international markets, the orientation and the location of different zones on the global map should be ascertained to understand how investing in one zone can make possible the future use of other zones around the globe. Finally, a comparison should 
be made between the nature and the main business of the firm to the orientation and the policies in place at the zone. Such a systematic decision process could help managers select the most suitable zone. Table 9.1 shows a typology of FTZs. Please note that the term "isomer" in the table represents the other possible names that are often used to denote the same zone type. These zones are mostly similar, but may differ very slightly in a few policy or organizational issues. This typology should offer a fast assessment of different zone types to help managers make zone selection decisions.

9. Finally, Figure 9.2 shows the role of FTZs in a marketing system. Keeping in mind the incentives offered by different zones and the possibility of using zones as a network, Figure 9.2 shows the prospect of how a given firm (in this case an automobile manufacturer) can combine a network of different zones based on their incentives and location to reach the final consumer. The implication here is that the money that tenants will save by operating in different zones should be eventually passed on to the final consumer. This is in line with a recent study by Papadopoulos and Malhotra (2007) that shows the importance of zones in a macro marketing system. 
$\sqrt[n]{n}$

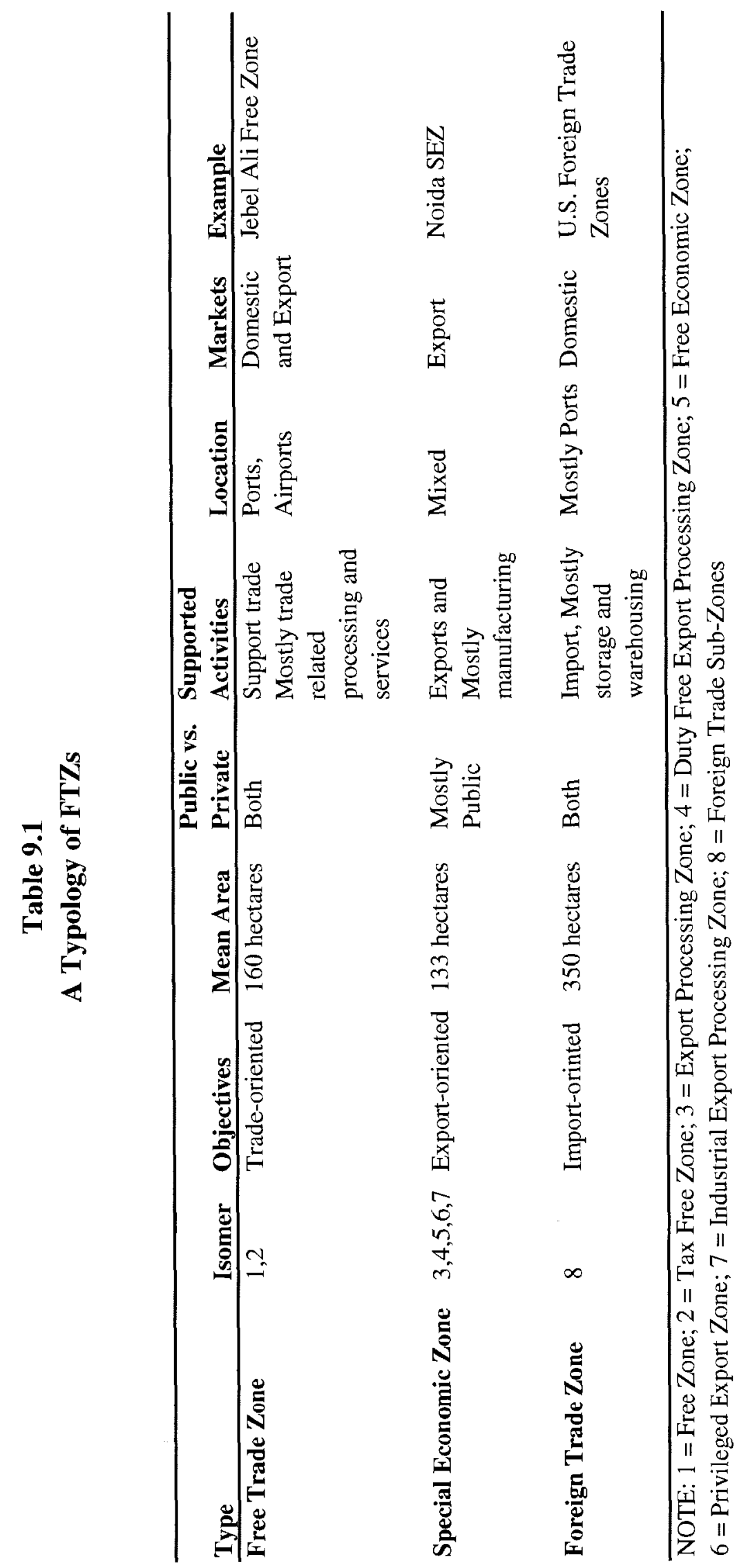


ฉ

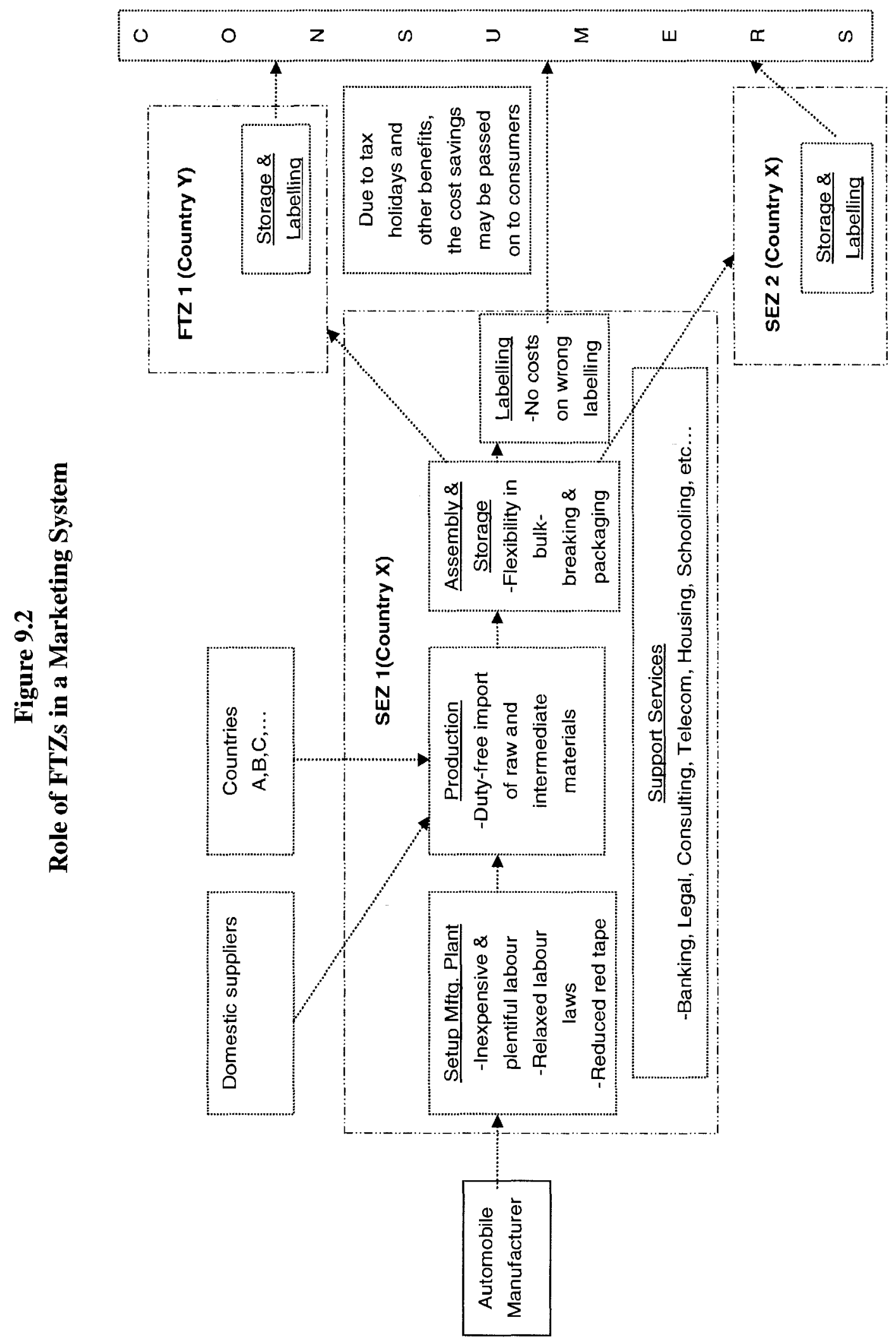




\section{Implications for Research and Future Research Directions}

The findings have a number of important implications for research on FTZs.

1. This research helps to fill several of the existing gaps in the FTZ literature. It was noted during the literature review that the existing literature was inconsistent in judging the impact and benefits of zones towards the firms and society at large. There is considerable void in the literature to explain why some zones are more successful than others. This study has helped to answer several questions that will remove some of the inconsistencies present in the literature. Some of the questions this research has helped to answer are: How do FTZs operate? How do different FTZ types differ in their operations? What are the major objectives of FTZs? How do zones promote themselves? What are the ownership structures of different FTZs?

2. The research on FTZ has been dominated for long by developmental and regional economists, with very little research by business scholars. Therefore, there was very little information available on the firms that operate in zones. This study helps to highlight the kind and type of firms that operate in different zones. Importantly, by adopting a three-phase research, this study helps to throw light into the thinking of tenants behind setting up operations in the zone, and what factors may influence their satisfaction within the zone environment.

3. Most of the extant research on FTZs has been confined to one or two zones. This is to the best of my knowledge the first study that compares four zones (during phase two), and carried out empirical research across two different types of zones. Thus the results from this study are more generalizable than most studies in this area. 
4. The literature has often confused one zone type with another. This is mainly because of a large number of different zone terminologies used by researchers. By proposing a typology of three main types of zones with a list of isomers, this should help researchers to follow a common terminology for a particular zone type, thus removing confusion and helping to promote standard zone terminologies that will make comparison across different research articles addressing different zone types easier.

5. This study helps towards developing a basic theory on FTZs from a business perspective, by showing a generic behaviour of tenant firms towards FTZs. Phase III results find support to a number of hypotheses, which helps to generate a set of assertions to understand the relationship between FTZs and tenant firms. More broadly, results from all three Phases suggest relationships, connections, and interdependencies between FTZs and tenant firms. Furthermore, by looking at zones from different business frameworks such as cluster theory, lifecycle phenomenon, and Porter's diamond, this study suggests testable models for FTZs. In this endeavor, it is hoped that this research has addressed Kinunda-Rutashobya's (2003) appeal of a more appropriate explanation of the FTZ phenomenon.

6. This study also makes an important contribution towards academia by integrating disparate fields of research. The study combines inputs from marketing, international business, business strategy, international trade, and economics. The outcome of this is a richer understanding of integration than what could have been achieved from within a single literature. 
7. The problems faced in conducting this study at different zones should act as guidelines for future researchers to plan their research accordingly.

8. Last but not least, it is hoped that this study spurs additional research on FTZs in business, most specifically in international business, marketing, and business strategy.

\section{Future Research}

Apart from future research that addresses specifically the limitations, this study also suggests other very interesting research possibilities. First and foremost is the need for a better secondary database. As mentioned earlier, the available databases are replete with errors, discrepancies, and omissions. It seems clear that a major research effort is needed to obtain reliable, up to date, and useful statistics on FTZs. These might include the number of zones within each of the categories in the typology developed above, data on employment, FDI, imports and exports, number of tenant firms, and composition of trade and investment, and other similar statistics on zone operations. This research suggests that this will be a phenomenal task.

In terms of empirical research, it would be interesting to test the robustness of the empirical results with studies on other zones. It may be worthwhile to consider a wider mix of the different types of zones. This can be done in a number of different settings. It can be performed as (1) a multi-country longitudinal study or (2) a single-country longitudinal study. A longitudinal study would involve examining the change in FTZ operations and the drivers and outcomes over a defined multi-year time frame. This can be studied in a single or multi-country setting. A longitudinal research design would allow for the assessment of "change in international competitive advantage", and "change 
in the level of internationalization." A cross-sectional study although feasible, would be somewhat limiting as some constructs need to be viewed over a multi-year time frame.

It may also be interesting to go back to the same zones after some years to see how these zones have evolved. This would make an interesting longitudinal study that would lead to more robust and generalizable results.

Another future research avenue will be to compare users and non-users at different zones. This will help to show, first, if there is any significant difference in the demographics of the users and non-users. Second, it will show whether users are more competitive than non-users. Finally, considering a control set of firms that are operating outside the zones in the host country mainland would enable a more compelling testing of a FTZ model, because this will enable studying the comparative advantage of firms operating in FTZs.

Studies can also be done on whether present zone users choose target countries first and then FTZs within them, or, conversely, select specific "destination" zones, largely ignoring the country(ies) in which these may be located, and the factors influencing one approach over another. This is of obvious importance to both investors and host nations, and is perhaps akin to a related question that has received some attention in the international business literature - whether firms looking to expand via greenfield investments versus mergers or acquisitions "buy the country" or "buy the company regardless of its location."

Future research could be directed at understanding the relationships and complexities between headquarters and subsidiaries at the zone by talking to managers at both places. 
The dependent variable in this study for the regression models was measured as tenant satisfaction; other measurements can be used for the dependent variable, which may bring forth new and interesting results. The variable can be operationalised as the intensity of a firm's operations in FTZs. It can also be measured as the volume of sales/exports from firm's FTZ operations, or the value of a firm's investments in the operation. The focal construct may also be conceptualized as a nominal variable (the preand the post- FTZ firm), where FTZ operation can be perceived as a discrete event.

Finally, future research can study the cluster effect at zones more closely. This would help to show whether firms inside the zone have substantial backward linkages with domestic firms inside and outside the zone.

In conclusion, this thesis is an initial exploration of FTZ characteristics and behaviour of firms that operate in them. It attempts to introduce a framework or structure to an unsystematic area of research that is devoid of empirical studies, by adopting an extensive and a systematic three-phase methodology. The thesis shows that FTZs are important strategic institutions for both business firms and host countries. It provides a broader, more complete, and more realistic view for understanding FTZ-tenant arrangement. Furthermore, it provides a rich account of the orientation, objectives, working, benefits, and marketing of FTZs, as also the types, motives, perceptions, and zone-usage decisions of tenant firms. The results from this thesis should benefit the academic and business community alike. In the end, it is hoped that this thesis will help to shake off the "now-archaic" accepted views on FTZs, and inspire more business research in this increasingly important institution. 


\section{REFERENCES}

Agarwal, S., \& Ramaswami, S. N. (1992). Choice of Foreign Market Entry Mode: Impact of Ownership Location and Internalization Factors. Journal of International Business Studies, First Quarter, 1-27.

Aggarwal, A. (2005). Performance of Export Processing Zones: A Comparative Analysis of India, Sri Lanka and Bangladesh. ICRIER Working paper, No.155 (March), 1-89.

Ahmed, Z. U., Mohammad, O., Tan, B., \& Johnson, J. P. (2002), International risk Perceptions and Mode-Of-Entry: A Case Study of Malaysian Multinationals. Journal of Business Research, 55, 803-813.

Aikat, D. (1995). Adventure in Cyberspace: Exploring the Information Content of the World Wide Web Pages on the Internet. Unpublished doctoral dissertation, University of Ohio, Akron, $\mathrm{OH}$.

Andhra Pradesh website. (2006). About SEZ. Retrieved June 19, 2006, from http://www.apsez.com/about/overview.htm

Barney, J. B. (1991). Firm Resources and Sustained Competitive Advantage. Journal of Management, 17(1), 99-120.

Basile, A., \& Germidis, D. (1984). Investing in Free Export Processing Zones. Paris: OECD - Organization for Economic Co-operation and Development.

Beenhakker, A., \& Damanpour, F. (1992). Globalization of Foreign Trade Zones: The Case of the United States. International Trade Journal, 7(2), 181-203.

Bhagwati, J. (2002). Coping with Antiglobalization. Foreign Affairs, 81(1), 2-7.

Black, C. (2002). The PR Practitioner's Desktop Guide. London: Thorogood Publishing. 
Brenes, E. R., \& Ruddy, V. (1997). Free Zones in El Salvador. Journal of Business Research, 38(1), 57-66.

Brouthers, K. D. (1993). The Influence of International Risk on Entry Mode Strategy in the Computer Software Industry. Management International Review, 35(1), 7- 28.

Browne, M.W. (1968). A Comparison of Factor Analysis Techniques, Psychometrika, 33, 267-233.

Brown S. L., \& Eisenhardt K. M. (1997). The Art of Continuous Change: Linking Complexity Theory and Time-Paced Evolution in Relentlessly Shifting Organizations, Administrative Science Quarterly, 42(1), 1-34.

Buckley, P. J., \& Casson, M. C. (1976). The Future Of Multinational Enterprise. New York: Holmes \& Meier Publishers.

Budd, R. W., Thorp, R. K., \& Donohew, L. (1967). Content Analysis of Communications, New York: Macmillan.

Cabezas-Navas, N. (2007). Identification of Key Characteristics of Main Types of Free Trade Zones. Unpublished Master's thesis. MBA program, Carleton University, Canada.

Cattell, R.B. (1966). The scree test for the number of factors. Multivariate Behavioral Research, 1, 245-76.

Cattell, R.B. \& Jaspers, J. (1967). A General Plasmode for Factor Analytic Exercises and Research. Multivariate Behavioral Research Monographs, 3, 1-212.

Caves, R. E. (1971). International Corporations: The Industrial Economics of Foreign Investment. Economica, 38(149), 1-27. 
Chen, X. (1994). The Changing Roles of Free Economic Zones in Development: A Comparative Analysis of Capitalist and Socialist Cases in East Asia. Studies in Comparative International Development, 29(3, Fall), 3-25.

Cho, C-H., \& Cheon, H. J. (2005). Cross-Cultural Comparisons of Interactivity on Corporate Web Sites. Journal of Advertising, 34(2), 99-115.

Choi, I. (1995). Export-Oriented Foreign Direct Investment in East Asian and Latin America: Determinants of Location. Unpublished Ph.D. dissertation, Department of Economics, University of South Carolina.

Clark Special Economic Zone. (2006). Why Choose Clark. Retrieved June 5, 2006, from http://www.visitclark.com/investors/why-clark.asp

Colon Free Zone website. (2006). General Information. Retrieved June 10, 2006, from http://www.colonfreezone.com/info/default.htm

Confederation of Indian Industry. (2006). Special Economic Zones - Engines for Growth. Chandigarh, India.

Cornwell, T. B. (1989). Foreign-Trade Zones in the United States: A Longitudinal Management Perspective. International Marketing Review, 6(6), 42.

Contractor, F.J. \& Lorange, P. (1988). Competition vs. Cooperative: A Benefit/Cost Framework for Choosing Between Fully-Owned Investments and Cooperative Relationships. Management International Review, Special Issue, 5-18.

Cote, J., \& Buckley, M. R. (1987). Estimating Trait, Method, and Error Variance: Generalizing Across 70 Construct Validation Studies. Journal of Marketing Research, 24, 315-318. 
Cullen, J. B., Johnson, J. L., \& Sakano, T. (1995). Japanese and Local Partner Commitment to IJVs: Psychological Consequences of Outcomes and Investments in the IJV Relationship. Journal of International Business.

Czapor, Beata (2000), Foreign Direct Investment in an Economy in Transition: An Exploratory Study of the Polish Investment Climate, unpublished Master's thesis, Master of Management Studies program, Carleton University

Dawson, S., \& Dickinson, D. (1988). Conducting International Mail Surveys: The Effect of Incentives on Response Rates within an Industrial Population. Journal of International Business Studies, 19, 491-496.

de Mooij, R. A., \& Ederveen, S. (2003). Taxation And Foreign Direct Investment: A Synthesis of Empirical Research. International Tax and Public Finance, 11, 775-802.

Desai, M. A., Foley, C. F., \& Hines Jr., J. R. (2006). Do Tax Havens Divert Economic Activity?. Economics Letters, 90, 219-224.

Diamond, W. (1979). Free Trade Zones Offer Worldwide Opportunities. Area Development, (December), 12.

Diamond, W., \& Diamond, D. B. (2003). Tax Havens of the World. New York, NY: Mathew Bender \& Co. Inc.

Diamond, W., and Diamond, D. B. (1984). Tax-free Trade Zones of the World. New York, NY: Mathew Bender \& Co. Inc.

Dillman, D. A. (1978). Mail and Telephone Surveys: The Total Design Method. New York: John Wiley.

Dillman, D. A. (2000). Mail and Internet Surveys: The Tailored Design Method. New York: John Wiley. 
D'Souza, Ritoo (1993), The Canadian Investment Climate: Foreign Investors' Experiences and Perceptions. Unpublished Master's thesis, Master of Management Studies program, Carleton University

Dubai Chamber of Commerce and Industry. (2004). Foreign Trade of Dubai's Free Zones 2001 - 2002. Data Management \& Business Research Department, Dubai

Dunning, J. (1993). Multinational Enterprises and the Global Economy. Great Britain:Addison-Wesley.

Edison, S. W., \& Geissler, G. L. (2003). Measuring Attitudes towards General Technology: Antecedents, Hypotheses and Scale Development. Journal of Targeting, Measurement and Analysis for Marketing, 12(2), 137-156.

Eisenhardt, K. M. (1989). Building Theories from Case Study Research. Acadamy of Management Review, 14 (4), 532-550.

El Pedregal website. (2006). Key Reasons to Invest in El Salvador. Retrieved May 25, 2006 from http://www.elpedregalsal.com/en/index.html.

Ettore, B. (1998). Considering Free Zones. Management Review, 87(10), November, 8.

Field, A. P. (2006). Discovering statistics using SPSS ( $2^{\text {nd }}$ ed). London: Sage.

Firoz, N. M., \& Murray, H. A. (2003). Foreign Investment Opportunities and Customs Laws in China's Special Economic Zones. International Journal of Management, 20(1), 109.

Firoz, N. M., Rezvani, F., Ramin, T., \& Abdallah, W. (2003). Investing in China's Economic Development Zones: A Managerial Guide. International Journal of Management, 20(2), 223. 
Fornell, C., \& Larcker, D. F. (1981). Evaluating Structural Equation Models with Unobservable Variables and Measurement Error. Journal of Marketing Research, $18(1), 39-50$.

Foster, M. J., \& Alkan, I. (2003). Understanding Patterns of FDI: the Case of Turkey and its Auto Industry. European Business Journal, 15(2), 61-69.

Fujimori, H. (1978). Export Processing Zones in Asian Countries. Tokyo, Japan: Institute of Development Economies.

Ge, W. (1999). Special Economic Zones and the Opening of the Chinese Economy: Some Lessons for Economic Liberalizations. World Development, 27(7), 1267-1285.

Ghoshal, S., \& Nohria, N. (1993). Horses for Courses: Organizational Forms for Multinational Corporations. Sloan Management Review, 34, 23-35.

Gross, B., \& Sheth, J. N. (1989), Time-oriented Advertising: A Content Analysis of United States Magazine Advertising, 1890-1988. Journal of Marketing, 53(October), 76-83.

Grubel, H. (1983). Free Market Zones-Deregulating Canadian Enterprise. Vancouver, B.C.: Fraser Institute.

Grubert, H., \& Mutti, J. (1991). Taxes, Tariffs and Transfer Pricing in Multinational Corporate Decision Making. Review of Economics and Statistics, 73(2), 285-93.

Gujarati, D. (2003). Basic Econometrics (4 $4^{\text {th }}$ ed.). McGraw-Hill-Irwin.

Hamada, K. (1974). An Economic Analysis of the Duty-Free Zone. Journal of International Economics, 4, 225-41.

Hamilton, C., \& Svensson, L. E. O. (1982). On the Welfare Effects of a 'Duty-Free Zone'. Journal of International Economics, 13(1/2), 45-64. 
Hammoutene, A. (2004). Relationship Marketing in the Export Sector: Empirical Evidence from Dubai's Jebel Ali Free Trade Zone. Journal of American Academy of Business, Cambridge, 5(1/2), 294-301.

Harris, S. G., \& Sutton, R. I. (1986). Functions of Parting Ceremonies in Dying Organizations. The Academy of Management Journal, 29(1), 5-30.

Harzing, A. W. (2000). Cross-national Industrial Mail Surveys: Why do Response Rates Differ between Countries?. Industrial Marketing Management, 29(3), 243-54.

Haywood, R. C. (2000). Free Zones in the Modern World. WEPZA, 5(1).

Helleiner, G. K. (1973). Manufacturing for Export, Multinational Firms and Economic Development. World Development, 7(13), 21.

Hofstede, G. (1980). Culture's Consequences. Beverly Hills, CA: Sage.

Hong Kong Trade Development Council. (1990). Recent investment environments of Guangdong, Fujian and Hainan. Hong Kong: Research Department of HKTDC.

Hong, M., \& Chen, L. S. (2001). Quantitative and Dynamic Analysis of the OLI Variables Determining FDI in China. The Applied Regional Science Conference (ARSC), 13(2).

Hood, N., \& Young, S. (1979). The Economics of Multinational Enterprise. London: Longman Group Ltd.

Hulland, J. (1999). Use of Partial Least Squares (PLS) in Strategic Management Research: a Review of Four Recent Studies. Strategic Management Journal, 20, 195-203.

Hymer, S. (1976). The International Operations of National Firms: A Study of Direct Foreign Investment, Cambridge, Doctoral Dissertation, MA: MIT Press, MIT, 1970. 
ILO - International Labor Organization. (2003). Employment and Social Policy in Respect of Export Processing Zones (EPZs). Committee on Employment and Social Policy (286 ${ }^{\text {th }}$ session). (March1-22), ILO. Geneva.

ILO - International Labor Organization. (2004). Database on Export Processing Zones. ILO Sectoral Activities Department. Vienna, Austria. Retrieved January 12, 2006, from www.ilo-mirror.cornell.edu/public/english/dialogue/sector/themes/epz.htm ILO - International Labor Organization. (2007). Database on Export Processing Zones, ILO Sectoral Activities Department; Vienna, Austria. Retrieved August 10, 2007, from www.ilo.org/public/english/dialogue/sector/themes/epz.htm

ILO/UNCTC - International Labor Organization and United Nations Center for Transnational Corporations. (1988). Economic and social effects of multinational enterprises in export processing zones. Geneva, Switzerland.

IMF - International Monetary Fund. (2003). Direction of Trade Statistics. Washington, D.C.

Indian Ministry of Statistics website. (2007). New Delhi, India. Retrieved September 15, 2007, from http://mospi.nic.in/

Jebel Ali Free Zone website. (2006). Miscellaneous information from zone website. Dubai, UAE. Retrieved March 10, 2007, from http://www.jafza.co.ca/jafza/index.aspx

Jebel Ali Free Zone Association corporate brochure. (2007). Freedom Matters. Dubai. Jebel Ali Free Zone website. (2007). History and Future. Dubai. Retrieved August 18, 2007, from www.jafza.co.ae/jafza/content/section1/s1_2.aspx 
Jatusripitak, S., Faey, L., \& Kotler, P. (1985). Strategic Global Marketing: Lessons Form the Japanese. Columbia Journal of World Business, Spring, 47-53.

Jauch, H. (2002). Export Processing Zones and the Quest for Sustainable Development: A Southern African Perspective. Environment \& Urbanization, 14(1), 101-113.

Jayawardena, D. L. U. (1983). Free-Trade Zones. Journal of World Trade Law, 17 (September-October), 427-444.

Jenkins, M. (2000). Export Processing Zones in Developing Economies: Theoretical and Empirical Consideration. Doctoral Thesis. Brandeis University.

Jenkins, M. (2006). Sourcing patterns of firms in Export Processing Zones (EPZs): An empirical analysis of firm-level determinants. Journal of Business Research, 59(3), $331-334$

Jenkins, M., Esquivel, G., \& Gerardo, L.B. (1998). Export Processing Zones in Central America. Harvard Institute of International Development, Development Discussion Papers, Central America Project Series, (August), 1-57.

Jobber, D., Mirza, H., \& Wee, K. H. (1991). Incentives and Response Rates to Crossnational Business. Journal of International Business Studies, 22(4), 711-721.

Johanson, J., \& Vahlne, J. (1977). The Internationalization Process of the Firm: A model of Knowledge Development and Increasing Foreign Market Commitments. Journal of International Business Studies, 8(1), 23-32.

Johanson, J., \& Wiedersheim-Paul, F. (1975). The Internationalization of the Firm: Four Swedish Cases. Journal of Management Studies, October, 305-322.

Johansson, H., \& Nilsson, L. (1997). Export Processing Zones as Catalysts. World Development, 25(12), 2115-2128. 
Johnson, J. C. (1986). Seven Transportation Megatrends for the Late 1980s. Transportation Practioners Journal, 53(2), 164-180.

Journal of Commerce. (1983). Special Issue on FTZs (New York, November 8)

Kalligatsi, Katerina (1996), Greece in the Eyes of Foreign Investors: An Exploratory Study. Unpublished Master's thesis, Master of Management Studies program, Carleton University

Kassarjian,H. H. (1977). Content Analysis in Consumer Research. The Journal of Consumer Research, 4(1), 8-18.

Kim, W. C., \& Hwang, P. (1992). Global Strategy and Multinationals' Entry Mode Choice. Journal of International Business Studies, First Quarter, 29-53

Kinunda-Rutashobya, L. (2003). Exploring the Potentialities of Export Processing Free Zones (EPZs) for Economic Development in Africa: Lessons from Mauritius. Management Decision, 41(3), 226-232.

Klein, T., \& Nason, R. W. (2001). Marketing and Development: Macromarketing Perspectives: Handbook of Marketing and Society. Thousand Oaks, CA: Sage Publications, 263-297.

Kopp, R. (1994). International Human Resource Policies and Practices in Japanese: European and United States Multinationals. Human Resource Management, 33, 581599.

Krippendorff, K. (1980). Content Analysis. Beverly Hills, CA: Sage Publications.

Kumar, D. N. (1994). Determinants of Export Orientation of Foreign Production by U.S.Multinationals: An Inter-Country Analysis. Journal of International Business Studies, 25(1), 141-56. 
Kumar, M.S. (1984). Growth, Acquisitions, and Investment: An Analyst of the Growth of Industrial Firms And Their Overseas Activities. Cambridge: Cambridge University Press.

Kundra, A.K., \& Sharan, V. (2000). Performance Evaluation of Indian Export-Processing Zones since Economic Liberalization. International Economics (Economica Internazionale), 53(3), 339-357.

Kusago, T., \& Tzannatos, Z. (1998). Export Processing Zones: A Review in Need of Update (World Bank Social Protection Discussion Paper No. 9802). Washington, D.C.

Linn, R.L. (1968). A Monte Carlo Approach to the Number of Factors Problem. Psychometrika, 33, 37-71.

List of Foreign Trade Zones. (n.d.). Retrieved May 1, 2006, from http://ia.ita.doc.gov/ftzpage/letters/ftzlist.html

Liu, G., \& Li, J. (1993). Economic Development Strategies for the Shenzhen Special Economic Zone in the 1990s. Shenzhen Jingji Tequ Jiushi Jingji Fazhan Zhanlue, Beijing: Economic Management Press.

Mackerras, C., Taneja, P., \& Young, G. (1994). China since 1978: Reform, modernization and socialism with Chinese characteristics. New York; Melbourne: St. Martin's Press; Longman Cheshire.

Madani, D. (1997). A Review of the Role and Impact of Export Processing Zones. World Bank Research Report, Washington, D.C.

Makabenta, M. P. (2002). FDI Location and Special Economic Zones in the Philippines. Review of Urban \& Regional Development Studies, 14(1), 59. 
Malhotra, N. K., Dixit, A., \& Uslay, C. (2002). Integrating Internet Technology in Marketing Research Education. Marketing Education Review, 12(3), 25-34.

Malhotra, S., \& Papadopoulos, N. (2007). Free Trade Zones: Concept and an International Marketing Perspective. Competitive Paper Presentation and Proceedings, Academy of International Business Annual Conference, Indianapolis

Malhotra, S., Papadopoulos, N., \& Lihuan H. (2007). Special Economic Zones: Role in an Aggregate Marketing System and an In-Depth Analysis of Chinese Special Economic Zones. Proceedings, 2nd Indian Institute of Management Conference on Research in Marketing, Ahemadabad.

Manezhev, S. (1993). Free Economic Zones in the Context of Economic Changes in Russia. Europe-Asia Studies, 45(4), 609.

Martin, J. (1998). Gateways for the Global Economy. Management Review, 87(11), 22.

Mathur, L. K. (1993). Reducing Sourcing Costs through Foreign Trade Zones. Journal of General Management, 19(1), 64-75.

Mathur, L. K. (1994). Are Foreign-Trade Zone Users More Cost Competitive in International Marketing?. Journal of Transnational Management Development, 1(2), 73-91.

McDermott, M. J. (1994). Is international marketing a game of spy versus spy?. Brandweek, 35(25).

McGilvray, A. J. (2004). Enhancing the Foreign-Trade Zones Program For Small And Medium-Sized Manufacturers. Staff Report: Foreign-Trade Zones Board; U.S. Foreign-Trade Zones Board; Washington, D.C. 
Mcintyre, J. R., Narula, R., \& Trevino, L. J. (1996). The Role of Export Processing Zones for Host Countries and Multinationals: A Mutually Beneficial Relationship?. International Trade Journal, 10(4), 435-466.

Miles, H., \& Huberman, M. (1994). Qualitative Data Analysis: A Sourcebook, Beverly Hills, CA: Sage Publications.

Miles, M., \& Huberman, A. (1984). Qualitative Data Analysis: A Sourcebook of New Methods. Newbury Park: Sage.

Miyagiwa, K. F. (1986). A Reconsideration of the Welfare Economics of a Free-Trade Zone. Journal of International Economics, 21(3/4), 337-350.

Nachum, L., \& Wymbs, C. (2005). Product Differentiation, External Economies and MNE Location Choices: M\&As In Global Cities. Journal of International Business Studies, 415-434.

National Association of Foreign Trade Zones Report. (2003). U.S. FTZs: A Positive Force in Trade \& Economic Development. Washington, D.C.

National Bureau of Statistics of China. (2005). Statistical data. Retrieved November 25, 2005, from http://www.stats.gov.cn/tjsj/

Noida Special Economic Zone website. (2007). Retieved January 1, 2007, from http://www.nsez.gov.in/

Noida Special Economic Zone. (2006). Internal Documents, Retrieved on December 20, 2006.

Noland, M., \& Flake, L. G. (1997). Opening Attempt: North Korea and the Rajin-Sonborg Free Economic and Trade Zone. Journal of Asian Business, 13(2), 99-116.

Nunnally, J. C. (1978). Psychometric Theory New York, NY: McGraw Hill. 
OECD. (2000). International Trade and Core Labour Standards, Research Report, Organization for Economic Co-operation and Development; Paris, France.

Papadopoulos, N. (1985). The Free Trade Zone as a Strategic Element in International Business. Canadian Business Review, 12(1), 51-55.

Papadopoulos, N. (1987). The Role of Free Zones in International Strategy. European Management Journal, 5(2), 112-120.

Papadopoulos, N. Heslop, L. A., Jog, V. M., \& D'Souza, R. (1997). The Investment Climate in Canada: Foreign Investor Experiences and Perceptions, Proceedings of the Administrative Sciences Association of Canada, New Foundland.

Papadopoulos, N., \& Malhotra, S. (2005a). The Role of Export Processing Zones in Development and International Marketing Strategy: Review of Key Issues and Suggestions for Research. Proceedings, International Conference on Marketing \& Development, (Greece, June 8-11).

Papadopoulos, N., \& Malhotra, S. (2005b). U.S. Foreign Trade Zones in International Marketing Strategy: Review, Analysis, and Suggestions for Research. Proceedings, European International Business Academy Annual Conference, (Oslo, December 1013).

Papadopoulos, N., \& Malhotra, S. (2005c). Free Trade Zones and Export Processing Zones as Instruments for International Strategy: Review, Typology, and Suggestions for Research. (Poster). Academy of International Business Annual Conference, (Quebec City, July 9-12). 
Papadopoulos, N., \& Malhotra, S. (2007). Export Processing Zones in Development and International Marketing Strategy: An Integrative Review and Research Agenda. Journal of Macromarketing, 27(2), 148-161.

Peteraf, M. A. (1993). The Cornerstones of Competitive Advantage. Strategic Management Journal, 14(3), 179-191.

Port of New Orleans website. (2007). Retrieved on May 25, 2007, from www.portno.com/index.htm

Porter, M. E. (1990). Competitive Advantage of Nations, New York: The Free Press.

Porter,M. E. (1998). Clusters and the New Economics of Competition. Harvard Business Review, 76(6), 77-90.

Prahalad, C. K., \& Hamel, G. (1990). The Core Competence of the Corporation. Harvard Business Review, 68, 79-91

Richardson, L., \& Luchsinger, V. (2007). Strategic Marketing Implications In Competitive Intelligence And The Economic Espionage Act Of 1996. Journal of Global Business Issues, I(2), 41-45.

Romero, A. T. (1998). Export Processing Zones in Africa: Implications for Labour. Competition \& Change, 2(4), 391.

Rondinelli, D. A. (1987). Export Processing Zones and Economic Development in Asia: A Review and Reassessment of a Means of Promoting Growth and Jobs. American Journal of Economics \& Sociology, 46(1), 89-106.

Rouse, M. J., \& Daellenbach, U. S. (1999). Rethinking Research Methods for the Resource-based Perspective: Isolating Sources of Sustainable Competitive Advantage. Strategic Management Journal, 20, 487-494. 
Sargent, J., \& Matthews, L. (2001). Combining Export Processing Zones and Regional Free Trade Agreements: Lessons from the Mexican Experience. World Development, 29(10), 1739.

Sargent, J., \& Matthews, L. (2004). What Happens When Relative Costs Increase in Export Processing Zones? Technology, Regional Production Networks, and Mexico’s Maquiladoras. World Development, 32(12), 2015-30.

Schneider, K. C., \& Schneider, S. B. (1979). Trends in Sex Roles in Television Commercials. Journal of Marketing, 43(3), 79-84.

Sen, P. (2003). China special economic zone and development areas yearbook. Beijing, China: China Financial and Economic Publishing House.

Shenzhen Government Online. (2007). Economy. Retrieved May 1, 2007, from http://english.sz.gov.cn/economy/

Shenzhen Statistic Bureau. (2005). 2004 annual report. Retrieved November 21, 2005, from http://www.sztj.com/pub/sztjpublic/tjsj/tjnb/default.html

Singer, H. W., \& Gray, P. (1988). Trade policy and growth of developing countries: Some new data. World Development, 16(3), 395403.

Sklair, L. (1993). Capitalism \& development. Londres: Routledge

Statistic Bureau of Hainan Province. (2004). Statistical data. Retrieved November 24, 2005, from http://www.statistic.hainan.gov.cn/

Stempel, G. H. (1989). Content Analysis, In Stempel, G.H. and Westley B.H. (Eds.) Research Methods in Mass Communication (pp. 124-136). Englewood Cliffs, NJ: Prentice Hall 
Stevens, J. (1996). Applied Multivariate Statistics For The Social Sciences ( $3^{\text {rd }}$ ed.). Lawrence Erlbaum Assoc.

Summerfield, G. (1995). The Shadow Price of Labour in Export Processing Zones. A Discussion of the Social Value of Employing Women in Export Processing in Mexico and China. Review of Political Economy, 7(1), 28.

Sunstein, C. (1986). Legal Interference with Private Preferences. The University of Chicago Law Review, 53(4), 1129-1174.

Tansuhaj, P. S., \& Gentry, J. W. (1987). Firm Differences in Perceptions of the Facilitating Role of Foreign Trade Zones in Global Marketing and Logistics. Journal of International Business Studies, 18(1), 19-33.

Tansuhaj, P. S., \& Jackson, G. C. (1989). Foreign Trade Zones: A Comparative Analysis of Users and Non-Users. Journal of Business Logistics, 10(1), 15-30.

U.S./FTZB - U.S. Foreign-Trade Zones Board. (2002). $64^{\text {th }}$ Annual Report of the ForeignTrade Zones Board to the Congress of the United States. Washington, D.C.

U.S.FTZB - U.S. Foreign-Trade Zones Board. (2004). Miscellaneous information from Board website. Washington, D.C. Retrieved September-October 2004 from http://ia.ita.doc.gov/ftzpage/

U.S. Foreign Trade Zones Board. (2006). U.S. Foreign Trade Zone (Annual Report for FTZ. No. 2). Washington, D.C.

U.S./FTZB - U.S. Foreign-Trade Zones Board. (2007). $67^{\text {th }}$ Annual Report of the ForeignTrade Zones Board to the Congress of the United States. Washington, D.C. 
UNCTAD - United Nations Conference on Trade and Development (1983), Export Processing Free Zones in Developing Countries (January Doc. TD/B/C.2/211). Geneva, Switzerland.

UNCTAD - United Nations Conference on Trade and Development (2002), World Investment Report 2002: Transnational corporations and export competitiveness. Geneva, Switzerland.

UNCTAD - United Nations Conference on Trade and Development. (2002b). World Investment Report 2002: Transnational corporations and export competitiveness. United Nations Conference on Trade and Development. Geneva, Switzerland.

UNCTAD - United Nations Conference on Trade and Development. (2002a). Imports/Exports of reporting countries from/to Free Zones. United Nations Conference on Trade and Development. Geneva, Switzerland.

UNCTAD - United Nations Conference on Trade and Development. (2004). Imports/Exports of Reporting Countries from /to Free Zones, Geneva, Switzerland

UNIDO - United Nations Industrial Development Organization. (1995). Export Processing Zones: Principles and Practice. Vienna: United Nations Industrial Development Organization.

Ver Beek, K. A. (2001). Maquiladoras: Exploitation or Emancipation? An Overview of the Situation of Maquiladora Workers in Honduras. World Development, 29(9), 155367.

Vernon, R. (1966). International Investment and International Trade in the Product Cycle. Quarterly Journal of Economics, 80, 190-207. 
Volckner, F., \& Sattler, H. (2006). Drivers of Brand Extension Success. Journal of Marketing, 70, 18-34.

Wall, D. (1976). Export Processing Zones. Journal of World Trade Law, 10, 478-489.

Wall, D., Jiang, B., \& Yin, X. (1996). China's opening door. London, England: The Royal Institute of International Affairs.

Warig, M. Y., \& Meng, X. C. (2004). Global-local Initiatives in FDI: The Experience of Shenzhen, China. Asia Pacific Viewpoint, 45(2), 181-196.

Warr, P. (1987). Export Promotion via Industrial Enclaves: The Philippines' Bataan Export Processing Zone. The Journal of Development Studies, 220-41.

Wei, X. (2000). Acquisition of Technological Capability through Special Economic Zones (SEZs) the Case of Shenzhen SEZ. Industry \& Innovation, 7(2), 199-221.

Wells, L. (1986). Investment Incentives: An Unnecessary Debate. CTC Reporter, Autumn, 58-60.

WEPZA - World Economic Processing Zones Association. (2004). International directory of export processing zones and free trade zones. Flagstaff, Arizona.

WEPZA - World Economic Processing Zones Association. (2006). WEPZA Table of Zone Countries. Retrieved May 25, 2006, from http://www.wepza.org/

WEPZA - World Economic Processing Zones Association. (2007). WEPZA Table of Zone Countries, Retrieved August 25, 2006, from http://www.wepza.org/

White, J. C. P., Varadarajan, R., \& Dacin, P. A. (2003). Market Situation Interpretation and Response: The Role of Cognitive Style, Organizational Culture, and Information Use. Journal of Marketing, 67(July), 63-79. 
Wikipedia Encyclopedia. (2007). Port of New Orleans. Retrieved August 5, 2005, from http://en.wikipedia.org/wiki/Port of New Orleans

Willmore, L. (1995). Export Processing Zones in the Dominican Republic: A Comment on Kaplinsky. World Development, 23 (3), 529-535.

Wilson, P. A. (1992). Exports and Local Development: Mexico's New Maquiladoras. Austin: University of Texas Press.

Wong, K. Y., \& Chu, D. (1985). Export Processing Zones and Special Economic Zones as Locomotives of Export-led Economic Growth, Modernization in China. Oxford, UK: Oxford University Press.

Woodward, D., \& Rolfe, R. (1993). The Location of Export-Oriented Foreign Direct Investment in the Caribbean Basin. Journal of International Business Studies, $24(1), 121-44$.

World Bank. (1992). Export Processing Zones, World Bank Industry and Development Division. Washington, D.C.

World Bank. (2000). Trade blocks. World Bank Policy Research Report. Carleton University library 2nd floor, 1-144.

World Bank. (2007). Data and Statistics, Retrieved July 1, 2007, from http://web.worldbank.org/wbsite/external/datastatistics/.html

Xiamen Statistic Bureau. (2003). Xiamen special economic zone yearbook 2003.

Retrieved November 23, 2003, from http://www.statsxm.gov.cn/tjxx/tqnj/2003/indexmenu.htm

Yabuuchi, S. (2000). Export Processing Zones, Backward Linkages, and Variable Returns to Scale. Review of Development Economics, 4(3), 268. 
Yin, R. (2003). Case Study Research ( $3^{\text {rd }}$ ed.). Thousand Oaks, CA: Sage Publications.

Young, L., \& Miyagiwa, K. (1987). Unemployment and the Formation Of Duty-Free Zones. Journal of Development Economics, 26, 397-405.

Yuan, J. (1993). Mainland China's special economic zones: Performance, problems, and perspectives. Issues and Studies, 29(3), 81.

Zhai, J. (Ed.). (1999). China today '99. Beijing, China: Chinese Statistic Press.

Zhang, X. (2000). Motivations, Objectives, Locations and Partner Selections of Foreign Direct Investments in China. Journal of the Asia Pacific Economy, 5(3), 190-203.

Zhuhai Statistic Bureau. (2005). Yearly index. Retrieved November 21, 2005, from http://www.stats-zh.gov.cn/year/index.htm

Zonas Francas Net (n.d.). Zonas Francas. Retrieved June to September 2006 on June 10, 2006, from http://www.zonasfrancas.net/zonas.php.

Zones of Confusion... And Loans of Frustration (1985), China Trade Report, (July) 8-9. 


\section{APPENDICES}




\section{Appendix A}

\section{Interview Guide: Zone Official}

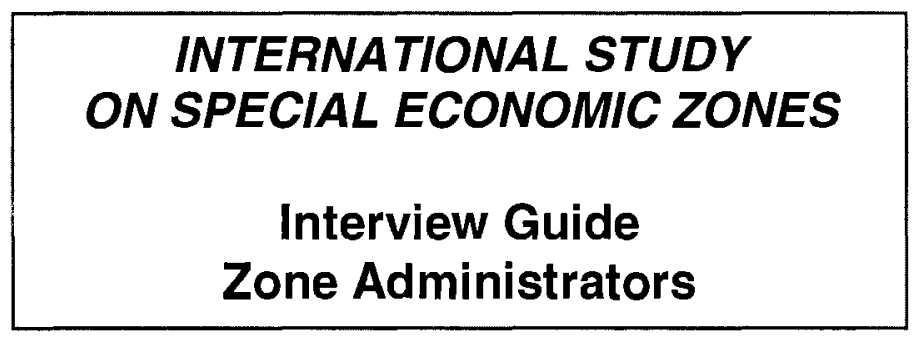

First, I would like to get some background information about the zone and yourself. There are some more questions about this in the structured questionnaire afterwards, but let me ask you some general ones first so that I can better understand your answers on the main topics later. Let me remind you that the entire interview will be strictly confidential and anonymous, and I will only report summary statistics from all my interviews.

\section{A. BACKGROUND OF RESPONDENT}

1. What is your present job title and responsibilities?

2. And how long have you worked in this zone, or at any other zone or organization elsewhere?

PROBES

a. Have you been with this zone since it was first established?

b. Were you working in zone administration before you were transferred here? Where?

c. Have you worked in other types of positions in government or business before? Where? 


\section{B. BACKGROUND ABOUT ZONE OBJECTIVES AND OPERATIONS}

3. Turning now to the zone itself, when was it first established? (month \& year)

4. To the best of your knowledge, what were the main reasons that lead the government to set up this zone at this particular place?

PROBES

a. Reasons: to attract investment, generate employment, promote exports, help to improve local skills, encourage linkages with local firms, enhance country's global competitiveness (especially, perhaps, against major comopeting countries in the region), etc. ...

b. Why in this region or city?

c. What were the national circumstances (economy, political, etc.) at the time?

5. What is the present ownership and organizational structure of the zone? PROBES

a. Central or State government, private ownership, joint

b. What is the management hierarchy?

c. Who runs the zone - government officials or appointed employees?

d. (ASSUMING ZONE IS GOVERNMENT OWNED:) Is the zone organized as a unit within a ministry, or as a separate agency or corporate entity?

IF MINISTRY: Which?

Is it

IF AGENCY/CORPORATION: Which ministry oversees zone operations?

"listed" and publicly traded in a stock exchange?

(IF PRIVATELY OR JOINTLY OWNED: Which firm / organization?)

e. What is the reporting hierarchy, for example, does the zone report directly to a minister or other senior government official, or is it part of a lower-level department (which)? 
6. Concerning the zone's own operations, how is it organized and funded? PROBES

a. Does the zone have different departments to handle its various functions? How many? Which?

b. Does the zone produce annual reports? If yes, to whom are they distributed?

c. How does the zone get funded? (THIS IS A VERY IMPORTANT QUESTION) For example,

- Is there an annual process whereby the management requests the funding it needs?

- Is zone funding part of another broader government budget, such as a 5-year plan?

- Does the zone generate any of its own funding?

d. COLLECT AN ORGANIZATIONAL CHART IF THEY HAVE ONE

7. How would you say has the zone evolved since it was first set up? PROBES

a. Has the zone met the original expectations of its founders?

b. Has its business volume increased over time, specifically its exports? imports? inward investment?

c. Has the ownership structure changed at all?

d. Has the government increased its own investment in the zone facilities?

8. Overall, how do you think this zone fits within the country's general strategy for attracting investment, promoting exports, or other objectives it may have?

9. What are the main functions performed by the zone today, for example, does it focus more on production or warehousing and distribution, on exports or on investment? PROBES

a. Manufacturing, trade, services, distribution, finance, insurance, etc. ...

b. Specify main product lineso

10. What are the major objectives of the zone today? (SAME AS ABOVE - Q.9) PROBES

a. To encourage exports, imports, trade in general, or investment?

b. Does the zone specify performance objectives for each year, for example in terms of volume of investment or exports, or of how many new investors to attract in a year?

c. Is the zone oriented more towards domestic or foreign tenants?

d. Does the zone have any specific "profit" objectives of its own? 


\section{ZONE BENEFITS AND INVESTMENT CLIMATE}

11. From the technical and administrative standpoint, what kinds of incentives does the zone offer?

PROBES - (VERY IMPORTANT QUESTION)

a. Tax holidays (number of years) and / or other tax incentives (SPECIFY)

b. Duty-free imports (OF WHAT? SPECIFY raw materials, intermediate / finished goods, machinery and equipment...)

c. Better infrastructure than elsewhere in the country

d. Plentiful labour (SPECIFY skilled/unskilled, managers/professionals...), and/or low wages

e. Various services, such as finance, warehousing, legal, consulting, etc. ...

f. Plentiful labour (SPECIFY skilled / unskilled workers, managers, professionals...)

g. Ability for investors to set up fully-owned subsidiaries or majority joint ventures (ELABORATE WHETHER THIS IS AVAILABLE ELSEWHERE IN THE COUNTRY)

h. Ability for investors to repatriate their capital and / or profit

i. Good housing, schooling, and other facilities for expatriate personnel of investors

j. Other ... (SPECIFY)

12. Focusing more on the various facilities offered by the zone, in terms of infrastructure, 12a. Does the zone offer standardized manufacturing, processing, assembly, storage, or other buildings for potential tenants?

12b. What other facilities does it offer? (e.g., perimeter security, in-zone medical services, ...)

12c. Of all these infrastructure facilities, are there any that are not normally available in the country's mainland, or that are available but not as good or advanced as in the zone?

13. Overall, what do you see as the zone's most important benefits for investors? PROBES

a. In your own opinion, how would you assess the investment climate in this zone today?

b. Why do you say that? What do you think is attractive or unattractive about it?

14. In terms of assessing the zone's investment climate, do you think that others share your views or are they less or more positive? We are interested in the views of (NOT SURE)

14a. Others in your country - the government, the people in general, Investors in the zone

14b. Others abroad - for example, the international investment community 
15. Do you think there is anything the zone should do to improve the investment climate and to attract foreign and domestic investment?

16. Given all the above, what are the zone's plans over the next 5 years? PROBES

a. Is it likely to grow, stay at about the present level, change ...?

\section{BACKGROUND ABOUT THE COMPANIES IN THE ZONE (TENANTS)}

Now we would like to know a little about the companies that invest and operate here in the zone.

17. Would you tell me, first, how many companies are operating here at this time? What kinds of business are they? And what kinds of operations do they have in the zone? PROBES (DO WE REPEAT SUCH Qs.)

a. Number of companies

b. Breakdown between domestic and international (BY COUNTRY FOR MOST IMPORTANT COUNTRIES)

c. Characteristics and breakdowns by company size (volume of business, number of employees)

d. What do the tenants generally use the zone for - manufacturing? assembly? warehousing? logistics centre?

18. What is the process of selecting or approving tenants? (GET AS FULL A DESCRIPTION AS POSSIBLE)

19. In your experience, do investors typically come to this country starting from the inzone operation, and maybe later expanding to the domestic territory, or the other way around - for example, a company used to import its products to the mainland from abroad, and then decided to also invest in the zone? (IMPORTANT QUESTION)

20. For companies that expand from the mainland to the zone or from the zone to the mainland, what do you think are the factors that influence their activities? 


\section{E. ATTRACTING AND SERVICING INVESTORS}

21. What do you think is the most important to investors when they decide to locate here - the specific advantages of the zone, or the characteristics of the country in general?

\section{PROBE TO UNDERSTAND - VERY IMPORTANT QUESTION}

22. When it comes to attracting investors, how does this zone differentiate itself from other zones that are competing for the same investors' attention? For example, how does this zone differentiate itself from others that are -

22a. Nearby, in this or other neighbouring regions?

22b. Farther away in this country?

22c. In other countries?

23. How does the zone market/promote itself?

PROBES

a. Promotion by the government - how?

POSSIBILITIES: Media advertising, published reports, participation in trade fairs, personal contacts or selling ...

b. Promotion by tenant companies (e.g., company executives making speeches at international conventions to attract other investors)

24. Does the zone have a "Unique Selling Proposition", in other words a brief statement that encapsulates what it is all about and what are the main benefits it offers?

25. What methods are used to convey information and promote the zone to potential investors?

were used by the company to learn about the zone and evaluate it as a possible location for investment?

PROBES

a. Where / how did you learn about this zone? (e.g., government promotion, media stories, from other companies, etc.)

b. Which sources did you use to decide if this was a suitable place to invest? (e.g., government information, other investors, lawyers or consultants, media, etc.)

26. What methods are used to help investors to evaluate the zone as a possible place for investment? (NOT SURE)

27. Which of these information sources influenced decision making? 
28. Overall, how easy or difficult do you think it is, from the investor's standpoint, to get information about the zone and then to set up their operation here? Specifically, 28a. Finding information (e.g. market, zone regulations) before investing

$28 \mathrm{~b}$. How easy or difficult is it for them to get help to operationalize their investment decision? (e.g. help from lawyers, realtors, consultants, government, etc.)

28c. How simple or complex do you think is, from the investor's perspective, the process of applying for permission to invest and operate in the zone?

(ELABORATE - VERY IMPORTANT QUESTION)

\section{F. ZONE, GOVERNMENT, AND INVESTOR INTERACTIONS}

29. What would you say is the level of interaction between personnel from the zone itself and the supervising authorities?

PROBES

a. Do zone managers regularly meet with the government supervisors at the ministry?

b. Do the government supervisors visit the zone? How oftern? For what purposes?

c. What types of personnel are involved in these interactions? (positions, specialty areas...)

30. Overall, what level of autonomy does the management of the zone itself has in decision-making, would you say, in relation to its supervising authority?

PROBES

a. What decisions can be made here without further approval, and what has to be referred to senior government officials?

b. Generally, are there any mechanisms that are used to involve the views of both the zone managers and their supervisors in decisions concerning the operations of the zone?

c. Generally, how influential would you say are your and their views in decision making?

31. Do you find that the investors here interact with one another, since they are all located within the same zone, or do they limit their interactions generally with their parent companies abroad?

PROBES

a. What kinds of interactions are these?

b. Among what types of companies? 
32. And does the zone administration interact with the companies in any substantive way, apart from just ensuring that they meet the regulations and so on?

PROBES

a. What kinds of interactions are these?

b. With all investors in general or with some particular types?

33. We also wonder about any relationships that companies operating in the zone may have with service or other suppliers in the mainland. For example, would you say that they can "find everything they need" within the zone or by importing it from the domestic territory of the country, or do they often procure services or products from other countries? Why?

PROBES

a. Do investors tend to import legal, consulting, or other services from the domestic market?

b. When and if they deal with domestic suppliers of services or products outside the zone, do they tend to maintain close, long-term relationships with them or are these dealings "one-off" only when the need arises? (ELABORATE)

c. Is the level of procurement by zone companies from the domestic market satisfactory to you, or do you feel they import too much from other countries? Why?

\section{G. FOCUS ON THE ZONE'S INVESTMENTS AND TRADE}

The way we understand it, the main function of zones such as this is that they permit duty-free imports so long as the products made by the companies are exported. So, now I would like to learn a bit more about the investment and trade carried out here.

34. Which countries account for most of the investment in this zone? PROBES

a. What is the percent share of the top-four investing nations?

(NAME COUNTRIES AND GET APPROXIMATE \% PER COUNTRY)

b. Is there investment here by domestic companies from this country? If yes, what is their percentage share?

35. Which sectors account for most of the investment in this zone, and what would be an approximate breakdown by sector?

PROBES

a. What is the percent share of the top-four sectors?

(NAME SECTORS AND GET APPROXIMATE \% PER SECTOR)

b. POSSIBLE SECTORS: Chemicals, Electronics, Food, Textiles, Jewellery ...

c. IF POSSIBLE, GET SUB-SECTORS (E.G., "APPLIANCES" WITHIN MANUFACTURING) 
36. What are the most important input materials, in terms of products and services, that are imported into this zone, and where do they come from?

PROBES

a. POSSIBLE INPUTS: Raw/intermediate/finished goods, machinery, services ...

b. Do any of these inputs come from the domestic territory of this country? If yes, which, and what is their percentage share? (ELABORATE TO UNDERSTAND FULLY)

c. Which other countries do these inputs come from, and what are their shares?

37. Turning to exports, what are the most important categories, in terms of products and services, that are exported from this zone, and which countries are they exported to? PROBES

a. POSSIBLE EXPORTS: Intermediate/finished goods, machinery, services, etc. ...

b. Do any of these exports go to the domestic territory of this country? If yes, which, and what is their percentage share? (ELABORATE TO UNDERSTAND FULLY)

c. Which other countries do these exports go to, and what are their shares?

38. And finally, apart from their investment here for imports and exports, are there any companies in the zone that have been assigned more important international duties by their parent firms? For example, some zone-based subsidiaries may have been assigned a role as "headquarters" for licensing or joint ventures with firms in other countries - does this ever happen, in your experience? (IF YES, ELABORATE)

\section{H. COMPARING THE ZONE INVESTMENT CLIMATE WITH OTHERS}

We have arrived at the last question, thanks so much for your patience and for all the insights you have provided.

39. First, would you say that the business environment within the zone is similar to, or better or worse than, the general business environment in this country outside the zone? Why?

40. And specifically concerning special zones, are there any zones nearby in this country which would be considered as "competitors" to this one in terms of attracting investors? 
41. Of these competing zones in this country, which one do you see as the most important competitor?

(WRITE NAME OF ZONE:

41a. Overall, do you think that zone offers more, fewer, or about the same benefits for investors compared to this one?

41b. Generally, what differences do you perceive between the investment climate between the two zones?

42. Turning to zones internationally, are there any in neighbouring or other countries which would be considered as "competitors" to this one in terms of attracting investors?

43. And lastly, of these competing zones in other countries, which one do you see as the closest competitor to this one?

WRITE NAME OF ZONE:

COUNTRY:

43a. Overall, do you think that zone and that country offer more, fewer, or about the same benefits for investors compared to this one?

43b. Generally, what differences do you perceive between the investment climate between the two zones and the two countries?

Thank you for your help!

Now, I would ask you to fill out this short questionnaire.

While you do so, I can check over my notes to ensure I have all the information that I need and then we will have completed everything.

THANK RESPONDENT AGAIN.

IF THEY HAVE INDICATED INTEREST, PROMISE TO GET BACK WITH THE FEEDBACK ON RESULTS OF THE STUDY. 


\title{
Appendix B
}

\author{
Interview Guide: Zone Tenant
}

\section{INTERNATIONAL STUDY ON SPECIAL ECONOMIC ZONES}

\author{
Interview Guide \\ Executives of Tenant Firms
}

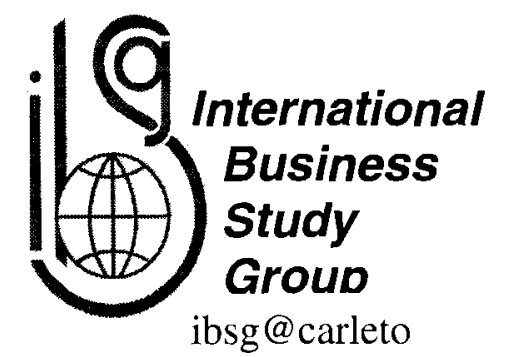

First, I would like to get some background information about the parent company, your company here, and yourself. There are some more questions about this in the structured questionnaire afterwards, but let me ask you some general ones first so that I can better understand your answers on the main topics later. Let me remind you that the entire interview will be strictly confidential and anonymous, and I will only report summary statistics from all my interviews.

\section{A. BACKGROUND OF RESPONDENT}

1. What is your present job title and responsibilities?

2. And how long have you worked with this company and with zone operations? PROBES
a. Have you been with this firm since its establishment in the zone?
b. Were you working with the parent company before you were transferred to the zone?
c. Have you worked for any other zone tenants, in this or any other zone, prior to this?




\section{B. BACKGROUND OF PARENT COMPANY - If Applicable}

3. Turning now to the parent company, what is the company's business? PROBES

a. Manufacturing, trade, services, distribution, finance, insurance, etc. ...

b. Specify what kinds of product lines

4. Would you please tell me a little bit about the foreign investment activities of your company, if there are any beyond this zone. For example, when did it first invest outside its home country, where and why? (MAY NOT KNOW - PROB. SECONDARY DATA) PROBES

a. When did the company first begin foreign direct investment?

b. In how many countries does the company have investments today?

c. Do any of these investments stand out as being especially important to your company? Why?

d. How does this zone operation compare to other investments of your company, for example, in terms of overall importance and value/size, whether this investment was made early or late in the international expansion of your company, and so on?

5. Does your company have investments in others zones in this country or in any other country?

PROBES - (THIS IS A VERY IMPORTANT QUESTION)

a. IF YES "OTHER ZONES IN THIS COUNTRY": Which, where, since when, how big, etc.

b. IF YES "OTHER ZONES ELSEWHERE": Which, where, since when, how big, etc.

6. Did your company have any operations in this country prior to investing in this zone? PROBES

a. Importing products (or services) into this country from somewhere else?

b. Licensing agreement with another company in this country?

c. Joint venture with another company in this country?

d. Manufacturing in this country?

e. Exporting products (or services) from this country to somewhere else? 
6a. IF YES TO ANY OF THE ABOVE:

What was it that made the company decide to invest in this zone operation? Please elaborate on the important reasons and objectives in deciding to invest in this zone operation...

6b. IF NO (COMPANY DID NOT OPERATE IN COUNTRY BEFORE INVESTING IN ZONE):

Why did the firm decide to invest in the zone? Please elaborate on the important reasons and objectives in deciding to invest in this zone operation...

\section{BACKGROUND OF ZONE COMPANY}

7. Now, concerning your company here, when was it established in this zone?

8. What is the ownership structure of this company?

PROBES

a. Is it one of the following? sole owner - majority ownership and control - joint venture with local or other foreign company (SPECIFY) - minority owned affiliate

b. ELABORATE ON THE ANSWER TO UNDERSTAND THE COMPANY STRUCTURE.

c. Is the company ownership mainly "domestic" (from the country in which the zone is located) or "international"?

9. What business functions does the firm perform inside the zone or outside it but within this country? (THIS IS A VERY IMPORTANT QUESTION - ELABORATE) PROBES

a. POSSIBLE IN-ZONE FUNCTIONS: Production, storage, warehousing, logistics, product development, sales, marketing, finance, human resource, R\&D, etc. ...

b. POSSIBLE OFF-ZONE FUNCTIONS: Procurement of raw materials or of consulting / management / accounting / legal services, storage, sales and marketing, etc.

c. ELABORATE ON THE ANSWER TO UNDERSTAND HOW THE COMPANY INTEGRATES IN-ZONE AND OFF-ZONE OPERATIONS.

10. Administratively, where does this zone operation report to? PROBES

a. Directly to corporate headquarters (WHERE?)

b. A regional office located in this country (WHERE?) or in another country (WHERE?) 
11. What would you say is the level of interaction between personnel from this operation and the home office - for example, is it mostly limited to phone and email or are there in-person exchanges too? (e.g., visits from here to home office or vice-versa) (TRY TO UNDERSTAND - WHAT TYPE OF PERSONNEL VISIT? HOW OFTEN? ETC.)

12. Overall, what level of autonomy does your company have in decision-making, would you say, in relation to the parent firm? For example, what decisions can be made here without further approval, and what has to be referred to the head office? How influential would you say are your and their views in zone-related decision making?

13. And how about the zone administration? Does your company interact with the zone managers in any substantive way apart from just meeting the regulations and so on? PROBES

a. What kinds of interactions are these?

b. With which part of the zone administation?

\section{OBJECTIVES AND EXPERIENCE WITH INVESTMENT}

14. At the time that your company was making the decision to invest in this zone, were you involved in the decision making process? How?

PROBES IF YES

a. Collected information

b. Came to scout the environment

c. Was part of the decision making group

d. Helped to operationalize the investment decision

15. We would like to know a little about your company's experience with this investment decision up to the time that the business was established. (IF RESPONDENT WAS INVOLVED, ASK FOR HIS/HER OWN VIEWS - IF NOT INVOLVED, ASK "Based on what you know...)

16. What were the specific factors for choosing this particular country and zone to invest in?

17. What was most important to your company - to take advantage of characteristics of this country in general, or specifically of this zone? (VERY IMPORTANT QUESTION) 
18. How does the investment in this zone fit within your firm's overall strategy for international trade and investment activities? (VERY IMPORTANT QUESTION ELABORATE)

19. What information sources were used by the company to learn about the zone and evaluate it as a possible location for investment? For example, did you use government materials, information from other companies, lawyers or consultants, media, etc.?

20. Which of these information sources influenced decision making?

21. How easy or difficult was it to access needed information about the zone's investment climate (e.g. market, regulations) before making the investment decision? (ELABORATE)

22. How easy or difficult was it to get help to operationalize the investment decision? (e.g. help from lawyers, realtors, consultants, government, etc.) In what way, can you please elaborate? - (NOT SURE)

23. How simple or complex was the process of applying to government for permission to invest and operate in the zone? In what way, can you please elaborate?

24. Turning to within the zone, does your company ever interact with any of the other investors?

PROBES

a. What kinds of interactions are these?

b. With what types of companies?

\section{E. ASSESSMENT OF THE INVESTMENT CLIMATE IN THE ZONE}

25. In your own opinion, how would you assess the investment climate in the zone at this time? Specifically, what do you feel are the most important benefits that are offered by this zone? What do you think is attractive or unattractive about it?

26. Would you elaborate on any tax related advantages your company has by operating in the zone... For example, are you given a tax holiday? (GET no. OF YEARS) Dutyfree status? Other?

27. And how would you personally assess it in comparison to your initial expectations? 
28. In terms of assessing the zone's investment climate, do you think that others in your company generally shares your views or do others feel more positively or less positively about it?

PROBES

a. Assessing the investment climate "as-is" at the present time.

b. Assessing the present investment climate compared to the company's initial expectations.

29. Overall how satisfied/dissatisfied is your company with the investment experience in the zone to date? Why?

30. Overall how satisfied/dissatisfied are you personally with the investment experience in the zone to date? Why?

31. How do you think other investors view this zone as a place for investment? PROBES

a. Investors from your own country

b. Investors from other countries

32. What do you think the zone should do to improve the investment climate and to attract foreign and domestic investment? (VERY IMPORTANT QUESTION)

33. Given all the above, what are your firm's plans for your zone operation over the next 5 years?

PROBES

a. Are you likely to expand or contract your investment, or stay at about the present level?

34. By the way, does it ever happen that executives from other companies ask your opinion about investing in this zone?

PROBES

a. IF YES: How often would you say this happens, and what do you say when they ask?

b. IF NO: What would you say if someone asked?

c. (EITHER): More generally, would you recommend investment in this zone to others? 


\section{F. FOCUS ON IMPORTS TO / EXPORTS FROM THE ZONE}

Now I would like to learn a bit more about your operation in this zone. The way we understand it, the main function of zones such as this is that they permit duty-free imports so long as the products you make are exported. So,

35. What does your the firm import for its purposes? From where, and which of these can you import duty-free?

PROBES

a. Types of imports: raw materials, intermediate goods, technology, machinery, services, etc. ...

b. Are any of these brought in from the domestic market?

IF YES, Why? (e.g., can't find from elsewhere) Which? (product types)

Percentage share in the total imports?

IF NO: Why not? (e.g., unavailable / unreliable supply / better products elsewhere / our company makes them)

c. Which other countries account for the bulk of your imports? What products? Percentage share of the most important ones?

36. More generally, we wonder about any relationships your company within the zone may have with service or other suppliers in the rest of the country. For example, would you say that you can "find everything you need" within the zone or by importing it from some other country, or do you often procure services or products from elsewhere in this country?

PROBES

a. Do you import any managerial, legal, consulting, or other services from the domestic market?

b. If you deal with any domestic suppliers of services or products outside the zone but within this country, would you say you maintain close, long-term relationships with them or are these dealings "one-off" only when the need arises? (ELABORATE)

37. Turning to exports, what kind of products and/or services does your company export? Where to?

PROBES

a. Types of products/services: intermediate goods, finished goods, raw materials, technology, machinery, services, etc. ...

b. Do you export at all to the domestic market?

IF YES: Why? (e.g., the law allows it, market very attractive) Which? (product types) Percentage share in your exports?

IF NO: Why not? (e.g., the law does not allow it)

c. Which other countries account for the bulk of your exports? What products? Percentage share of the most important ones? 
38. And finally, apart from imports and exports, is your company here in the zone responsible for any other international operations? For example, is this company acting as "headquarters" for licensing or joint ventures in other countries? (IF YES, ELABORATE)

\section{G. COMPARING THE ZONE INVESTMENT CLIMATE WITH OTHERS}

We have arrived at the last question, thanks so much for your patience and for all the insights you have provided.

39. First, would you say that the business environment within the zone is similar to, or better or worse than, the general environment in the country outside the zone? Why?

40. And specifically concerning special zones, which other zone in this country do you see as the most important competitor to this one?

(WRITE NAME OF ZONE:

Does your company have any operations there?

IF YES: Which of the two does your company see as the most important?

Why?

IF NO: Why was this zone chosen over the other one for this investment? Regardless of whether or not your company also operates in that other zone, what differences do you perceive between the investment climate in the two zones?

41. And lastly, which other zone in any other country do you see as the most important competitor to this one?

WRITE NAME OF ZONE:

COUNTRY:

Does your company have any operations there?

IF YES: Which of the two does your company see as the most important?

IF NO: Why was this zone chosen over the other one for this investment? Regardless of whether or not your company also operates in that other zone, what differences do you perceive between the investment climate in the two zones?

Thank you for your help! Now, I would ask you to fill out this short questionnaire.

While you do so, I can check over my notes to ensure I have all the information that I need and then we will have completed everything.

THANK RESPONDENT AGAIN.

IF THEY HAVE INDICATED INTEREST, PROMISE TO GET BACK WITH THE FEEDBACK ON RESULTS OF THE STUDY. 


\section{Appendix C}

\section{Leave-behind Questionnaire: Zone Officials}

\begin{tabular}{c}
\hline INTERNATIONAL STUDY \\
ON SPECIAL ECONOMIC ZONES \\
Follow-up Questionnaire \\
Zone Administrators
\end{tabular}

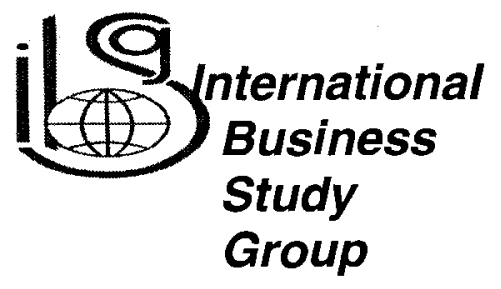

On behalf of all of us who are working on this study, a great "thanks again!" for agreeing to participate.

\section{Please answer this questionnaire as completely as possible.}

(As I mentioned, we repeat here some of the topics from the interview because they are essential for the statistical analysis. We assure you again that all information will be held

in strict confidence and anonymously, only summary statistics will be reported.)

\section{YOUR BACKGROUND}

Number of years: with the Zone

with other zones

in the workforce

Which department do you work for?

What is your approximate education level? ( $\square$ one):

High School $\square \quad$ University $\square \quad$ Post graduate $\square$

In general, would you describe your background as being in... ( $\square$ one):

Engineering $\quad \square \quad$ Finance $\quad \square \quad$ General Management $\square$

Marketing/Sales $\square \quad$ Human Resources $\square$

Other (pls. specify)

Have you worked in any other countries? (number) Where?

What other languages do you speak, if any, other than your native language? 


\section{BACKGROUND INFORMATION ABOUT THE ZONE}

Formal name of the zone:

Year of establishment:

Concerning the incentives that the zone offers to companies that may consider investing in the zone:

Does the zone offer duty-free imports on the following inputs that may be used in an investor's operation?

Raw materials:

No $\square \quad$ Yes

Intermediate goods (e.g., parts/spares/ingredients ...):

No $\square$ Yes

Finished goods (e.g., used as components in assemblies):

No $\square$ Yes

Equipment:

No $\square$ Yes

Machinery:

No $\square \quad$ Yes

Other (please specify:

):

No $\square \quad$ Yes

Does the zone offer duty-free exports on goods exported to other countries?

Intermediate goods:

No $\square$ Yes $\square$

Finished goods:

No $\square$ Yes

Other (please specify: ):

Are exports to the country's domestic territory allowed?

Does the zone offer tax exemptions on investments?

Is there a tax holiday period for new investors?

No $\square$ Yes

How long is this period? (years)

Does the zone allow investors to repatriate:

Profits: $\quad$ Yes, with conditions/limited $\square$ Yes, unrestricted $\square \quad$ No Investment capital: $\quad$ Yes, with conditions/limited $\square$ Yes, unrestricted $\square \quad$ No 


\section{SUMMARY INFORMATION ABOUT THE COMPANIES IN THE ZONE}

In this section we would like to ask for some general information concerning the combined activities of all investor (tenant) firms for the two most recent fiscal years:

Taking together all the companies that operate in the zone, what is the relative importance of the activities that they engage in? Please answer this question by checking "No activity" if no companies engage in it, or, for those activities that do take place in the zone, by circling the appropriate number in the table below:

Importance (if there is activity)

\begin{tabular}{|c|c|c|c|c|c|c|}
\hline \multirow[b]{2}{*}{ Manufacturing / Processing } & \multicolumn{2}{|c|}{$\begin{array}{l}\text { No } \\
\text { Activity } \\
\text { important }\end{array}$} & \multicolumn{3}{|c|}{$\begin{array}{l}\text { Not at all } \\
\text { important }\end{array}$} & Very \\
\hline & 0 & 1 & 2 & 3 & 4 & 5 \\
\hline Assembly & 0 & 1 & 2 & 3 & 4 & 5 \\
\hline Exports & 0 & 1 & 2 & 3 & 4 & 5 \\
\hline Imports & 0 & 1 & 2 & 3 & 4 & 5 \\
\hline Warehousing & 0 & 1 & 2 & 3 & 4 & 5 \\
\hline Distribution/Logistics & 0 & 1 & 2 & 3 & 4 & 5 \\
\hline Retailing & 0 & 1 & 2 & 3 & 4 & 5 \\
\hline Other services (pls. specify & 0 & 1 & 2 & 3 & 4 & 5 \\
\hline \multicolumn{7}{|c|}{$\begin{array}{l}\text { What are the types of companies that operate in the zone, in terms of the major sectors to } \\
\text { which they belong? Please indicate the approximate number of companies for each sector } \\
\text { below. }\end{array}$} \\
\hline Food and Beverages & & & & & & \\
\hline Textiles and clothing & & & & & & \\
\hline Footwear & & & & & & \\
\hline Electronics & & & & & & \\
\hline Gems & & & & & & \\
\hline Automotive & & & & & & \\
\hline Drugs and Pharmaceuticals & & & & & & \\
\hline Chemicals and Petroleum & & & & & & \\
\hline Engineering & & & & & & \\
\hline Services & & & & & & \\
\hline Other & & e sp & $f y:$ & & & \\
\hline Other & & $\mathrm{esp}$ & fy: & 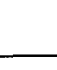 & & \\
\hline Other & & $\mathrm{esp}$ & & & & \\
\hline
\end{tabular}


(continued - 3. SUMMARY INFORMATION ABOUT THE COMPANIES IN THE ZONE)

Lastly in this section, we would like to get an idea of the volume and type of business that all the companies in the zone do, concerning the two most recent fiscal years:

For the figures below, please specify the currency you use: million US\$ $\square$ or

\begin{tabular}{ll}
$\begin{array}{l}\text { Most recent year } \\
\text { (ending in }\end{array}$ & $\begin{array}{c}\text { Year before } \\
\text { (ending in }\end{array}$ \\
$\underline{2006 \text { or 2005) }}$ & $\underline{2005 \text { or 2004) }}$ \\
\hline
\end{tabular}

Total investment in zone from all countries:

Of which, investment from foreign countries

Total exports from zone (worldwide):

Of which, "domestic" exports to mainland:

Total imports to zone (worldwide):

Of which "domestic" imports from mainland:

$(\%)$

Overall, what approximate share do local producers have in the total inputs of zone companies? $(\%)$

Total number of employees (by all firms in the zone):

Of which, percentage of female workers: $(\%)$ $(\%)$

Approximate composition of the zone workforce today:

Managerial and Professional

Supervisory and Skilled

Clerical

Semi-skilled and Unskilled

What is their hourly wage rate of unskilled workers in the zone? Minimum Average

Lastly, if you feel it is possible to give us an idea of the zone administration itself:

How many employees work in zone administration? (number)

What is the zone's annual budget? (US\$ $\square$ or

In percentage terms, where is this budget covered from?

the government $\%$ investor fees $\%$ other sources $\%$

And overall, on a net basis, would you say that the zone operates ( $\nabla$ one): at a profit $\square$, at a loss $\square$, or on a break-even basis 


\section{ZONE vS. COUNTRY INVESTMENT CLIMATE: ASSESSMENT}

What are your views about the investment climate in the zone compared to the regular territory of the country as a whole? Various factors of evaluation are listed below. Please indicate your views of the zone versus the country environment for investment by placing an $\mathrm{X}$ in the most appropriate space in each column for each of the factors below.

\begin{tabular}{|l|c|c|}
\hline $\begin{array}{l}\text { Market Related Factors } \\
\text { (if selling to the domestic } \\
\text { market is allowed) }\end{array}$ & Environment in the ZONE & $\begin{array}{c}\text { General environment of } \\
\text { CoUNTRY }\end{array}$ \\
\hline $\begin{array}{l}\text { Current market size } \\
\text { Future market size } \\
\text { potential }\end{array}$ & & $\begin{array}{l}\text { Small:_:____:____: Large } \\
\text { Small:_:________: Large }\end{array}$ \\
Distribution costs & Low:_:_:__:___: High \\
\hline
\end{tabular}

\begin{tabular}{|c|c|c|}
\hline $\begin{array}{l}\text { Production Related } \\
\text { Factors }\end{array}$ & Environment in the ZONE & $\begin{array}{c}\text { General environment of } \\
\text { COUNTRY }\end{array}$ \\
\hline Cost of energy & Low:__:__:_:_: High & Low:___:_:____: High \\
\hline Manufacturing costs & Low:___:_:_:__: High & Low:___:_:_:_: High \\
\hline Labour costs & Low:____:_:____: High & Low:__:_:_:_:__: High \\
\hline Availability of skilled labour & Low:___:_:_:_: High & Low:_____:_:_: High \\
\hline $\begin{array}{l}\text { Availability of expert } \\
\text { managers }\end{array}$ & Low:___:_:_:_: High & Low:_:_:_:_:_: High \\
\hline Labour productivity & Low:____:____: High & Low:_:_: : _: : High \\
\hline Technology level & Low:___:__:_:_:High & Low:___:_:_:_: High \\
\hline $\begin{array}{l}\text { Quality of transportation } \\
\text { system }\end{array}$ & Poor:_:_:__:____: Good & Poor:____:___:__: Good \\
\hline $\begin{array}{l}\text { Quality of communication } \\
\text { system }\end{array}$ & Poor:_________:_: Good & Poor:__:___:__:_: Good \\
\hline Customs procedures & Difficult:_:_:___:__: Easy & Difficult:___:_:_:_: Easy \\
\hline Inventory control & Difficult:_:_:_:____: Easy & Difficult:___:_:_:_: Easy \\
\hline $\begin{array}{l}\text { Availability of raw materials } \\
\text { Cost of raw materials }\end{array}$ & & $\begin{array}{l}\text { Low:__________ High } \\
\text { Low:_:______ High }\end{array}$ \\
\hline
\end{tabular}

\begin{tabular}{|c|c|c|}
\hline Finance Related Factors & Environment in the ZONE & $\begin{array}{c}\text { General environment of } \\
\text { COUNTRY }\end{array}$ \\
\hline Tax structure & Complex:_:_:_:____: Simple & Complex:__:_:_____: Simple \\
\hline Tax advantages & Low:_:_:_:_:__: High & Low:_:_:_:___: High \\
\hline Inventory tax & Low:__________: High & Low:___________: High \\
\hline Insurance cost & Low:______:___: High & Low:___:_____: High \\
\hline Subsidies & Low:__________: High & Low:___:___:__ High \\
\hline Duties on imports & Low:__________: High & Low:___:______: High \\
\hline
\end{tabular}


Duties on exports

Repatriation of profit and capital

Currency exchange rate
Low:_:_:_:_:_: High

Difficult:_:__:____: Easy
Low:_:_:__:_: High

Difficult:_:_:_____: Easy

Unstable:____:______: Stable

(continued - 4. ZONE vs. COUNTRY INVESTMENT CLIMATE: ASSESSMENT)

\begin{tabular}{|c|c|c|}
\hline $\begin{array}{l}\text { Economic and Legal } \\
\text { Factors }\end{array}$ & Environment in the ZONE & $\begin{array}{c}\text { General environment of } \\
\text { COUNTRY }\end{array}$ \\
\hline Bureaucratic bottlenecks & Few:_:_:_:_: Many & Few:__________: Many \\
\hline Setting up operations & Difficult:______:___: Easy & Difficult:___________: Easy \\
\hline Obtaining licenses & Difficult:___________: Easy & Difficult:____________: Easy \\
\hline $\begin{array}{l}\text { Obtaining work permits for } \\
\text { expatriates }\end{array}$ & Difficult:_:_:_:_:_: Easy & Difficult:_:________: Easy \\
\hline \multirow{3}{*}{$\begin{array}{l}\text { Legal system } \\
\text { Restrictions on ownership } \\
\text { Inflation rate }\end{array}$} & Complex:___________: Simple & \multirow{3}{*}{$\begin{array}{c}\text { Complex:_________ Simple } \\
\text { Low:_________: High } \\
\text { Low:_________: High }\end{array}$} \\
\hline & Low:_:_:______: High & \\
\hline & xis & \\
\hline
\end{tabular}

\begin{tabular}{|c|c|c|}
\hline $\begin{array}{l}\text { Political and Social } \\
\text { Factors }\end{array}$ & Environment in the ZONE & $\begin{array}{l}\text { General environment of } \\
\text { COUNTRY }\end{array}$ \\
\hline $\begin{array}{l}\text { Government attitude to } \\
\text { foreign investment }\end{array}$ & Negative:______:____: Positive & Negative:___________: Positive \\
\hline $\begin{array}{l}\text { Public's attitude towards } \\
\text { foreign investment }\end{array}$ & Negative:__:___:__: & Negative:_:_:_:_:__: Positive \\
\hline Quality of life style & Low:______:____: High & Low:____:_:___: High \\
\hline Crime level & High:___________: Low & High:____________ Low \\
\hline Overall political climate & & Unstable:___________: Stable \\
\hline $\begin{array}{l}\text { Receptivity to new } \\
\text { products, methods, ideas }\end{array}$ & & Low:_:_:_:___: High \\
\hline $\begin{array}{l}\text { Cultural similarity to parent } \\
\text { dirm's country }\end{array}$ & & Far:________:_: Near \\
\hline $\begin{array}{l}\text { Attitude to various cultures, } \\
\text { religions, races }\end{array}$ & & Closed:_:___:___: Open \\
\hline
\end{tabular}

\begin{tabular}{|c|c|c|}
\hline Infrastructure Factors & Environment in the ZONE & $\begin{array}{c}\text { General environment of } \\
\text { COUNTRY }\end{array}$ \\
\hline Proximity to a bigger city & Poor:_:__:____:_:Good & \\
\hline $\begin{array}{l}\text { Proximity to industry } \\
\text { clusters }\end{array}$ & Poor:__:_:_____: Good & \\
\hline $\begin{array}{l}\text { Connectivity to ports, } \\
\text { railways, and airports }\end{array}$ & Poor:______:____: Good & \\
\hline Container handling facilities & Poor:__:___: : : : Good & Poor:_:_:_:_:_: Good \\
\hline Warehouse facilities & Poor:_:_:__:_:_: Good & Poor:__:__:_:_: Good \\
\hline Banking facilities & Poor:_:_:__:_:_: Good & Poor:_:_:__:_:_: Good \\
\hline Transport facilities & Poor:_:_:__:_:_: Good & Poor:___:__:_:__: Good \\
\hline $\begin{array}{l}\text { Communication facilities } \\
\text { (Internet, phone) }\end{array}$ & Poor:_:________: Good & Poor:__:___:___: Good \\
\hline Housing facilities & Poor:__:_:______: Good & Poor:__:__________: Good \\
\hline
\end{tabular}


Schools \& facilities for expatriates' children

Poor:__:_______: Good

\begin{tabular}{|c|c|c|}
\hline $\begin{array}{l}\text { General view of country } \\
\text { and people }\end{array}$ & Environment in the ZONE & $\begin{array}{c}\text { General environment of } \\
\text { COUNTRY }\end{array}$ \\
\hline National country image & & Bad:______:___: Good \\
\hline $\begin{array}{l}\text { General zone and country } \\
\text { outlook } \\
\text { Likeability of the people }\end{array}$ & $\begin{array}{c}\text { Negative:_:_:___: Positive } \\
\text { Low:_:_:_:_ : : High }\end{array}$ & $\begin{array}{c}\text { Negative:_:______ Positive } \\
\text { Low:_:_______: High }\end{array}$ \\
\hline $\begin{array}{l}\text { Trustworthiness of the } \\
\text { people }\end{array}$ & Low:____:___:_: High & Low:___:_____: High \\
\hline Friendliness of the people & Low:___:___:_: High & Low:_:_:_:_: : High \\
\hline $\begin{array}{l}\text { Industriousness of the } \\
\text { people }\end{array}$ & Low:___:_:_:_: High & Low:___:_:_:_: High \\
\hline
\end{tabular}

\section{ZONE INVESTMENT CLIMATE: FACTOR IMPORTANCE}

Of the above factors, you may feel that some are more important than others in influencing the decisions of investors. Please rate the importance of each category of factors on a scale of 1 to 5 , where 1 means the factor is not important and 5 that it is very important. (Note: You may wish to refer back to the previous two pages which give examples of the factors within each category.) (please circle the number).

Market Related Factors

Production Related Factors

Finance Related Factors

Economic and Legal Factors

Political and Social Factors

Infrastructure Factors
Not Important

$\begin{array}{ll}1 & 2 \\ 1 & 2 \\ 1 & 2 \\ 1 & 2 \\ 1 & 2 \\ 1 & 2\end{array}$

Very Important

$\begin{array}{ll}2 & 3 \\ 2 & 3 \\ 2 & 3 \\ 2 & 3 \\ 2 & 3 \\ 2 & 3\end{array}$

$\begin{array}{crr} & \text { Very Important } \\ 3 & 4 & 5 \\ 3 & 4 & 5 \\ 3 & 4 & 5 \\ 3 & 4 & 5 \\ 3 & 4 & 5 \\ 3 & 4 & 5\end{array}$

\section{ZONE INVESTMENT CLIMATE: EXPERIENCE}

How satisfied or dissatisfied do you feel investors are with the zone investment experience? Please rate the following categories of factors on a scale of 1 to 5 , where 1 means very dissatisfied, and 5 means very satisfied, with the zone investment experience. (please circle the number)

Market Related Factors

Production Related Factors

Finance Related Factors

Economic and Legal Factors

Very Dissatisfied

Political and Social Factors

$\begin{array}{ll}1 & 2 \\ 1 & 2 \\ 1 & 2 \\ 1 & 2 \\ 1 & 2 \\ 1 & 2\end{array}$

Very Satisfied

Infrastructure Factors

$\begin{array}{ccc} & \text { Very Satisfied } \\ 3 & 4 & 5 \\ 3 & 4 & 5 \\ 3 & 4 & 5 \\ 3 & 4 & 5 \\ 3 & 4 & 5 \\ 3 & 4 & 5\end{array}$




\section{ZONE INVESTMENT CLIMATE: COMPARISON TO AREA OUTSIDE ZONE}

Based on your experience, how would you compare the zone's investment climate to the country's regular territory, the domestic mainland? Please rate the following factors on a scale of 1 to 7 , where 1 means that investing in the zone is worse, and 7 means it is better, than the mainland. (please circle the number)

\section{Contractual Risk}

Zone worse Zone better

than mainland than mainland

Costs of making and enforcing contracts

Maintenance of quality of services with a local partner

Risk of misuse of your proprietary knowledge

$\begin{array}{lllllll}1 & 2 & 3 & 4 & 5 & 6 & 7 \\ 1 & 2 & 3 & 4 & 5 & 6 & 7 \\ 1 & 2 & 3 & 4 & 5 & 6 & 7 \\ & & & & & & \\ 1 & 2 & 3 & 4 & 5 & 6 & 7 \\ 1 & 2 & 3 & 4 & 5 & 6 & 7 \\ 1 & 2 & 3 & 4 & 5 & 6 & 7\end{array}$

\section{Market Risk}

Stability of political, social, and economic conditions

Risk in repatriating your income

Risk of expropriation of firms 


\section{Thank pou veny much for completing the questionnaire and helping us out with this study - Tour contribution is invaluable and we truly appreciate it.}

If you would like to make any additional comments, it will be a great help to the researchers and business or government executives who will read the results. Of course, your comments will remain confidential and anonymous, as we have already noted - but they will certainly be taken into account when analysing the aggregate statistical results.

You could comment further on the above questions, or on any related issue which we may not have covered here. Depending on your time availability, you could comment as follows:

- Using this page, and returning it to me now.

- Using this page and returning it later by mail to:

Dr. Nicolas Papadopoulos, Director International Business Study Group Eric Sprott School of Business 1125 Colonel By Drive Ottawa, Canada K1S 5B6

- Emailing your comments later, either to me at <smalhotr@connect.carleton.ca>, or to Dr. Papadopoulos at<npapadop@carleton.ca> or ibsg@carleton.ca. 


\section{Appendix D}

\section{Leave-behind and Survey Questionnaire: Zone Tenant}

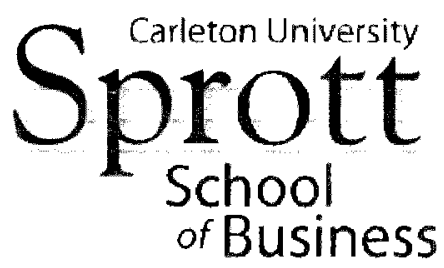

710 Dunton Tower

1125 Colonel By Drive

Ottawa, ON K1S 5B6 Canada

Tel: (613) $520-2388$

Fax: (613) $520-4427$

www.business.carleton.ca

I am writing to kindly request your participation in a major survey of the companies that operate in [NAME OF ZONE], which is carried out with the participation of the International Business Study Group of the Eric Sprott School of Business of Carleton University, in Ottawa, the capital of Canada. The study is part of a large international project supervised by Dr. Nicolas Papadopoulos, Professor of Marketing and International Business at the Sprott School and Director of IBSG, and I am working on it for my Ph.D. thesis.

The objective of our project is to study free zones, their characteristics, and their role in international business and trade. As you know, Special Economic Zones, Export Processing Zones, and other types of free zones, are very important to the host country and the firms that operate in them. However, there is very little business research about them and so very little is known about how they work. The results will be made available to, and benefit, business participants such as yourself, the host governments, and researchers.

We have already interviewed a number of government administrators in India and other countries, and in this study we are interviewing executives of companies at major zones such as this to examine how zones are used in international business.

Your replies will be kept anonymous and strictly confidential and will be analysed statistically without identification. The attached page contains further provisions regarding the ethical conduct of research, as prescribed by Carleton University's Research Ethics Committee.

Your participation is essential to ensure a representative sample and enable us to produce useful results for business and government, and for me to complete my doctoral thesis. Therefore, I will very much appreciate your help in completing this questionnaire, which is brief and will only take a few minutes of your time.

Yours Sincerely,

Shavin Malhotra

Ph.D. Candidate

Sprott School of Business 


\section{Ethics considerations related to participation in the international study on Free Trade Zones}

(As required by the Carleton University Research Ethics Committee and the Social Sciences and Humanities Research Council of Canada)

- As noted in the letter on the previous page, your replies will be kept strictly confidential and analysed without identification. In the event that you would like to receive an executive summary of the results, please put a check-mark in the appropriate box on the front cover of the questionnaire, next to the serial number. The person who will receive the questionnaires will detach the front cover from the main part, make note of the respondents who wish to receive the executive summary, and forward to me the questionnaires separately. This will preserve your anonymity since it prevents any possibility of "matching" survey responses with those requesting the executive summary.

- The data obtained from the study participants will be kept on file indefinitely, anonymously since the participants are not identified, for possible future analyses.

- You may decline answering any specific questions, and/or withdraw your agreement to participate at any time during the study and have your responses, if any to your time of withdrawal, deleted from the database without reprisal.

- This project was reviewed and received ethics clearance by the Carleton University Research Ethics Committee.

- Should you have any questions or concerns about the study, please contact:

- The project supervisor:

Dr. Nicolas Papadopoulos

Director, International Business Study Group

Eric Sprott School of Business

Carleton University

1125 Colonel By Drive, Ottawa, Ontario K1S 5B6

Tel: + (1) (613) 520-2388

E-mail: npapadop@carleton.ca

- and/or, the Ph.D. student who is working on this project for his thesis:

Mr. Shavin Malhotra, Doctoral Candidate

Sprott School of Business

Carleton University

1125 Colonel By Drive, Ottawa, Ontario K1S 5B6

Tel: + (1) (613) 520-2388

E-mail: smalhotr@connect.carleton.ca

- and/or, Professor Antonio Gualtieri,

Chair, Carleton University Research Ethics Committec

Carleton University

1125 Colonel By Drive, Ottawa, Ontario K1S 5B6

Tel: + (1) (613) 520-2517

E-mail: ethics@carleton.ca 


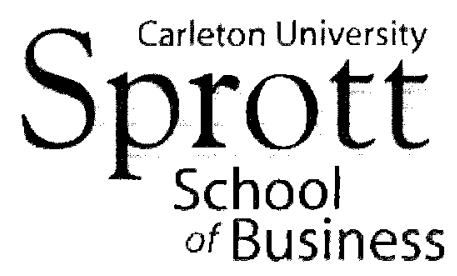

[Date]
710 Dunton Tower

1125 Colonel By Drive

Ottawa, ON K1S 5Bo Canada

Tel: (613) 520-2388

Fax: (613) $520-4427$

mww.business.carleton.ca

\section{E R T I F I C A T E}

I hereby certify that Mr. Shavin Malhotra, a Ph.D. student of mine at the Sprott School of Business, is working on a survey about free zones, which is related to his studies. The survey is part of a large international project carried out by the International Business Study Group (IBSG), a research unit of the Sprott School. I am the Director of IBSG, and Mr. Malhotra is a member.

At the present time Mr. Malhotra is collecting data for the study in India. He has been fully briefed on the technical details of the sampling and related processes. Should you have any questions about the project or Mr. Malhotra's work, please do not hesitate to contact me.

Sincerely,

Dr. Nicolas Papadopoulos

Professor of Marketing and International Business

Director, International Business Study Group

Associate Dean (Research)

Sprott School of Business 


\section{INTERNATIONAL STUDY ON SPECIAL ECONOMIC ZONES \\ Questionnaire \\ Executives of Zone-based Companies}

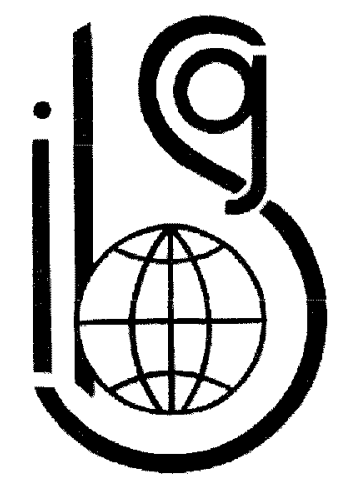

International Business Study Group

ibsg@carleton.ca

\begin{tabular}{|c|c|}
\hline $\begin{array}{l}\text { Please return the completed } \\
\text { questionnaire to: } \\
\end{array}$ & $\begin{array}{l}\text { Questionnaire serial number: } \\
\text { If you would like to receive the executive } \\
\text { summary, } \\
\text { please check here: } \\
\text { and provide your address: }\end{array}$ \\
\hline
\end{tabular}




\section{INTERNATIONAL STUDY ON SPECIAL ECONOMIC ZONES \\ Questionnaire Executives of Zone-based Companies}

On behalf of all of us who are working on this study, a great "thanks again!" for agreeing to participate.

Please answer this questionnaire as completely as possible.

(All information will be held in strict confidence and only summary statistics will be reported.)

\section{BACKGROUND INFORMATION ABOUT THE PARENT COMPANY}

(If the zone company itself is the parent,

please answer this section for the company overall.)

Company Name: ___ Home country: _____ Year of founding:

Primary business (check as many as apply): Manufacturing Trade Services

Major product group(s):

Please provide some general information about the Most recent year (parent) company overall for the two most recent fiscal years: (ending in

Number of emplovees worldwide (including home country)

Total sales worldwide (incl. home country)(million US\$ or

Total exports from/to all countries(million US\$

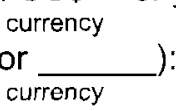

Number of countries where the (parent) company overall currently operates or exports to:

Year of parent company's first international venture (export, investment, etc.) 


\section{BACKGROUND OF RESPONDENT}

Number of years: in the workforce _ with the Zone company

with the Parent company

Which department do you work for?

What is your approximate education level? ( $\square$ one): High School University

Post graduate

In general, would you describe your background as being in... ( $\square$ one):

Engineering Finance General Management

Marketing/Sales Human Resources Other (pls. specify)

Which country are you from?

Apart from this and/or your home country, how many countries have you worked in, if any? (number)

What other languages do you speak, if any, other than your native language? 


\section{ZONE COMPANY INFORMATION}

(If the zone company is also the parent company, you may have already answered some of these questions for the company overall in Section 1 - but here we focus specifically on the zone-based operations.)

Formal name of zone company: Year zone company was established:

Primary business carried out from the zone (please check $\nabla$ as many as apply):

Manufacturing (including processing)

Assembly

Trade (import/export)

Logistics center

Other transport and distribution

Wholesale

Retail

Construction

Communications, utilities

Finance, insurance, real estate

Other services

(please specify

Other (please specify

Major product group(s) of zone business:

Does the zone company produce: Intermediate goods

Finished goods

General information about the zone company

for the two most recent fiscal years:

Most recent year

(ending in $\underline{2006 \text { or 2005) }}$
Year before (ending in 2005 or 2004

Number of employees:(number)

Total sales from zone(currency: million US\$ or ___

Total exports from zone(currency: million US\$ or ___ )

Total imports to zone(currency: million US\$ or ___ )

Percent of total zone exports made to the domestic/local market, if any: (\%)

Total number of countries to which the zone company exports: (number)

What is the ownership structure of the zone company? (check $\nabla$ one)

Sole private ownership Joint Venture with local company (majority ownership)

Public Limited firm Joint Venture with local company (minority ownership)

Private Limited firm Joint Venture with foreign company (majority ownership)

Other

(pls. specify: Joint Venture with foreign company (minority ownership)

If the company's ownership includes a joint venture or a partnership of any kind, please provide some general information about the partner:

Company name Its home country

$\%$ Equity

Does the government provide your zone company with a tax holiday? Yes (no. of years? No 


\section{ZONE vS. COUNTRY INVESTMENT CLIMATE: ASSESSMENT}

What are your views about the investment climate in the zone compared to the regular territory of the country as a whole?

Various factors of evaluation are listed below. Please indicate your views of the zone versus the country environment for investment by placing an $X$ in the most appropriate space in each column for each of the factors below.

\begin{tabular}{|c|c|c|}
\hline Production Related Factors & Environment in the ZONE & General environment of COUNTRY \\
\hline Cost of energy & Low :___:_____: High & Low :_:_:_ : \\
\hline Manufacturing costs & Low :___:______: High & ________:_: High \\
\hline Labour costs & Low :___:__:___: High & _________:_: High \\
\hline Availability of skilled labour & Low :_:_:_:_:__: High & _: : : : : : : High \\
\hline Availability of expert managers & Low :__:___:__: High & :__:_:_: High \\
\hline Labour productivity & Low :___:______: High & _:_: High \\
\hline Technology level & Low : : : : : :_:_: High & $: \quad: \quad: \quad:$ High \\
\hline Quality of transportation system & Poor :___:_:_:_: Good & Poor :____:__:_: Good \\
\hline $\begin{array}{l}\text { Quality of communication } \\
\text { system }\end{array}$ & Poor :__:_:__:_:_: Good & Poor :__:_:_:_:_: Good \\
\hline Customs procedures & Difficult :_:______:_: Easy & Difficult :_:_________: Easy \\
\hline Inventory control & Difficult :_:_:___:__: Easy & Difficult :___:___:_: Easy \\
\hline Availability of raw materials & & Low :____:___:_: High \\
\hline Cost of raw materials & 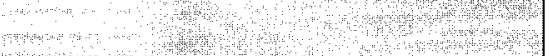 & Low :___:___: : High \\
\hline
\end{tabular}

\begin{tabular}{|c|c|c|}
\hline Finance Related Factors & Environment in the ZONE & General environment of COUNTRY \\
\hline Tax structure & Complex :_:_:_:_:_: Simple & Complex :_:_:_:___: Simple \\
\hline Tax advantages & Low :___________: High & Low :__:________: High \\
\hline Inventory tax & Low :_:_:_:___: High & Low :____:____: High \\
\hline Insurance cost & Low :___:__:_: : High & Low :__:______:_High \\
\hline Subsidies & Low :__:_:_:__: High & Low :____:_:_:_: High \\
\hline Duties on imports & Low :__:_:__:_: High & Low :___:__:__: High \\
\hline Duties on exports & Low :_________: High & Low :__:__:___: High \\
\hline Repatriation of profit and capital & Difficult :_:_:_:___: Easy & Difficult : _ :__:_____: Easy \\
\hline Currency exchange rate & 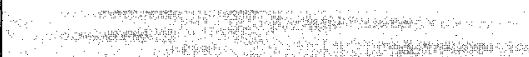 & Unstable :________ Stable \\
\hline
\end{tabular}

\begin{tabular}{|l|r|r|}
\hline $\begin{array}{l}\text { Market Related Factors (your } \\
\text { views about the domestic } \\
\text { market of the zone's country } \\
\text { are important, even if domestic } \\
\text { sales from the zone are not } \\
\text { allowed and/or you do not } \\
\text { pursue such sales) }\end{array}$ & Environment in the ZONE & General environment of COUNTRY \\
\hline $\begin{array}{l}\text { Current narket size } \\
\text { Future market size potential }\end{array}$ & & \\
Distribution costs & & Small:_:_:_:_: Large \\
\end{tabular}


(continued - 4. ZONE vs. COUNTRY INVESTMENT CLIMATE: ASSESSMENT)

\begin{tabular}{|c|c|c|}
\hline Economic and Legal Factors & Environment in the ZONE & General environment of COUNTRY \\
\hline Bureaucratic bottlenecks & Few : : : : : : : : Many & Few :______:___: Many \\
\hline Setting up operations & Difficult : : : : : : : Easy & Difficult :_:_:_____: Easy \\
\hline Obtaining licenses & Difficult :_:_:_:_:_: Easy & Difficult :_:______:_: Easy \\
\hline $\begin{array}{l}\text { Obtaining work permits for } \\
\text { expatriates }\end{array}$ & Difficult :_:_:_:_: Easy & Difficult :_:_:_:_: Easy \\
\hline Legal system & Complex :__:_:______: Simple & Complex :__:_____:_: Simple \\
\hline Restrictions on ownership & Low :__:___: High & Low : : $:$ : $:$ : High \\
\hline Inflation rate & (2) & Low :__:_______: High \\
\hline
\end{tabular}

\begin{tabular}{|c|c|c|}
\hline Political and Social Factors & Environment in the ZONE & General environment of COUNTRY \\
\hline $\begin{array}{l}\text { Government attitude to foreign } \\
\text { investment }\end{array}$ & Negative :______:____: Positive & Negative :_:_:______: Positive \\
\hline $\begin{array}{l}\text { Public's attitude towards foreign } \\
\text { investment }\end{array}$ & Negative :______:___: Positive & Negative : : : :____:_: Positive \\
\hline Quality of life style & Low : _ :_______: High & Low : :__:_:_: High \\
\hline Crime level & High :_____:_: Low & High :__:___:___: Low \\
\hline Overall political climate & & Unstable :_: $: \ldots:$ : Stable \\
\hline $\begin{array}{l}\text { Receptivity to new products, } \\
\text { methods, ideas }\end{array}$ & tets & Low :_:_:_:_:_: High \\
\hline $\begin{array}{l}\text { Cultural similarity to parent } \\
\text { dirm's country }\end{array}$ & & Far : : : _ :___:_: Near \\
\hline $\begin{array}{l}\text { Attitude to various cultures, } \\
\text { religions, races }\end{array}$ & & Closed :____:_:___: Open \\
\hline
\end{tabular}

\begin{tabular}{|c|c|c|}
\hline Infrastructure Factors & Environment in the ZONE & General environment of COUNTRY \\
\hline Proximity to a bigger city & Poor :_:_:_:_:_: Good & \\
\hline Proximity to industry clusters & Poor :_:_:_:_:_: Good & \\
\hline $\begin{array}{l}\text { Connectivity to ports, railways, } \\
\text { and airports }\end{array}$ & Poor :__:_:_:_:_: Good & \\
\hline Container handling facilities & Poor :_:_:_:_:_: Good & _ : : $:$ : : : Good \\
\hline Warehouse facilities & Poor :__:_:_:_:_: Good & Poor : : :_:_: : : : Good \\
\hline Banking facilities & Poor :__:_:_:_: : Good & Poor :_:_:_:_: : : Good \\
\hline Transport facilities & Poor :____:_:_:_: Good & Poor :____:_:_:_: Good \\
\hline $\begin{array}{l}\text { Communication facilities } \\
\text { (Internet, phone) }\end{array}$ & Poor :__:_:___:_: Good & Poor :__:_:_:_: : Good \\
\hline Housing facilities & Poor :__:___:__:_: Good & Poor :_: : : : : : : : : Good \\
\hline $\begin{array}{l}\text { Schools \& facilities for } \\
\text { expatriates' children }\end{array}$ & Poor :____:_:_:_: Good & Poor :__:___:__:_: Good \\
\hline
\end{tabular}

\begin{tabular}{|l|c|c|}
\hline $\begin{array}{l}\text { General view of country and } \\
\text { people }\end{array}$ & Environment in the ZONE & General environment of COUNTRY \\
\hline National country image & Bad : $:$ : : : : : : : Good \\
\hline
\end{tabular}


General zone and country outlook

Likeability of the people

Trustworthiness of the people

Friendliness of the people

Industriousness of the people

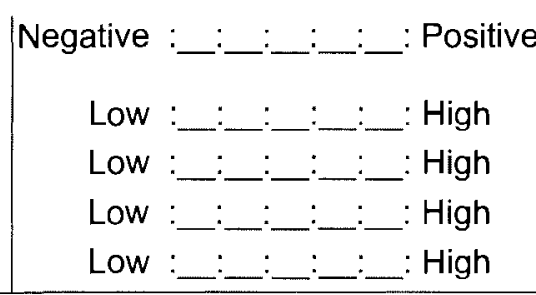

Negative : : Positive

\section{ZONE INVESTMENT CLIMATE: FACTOR IMPORTANCE}

Of the above factors, you may see some as more important than others in influencing an investment decision. Please rate the importance of each category of factors on a scale of 1 to 5 , where 1 means the factor is not important and 5 that it is very important. (Note: You may wish to refer back to the previous two pages which give examples of the factors within each category.) (please circle the number).

\begin{tabular}{lllllll} 
& \multicolumn{3}{c}{ For investing in a ZONE } \\
\cline { 5 - 7 } & $\begin{array}{c}\text { Not } \\
\text { Important }\end{array}$ & & \multicolumn{3}{c}{$\begin{array}{c}\text { Very } \\
\text { Important }\end{array}$} \\
\cline { 2 - 6 } Market Related Factors & 1 & 2 & 3 & 4 & 5 \\
Production Related Factors & 1 & 2 & 3 & 4 & 5 \\
Finance Related Factors & 1 & 2 & 3 & 4 & 5 \\
Economic and Legal Factors & 1 & 2 & 3 & 4 & 5 \\
Political and Social Factors & 1 & 2 & 3 & 4 & 5 \\
Infrastructure Factors & 1 & 2 & 3 & 4 & 5 \\
Country and people & 1 & 2 & 3 & 4 & 5
\end{tabular}

For investing in a COUNTRY Not $\underline{\text { Important }}$

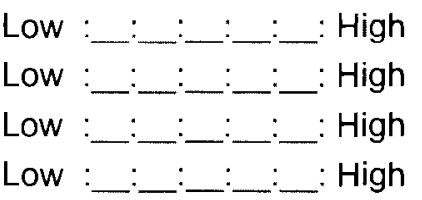

people

\begin{tabular}{ccccc} 
Important & & \multicolumn{3}{l}{ Important } \\
\cline { 1 - 2 } 1 & 2 & 3 & 45 \\
1 & 2 & 3 & 45 \\
1 & 2 & 3 & 45 \\
1 & 2 & 3 & 45 \\
1 & 2 & 3 & 45 \\
1 & 2 & 3 & 45 \\
1 & 2 & 3 & 45
\end{tabular}

\section{ZONE INVESTMENT CLIMATE: EXPERIENCE}

By investing in the zone, your firm has also indirectly invested in the country. How satisfied or dissatisfied are you with the investment experience in relation to the zone itself versus the country as a whole? Please rate the following categories of factors on a scale of 1 (very dissatisfied) to 5 (very satisfied) with your investment experience. (please circle the number)

\begin{tabular}{llllllll} 
& \multicolumn{3}{c}{$\begin{array}{c}\text { Investing in the ZONE } \\
\text { Very } \\
\text { Dissatisfied }\end{array}$} & & $\begin{array}{c}\text { Very } \\
\text { Satisfied }\end{array}$ \\
\cline { 2 - 6 } Market Related Factors & 1 & 2 & 3 & 4 & 5 \\
Production Related Factors & 1 & 2 & 3 & 4 & 5 \\
Finance Related Factors & 1 & 2 & 3 & 4 & 5 \\
Economic and Legal Factors & 1 & 2 & 3 & 4 & 5 \\
Political and Social Factors & 1 & 2 & 3 & 4 & 5 \\
Infrastructure Factors & 1 & 2 & 3 & 4 & 5 \\
Country and people & 1 & 2 & 3 & 4 & 5
\end{tabular}

Investing in the COUNTRY Very Very Dissatisfied Satisfied

$\begin{array}{lllll}1 & 2 & 3 & 4 & 5 \\ 1 & 2 & 3 & 4 & 5 \\ 1 & 2 & 3 & 4 & 5 \\ 1 & 2 & 3 & 4 & 5 \\ 1 & 2 & 3 & 4 & 5 \\ 1 & 2 & 3 & 4 & 5 \\ 1 & 2 & 3 & 4 & 5\end{array}$




\section{ZONE INVESTMENT CLIMATE: COMPARISON TO AREA OUTSIDE ZONE}

Based on your experience, how would you compare the zone's investment climate to the country's regular territory, the domestic mainland? Please rate the following factors on a scale of 1 to 7 , where 1 means that investing in the zone is worse, and 7 means it is better, than the mainland. (please circle the number)

\begin{tabular}{|c|c|c|c|c|c|c|c|}
\hline \multirow[b]{2}{*}{ Costs of making and enforcing contracts } & \multicolumn{2}{|c|}{$\begin{array}{l}\text { Zone worse } \\
\text { than mainland }\end{array}$} & \multirow[b]{2}{*}{3} & \multirow[b]{2}{*}{4} & \multicolumn{3}{|c|}{$\begin{array}{l}\text { Zone better } \\
\text { than mainland }\end{array}$} \\
\hline & 1 & 2 & & & 5 & 6 & 7 \\
\hline Maintenance of quality of services with local $p$ & er1 & 2 & 3 & 4 & 5 & 6 & 7 \\
\hline Risk of misuse of your proprietary knowledge & 1 & 2 & 3 & 4 & 5 & 6 & 7 \\
\hline Stability of political, social, and economic cone & $\mathrm{ns1}$ & 2 & 3 & 4 & 5 & 6 & 7 \\
\hline Risk in repatriating your income & 1 & 2 & 3 & 4 & 5 & 6 & 7 \\
\hline Risk of expropriation of firms & 1 & 2 & 3 & 4 & 5 & 6 & 7 \\
\hline
\end{tabular}

\section{Chank you very much for completing the questionnaire and helping us out with this study - Aour contribution is invaluable and we truly appreciate it.}

If you would like to make any additional comments, it will be a great help to the researchers and business or government executives who will read the results. Of course, your comments will remain confidential and anonymous, as we have already noted - but they will certainly be taken into account when analysing the aggregate statistical results.

Please return the completed questionnaire to: 